\title{
HYDRAULIC PERFORMANCE OF COMPACTED CLAY LINERS (CCLS) UNDER SIMULATED LANDFILL CONDITIONS
}

\author{
A thesis submitted to \\ the Faculty of Graduate and Postdoctoral Affairs \\ in Partial Fulfillment of the requirements for the degree \\ Master of Applied Science \\ by \\ Abdulghader Abdulrahman Hassan \\ Department of Civil and Environmental Engineering \\ Carleton University \\ Ottawa-Carleton Institute of Civil and Environmental Engineering
}

January, 2014

CAbdulghader Abdulrahman Hassan 


\section{ABSTRACT}

Experimental investigations were carried out to evaluate the hydraulic performance of Compacted Clay Liners (CCLs) under simulated landfill conditions, i.e., daily thermal cycles before waste placement and thermo-chemical exposures after waste placement. Results exhibited positive correlation between CCLs' hydraulic conductivity and plasticity indices when the CCLs exposed to daily thermal or wet-dry cycles. CCLs with plasticity indices ranging from $25 \%$ to $37 \%$ showed a reliable hydraulic performance when exposed to different simulated weather circumstances. However, low plasticity CCL (9.5\%) experienced significant increase in hydraulic conductivity, which reached almost an order of magnitude, when exposed to wet-dry or daily thermal cycles. Overlaying the CCL with a layer of geomembrane minimized the effects of daily thermal cycles as well as wet-dry cycles. After waste placement, the hydraulic conductivity for most CCL specimens increased by two to three times their initial values when exposed to $55^{\circ} \mathrm{C}$ for 75 days. Initial increase in hydraulic conductivities for all CCL specimens occurred due to change in viscosity when the permeant was changed from tap water to leachate. However, as the leachate exposure time increased, hydraulic conductivity readings decreased to as low as one order of magnitude after 75 days of leachate permeation at room temperature. The gradual decreases in CCLs hydraulic conductivities were most likely due to chemical precipitation and clogging of pore voids within the soils. The rate of hydraulic conductivity reduction due to leachate permeation was slower at higher temperatures, which was attributed to lower permeant viscosity and lower clogging. 
Dedicated to my wife and lovely parents 


\section{Acknowledgements}

I would like to express my gratitude to my supervisor, Dr. Mohammad Rayhani, whose expertise, understanding, and patience, added considerably to my graduate experience. I appreciate his vast knowledge and skill in many areas (e.g., vision, aging, ethics, interaction with participants), and his assistance in writing reports and this thesis. I would like to thank my thesis examination committee, Dr. Paul. H. Simms and Dr. Mamadou Fall for their valuable time and comments.

Moreover, I would like to thank my friends for their understanding and support, also all of my lab-mates who supported me in this research.

Last, but not least, I would like to thank my wife "Hanan" for her understanding and love during the past few years. Her support and encouragement was in the end what made this dissertation possible. My Father "Abdulrahman" and my mother "Amna" receive my deepest gratitude and love for their dedication and the many years of support during my undergraduate studies that provided the foundation for this work. 


\section{Table of Contents}

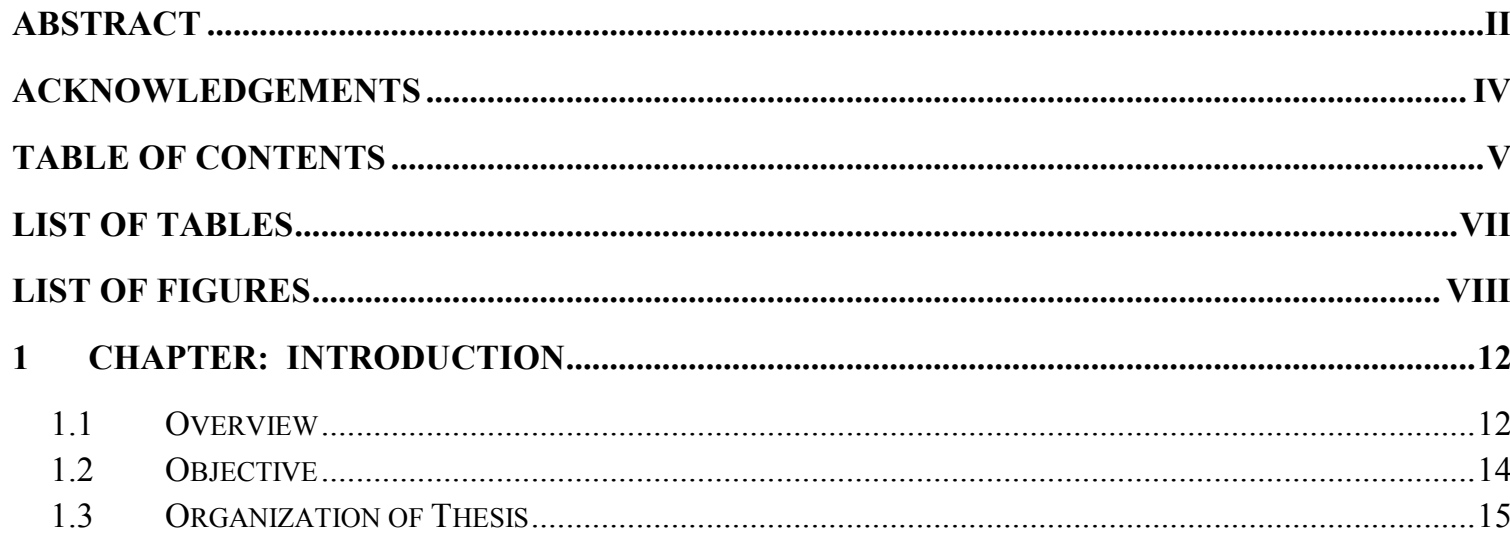

2 CHAPTER: LITERATURE REVIEW..........................................................................................17

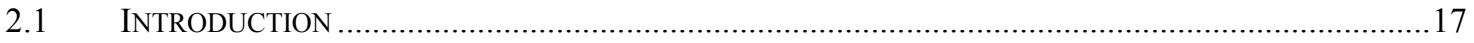

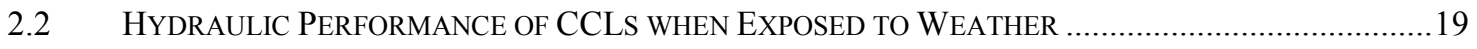

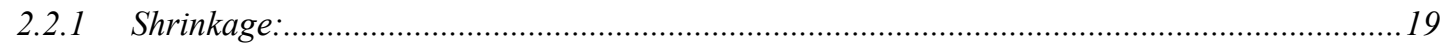

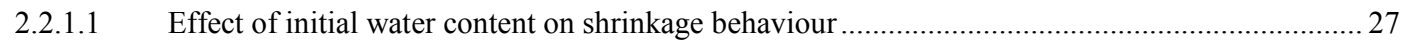

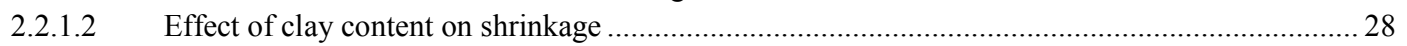

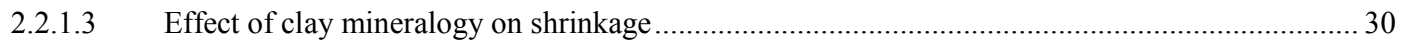

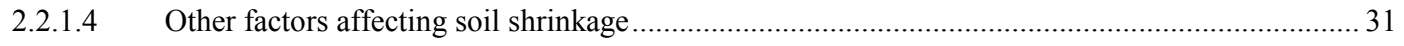

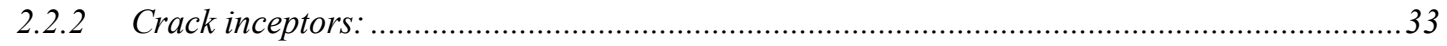

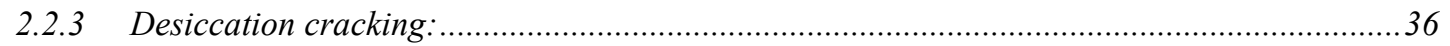

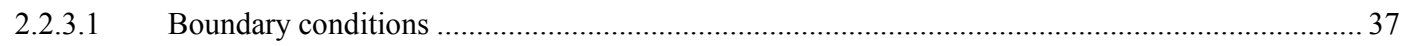

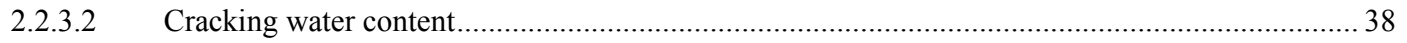

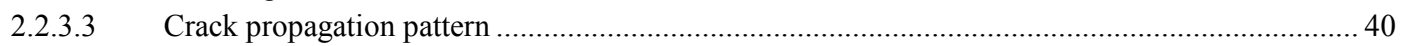

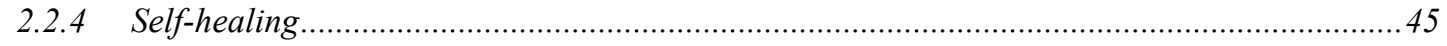

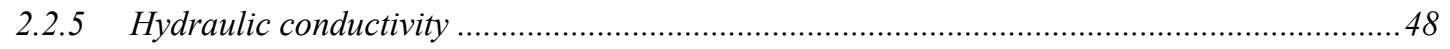

2.2.5.1 Laboratory method for hydraulic conductivity measurement .................................................... 50

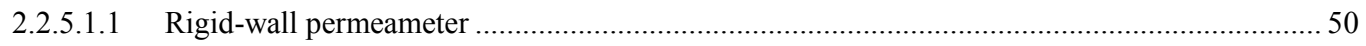

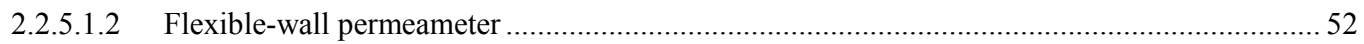

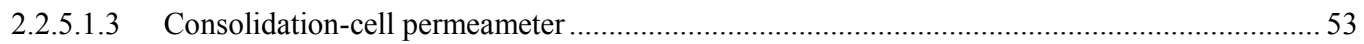

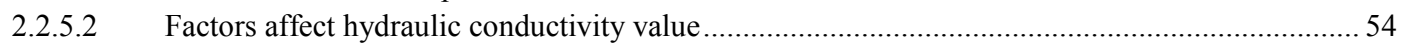

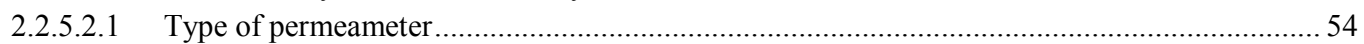

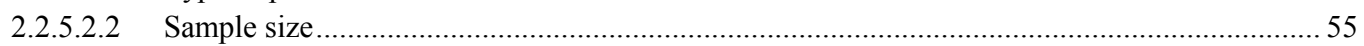

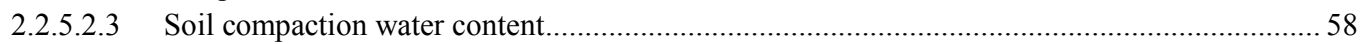

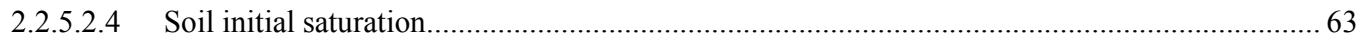

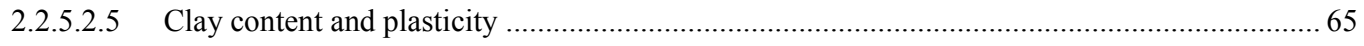

2.3 Hydraulic Performance of CCL AFter Waste Placement ...............................................67

2.3.1 Influence of elevated temperature on the hydraulic performance of landfill barrier system...67

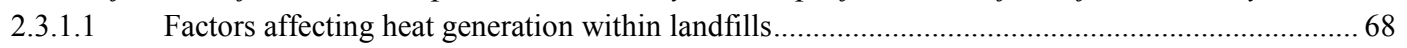

2.3.1.2 Effect of elevated temperature on physical and mechanical properties of clay soils ....................... 72

2.3.2 Influence of landfill leachate on hydraulic performance of landfill liners ...............................79

2.3.2.1 Effect of leachate on chemistry and mineral composition of clay liners ......................................... 80

2.3.2.2 Effect of leachate on physical properties (Atterberg limits) of clay liner ....................................... 86

2.3.2.3 Impact of leachate properties on hydraulic performance of clay liner........................................... 88

3 CHAPTER: HYDRAULIC PERFORMANCE OF COMPACTED CLAY LINERS UNDER SIMULATED DAILY THERMAL CYCLES .......................................................................................92 


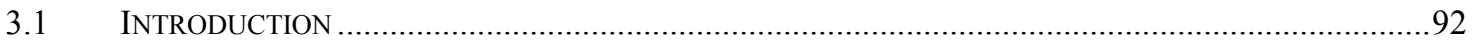

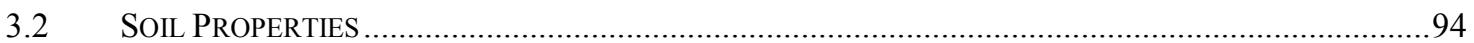

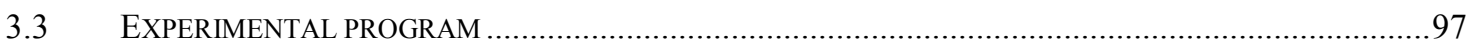

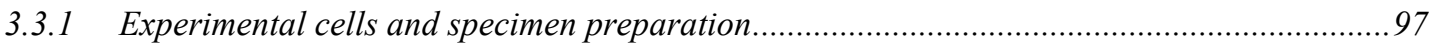

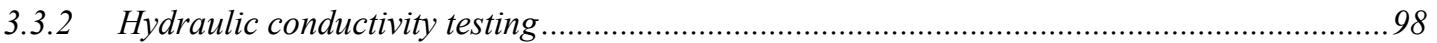

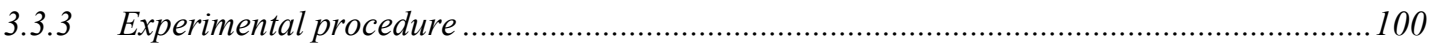

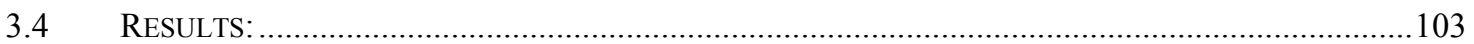

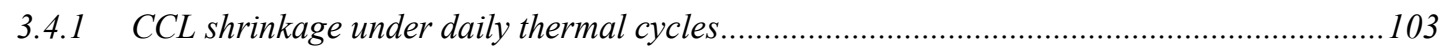

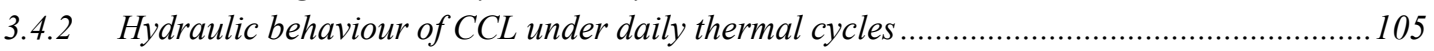

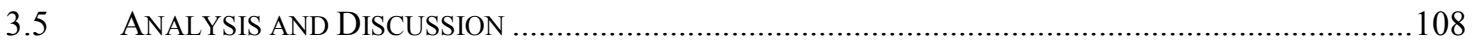

3.5.1 Correlation between Soil-Water Characteristic Curves and CCL shrinkage ........................ 108

3.5.2 Effect of soil index properties on CCL shrinkage and hydraulic conductivity .......................109

3.5.2.1 Effect of plasticity index on shrinkage and hydraulic conductivity ............................................ 109

3.5.2.2 Influence of shrinkage index on shrinkage and hydraulic conductivity ..................................... 112

3.6 IMPACT OF GEOMEMBRANE IN A COMPOSITE LINER ON CCL SHRINKAGE AND HYDRAULIC

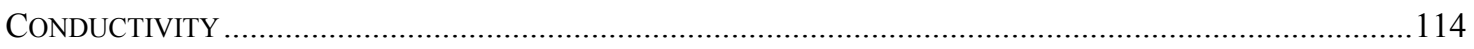

3.7 EFFeCt OF Wet/Dry CyCles on the Hydraulic Performance of CCLS ............................116

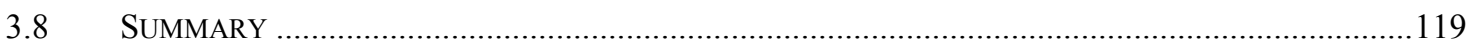

\section{CHAPTER: HYDRAULIC PERFORMANCE OF CCLS UNDER COMBINED}

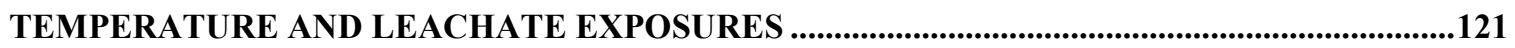

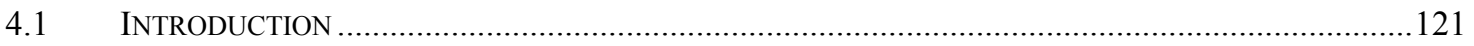

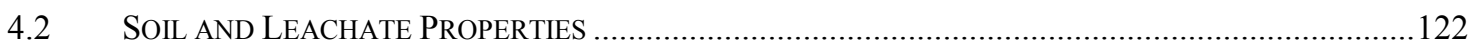

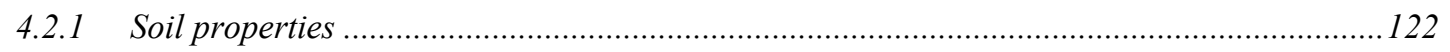

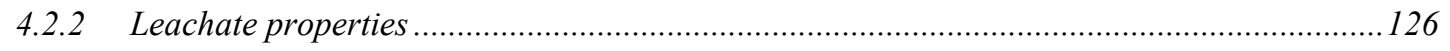

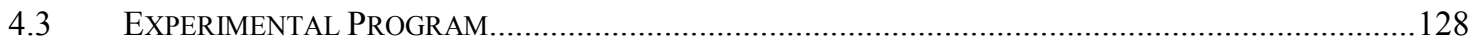

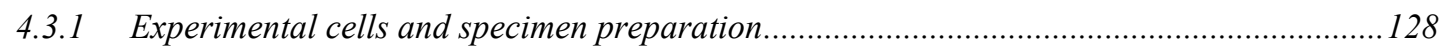

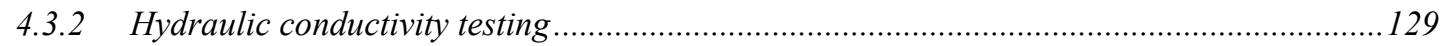

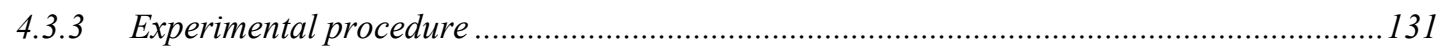

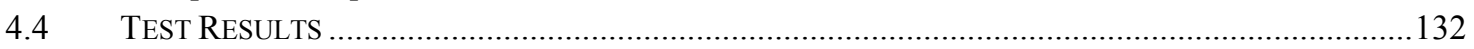

4.4.1 Hydraulic performance of CCLs under combined thermo-chemical effects ..........................132

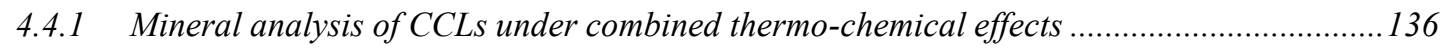

4.4.2 Chemical alternation of CCLs under combined thermo-chemical effects .............................137

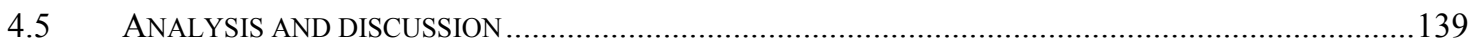

4.5.1 Effect of elevated temperature on hydraulic performance of CCLs .....................................139

4.5.2 Effect of leachate exposure on hydraulic performance of CCLs ........................................141

4.5.3 Combined thermo-chemical exposure effects on hydraulic performance of CCLs.................146

4.5.4 Effect of soil properties on CCLs response to combined thermo-chemical exposure.............149

4.5.5 Combined thermo-chemical exposure effects on Atterberg limits .....................................150

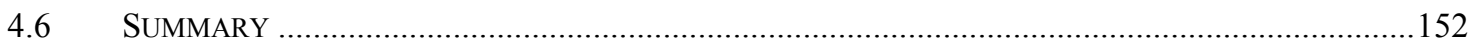

5 CHAPTER: CONCLUSIONS AND RECOMMENDATIONS .................................................154

5.1 CONCLUSIONS................................................................................................................................154

5.2 RECOMMENDATIONS .....................................................................................................................157

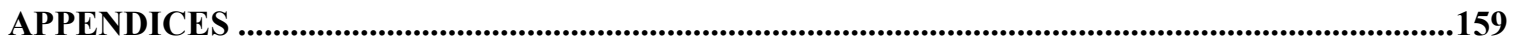

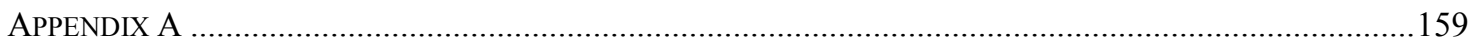

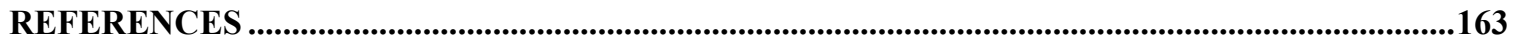




\section{List of Tables}

Table 2.1 Geotechnical properties of clayey soils used by Schuster (1986)............................... 47

Table 2.2 Comparison between different types of permeameters (Boynton and Daniel 1985)....56

Table 2.3 Changes in Atterberg limits upon leachate permeation (Frempong, 2006) ................. 87

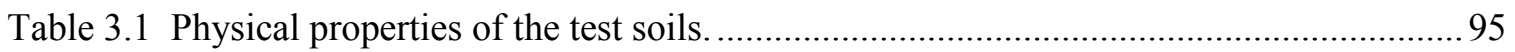

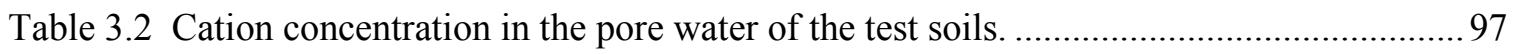

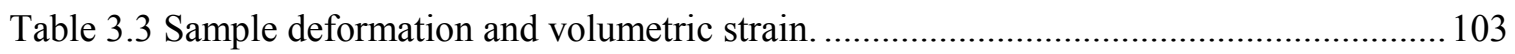

Table 3.4 Results of hydraulic conductivity at the beginning and after exposure to daily thermal

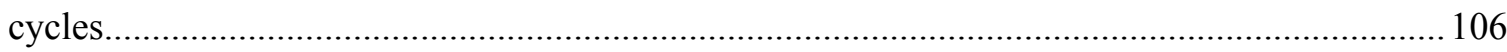

Table 3. 5 Results of hydraulic conductivity $(\mathrm{m} / \mathrm{sec})$ at the start and after exposure to daily thermal cycles when geomembrane overlays the CCLs. .......................................................... 116

Table 3. 6 Effect of wet-dry cycles on the hydraulic performance of CCL................................ 117

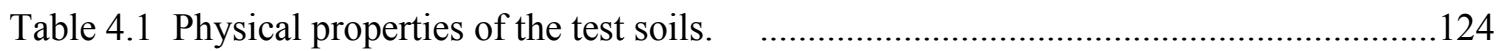

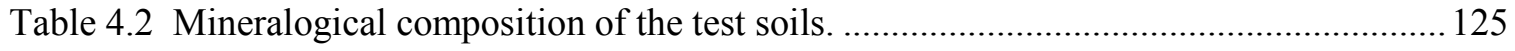

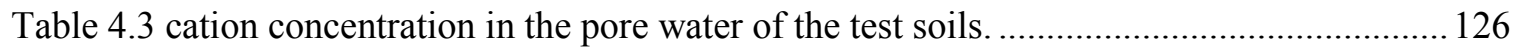

Table 4.4 Composition of synthetic leachates and trace metal solution (Hrapovic 2001)......... 127

Table 4.5 Hydraulic conductivity of specimens permeated with leachate at room temperature

Table 4.6 Hydraulic conductivity of specimens permeated with leachate and exposed to $40^{\circ} \mathrm{C}$

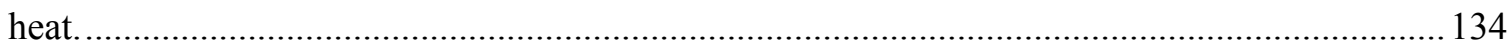

Table 4.7 Hydraulic conductivity of specimens permeated with leachate and exposed to $55^{\circ} \mathrm{C}$

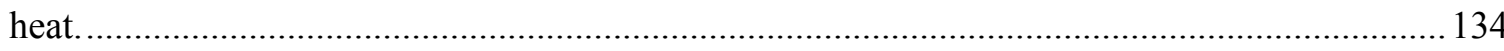

Table 4.8 Hydraulic conductivity of specimens permeated with water and exposed to $40^{\circ} \mathrm{C}$ heat.

Table 4.9 Hydraulic conductivity of specimens permeated with water and exposed to $55^{\circ} \mathrm{C}$ heat.

Table 4.10 Clay minerals initially and after exposure to combined thermo-chemical effects.... 137

Table 4.11 Cation concentration in the pore water of the test soils. ......................................... 138

Table 4.12 Hydraulic performance of CCL specimens with different permeates at room

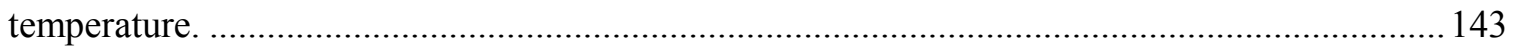

Table 4.13 Atterberg limits initially and after thermo-chemical exposure. ............................... 151

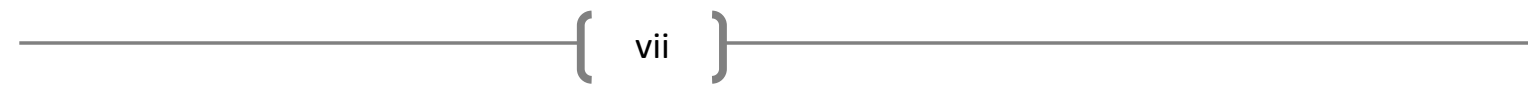




\section{List of Figures}

Figure 2.1 General form of soil shrinkage characteristic with three shrinkage phases (Bronswijk, 1988).

Figure 2.2 Shrinkage characteristic of two clay soils; (a) Oosterend marine clay ( $41 \%$ clay content) shows mostly normal shrinkage; (b) Kats marine clay (31\% clay content) shows mostly residual shrinkage (Bronswijk, 1988).

Figure 2.3 Progress of crack depths with time during surface drying (Abuhejleh \& Znidarcic 1995).

Figure 2.4 Shrinkage paths for specimens: (a) contain 10\% bentonite, and (b) contains $20 \%$

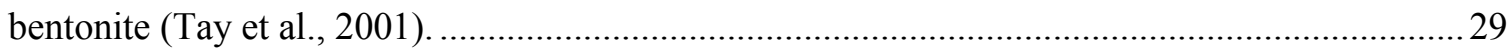

Figure 2.5 Relationship between clay percentage and COLEstd, (Gray and Allbrook 2002)..... 30 Figure 2.6 Vertical applied pressure. V.s. void ratio (Srldharaan and Rao 1971). ...................... 33

Figure 2.7 Mechanism of drying and formation of the drying front (Peron et al., 2009). ............ 34

Figure 2.8 Effect of boundary conditions on crack geometry; a) uncoated bottom, b) $2 \mathrm{~mm}$ grease coated bottom, and c) $6 \mathrm{~mm}$ Vaseline coated bottom (Groisman and Kaplan 1993).....................38 Figure 2.9 Changes of water content $(\mathrm{w})$ and evaporation rate $(\mathrm{Re})$ of soil specimens with drying

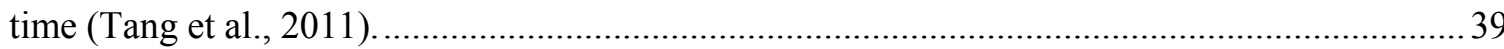

Figure 2.10 Different stages of crack propagation (Konrad and Ayad 1997) ..............................43

Figure 2.11 Rigid-wall permeameter cross section (Benson and Daniel 1990)..........................51

Figure 2.12 Rigid-wall permeameter (double-ring) cross section (Benson \& Daniel 1990). .......52

Figure 2.13 The cross- section of the flexible-wall permeameter cell (Benson and Daniel 1990).

Figure 2.14 The cross- section in the flexible wall permeameter cell (Boynton and Daniel 1985).

Figure 2.15 A plot illustrating the correlation between (k) and sample diameters (Boynton and Daniel 1985)..... .57

Figure 2.16 The correlation between clay soil fabric and water content (Benson and Daniel 1990). .59

Figure 2.17 Mechanism of water flow based on theory of clods (Benson and Daniel 1990).......60 Figure 2.18 Correlation between water content and hydraulic conductivity for different clod sizes of compacted clays (Benson and Daniel 1990).

Figure 2.19 Scanning Electronic Photomicrography of soil compacted with stander proctor at water content of A) 12\% and B) 16\% (Benson and Daniel 1990).

Figure 2.20 Dry unit weight V.s hydraulic conductivity (Benson and Daniel 1990)...................62

Figure 2.21 Water content V.s hydraulic conductivity (Benson et al., 1999) ..............................63 Figure 2.22 Correlation between initial water content and hydraulic conductivity (Benson et al., 1994).

Figure 2.23 Hydraulic conductivity versus: (a) liquid limit; (b) plasticity index (Benson et al., 1994).

Figure 2.24 Hydraulic conductivity versus: (c) percentage of fines; (d) percentage of clay (Benson and Trast 1995). .66

Figure 2.25 Relationship between temperature, leachate head, and waste thickness within Keele Valley Landfill, Canada (Barone et al., 1997). 
Figure 2.26 Correlation between temperature and depth in an old German's landfill (Collins, 1993).

Figure 2.27 Correlation between temperature and depth in Japanese landfill (Yoshida et al., 1996).

Figure 2.28 Temperature profile for frozen and unfrozen waste in Alaska (Hanson et al., 2010).

Figure 2.29 Relationship between Liquid limit and temperature (Jefferson and Rogers 1998).... 74

Figure 2.30 Normalized liquid limit versus temperature (Jefferson and Rogers 1998)............... 74

Figure 2.31 Water retention curves for compacted bentonite at different temperature (Villar and

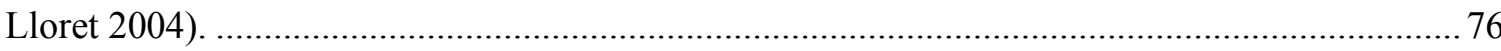

Figure 2.32 Temperature versus total suction at constant water content (Romero et al., 2001)...76

Figure 2.33 Changes in water content and volumetric strain during wet-dry cycles at two

different temperatures and constant vertical stress (Romero et al., 2005).

Figure 2.34 Comparison between experimental hydraulic conductivity and predicted hydraulic

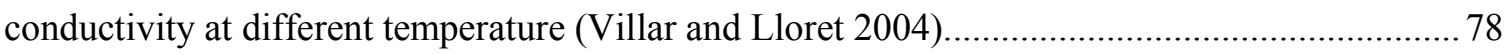

Figure 2.35 Relationship between swelling pressure and temperature (Villar et al., 2005). ........79

Figure 2.36 No. of pore volumes versus effluent chemistry that passed through samples with two different void ratios: (a) $\mathrm{e}=0.74$; (b) $\mathrm{e}=0.54$ (Quigley et al. 1988).

Figure 2.37 Hydraulic conductivity for homoionic clays at different level of vertical stress

(Narasimha and Mathew 1995).

Figure 2.38 Plasticity indices for bentonite permeated with different salt types and concentrations (Allen, 2005).

Figure 2.39 Hydraulic conductivity of water-compacted Sarnia clay permeated with leachateethanol mixtures. Black dots show reference water conductivity, while rectangular shape shows conductivity of leachates that vary from leachate to commercial ethanol (Fernandez \& Quigley 1988).

Figure 2.40 Hydraulic conductivity of water-compacted Sarnia clay permeated with leachatedioxane mixtures. Black dots show reference water conductivity, while rectangular shape shows conductivity of leachates that vary from leachate to dioxane (Fernandez and Quigley 1988)..... 90

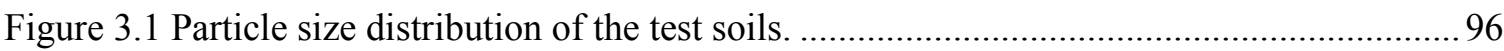

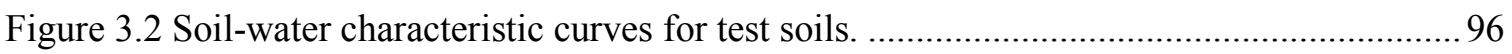

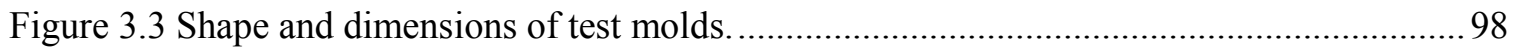

Figure 3.4 Schematic diagram of the falling head method for hydraulic conductivity test. ........ 100

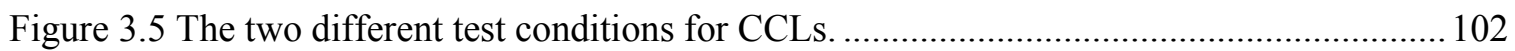

Figure 3.6 Volume shrinkage after 30 daily thermal cycles, and the subsequent swelling and selfhealing following saturation and hydraulic conductivity measurement.................................... 105

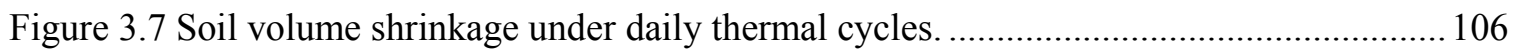

Figure 3.8 Normalized hydraulic conductivity versus the number of daily thermal cycles......... 107

Figure 3.9 Correlation between soil plasticity and normalized hydraulic conductivity............... 111

Figure 3.10 Correlation between shrinkage index and soil deformation. ................................ 113

Figure 3.11 Correlation between volumetric shrinkage and normalized hydraulic conductivity

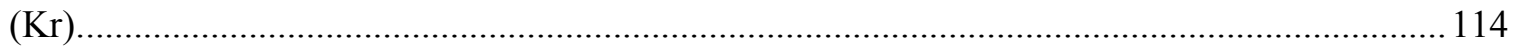

Figure 3.12 Hydraulic performances of Halton clay with and without geomembrane............... 116

Figure 3.13 Effect of wet-dry cycles on the hydraulic performance of CCL............................ 118 
Figure 3.14 A) Shrinkage and cracking after 15 thermal cycles for Leda clay+bent. B) Swelling and self-healing effect after wetting and hydraulic conductivity measurement.......................... 118

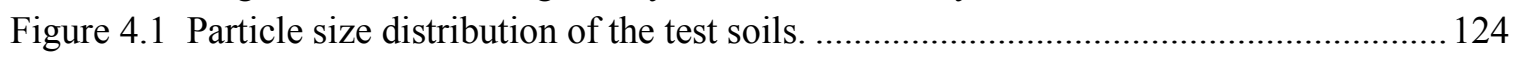

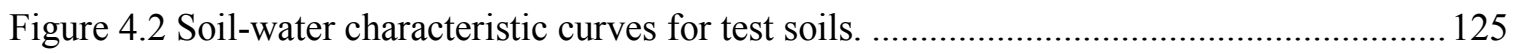

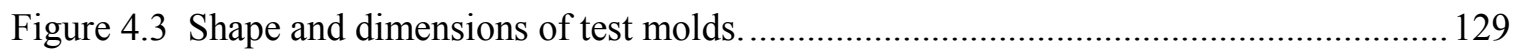

Figure 4.4 Testing platform and the experimental setup....................................................... 130

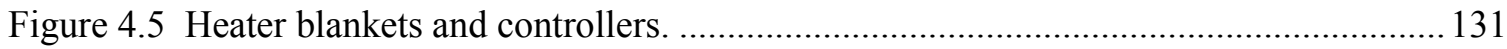

Figure 4.6 Hydraulic performance of CCL specimens when exposed to $40^{\circ} \mathrm{C}$ and $55^{\circ} \mathrm{C}$......... 140

Figure 4.7 Hydraulic performance for CCLs when exposed to leachate permeation at room temperature.

Figure 4.8 Biofilm formation on the surface of Halton clay specimen after 75 days of leachate exposure at room temperature. A) Prior to leachate exposure B) After leachate exposure. ........ 146 Figure 4.9 Normalized hydraulic conductivity values versus time for soil specimens permeated with synthetic leachate under $22^{\circ} \mathrm{C}, 40^{\circ} \mathrm{C}$, and $55^{\circ} \mathrm{C}$. 147

Figure 4.10 Influence of temperature on hydraulic performance of CCLs when exposed to leachate.

Figure 4.11 Effect of temperature on biofilm formation during leachate permeation. 149 Figure 4.12 Effect of plasticity index on hydraulic performance of CCLs when subjected to combined thermo-chemical affects. 150 


\section{CHAPTER: INTRODUCTION}

\subsection{Overview}

Landfills have long been used as engineered containment systems to mitigate the environmental footprint of disposed waste. Due to their low permeability, Compacted Clay Liners (CCLs) are used as barrier systems in landfill design to minimize the escape of contaminants from landfills and mitigate their impact on public health and the environment. Therefore, the functional integrity of landfills depends heavily on the hydraulic performance of their barrier systems. CCL is a thick compacted layer of finegrained soil (i.e., $0.75-1.0 \mathrm{~m}$ thick) that constructed in the field based on the soil's maximum dry density and optimum moisture content. Laboratory and field investigations have shown that the application of either the CCL or Geosynthetic Clay Liner (GCL) while underlain by a Geomembrane could effectively prevent the advection and diffusion of the contaminants into the surrounding environment (e.g., Rowe, 2011; Bostwick, 2009).

CCL is desired to provide reliable hydraulic performance that can mitigate the migration and attenuate the concentration of the contaminated liquids into ground water. However, the hydraulic performance of the CCLs depends on many factors including method of instillation and compaction, the mineralogy, and clay/leachate compatibility. In landfill environment, CCLs would be exposed to different circumstances that might affect the volume stability of the CCL matrix on one hand, and/or alter their physical, mineral, and chemical compositions on the other hand. Prior to waste placement, CCL may be exposed to solar radiation for a period of time ranging from weeks to several 
years. Exposure to solar radiation can result in moisture loss from the CCL that could cause shrinkage and potential desiccation cracking. Moreover, CCL might be exposed to wet-dry cycles due to rainfall and following dry spells. These weather circumstances can cause severe changes in the hydraulic performance of the CCLs. Desiccation cracking and the relevant changes in hydraulic behavior of fine-grained soils have been widely investigated. However, field conditions that CCL materials would be exposed to were neither adequately, nor accurately, simulated. In the literature, most desiccation and dewatering processes were initiated by putting the entire test specimen in an oven thereby exposing it to an all-around (3D) heat. Furthermore, the heating interval, in many cases, was prolonged for several days. This exaggeration of circumstances could result in severe shrinkage and a subsequent increase in permeability of the CCL.

After waste placement in landfills, CCL would be exposed to simultaneous effects of elevated temperature and leachate chemicals. The temperature is generated by organic waste biodegradation, which also is responsible for generating considerable volume of landfill leachate. Temperatures of $60^{\circ} \mathrm{C}$ and $70^{\circ} \mathrm{C}$ were recorded in landfills in Germany (Collins, 1993) and Japan (Yoshida et al., 1996) 10 years and 6 years post-closure respectively. This high level of temperature accompanied with leachate exposure might impose chemical interactions that affect the hydraulic performance of the exposed CCLs. While a group of researchers focused on studying the effect of elevated temperature on hydraulic aspects of CCLs (e.g., Doll, 1997; Heibrock, 1997; Rowe, 1998; Yesiller and Yoshida, 2011; Hanson et al., 2010), others examined the solo effect of landfill leachate exposure on hydraulic performance of the CCLs (e.g., Quigley et al., 1988; Narasimha and Mathew 1995; Joseph at al,. 2001; Allen, 2005; Frempong, 2006). The combined 
effect of temperature and chemical exposures on hydralic performance of CCLs has not been widely investigated. Consequently, current performance and service life predictions are based on data that does not include all of the expected field exposure conditions, or capture the interrelationship between these conditions. Therefore, complete and realistic assessment of clay/leachate compatibility would require applying realistic boundary condition.

\subsection{Objective}

The purpose of this research is to complement the work of other researchers pertaining to the hydraulic performance of CCLs under different exposure conditions in municipal solid waste landfills. More specifically, one of the objectives of this research is to evaluate the effects of daily thermal and wet-dry cycles on the hydraulic performance of CCLs under simulated field conditions where only the upper surface of the CCLs are exposed to atmosphere. The other objective of this study is to investigate the hydraulic performance of CCLs when subjected to combinations of temperature and leachate effects after waste placement. The study also aims to correlate the hydraulic performance of the CCLs to their physical, chemical, and mineralogical properties when simulated field conditions are applied. This will enable creating broad fundamental concepts to assist in choosing appropriate clay materials for CCL design and construction. These objectives were approached by conducting extensive experimental analyses to investigate:

- The effect of weathering on hydraulic performance and volumetric shrinkage of the CCLs in landfills before waste placement. Experimental CCL profiles were subjected to one dimensional heat and moisture transfer imposed by applying 
simulated daily thermal and wet-dry cycles. The change in CCLs' hydraulic performance was assessed and the results were correlated to the SWCCs and physical properties of the test soils such as plasticity and shrinkage indices.

- The combined thermo-chemical impacts on the hydraulic performance of CCLs after waste placement in landfills. Typical profiles of CCL specimens were exposed to simultaneous heat and chemical effects simulating the elevated temperature and leachate generation due to organic waste biodegradation. Hydraulic conductivity measurements were recorded along the test at different elapsed time to evaluate the hydraulic performance of the CCLs under simulated field conditions. Possible chemical, physical and mineralogical changes for the test soils subjected to thermo-chemical exposures were investigated.

\subsection{Organization of Thesis}

This thesis contains 5 chapters. Chapter 1 presents an introduction regarding the CCL applications, advantages and possible problems along with the need for further investigation. Furthermore, the objectives of the research along with the organization of the thesis are illustrated. Chapter 2 includes a comprehensive literature review that presents the work that has been done regarding the desiccation cracking of CCL on one hand and clay/leachate compatibility on the other hand. Chapter 3 provides results for the experimental testing programmed to evaluate the hydraulic performance of Compacted Clay Liners (CCLs) under simulated daily thermal cycles. Chapter 4 illustrates a set experiment that employed to study clay/leachate compatibility under different temperature exposures simulating landfill conditions. Results of the experiments are 
thoroughly presented and discussed. Finally, the conclusions of the research and the recommendations for future studies are summarized in Chapter 5. 


\section{CHAPTER: LITERATURE REVIEW}

\subsection{Introduction}

Composite liner systems are used in landfills to isolate the landfill contents from the environment and, therefore, to protect the soil and ground water from pollution originating in the landfill. A typical composite liner system may consist of a layer of Compacted Clay Liner (CCL) or a Geosynthetic Clay Liner (GCL) overlain by a geomembrane (High Density Polyethylene, HDPE) to minimize the escape of contaminants from the landfill. Typically, CCLs consist of a $0.75-1.0 \mathrm{~m}$ thick layer of compacted clay with a permeability of less than $1 \times 10^{-9} \mathrm{~m} / \mathrm{s}$ in comparison to GCLs which consist of a dry bentonite clay layer between two woven or non-woven geotextiles for a total thickness of $0.5-1.0 \mathrm{~cm}$.

CCLs are expected to provide an adequate hydraulic performance when proper design and construction steps are maintained. However, exposing to desiccation after construction may inversely impact the hydraulic performance of CCLs. Desiccation may occur in one or more of these three scenarios:

- after construction and prior to geomembrane instillation,

- after installation of geomembrane and prior to waste placement, and

- after waste placement and leachate/heat generation.

Before waste placement, the risk of desiccation shrinkage and cracking would occur due to the exposure to daily thermal and wet-dry cycles imposed by solar radiation and 
rainfall events respectively. After waste placement, there would not be any immediate exposure of CCL to atmosphere. However, elevated temperatures and landfill leachates would be generated due to organic waste biodegradation and create a new exposure condition. Factors controlling the desiccation of CCLs after waste placement including: properties of the clay liner, properties of the attenuation layer, overburden pressure, temperature gradient, and the ground water depth beneath the landfill base were suggested by Holzlohner (1995). Elevated temperature might generate severe desiccation cracking in CCLs at the bottom of landfill (Rowe, 1998). The existing of geomembrane would prevent leachate to reach the underneath CCL. Therefore, CCLs would only be involved as a diffusion barrier as long as the geomembrane layer retains landfill leachate. On the other hand, the heat generation at this depth would result in thermal gradient between the top of the clay barrier and the underground water. This would enhance the water molecules to move toward underground water following the thermal gradient drag. Thus, voids would be left behind which would not be compensated as long as the geomembrane exists. Therefore, desiccation cracking will be expected as a result of water being withdrawn from the soil matrix. Furthermore, landfill leachate would be produced due to organic waste biodegradation and/or waste leaching and percolation. For long term performance, geomembrane failure would occur due to overburden pressure and the elevated temperature. Immediate contact between the leachate and the CCL barrier would then be resulted. By this time, the CCL most likely is desiccated and severely cracked. This would facilitate the movement of the contaminated water toward the ground water resources. Thus, ground water pollution may occur and threaten the health of the society (Doll, 1997). 


\subsection{Hydraulic Performance of CCLs when Exposed to Weather}

For optimal performance, CCLs usually hydrated and compacted at $2-4 \%$ wet of their optimum moisture contents. This procedure is believed to enable breaking down the clay clods and reducing the void volume which eventually would result in lower hydraulic conductivity. However, CCLs compacted at wet of optimum moisture contents would encounter larger mobilized pore water. If a CCL is left exposed, its moisture content would be withdrawn by the atmosphere to reach moisture equilibrium. This would enhance the CCL's desiccation and volumetric shrinkage especially in dry regions. The mechanisms of evaporation, shrinkage and desiccation cracking are thoroughly discussed and their impacts on the hydraulic conductivity of the CCLs are presented in the following sections based on the data collected from the literature.

\subsubsection{Shrinkage:}

Upon desiccation and evaporation, soils tend to lose considerable amount of their moisture content. Reduction in water content of the soil leads to decrease in pore-water pressure and gradually increase in metric suction (Konrad and Ayad 1997; Nahlawi and Kodikara 2006; Tang et al., 2011). Outgoing water flow, which is caused by a gradient of pore water pressure, occurs through the surface as well as certain depths within the soil. This upward water movement generates voids within soil particles. Following the voids generation, the soil particles are reorganized under an internal compression effect, which increases with an increase in soil suction. As a result, vertical and horizontal subsidence 
happens that causes reduction in the soil matrix volume, known as shrinkage (Albrecht and Benson 2001; Peron et al., 2009; Tang et al., 2011).

Generally, soils in the field are exposed to an ambient atmosphere and its consequent humidity and temperature. In dry climates, soils lose their moisture content under the effect of desiccation. As water loss proceeds, soil suction develops and leads to generation of horizontal inner compression stresses which concentrate on a thin surface layer and eventually causes soils to shrink. If the volumetric shrinkage is restricted, cracks occur when the soil's tensile strength fails to resist the growing tensile stresses (Nahlawi and Kodikara, 2006; Tang et al., 2011). Small air bubbles and surface defects are the preferable areas at where cracks are generated (Peron et al., 2009; Tang et al., 2011).

Bronswijk (1988) developed a simulation model to compute one-dimensional water flow within the soil matrix. He stated that the hydraulic conductivity and water retention curves cannot fully describe water flow within the soil matrix. Thus, a third soil-water function is required to describe the changes in volume of soil matrix as water content changes. Therefore, shrinkage characteristics curve was proposed to describe the correlation between soil water content and void ratio (Figure 2.1). This correlation is one of the most known shrinkage characteristic forms (Benson et al., 1999).

Early studies in soil shrinkage behaviour identified three stages of soil shrinkage due to water evaporation; normal shrinkage, residual shrinkage, and zero-shrinkage (Haines, 1923). In the normal shrinkage stage, the total volumetric shrinkage is equal to the volume of evaporated water where soil aggregates preserve their saturation condition. As the evaporation proceeds, the tendency of shrinkage curve changes and the soil 
particles are rearranged in smaller space. Residual shrinkage is reached when the soil particles get in contact to each other and air enters the pores. Due to particles contact, no more volumetric reduction occurs and water loss at this time is equal to the volume of air flow. This stage is defined as zero-shrinkage stage or rigid stage (Haines, 1923). Clay content plays an important role in determining the shrinkage severity. Soils show residual shrinkage when they contain low clay content, while normal shrinkage occurs over a broad range of water content in soils with high clay content (Fox, 1964; DeJong and Warkentin 1965; Bronswijk, 1988), (Figure 2.2).

Structural shrinkage was lately proposed by Stirk (1954) as the fourth stage of soil shrinkage that occurs even before normal shrinkage. Structural shrinkage happens when a large amount of water evaporates from relatively large and stable pores that formed due to structural development. Therefore, small particle rearrangement might occur, thus the amount of water lost at this stage would be much larger than the resulted volumetric shrinkage. 


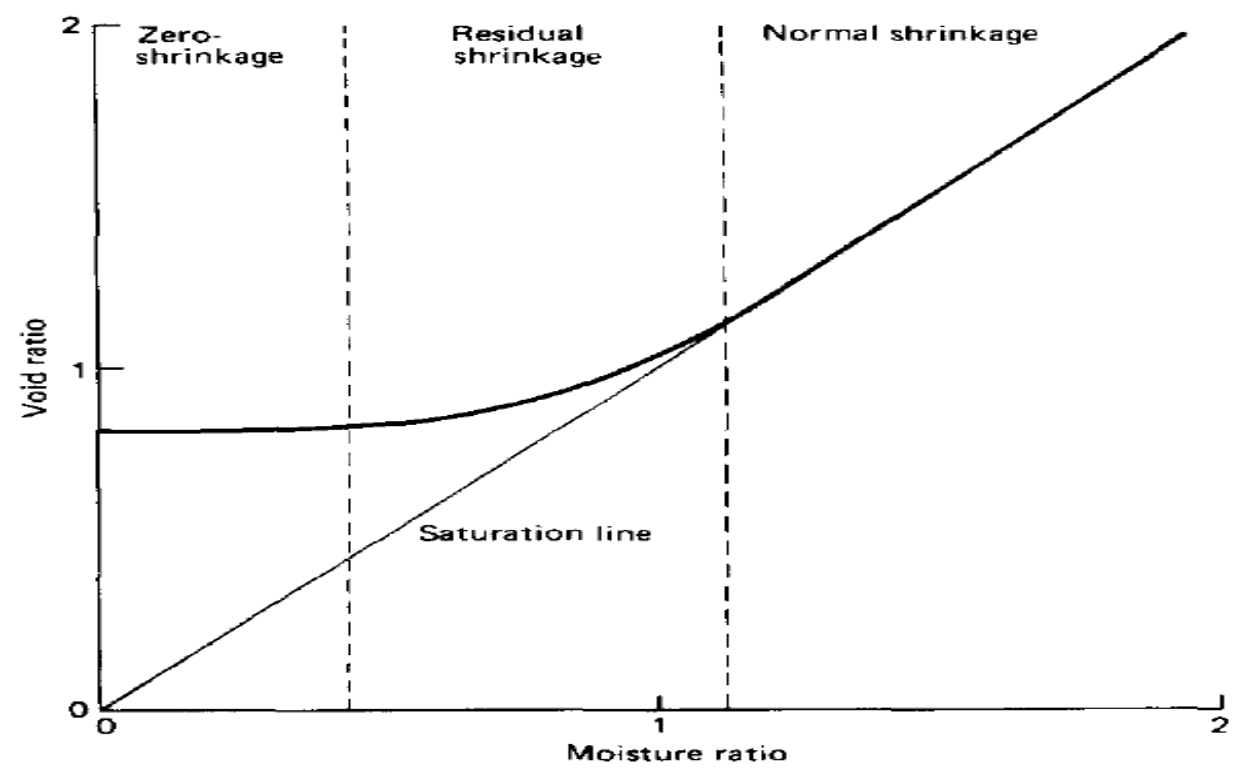

Figure 2.1 General form of soil shrinkage characteristic with three shrinkage phases (Bronswijk, 1988).
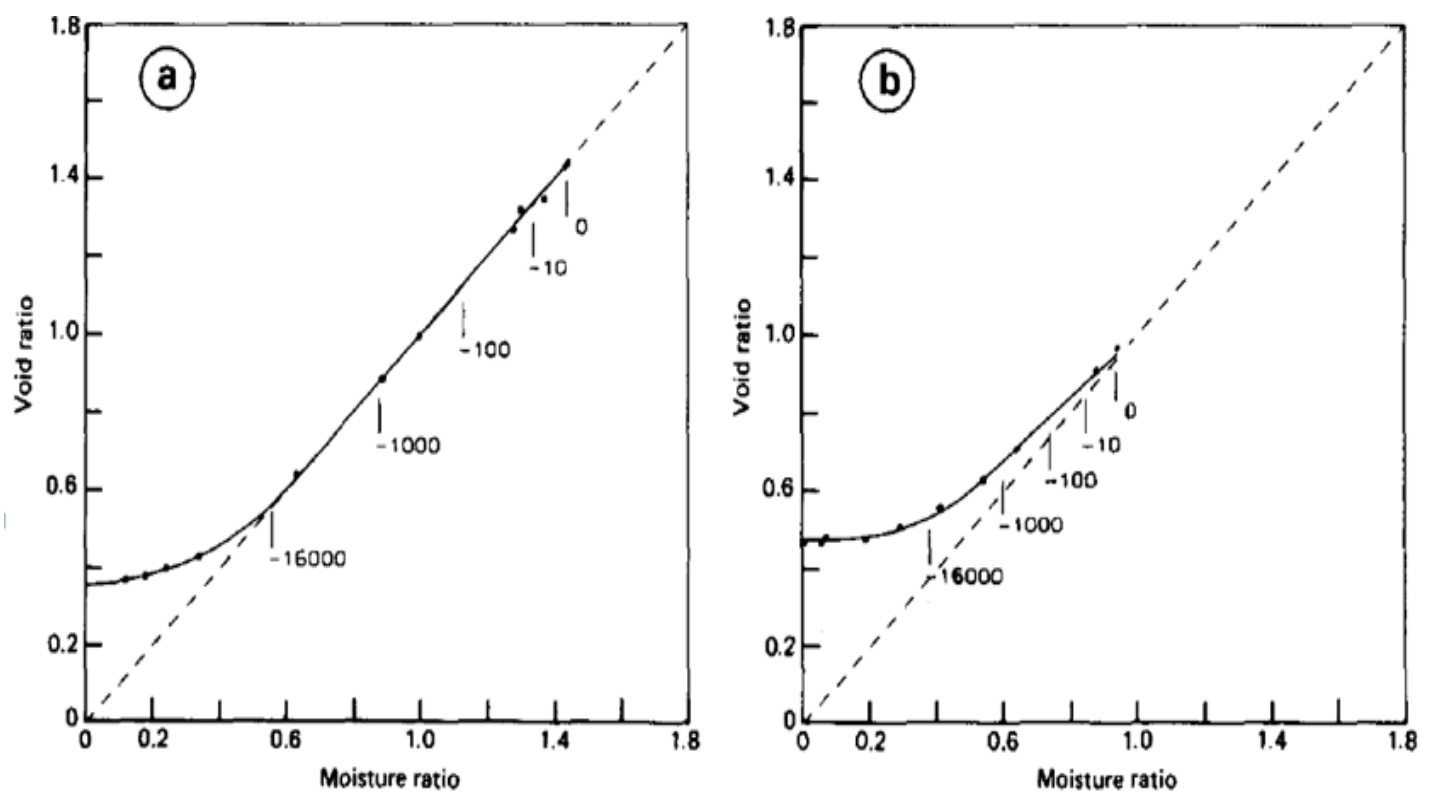

Figure 2.2 Shrinkage characteristic of two clay soils; (a) Oosterend marine clay (41\% clay content) shows mostly normal shrinkage; (b) Kats marine clay (31\% clay content) shows mostly residual shrinkage (Bronswijk, 1988).

Previous studies demonstrated a conversion from one-dimensional shrinkage to uniform three-dimensional shrinkage as the water loss increases (Fox, 1964; Abuhejleh 
and Znidarcic 1995; Tang et al., 2011). Fox (1964) observed a transition occurrence at relatively high water content of $46 \%$. Another study was carried out by Konrad and Ayad (1997) showed changes in intact soil properties during desiccation occurrence at different depths. A noticeable decrease in water content in the upper $40 \mathrm{~cm}$ was reported. This decrease was attributed to the transition from one-dimensional evaporation to threedimensional evaporation. Moreover, settlement was only recorded in the upper $5-7 \mathrm{~cm}$. This was referred to the formation of crust at ground surface along certain depths. This crust prevented further loss in water content as it gained very low hydraulic conductivity (as water content decreased and suction reached very high value) (Abuhejleh and Znidarcic 1995; Konrad and Ayad 1997). This phenomenon was termed as sealing phenomenon, which was reported to happen at water contents close to the soils shrinkage limits (Abuhejleh and Znidarcic 1995). Furthermore, a proportional relationship between the crust thickness and the evaporation rate was developed, when three samples of China clay were exposed to three different evaporation rates. As evaporation rate became severer, the shrinkage limit was reached faster and the desiccation process terminated sooner. Thus, the crust thickness became thinner and showed shallow cracks (Figure 2.3) (Abuhejleh and Znidarcic 1995). 


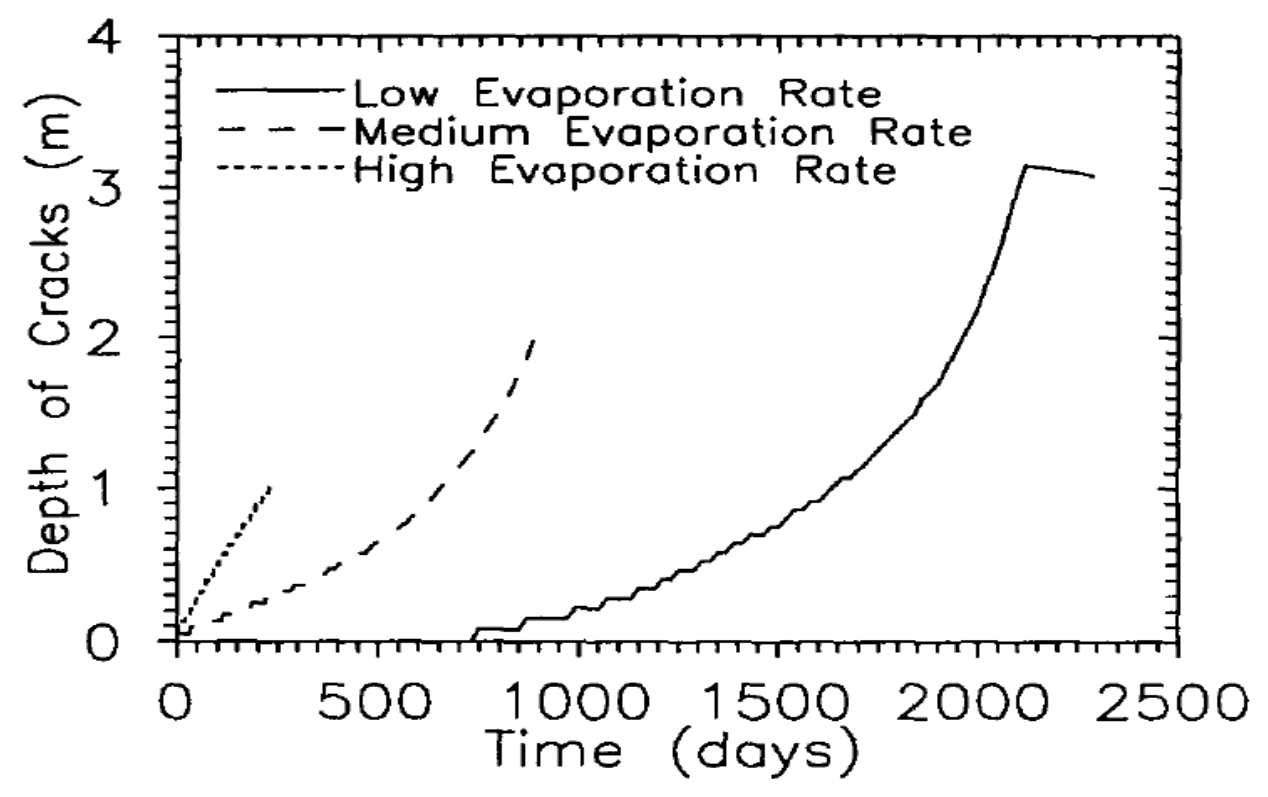

Figure 2.3 Progress of crack depths with time during surface drying (Abuhejleh \& Znidarcic 1995).

In addition to water loss, crack formation was also found to enhance the threedimensional shrinkage. That was stated when Abuhejleh and Znidarcic (1995) chronologically classified the consolidation process during desiccation. This classification consists of four consecutive phases illustrating the progress of consolidation that clay soil depositions might go through in the field. These phases are:

1. Consolidation under one-dimensional compression,

2. One-dimensional shrinkage,

3. Propagation of vertical cracks with tensile stress release, and

4. Three-dimensional shrinkage.

The dependence of three-dimensional shrinkage initiation on the crack formation was further confirmed when Konrad and Ayad (1997) reported an increase in the rate of moisture loss after crack formation due to 3-D nature of moisture transfer. 
Two factors were found to influence the final shrinkage volume; vertical subsidence and lateral cracks (Bronswijk, 1986; Bronswijk, 1988; Tang et al., 2011). Undamaged soils were proved not to experience any lateral deformation. Therefore, any observed shrinkage at this point would be attributed to the vertical subsidence. As dewatering proceeds and soil suction develops, an increase in tensile stresses within the upper soil layer occurs. Cracks generate when the applied tensile stress exceeds the soils' tensile strength. Crack openings create new exposed surfaces to the environment. Therefore, an increase in water loss from the subsurface layers occurs. Subsequently, horizontal shrinkage may be resulted, which beside the vertical subsidence, contributes to the total volume shrinkage (Tang et al., 2011).

Bronswijk (1986) calculated the total volumetric changes in a soil matrix by utilizing a dimensionless geometric factor (rs). This factor provides an estimation of total volumetric changes based on the soil layer thickness and the generated crack dimensions. Therefore, the following formula was proposed:

$$
\begin{aligned}
\mathrm{V} 1 & =(\mathrm{Z} 1)^{3} \\
\mathrm{~V} 2 & =(\mathrm{Z} 1)^{3-\mathrm{rs}}(\mathrm{Z} 2)^{\mathrm{rs}} \\
\frac{\mathrm{V} 2}{\mathrm{~V} 1} & =\left(\frac{\mathrm{Z} 2}{\mathrm{Z} 1}\right)^{\mathrm{rs}}
\end{aligned}
$$

where,

$\mathrm{V}_{1}, \mathrm{~V}_{2}=$ volume of soil matrix before and after shrinkage/swelling respectively $\left(\mathrm{m}^{3}\right)$, $\mathrm{z}_{1}, \mathrm{z}_{2}=$ layer thickness before and after shrinkage/swelling, respectively $(\mathrm{m})$, and $\mathrm{rs}=$ geometry factor. Geometric factor $=3$ at three-dimensional shrinkage, while it is given a value equal to the unity in one-dimensional subsidence. 
When geometric factor and the total soil matrix volume are known, both the changes in layer thickness and crack volumes can be calculated using the following equations:

$$
\begin{aligned}
& \Delta \mathrm{Z}=\mathrm{Z} 1-\left(\frac{\mathrm{V} 2}{\mathrm{~V} 1}\right)^{\frac{1}{\mathrm{rs}}} \mathrm{Z} 1 \\
& \Delta \mathrm{CR}=(\mathrm{V} 1-\mathrm{V} 2)-\mathrm{Z}^{2}(\mathrm{Z} 1-\mathrm{Z} 2)
\end{aligned}
$$

where, $\Delta \mathrm{CR}$ presents changes in crack volume $\left(\mathrm{m}^{3}\right)$, and $\Delta \mathrm{z}$ presents the change in layer thickness (m), (Bronswijk, 1986).

Terzaghi (1925) reported that soil volumetric shrinkage is a consequence of increase in effective stress. Since this finding, the effective stress concept has been widely used to describe the shrinkage phenomenon. An equation proposed by Lambe (1960) expresses the relationship between the internal stresses and total external stresses. This equation was modified by Sridharan (1960) to the following form:

$$
\mathrm{C}=\delta . \eta=\sigma-\mathrm{Uw}-\mathrm{Ua}-\mathrm{R}+\mathrm{A} \quad 2-6
$$

where, $\mathrm{C}=$ effective contact pressure, $\delta=$ mineral to mineral contact stress, $\sigma=$ externally applied stress on unit area, $\eta=$ fraction of the total interparticle area that is mineral to mineral contact, $\mathrm{u}_{\mathrm{w}}=$ effective pore water pressure, $\mathrm{u}_{\mathrm{a}}=$ effective pore air pressure, $\mathrm{R}=$ total interparticle electrical repulsion divided by total interparticle area, and $\mathrm{A}=$ total interparticle electrical attraction divided by total interparticle area.

During shrinkage test, providing an initially saturated soil $\left(\mathrm{u}_{\mathrm{a}}=0\right)$ and assuming a negligible dead weight of soil mass $\left(\mathrm{u}_{\mathrm{w}}=0\right)$, the external force was found not to be more 
than a force that generated due to surface tension (Srldharaan, 1971). Therefore, the equation (2-6) was modified to be in the following form:

$$
\mathrm{C}=\sigma_{\mathrm{TS}}-\mathrm{R}-\mathrm{A}
$$

where, $\left(\sigma_{\mathrm{Ts}}\right)$ expresses the surface tension force (Srldharaan, 1971).

Srldharaan and Rao (1971) concluded that the soil matrix resistance against shrinkage during desiccation is a form of soil shear strength. Thus, an increase in shear strength results in exhibiting higher resistance against the volumetric change and consequently smaller volumetric shrinkage. A linear relationship was detected between surface tension and volumetric shrinkage when Kingery and Franc (1954) studied different solutions with different capillary forces. It was found that the main motive of the volume shrinkage was the surface tension. Srldharaan and Rao (1971) argued that a combination of external load, dielectric constant, and surface tension is related to shrinkage occurrence. Many other studies have proposed other factors that believed to influence the shrinkage (DeJong and Warkentin 1965; Srldharaan and Rao 1971; Reeve et al., 1980; Omidi et al., 1996; Yuen et al., 1998; Albrecht and Benson 2001; Tay et al., 2001; Gray and Allbrook 2002; Zubaydi, 2011). These factors are related to the physical, chemical, and mineralogical properties of the soils.

\subsubsection{Effect of initial water content on shrinkage behaviour}

Several investigators have reported a considerable effect of initial water content on volumetric shrinkage of clayey soil. An increase in volumetric shrinkage was reported whether the soil is compacted wet or dry of optimum (Albrecht and Benson 2001). This 
was attributed to a decrease in the dry unit weight that would happen when the soil is compacted wet or dry of optimum. Decrease in dry unit weight, results in more water molecules and less solid particles in the soil matrix. Therefore, as water evaporates, more space is generated between soil particles which would result in larger volumetric shrinkage (Albrecht and Benson 2001). Tay et al. (2001) reported same results when bentonite-sand mixtures were examined against the volumetric shrinkage. The study showed a linear increase in volumetric shrinkage that occurred as moisture content decreased (Figure 2.4). Thus, as remolding water content increased, soil exhibited higher volumetric shrinkage.

\subsubsection{Effect of clay content on shrinkage}

Clay content is another factor that mainly contributes to soil shrinkage behaviour. Albrecht and Benson (2001) reported remarkable volumetric shrinkage as the clay content increased. A study conducted by Reeve et al. (1980) demonstrated a close relationship between total fine-grained content and volumetric shrinkage. However, insignificant effect was reported with clay fraction $(<0.0002 \mathrm{~mm})$. 


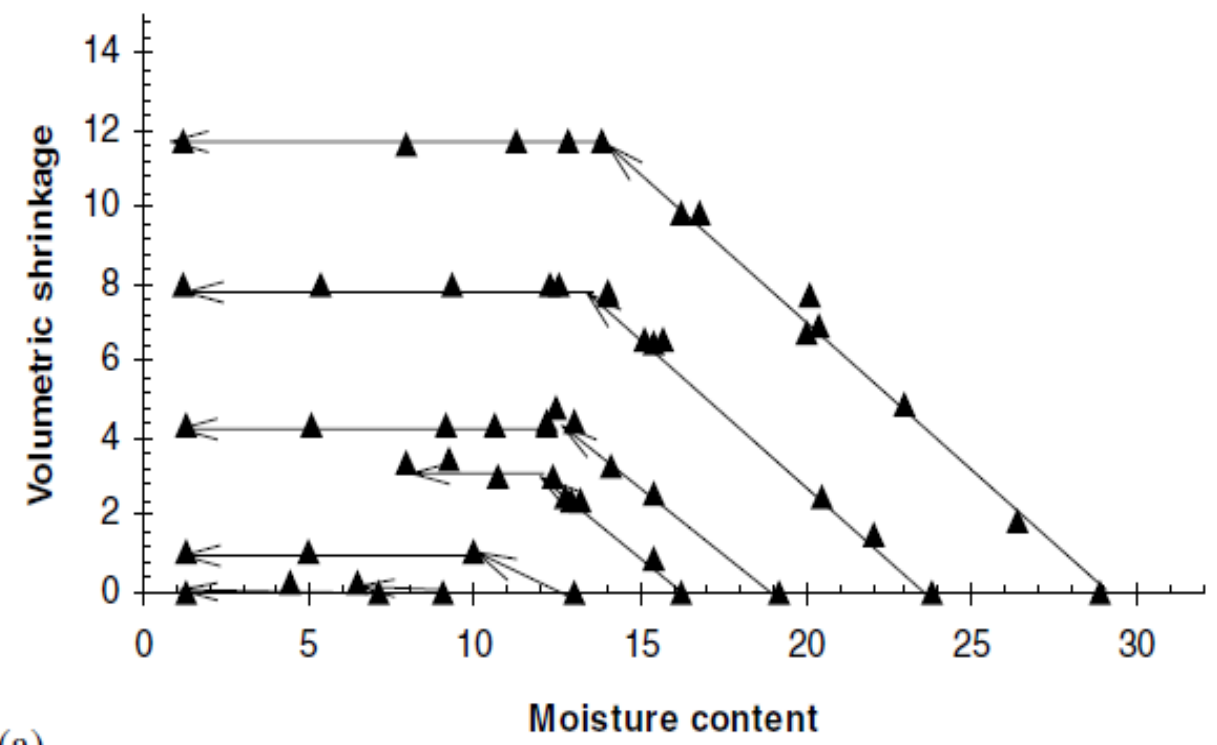

(a)

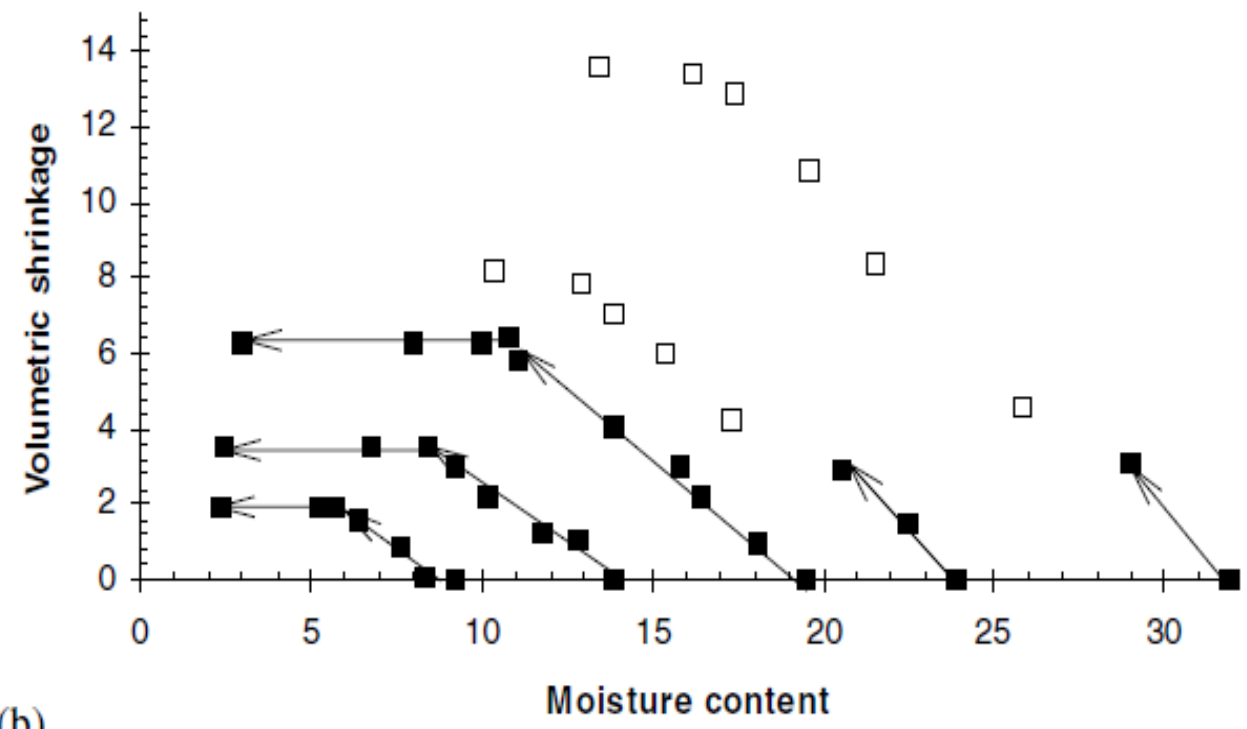

Figure 2.4 Shrinkage paths for specimens: (a) contain $10 \%$ bentonite, and (b) contains $20 \%$ bentonite (Tay et al., 2001). 
In contrast, Gray and Allbrook (2002) used Coefficient of Linear Extensibility (COLE) to examine the correlation between soil properties and soil shrinkage. A weak correlation between volumetric shrinkage and clay content was reported. However, the relationship became noticeably significant when allophane samples were extracted from the regression (Figure 2.5). "Allophane is a short-rang order clay mineral that differs in its particle arrangement" according to Gray and Allbrook (2002). Therefore, the correlation between volumetric shrinkage and clay content is better described within individual group of clay minerals (Gray and Allbrook 2002).

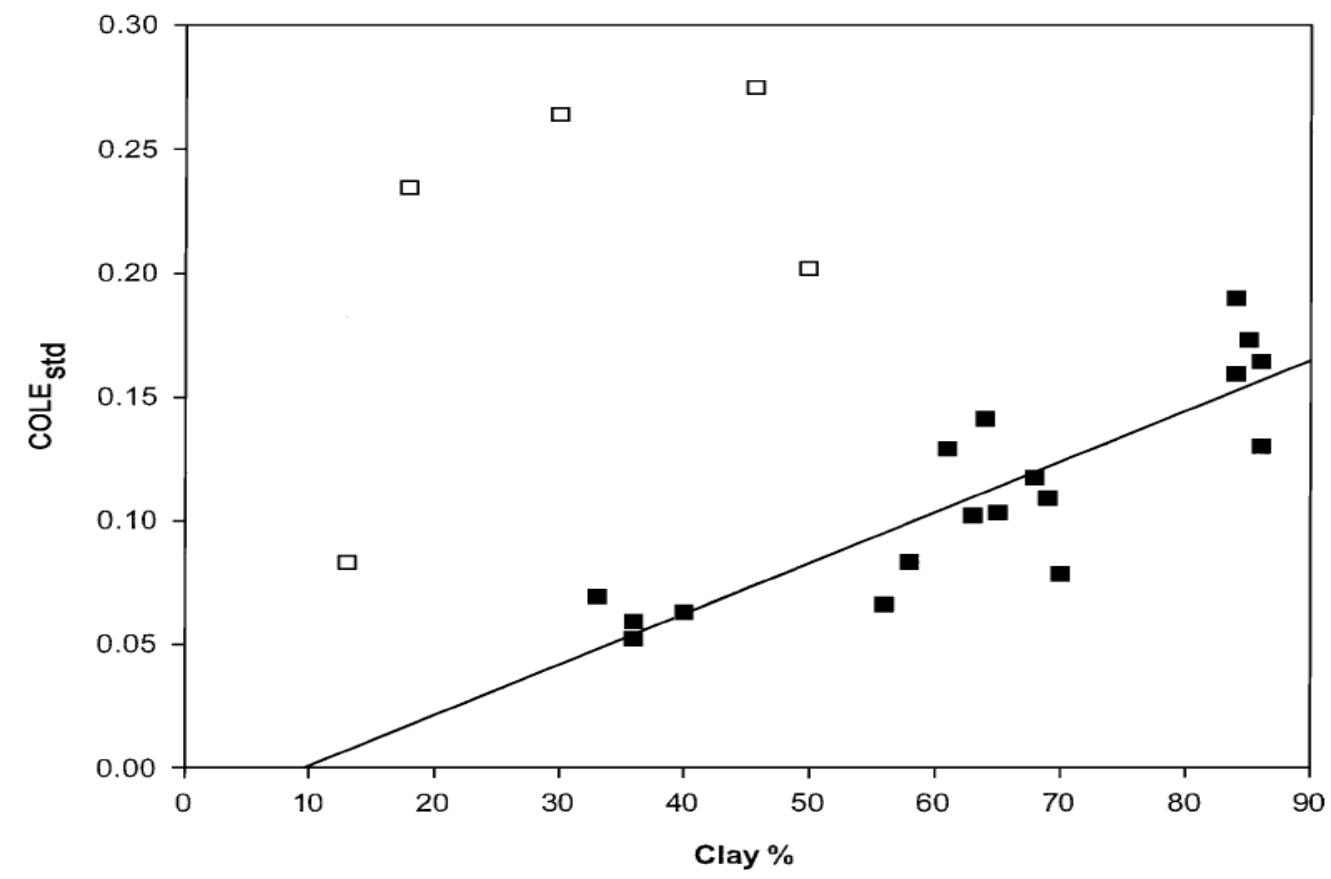

Figure 2.5 Relationship between clay percentage and COLEstd, (Gray and Allbrook 2002).

\subsubsection{Effect of clay mineralogy on shrinkage}

Several studies reported the important role of clay mineralogy as an indicator of total volumetric shrinkage. Smectite minerals, illite and mixtures of them with sand were 
tested to investigate the effect of mineralogy on the volumetric shrinkage (Omidi et al., 1996). Smectite soils showed higher amount of volumetric shrinkage (16.4\%) than the illite, which shrank up to $11.7 \%$ of its initial volume. However, adding $30 \%$ sand to smectite and illite caused reduction in their volumetric shrinkage of $10.3 \%$ and $6.2 \%$ respectively. Albrecht and Benson (2001) stated that when smectite was dominant, soils exhibited very high volumetric shrinkage, while illite, kaolinite, and quartz soils experienced less shrinkage. This was linked to the capability of smectite minerals to adhere more water and consequently would undergo higher shrinkage upon desiccation. Same finding was reported by Tay et al. (2001) when sandy soil was amended with different percentages of bentonite. Gray and Allbrook (2002) and Reeve et al. (1980) used COLE to study the volumetric shrinkage behaviour for different soil mineralogy. Gray and Allbrook (2002) proposed a rank from the most effective to less effective minerals on soil shrinkage. Accordingly, soils that dominantly contain allophane exhibited the highest amount of shrinkage, followed by smectite, kaolinite, and the least shrinkage was for illite. In contrast, Reeve et al. (1980) reported relatively low level of shrinkage for smectite. That was attributed to two possible reasons; either the presence of calcium carbonate or the presence of organic matter (Reeve et al., 1980).

\subsubsection{Other factors affecting soil shrinkage}

Cation exchange capacity (CEC) as well as organic matter was found to have a positive correlation with volumetric shrinkage (Reeve et al., 1980). In contrast, Gray and Allbrook (2002) underestimated their effect on soil shrinkage. On the other hand, both these studies agreed on the significance of the reverse relationship between bulk density and volumetric shrinkage according to COLE values. The effect of wet-dry cycles on soil 
shrinkage was widely discussed (DeJong and Warkentin 1965; Albrecht and Benson 2001; Zubaydi 2011). All reported a significant decrease in soil matrix volume at first wet-dry cycle, but the following cycles exhibited lower shrinkage potential. Beside wetdry cycles, Zubaydi (2011) investigated the effect of external applied load on volume reduction. He reported a decrease in volumetric shrinkage as the vertical applied load increased. Same finding was reported by Srldharaan and Rao (1971) who stated a decrease in shrinkage void ratio as the consolidation pressure increased (Figure 2.6). In addition, remarkable effect of clay fabric on volumetric shrinkage was stated when soil with parallel particle arrangement exhibited volume reduction larger than the random arrangement (Srldharaan and Rao 1971). DeJong and Warkentin (1965) argued the previous statement when a decrease in soil shrinkage was reported as soil particle became in parallel array. However, the variation in results was linked to the difference in mineral composition. 


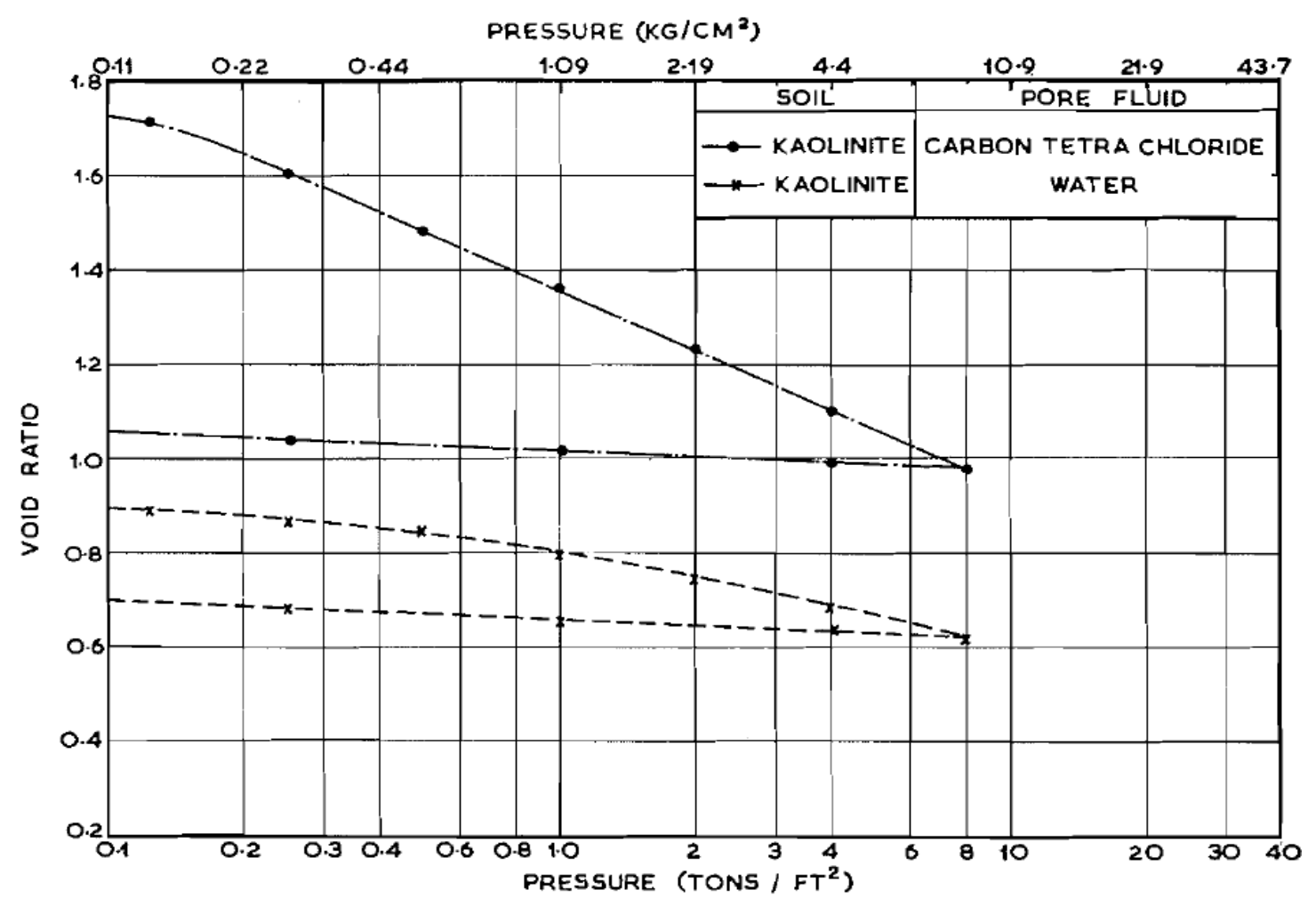

Figure 2.6 Vertical applied pressure. V.s. void ratio (Srldharaan and Rao 1971).

\subsubsection{Crack inceptors:}

As previously mentioned, cracks occur at specific location when the generated matrix suction exceeds soil's tensile strength at that location. Therefore, soil suction and soil strength substantially affect the crack initiation. Tang at al. (2011) termed soil suction as the mechanical initiator of cracking, and any parameter related to soil suction or soil tensile strength would widely influence the desiccation cracking. Pore air pressure and other defects were also classified as crack initiator (Morris et al., 1991).

Investigations on constrained and unconstrained desiccation of cohesive soil were carried out to track shrinkage and crack initiation (Peron et al., 2009). Onset of cracking was found to occur at a degree of saturation close to $100 \%$. Similar results were reported 
by Anderson and Klein (1987) when cracks initiated in gels at overall degree of saturation close to $100 \%$ and water content was not far of shrinkage limit. This phenomenon was attributed to a dry front formation in the gel at air entry value (Scherer, 1990). This front leads to separation of the gel matrix to de-saturated zone and almost fully saturated zone (Figure 2.7). The scatter of air-filled pores over the saturated zone creates drained channels that could be counted as defects in soil matrix that lead to crack inception (Peron et al., 2009).

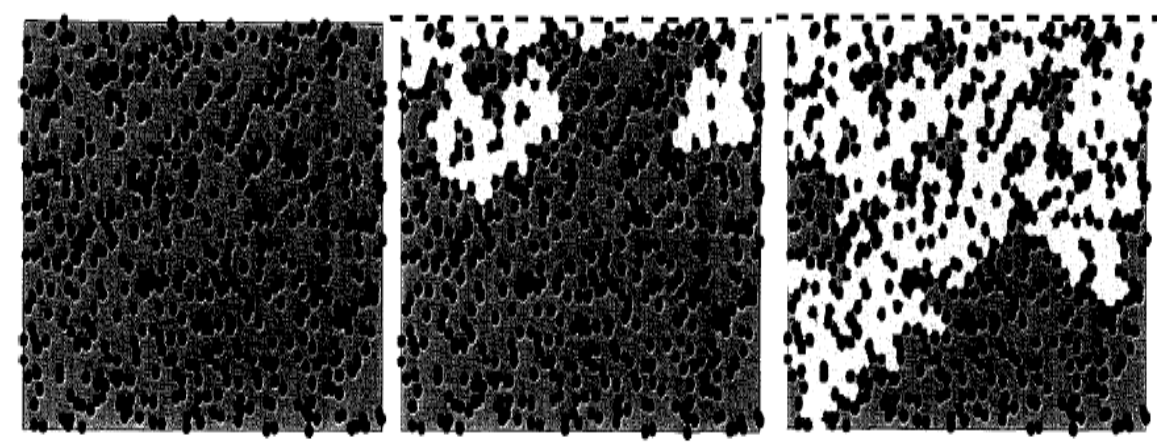

Figure 2.7 Mechanism of drying and formation of the drying front (Peron et al., 2009).

Dry zone also found to be generated within the saturated areas due to water cavitation phenomenon. Water cavitation occurs when water pressure drops below the water vapour pressure within a soil matrix. Providing local ambient temperature, water is exposed to alternation from liquidity to gas phase. This might lead to generation of vapour-filled pores or cavitation bubbles (Peron et al., 2009). The energy that is required for the gas bubbles to defeat the barrier resistance is expressed by Or and Tuller (2002) in the following equation:

$$
\Delta \mathrm{EB}=4 \pi \mathrm{rc}^{2} \mathrm{Ts}+\frac{4 \pi}{3} \mathrm{rc}^{3}(\mathrm{pa}-\mathrm{pw})
$$


where,

$r_{c}=$ the bubble radius, $T_{s}=$ the surface tension of the water vapour, and $\left(p_{a}-p_{w}\right)=$ the matrix suction.

In addition, Young-Laplace equation can provides the maximum energy for bubble radius as following:

$$
\mathrm{rc}^{*}=\frac{-2 \mathrm{Ts}}{\mathrm{pa}-\mathrm{pw}}
$$

From equation 2-9, it can be inferred that as the bubbles get smaller, suction gets higher without generating any cavitation. Cavitation can occur in two different conditions. First, when there are no pre-existing bubbles, water would be exposed to high value of suction without cavitation formation. However, as surface tension rises up, bubble formation energy is increased and leads to cavity occurrence. Second, which is the common case, when bubbles pre-exist in water and results in cavitation occurrence as water pressure achieves a value that corresponds to bubble radius value provided by Equation 2-9.

In case of crack initiation, the generated bubbles can only be released from the surrounding water pores when water vapour bubbles are extracted from the pours system. This extraction requires very high suction, even higher than air entry value. Thus, bubble cavitation is generated and behaves as defects, which promote crack initiation. Same pattern of cavitation may occur earlier in larger pores, which lose their water in early stage of the process (Peron et al., 2009).

Groisman and Kaplan (1993) digitally observed a crack initiation in a coffee-water mixture at surface defects. A tendency of generating a sharp shape at the air bubble 
locations was reported when the tensile stresses increase. That led to crack penetration within the entire depth at the defect locations and this process was termed as nucleation. Other type of crack inceptors related to surface topography was detected by Tang et al. (2011). A weak tensile strength at the concave surfaces was reported and attributed to the higher moisture content and porosity than the surrounding area. Thus, these depressed points presented a suitable environment for cracks to be formed. The convex surface on the other hand was distinguished with high tensile stress. This stress concentrated at the convex tips and caused cracking at that location earlier than at the surrounding areas (Tang et al., 2011).

\subsubsection{Desiccation cracking:}

Cracked soils are shown to lead to substantial changes in their hydraulic properties due to the change in their structure (Gray, 1989; Omidi, 1993; Rayhani et al., 2008). In waste disposal facilities, the integrity of clayey barrier systems is a crucial matter, which is widely influenced by the crack occurrence. Providing the same water content, cracks promote a higher hydraulic conductivity in fractured soils than the intact soils (Morris et al., 1991). Gray (1989) studied geotechnical factors that affect waste disposal systems. He stated that the presence of shrinkage and desiccation cracking could strongly affect the matrix stability as well as the matrix permeability of waste containments. $\mathrm{He}$ identified two kinds of flow that may happen throughout the soil matrix based on its integrity 1) Uncracked soil matrix shows liquid flow through and within the particle pores 2) Cracked soil matrix shows water flow through volume defects such as fissures, cracks, cavities, and pinholes. Gray (1989) also defined two categories of cracks based on their mechanisms of occurrence and their pathways, namely mechanically induced cracking 
and physic-chemically induced cracking. Mechanically induced cracking is divided into three types based on their causatives 1) Construction cracking induced by compaction of weak or laterally unconfined subgrades 2) Settlement cracking induced by severe subsidence or differential subsidence 3) Compaction cracking induced by poor connectivity between successive lifts, which causes transverse cracking between these lefts. Physic-chemically induced cracking is also divided into two types 1) Syneresis cracking induced by balance change of interparticle forces, and 2) Desiccation cracking induced by water loss (evaporation) (Gray, 1989).

Downward drying causes the cracks to initiate from the surface because soil surface has the lowest self-weigh and the highest soil suction. Furthermore, the formation of microcracks on the soil surface in shape of interparticle voids facilitates the cracks to propagate downward from the soil surfaces (Morris et al., 1991).

\subsubsection{Boundary conditions}

George (1968a) carried out experimental and theoretical study on pavement cracking and stated that the generation of tension stresses due to soil shrinkage is mainly related to boundary condition. If the soil is free to uniformly shrink and no considerable friction is provided by subgrade, then stresses will not have a chance to generate. In field conditions, only the upper part of the soil is exposed to the atmosphere. Therefore, desiccation will lead to non-uniform shrinkage and creating a friction between upper soils and underlying layer, which eventually results in cracking.

Groisman and Kaplan (1993) reported that the restriction of soil shrinkage could generate increasing horizontal stresses, which eventually would be relieved by cracking. Soil viscosity and boundary friction were identified as the main opposing forces that 
prevent crack occurrence. In order to investigate that, Groisman and Kaplan (1993) prepared three samples with various boundary conditions. The samples of coffee-water mixtures were placed in containers that had a) uncoated bottom, b) $2 \mathrm{~mm}$ grease coated bottom, and c) $6 \mathrm{~mm}$ Vaseline coated bottom. A decrease in crack segmentations and intersections were reported as the container bottom became smoother. It was concluded that the boundary condition was the main factor that influenced the stress development, (Figure 2.8). Similar results were achieved by Peron et al. (2009) who investigated the effects of boundary conditions on crack generation in slabs made out of fine-grained soils. The investigators reported that the stresses that resulted in crack onset were related to the appearance of restrained boundary conditions and (or) generating of water heterogeneity within the soil matrix.

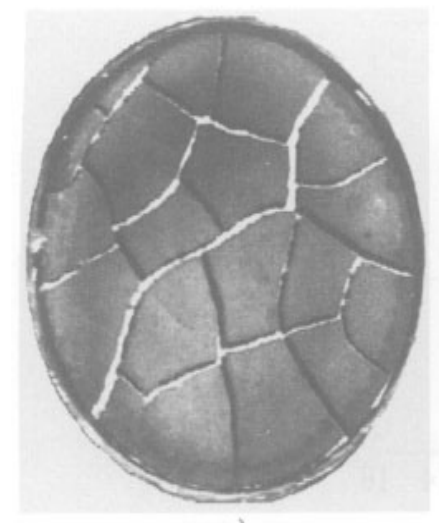

a)

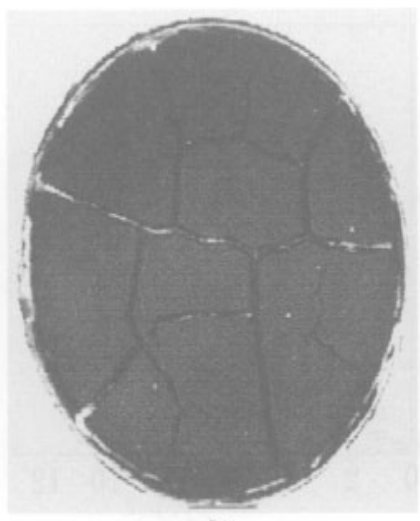

b)

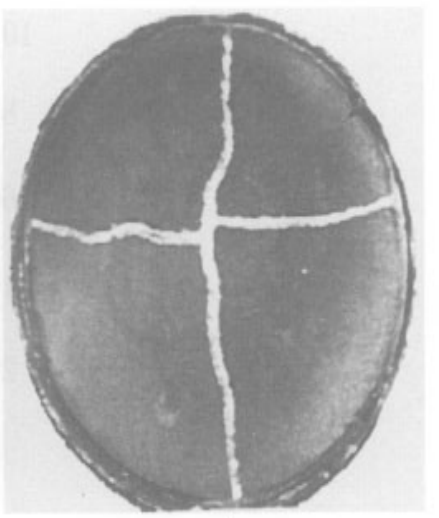

c)

Figure 2.8 Effect of boundary conditions on crack geometry; a) uncoated bottom, b) $2 \mathrm{~mm}$ grease coated bottom, and c) 6mm Vaseline coated bottom (Groisman and Kaplan 1993).

\subsubsection{Cracking water content}

Cracking water content is the water content measurement at the time of crack initiation. It was found that, as the thickness of soil layer increased the cracking water content 
increased as well (Nahlawi and Kodikara 2006). This was attributed to the water flow from the lower part to the upper part of the soil layer during the desiccation. This flow increased as the soil layer thickness increased, and in thicker layers the flow continued even after crack initiation which caused rising of cracking water content. Soil cracking, however, was reported to occur at early stage of desiccation at a degree of saturation close to $100 \%$ (Peron et al., 2009; Tang at al., 2011). Furthermore, Peron et al. (2009) stated that the cracking inception, air-entry value, and shrinkage limit all found to occur in very tight range in regard to the time of occurrence and water content value. Dissimilar finding was presented by Tang et al. (2011) when cracking water content recorded at $41 \%$, which was much higher than the air-entry value at $14.5 \%$, (Figure 2.9 ). The result variations were referred to the variations in materials, test conditions, and test methods.

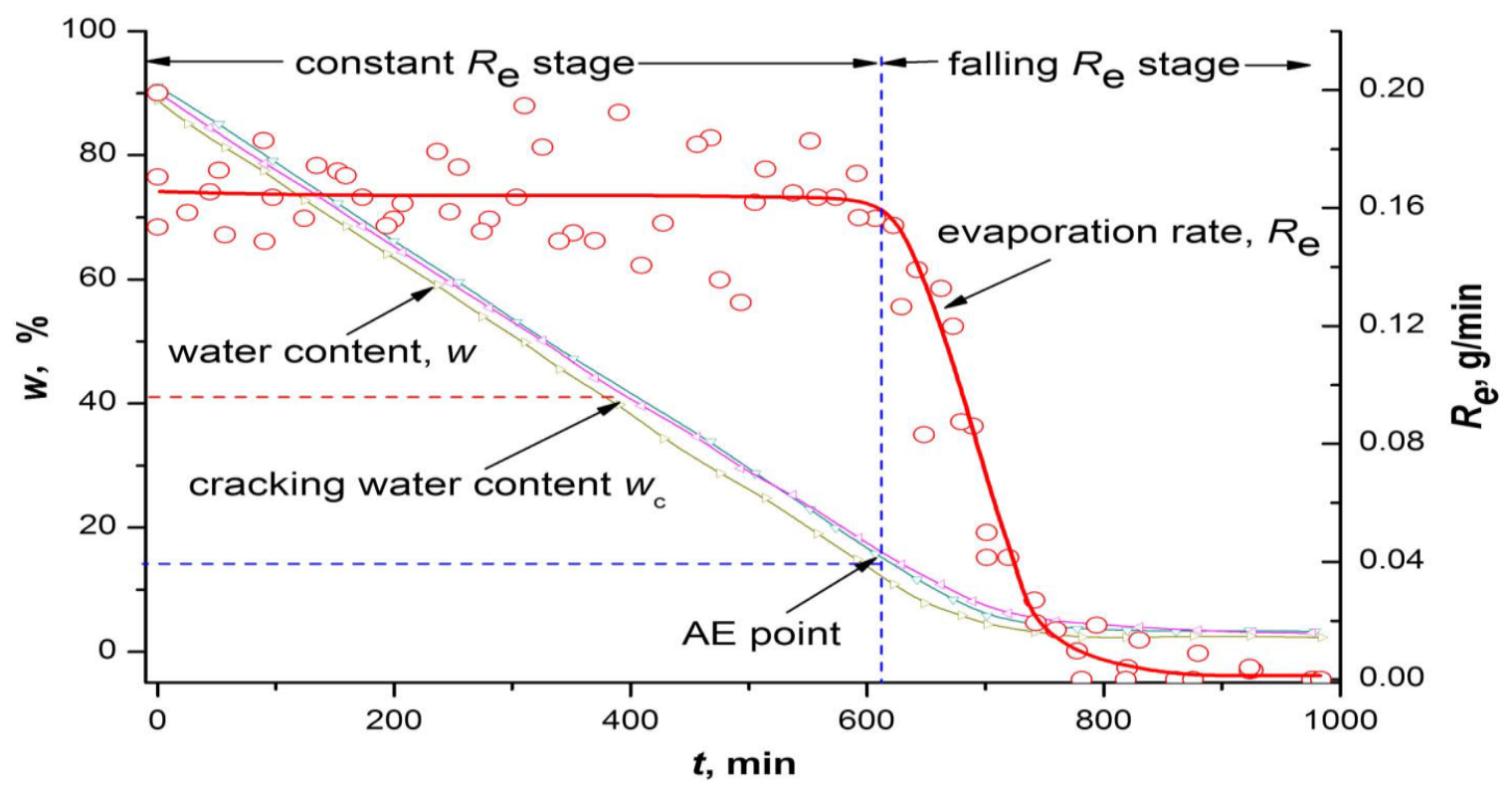

Figure 2.9 Changes of water content $(w)$ and evaporation rate $\left(R_{e}\right)$ of soil specimens with drying time (Tang et al., 2011). 


\subsubsection{Crack propagation pattern}

Once cracks initiate, they try to spread throughout the soil matrix following the same path of desiccation. Cracks tend to propagate in both vertical and horizontal directions. Vertical propagation is mostly restricted by increasing confining stresses due to selfweight of the soil. However, horizontal propagation is limited by crack intersections (Morris et al., 1991). Groisman and Kaplan (1993) suggested that the velocity of crack propagation is a complicated function of strength of the soil, applied stresses, and boundary conditions. In 1924, Griffith proposed two correlations that link crack length with matrix suction, on one hand, and crack length with tensile stress on the other hand. He stated that the transverse tensile stress required for causing a crack of length (2A) to propagate is inversely proportional to the square root of (A). In addition, matrix suction

was found to be higher in fine-grained soils and proportional to $\left(\mathrm{A}^{-1}\right)$. The above two correlations indicate that a higher tensile stress is required to cause crack to propagate in fine-grained soils than in coarser soils. (Griffith, 1924).

As desiccation proceeds, cracks in both directions (i.e., depth and length) become larger and crack net becomes clearer. Even though cracks tend to propagate randomly on the surface, they intersect each other in approximate right angles $\left(90^{\circ}\right)$. Subsequent secondary cracks appear and tend to break the blocks between existing cracks into smaller polygons. Secondary cracks initiate at the most restrained point within the existing blocks, which is at the middle of the longest side of these blocks. Vertically, secondary cracks are initiated at the soil surface and penetrate downwards, but horizontally they propagate perpendicular to the existing cracks and toward them until they intersect. Crack sides at the crack intersection provide new areas to be desiccated 
where they become more exposed to drying. This causes the suction to be maximized at these corners. However, the restrained stresses and the bottom frictions at these corners are less than the stresses at the middle of the blocks. This can explain the secondary crack initiation at the middle of existing blocks not at the corners. Block subdivisions will continue until the point that the size of the generated blocks decreases and defeats their own restrained stresses at the block bases (Morris et al., 1991).

In some cases, weak interfaces within the soil layers can appear and stop the vertical crack propagation. This issue can be found in mine tailings and Varved clays between fine and coarse layers (Morris et al., 1991). This horizontal interface, which lies in front of the existing vertical cracks, is exposed to vertical tensile stresses that can lead to tensile failure. The horizontal stresses that lead the vertical cracks to occur will be reduced by the new vertical stresses, which work parallel to the existing vertical cracks. As a result, sub-horizontal cracks are generated and stop the vertical cracks propagation. In contrast, the sub-horizontal cracks are produced by compressive stresses, which seldom allow them propagate far (Morris et al., 1991). Similar observation was reported by Konrad and Ayad (1997) who reported a sub-horizontal cracks that reached 3-4 cm which represented a third of the polygon sizes. However, they noted a formation of new vertical cracks that propagated downward and initiated at the sub-horizontal crack tips. This resulted in producing protuberance in size ranges between 4 and $6 \mathrm{~cm}$ as it is shown in (Figure 2.10), (Konrad and Ayad 1997).

Layer thickness, ambient temperature, and wet-dry cycles are some factors that found to influence the final crack patterns and dimensions (Groisman and Kaplan 1993; Nahlawi and Kodikara 2006; Tang et al., 2008; Peron et al., 2009). Groisman and Kaplan 
(1993) observed a linear relationship between the crack polygon areas and the fractured layer thickness. Their observation showed that the thinner the layer, the higher the drying rate. This led cracks to generate individually all over the surface at the same time without forming any defined shapes of polygons. Furthermore, these formed cracks intersected each other in angle close to 120 (Groisman and Kaplan 1993). 


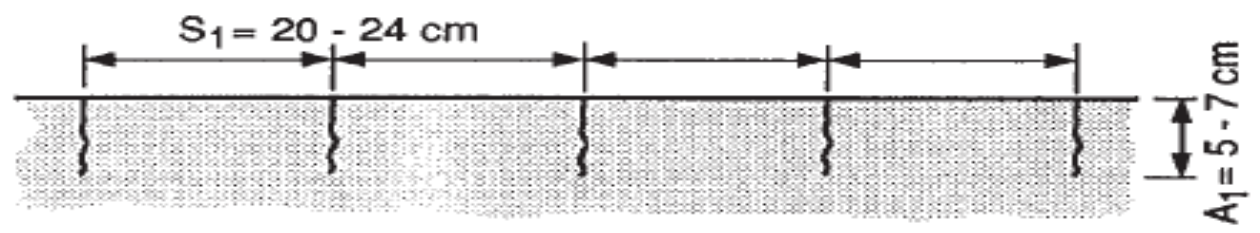

(a) Initiation of primary cracks for $\mathrm{t}<17 \mathrm{~h}$

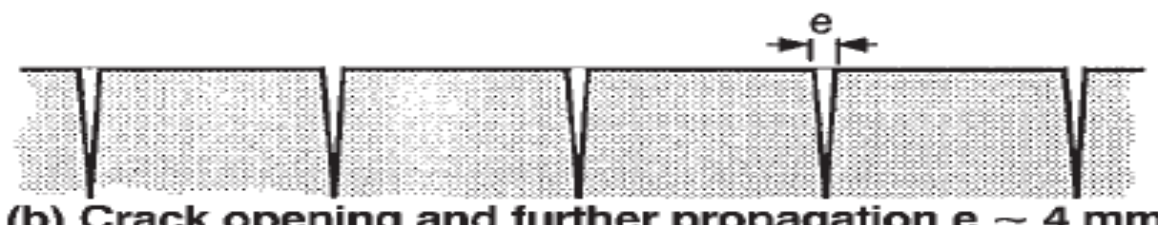

(b) Crack opening and further propagation $\mathrm{e}-4 \mathrm{~mm}$ at $80-100 \mathrm{~h}$

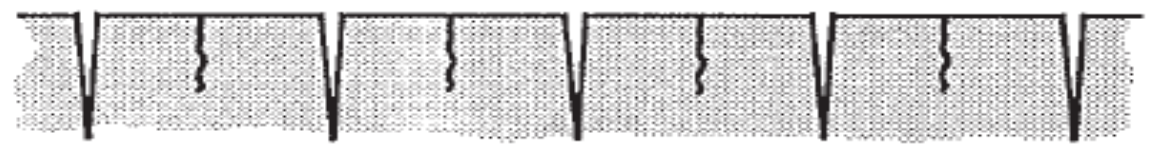

(c) Initiation of secondary cracks at $80-100 \mathrm{~h}$

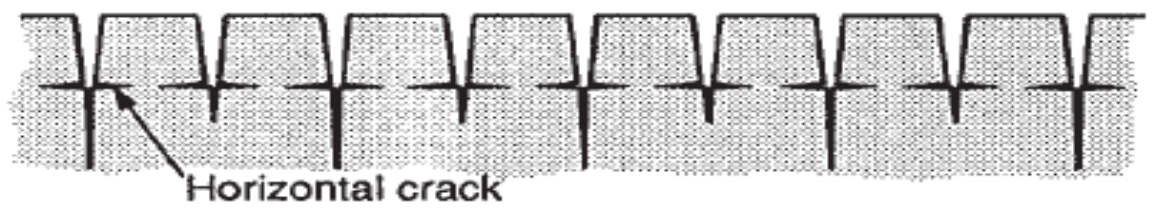

(d) Differential shrinkage - Horizontal crack propagation in mode II (in plane shear) at 100 - $150 \mathrm{~h}$

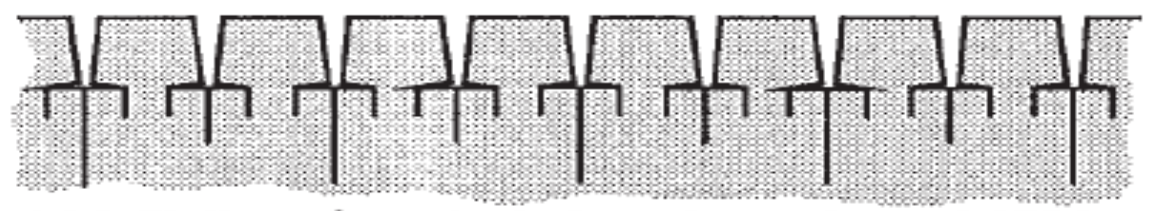

(e) Initiation of cracks below shear plane at $150 \mathrm{~h}$

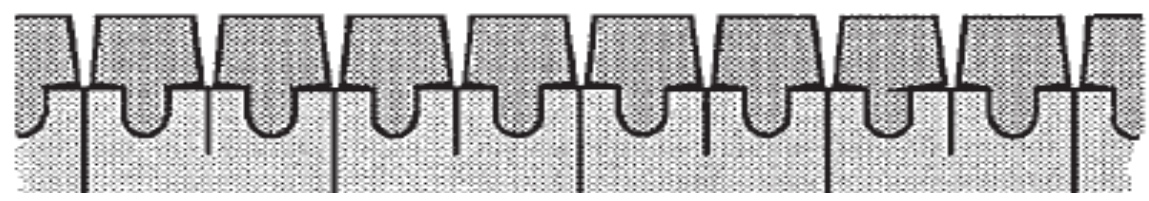

Figure 2.10 Different stages of crack propagation (Konrad and Ayad 1997).

Grain-water-bottom adhesion was referred as the causative factor of the bottom friction that would resist the contraction of the soil matrix and cause the materials to crack and break down. The bottom friction was found to be responsible for generating tensile stresses (q) that is defined as the ratio between tensile forces (p) and the unit thickness of the layer $(\mathrm{t})$. 


$$
\mathrm{q}=\mathrm{p} / \mathrm{t}
$$

On the other hand, the length of the formed polygons (L) was found to be proportional to the tensile stresses since the tensile stresses were functions of the bottom friction $(\mathrm{P} \sim \mathrm{L})$. That led to forming the following equations:

$$
\begin{aligned}
& \mathrm{q}=\frac{\mathrm{p}}{\mathrm{t}} \sim \frac{\mathrm{Lcr}}{\mathrm{t}} \\
& \mathrm{Lcr} \sim \mathrm{q} * \mathrm{t}
\end{aligned}
$$

From the equation (2-12), it can be inferred that the critical length $\left(\mathrm{L}_{\mathrm{cr}}\right)$ that is required to provide certain stress (q), which causes material to break down, is proportional to the thickness of the layer $(\mathrm{t})$. In other words, the fragmentation process will continually occur until the longest side of the formed polygon becomes shorter than the critical length $\left(\mathrm{L}_{\mathrm{cr}}\right)$. Furthermore, the final length of the formed polygon would increase as the final thickness of the layer increase (Groisman and Kaplan 1993). This statement came in agreement with the Nahlawi and Kodikara (2006) and Tang et al. (2008) observations, which reported an increase in the formed cells' areas when the layer thickness was increased. Tang et al. (2008) also defined the crack intensive factor (CIF) as a ratio between the areas of formed cracks to the total surface area. Significant increase in crack width and crack intensive factor (CIF) was reported as the layer thickness increased. This was attributed to the increase of normal and effective stresses as the layers become thicker (Tang et al., 2008).

Evaporation rate can vary based on the ambient temperature and humidity. Low evaporation rate causes cracks to be wider, longer, and deeper. The CIF value also becomes higher as the evaporation rate drops down. Crack length, crack width, and 
average area of segmentations were found to be sensitive to the temperature as well as to the number of wet-dry cycles. Increase in the ambient temperature leads to increase in crack length, crack width, and average area of segmentations. However, those aspects beside the CIF all decrease with an increase in the number of wet-dry cycles (Tang et al., 2008). An important role of the boundary conditions and the boundary flux conditions was reported to have impact on the crack geometry (Peron et al., 2009).

Generally, crack phenomenon is one of the most complicated issues in geotechnical and geo-environmental engineering. In field, soils are exposed to several cycles of wetdry and/or freeze-thaw during the year. These cycles result in crack formation as soil desiccates or freezes. However, the subsequent wetting or thawing can lead to partial crack closure, which results in what is known as self-healing phenomenon. Even though, self-healing widely contributes to cure the forming cracks, cracks continue working as macropores that serve water movement within the soil matrix. As a result, desiccation cracking degrades the hydraulic conductivity of the soils, and that is considered a big challenge when the problem related to the integrity of waste disposal containments.

\subsubsection{Self-healing}

Fractured clayey soils tend to change their behavior as they experience changes in their situations from dry to wet condition. In rainfall seasons, cracks and fissures are filled up with water, which quietly soaked up by the soil particles and causes the soil to rewet. Soil rewetting leads to decreasing soil strength and increasing its unit weight. Therefore, soil particles tend to collapse and slide on each other due to the decrease in the soil shear strength. Sliding leads soil particles to fall into the opening cracks and fractures, which results in partially crack closures. This induces re-establishing the soil permeability to be 
as closer as its intact permeability (Rayhani et al., 2007; Rayhani et al., 2008; Eigenbrod, 2003).

The effect of self-healing on hydraulic conductivity of fractured clayey soils was investigated by Rayhani et al. $(2007,2008)$ by exposing four clayey soils to wet-dry cycles followed by measurement of crack dimensions and volumetric shrinkage. The observation showed decrease in hydraulic conductivity upon wetting for the soils with medium and high plasticity index, while no significant change in hydraulic conductivity was recorded for other soils that had lower PI when subjected to hydration. Thereby, selfhealing effect was more pronounced in soils with medium and high plasticity and swelling potential. Another self-healing investigation was carried out on bentonite-sand mixtures after exposure to cycles of wet-dry by Schuster (1986). Three mixtures were prepared and categorized based on their activity (ratio between PI and clay content), (Table 2.1). In sodium bentonite-sand mixture, no change was recorded in hydraulic conductivity of mixtures with very low clay content of $2 \%$, while mixtures with higher clay content but less activity such as calcium bentonite and Opalinus clay mixtures, exhibited hydraulic conductivity increase by factors ranged between 12-200 and 6-10 respectively.

During dewatering, capillary pressures enhance water extraction from clay films that encircling sand grains and lead to cracking and separating this clay film layers from sand grains. In subsequent hydration, low active soils exhibit deficiency in reestablishing clay films surrounding sand grains due to inadequate electrical forces of clay particles. Moreover, flow force would cause erosion and damage for clay films, which eventually may result in increasing hydraulic conductivity. On the other hand, high active 
soils experience re-establishment of their clay films since the electrical forces provided by clay particles can bear the effect of capillary forces. Thus, hydraulic conductivity would decrease to be as low as the intact conductivity (Schuster, 1986).

Eigenbrod (2003) analyzed experimental data from several freeze-thaw tests conducted on fine-grained soils in an attempt to understand the mechanism of selfhealing. Three possible reasons are believed to be behind the occurrence of self-healing in fine-grained soils including:

1. Exposing soils to very high effective stress that exceeds their undrained shear strength,

2. Blocking up fractures and cracks by collapsed particles during permeation in low or non-plastic soils, and

3. When particles at cracked area experience swelling which occurs in highly swelling soils.

Table 2.1 Geotechnical properties of clayey soils used by Schuster (1986).

\begin{tabular}{lccccc}
\hline Clay type & PL (\%) & LL (\%) & PI (\%) & $(\%)<2 \square m$ & Activity (\%) \\
\hline & & & & & \\
Opalinus-clay & 18 & 44 & 26 & 50 & 0.52 \\
Ca-bentonite & 34 & 134 & 100 & 78 & 1.28 \\
Na bentonite & 33 & 518 & 485 & 78 & 6.2 \\
\hline
\end{tabular}




\subsubsection{Hydraulic conductivity}

Hydraulic conductivity is the main assessment tool that utilized to choose the most appropriate material for clay barrier construction. Fetter (1980) defined the hydraulic conductivity as the passing rate of a liquid through the porous material. Since 1956, water flow through soil matrix has been mostly analyzed based on Darcy's Law that proposed a proportional correlation between volumetric water flow through a porous medium on one hand, and hydraulic gradient, hydraulic conductivity and area cross-section of the medium on the other hand. Theoretically, the volumetric flow based on Darcy's Law can be expressed by the following equation:

$$
\mathrm{Q}=-\mathrm{K} * \mathrm{i} * \mathrm{~A}
$$

where, $\mathrm{Q}=$ volumetric flow rate $\left(\mathrm{cm}^{3} / \mathrm{sec}\right), \mathrm{A}=$ area cross section of porous medium $\left(\mathrm{cm}^{2}\right) . \mathrm{K}=$ hydraulic conductivity $(\mathrm{cm} / \mathrm{sec})$, and $\mathrm{i}=$ hydraulic gradient $(\mathrm{cm} / \mathrm{cm})$ which is defined by the ratio between the hydraulic head applied on a sample to the length of the sample.

Natures of the fluids and porous mediums were found to affect K (Fetter, 1980). Coefficient of permeability $(\mathrm{k})$ was employed to normalize hydraulic conductivity $(\mathrm{K})$ to fit different fluids with different densities and viscosities. An alternative form of Darcy's Law was proposed by De Wiest and Bear (1967) and used to express the volumetric flow of any liquid through a porous medium as following:

$$
\mathrm{Q}=\frac{(-\mathrm{k} * \rho * \mathrm{~g})}{(\mu * \mathrm{i} * \mathrm{~A})}
$$

where, $\rho=$ density of fluid $\left(\mathrm{g} / \mathrm{cm}^{3}\right), g=$ gravitation constant $\left(\mathrm{cm} / \mathrm{sec}^{2}\right), \mu=$ viscosity of the fluid ( $\mathrm{g} / \mathrm{cm} \cdot \mathrm{sec})$, and $\mathrm{k}=$ coefficient of permeability or intrinsic permeability $\left(\mathrm{cm}^{2}\right)$. 
Wide range of hydraulic gradients has been used by researchers for hydraulic conductivity measurement. However, excessively low or high hydraulic gradient could cause a flow pattern that may not comply Darcy`s law. Very low hydraulic gradient was reported to generate disproportional low flow through soil matrix (Oakes, 1960; Hansbro, 1960). Bowles (1979) suggested a minimum hydraulic gradient of 2 to 4 that may be needed for clay soils to overcome molecular force that restrains the mobile water to the clay particles. On the other hand, Yong and Warkentin (1975) believed that increasing the driving force of the flow would probably reduce the immobilized fluid thickness that surrounds soil particles, which would result in increase of the actual pore diameter as well as hydraulic conductivity. Olson and Daniel (1979) and Michell and Younger (1967) argued that the permeation under large hydraulic gradient may cause soil particles to migrate and densify the lower soil layer which could result in decreasing hydraulic conductivity. For liner design and other field applications, simulated hydraulic gradient in laboratory hydraulic conductivity measurement should be close to the anticipated field value (Olson and Daniel 1979).

Hydraulic conductivity can be measured by using either constant head or falling head test methods. Constant head method is used to measure $(\mathrm{K})$ for coarse-grained materials by applying a constant water head during permeation and measurement. Falling head is used to estimate $(\mathrm{K})$ for fine-grained soils, however, permeant head is allowed to drop down during measurement. Equations (2-15) and (2-16) show the formulas that are used to estimate hydraulic conductivity in falling head and constant head respectively.

$$
\begin{array}{ll}
\mathrm{K}=\frac{\mathrm{A} * \mathrm{~L}}{\mathrm{~A} * \mathrm{~L}} \ln \left(\frac{\mathrm{h} 1}{\mathrm{~h} 2}\right) & 2-15 \\
\mathrm{~K}=\frac{\mathrm{Q} * \mathrm{~L}}{\mathrm{~h} * \mathrm{~A}} & 2-16
\end{array}
$$


where $\mathrm{K}=$ hydraulic conductivity $(\mathrm{cm} / \mathrm{sec}), \mathrm{L}=$ length of sample $(\mathrm{cm}), \mathrm{Q}=$ volumetric

flow rate $\left(\mathrm{cm}^{3} / \mathrm{sec}\right), \mathrm{A}=$ cross section area of sample $\left(\mathrm{cm}^{2}\right), \mathrm{h}=$ hydraulic head, total head, $(\mathrm{cm}), \mathrm{t}=$ time interval over which outflow is collected $(\mathrm{sec}), \mathrm{a}=$ cross section area of inflow column $(\mathrm{cm})$, and $\mathrm{h}_{1}, \mathrm{~h}_{2}=$ height of permeant in-flow pipe at the beginning and at the end of the time interval $(\mathrm{t})(\mathrm{cm})$.

\subsubsection{Laboratory method for hydraulic conductivity measurement}

Three types of permeameters have been widely used to determine hydraulic conductivity of soils; rigid-wall, flexible-wall, and consolidation-cell permeameters. Researchers have a conflict regarding the preference of the three apparatuses upon each other to be used to estimate hydraulic conductivity. Supporters of rigid-wall tests refer to the ease of specimen preparation and the ability of testing samples immediately in the testing molds with no need to extract or disturb the specimen. On the other hand, proponents of flexible-wall tests debate the side leakage that may happen along the area of contact between the rigid-wall and the soil sample. Therefore, they emphasise the importance of confining the sample with flexible membrane to mitigate the side leakage (Boynton and Daniel 1985).

\subsection{Rigid-wall permeameter}

Rigid-wall apparatus is widely used for hydraulic conductivity measurement. Rigid-wall apparatus comes in standard 10 or $15 \mathrm{~cm}$ diameter steel compaction mold that equipped with top and bottom steel plates. The steel plates are manufactured to allow water to flow into and out of the sample during hydration and testing processes, (Figure 2.11). The test starts with compacting soil at its optimum moisture content in the compaction mold and 
sealing the mold between the top and bottom plates. A certain hydraulic head is applied on top of the sample until saturation achieved, then hydraulic conductivity measurement takes place. The main drawback in this method is the side leakage that may occur and affect the accuracy of the results. Double-ring permeameter that developed by Anderson (1983) was believed to overcome the side leakage issue in the rigid-wall permeameter, (Figure 2.12). In the double-ring permeameter, the bottom plate is equipped with a short cylindrical ring. This ring can separate the actual outflow through the sample from the side leakage flow. Disadvantage of this method is related to the difficulty of ensuring $100 \%$ saturation of the specimen.

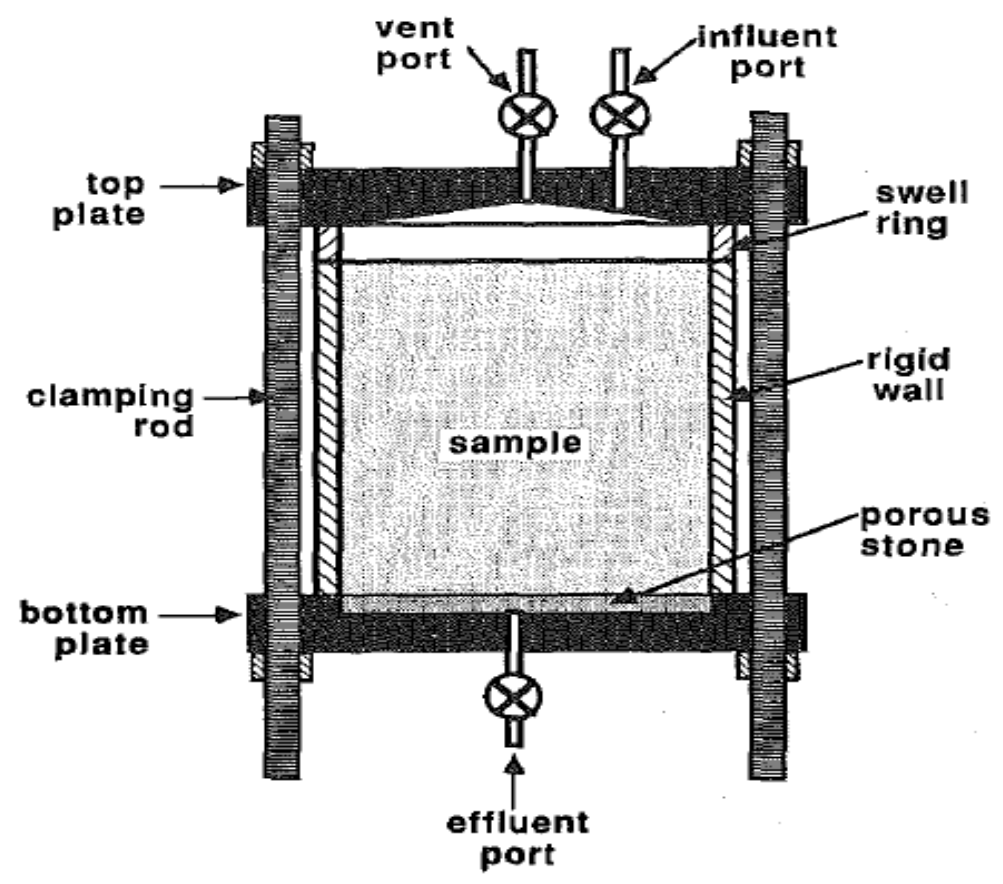

Figure 2.11 Rigid-wall permeameter cross section (Benson and Daniel 1990). 


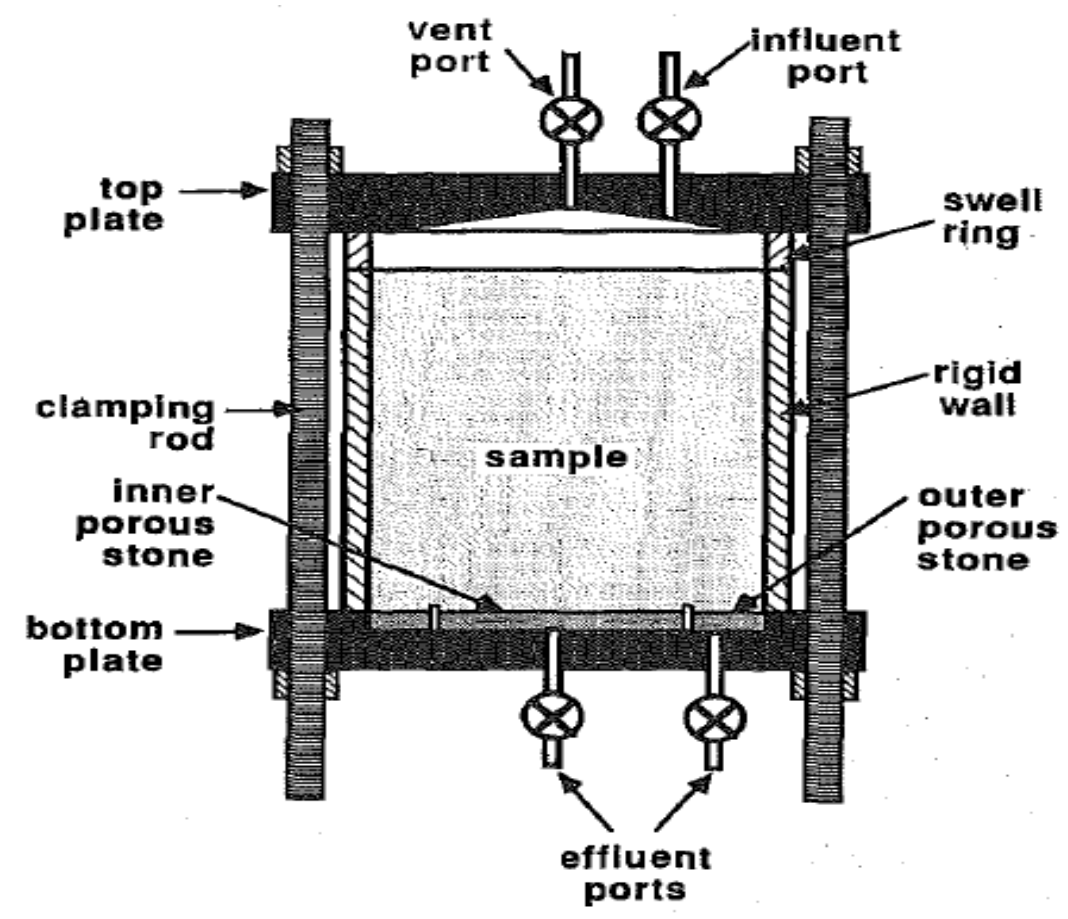

Figure 2.12 Rigid-wall permeameter (double-ring) cross section (Benson \& Daniel 1990).

\subsection{Flexible-wall permeameter}

Soil sample here is compacted in compaction mold and then extracted to be wrapped all around with a flexible membrane. The wrapped sample is placed in a cell that is similar to the triaxial shear strength test cell. Porous stones are placed on top and bottom of the sample. The cell is filled up with water to provide all around lateral pressure or confining pressure. The confining pressure has to be higher than the permeant pressure to prevent separation between the soil sample and the membrane (Figure 2.13). The advantage of this method is the ability of testing samples with an atypical surface and with less potential of side leakage. Since the vertical and horizontal pressures are controllable, this method can provide data about sample deformation during testing. Moreover, measuring the hydraulic conductivity for undisturbed samples is possible as well. However, if the 
sample is exposed to crack formation, the applied confining pressure could close the formed cracks, which can lead to underestimating the value of soil permeability (Benson and Daniel 1990).

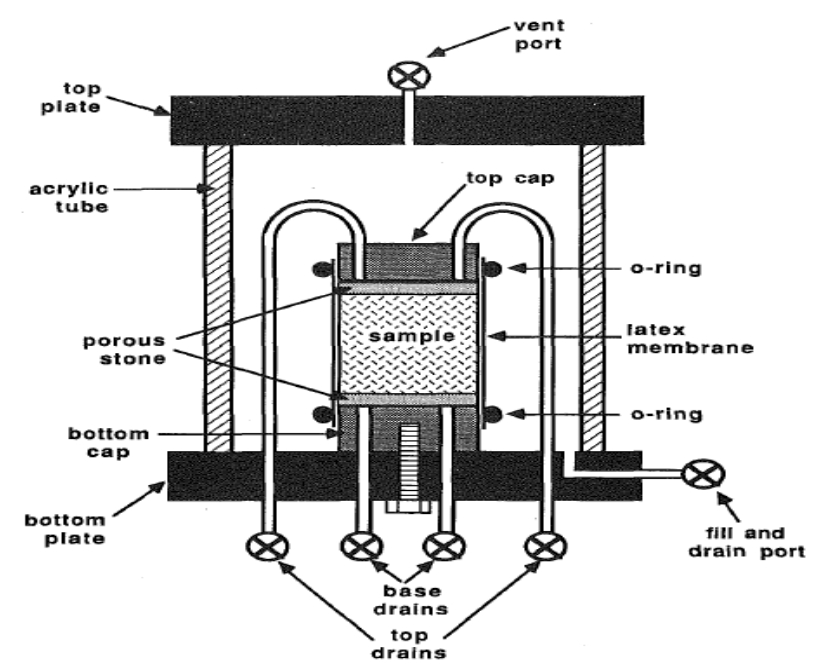

Figure 2.13 The cross- section of the flexible-wall permeameter cell (Benson and Daniel 1990).

\subsection{Consolidation-cell permeameter}

This apparatus consists of water reservoir that embraces the consolidation ring, which comes in $6.2 \mathrm{~cm}$ diameter and $1.9 \mathrm{~cm}$ height (Figure 2.14). Atmospheric pressure is maintained at the effluent on the top of the specimen by water that surrounds the consolidation ring. At the bottom base, hydraulic pressure is controlled with a system that proposed by Olson and Daniel (1981). 


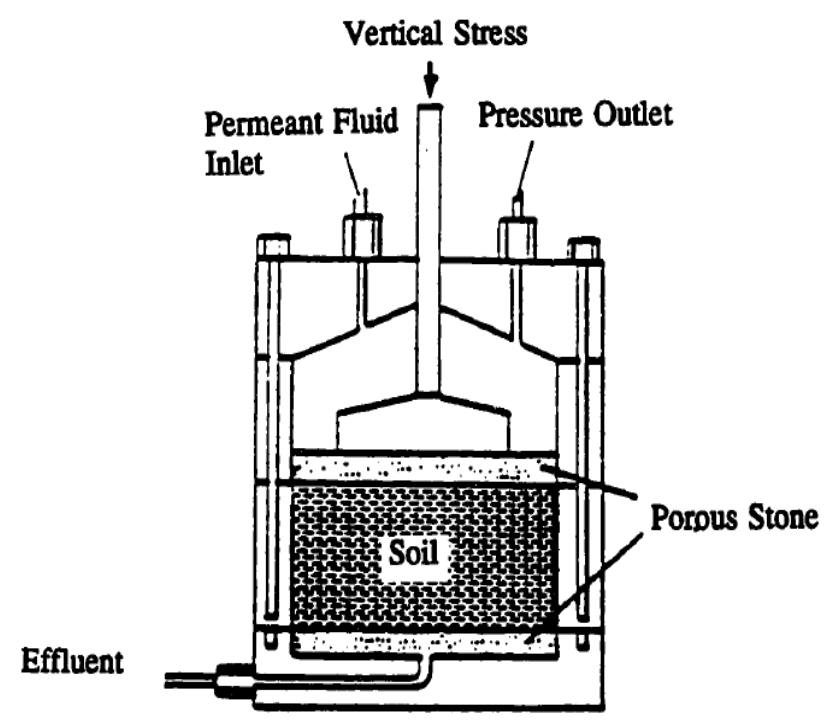

Figure 2.14 The cross- section in the flexible wall permeameter cell (Boynton and Daniel 1985).

\subsubsection{Factors affect hydraulic conductivity value}

Neither strength parameters nor settlement coefficients can vary over a wide range as the hydraulic behaviors of soils do (Madson and Mitchell 1989). Enormous variation in hydraulic conductivity of soils could be recorded due to changes of one or more factors such as method of testing, sample size, particle arrangement, molding water content, degree of saturation, mineral composition, and/or compaction effort.

\subsection{Type of permeameter}

Boynton and Daniel (1985) investigated the effect of permeameter type on the measured hydraulic conductivity. Three permeameter types were employed in this investigation;

rigid-wall, flexible-wall, and consolidation-cell permeameters. A slight variation was observed in hydraulic conductivity results that attained from different permeameter types. However, the differences in results, which were less than an order of magnitude, did not produce a clear trend that could be attributed to the differences in permeameter types. 
Therefore, the authors denied any relation between the hydraulic conductivity and the type of permeameters. Furthermore, a comparison was provided between the rigid and flexible wall permeameters included relative parameters, (Table 2.2).

\subsection{Sample size}

It has been realized that the hydraulic conductivity of fine-grained soils can widely be influenced by the occurrence of hydraulic defects within the soil matrix such as fissures, cracks and sand lenses. Since these defects have better chance to generate and present in a wider medium, determining the size of test sample has become a crucial issue. Boynton and Daniel (1985) carried out some experimental work to verify the relationship between specimen diameters and hydraulic conductivity. Slabs of a clay soil were compacted at three different molding water contents. Samples of different diameters were trimmed from the slabs and installed in flexible-wall permeameters to measure their hydraulic conductivity. The results indicated a proportional relationship between sample diameter and hydraulic conductivity. The correlation was clearer when samples were mixed at dry of optimum as well as wet of optimum water contents. However, no clear tendency of (K) was found for samples mixed at optimum water content to be sensitive to the sample diameter, (Figure 2.15). 
Table 2.2 Comparison between different types of permeameters (Boynton and Daniel 1985).

\begin{tabular}{|c|c|c|c|}
\hline Test & \multicolumn{3}{|c|}{ Type of Permeameter } \\
\hline parameter & Compaction mold & Flexible wall & Consolidation cell \\
\hline Side wall leakage & Leakage is possible & Leakage is unlikely & $\begin{array}{l}\text { Applied vertical stress } \\
\text { makes leakage unlikely }\end{array}$ \\
\hline Void ratio (e) & $\begin{array}{l}\text { Relatively high (e) because } \\
\text { applied vertical } \\
\text { stress is zero }\end{array}$ & $\begin{array}{l}\text { Relatively low (e) because } \\
\text { an all-round } \\
\text { confining pressure } \\
\text { is applied }\end{array}$ & $\begin{array}{l}\text { Relatively low (e) } \\
\text { because a vertical } \\
\text { stress is applied }\end{array}$ \\
\hline $\begin{array}{l}\text { Degree of } \\
\text { saturation }\end{array}$ & $\begin{array}{l}\text { Specimen may be } \\
\text { unsaturated }\end{array}$ & $\begin{array}{l}\text { Application of backpressure } \\
\text { is likely to cause essentially } \\
\text { full saturation }\end{array}$ & $\begin{array}{l}\text { Specimen may be } \\
\text { unsaturated }\end{array}$ \\
\hline $\begin{array}{l}\text { Voids formed } \\
\text { during trimming }\end{array}$ & $\begin{array}{l}\text { Impossible; soil is } \\
\text { tested in the compaction } \\
\text { mold and is } \\
\text { not trimmed }\end{array}$ & $\begin{array}{l}\text { Voids are not relevant; } \\
\text { the flexible } \\
\text { membrane tracks } \\
\text { the irregular surface } \\
\text { of the soil specimen }\end{array}$ & $\begin{array}{l}\text { Voids may have } \\
\text { formed, but application } \\
\text { of a vertical stress should } \\
\text { help in closing any voids }\end{array}$ \\
\hline $\begin{array}{l}\text { Portion of sample } \\
\text { tested }\end{array}$ & $\begin{array}{l}\text { All of the compacted } \\
\text { specimen is tested, } \\
\text { including the relatively } \\
\text { dense lower portion and the } \\
\text { relatively } \\
\text { loose upper portion; the } \\
\text { dense lower portion may } \\
\text { lead to measurement of } \\
\text { relatively low } \mathrm{k}\end{array}$ & $\begin{array}{l}\text { One centimeter of soil } \\
\text { is trimmed off both } \\
\text { ends of the compacted } \\
\text { sample }\end{array}$ & $\begin{array}{l}\text { Only the central portion } \\
\text { of the specimen } \\
\text { is tested; the } \\
\text { upper and lower } \\
\text { third of the specimen } \\
\text { are trimmed } \\
\text { away }\end{array}$ \\
\hline
\end{tabular}




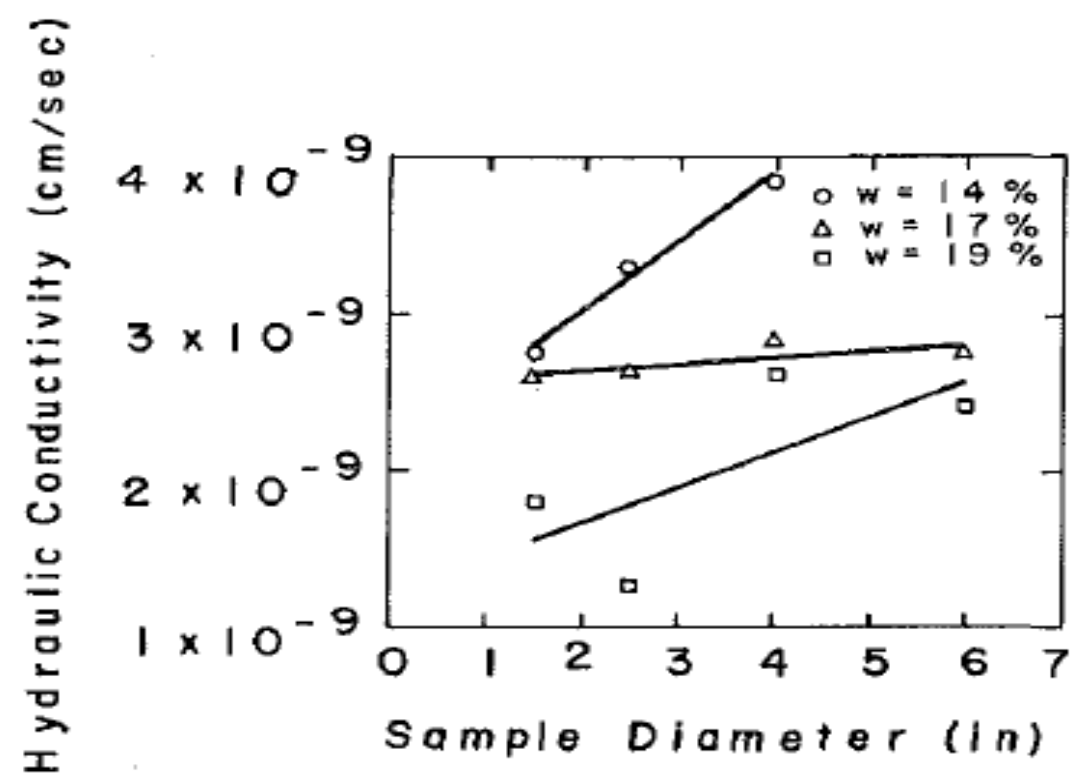

Figure 2.15 A plot illustrating the correlation between (k) and sample diameters (Boynton and Daniel 1985).

Further investigation was conducted by Omidi et al. (1996) to evaluate the effect of sample diameter on the hydraulic conductivity. Both smectite and illite clays were used to prepare pure fine-grained samples and amended samples with sand. The samples were tested in a laboratory scale permeameter and large scale permeametere $(57.5 \mathrm{~cm}$ diameters). The results showed very low laboratory hydraulic conductivity for unamended smectite, which was about $7.8 \times 10^{-10} \mathrm{~cm} / \mathrm{s}$. However, large scale samples of the same soil yielded a hydraulic conductivity equal to $3 \times 10^{-8} \mathrm{~cm} / \mathrm{s}$ which was 39 times greater than the laboratory measurement. For unamended illite, smectite amended with $30 \%$ sand, and illite amended with $30 \%$ sand the ratios between large scale and the small scale of measured conductivities were 8.3, 1.2, and 6.7 respectively. Results clearly stated the effects of specimen size on hydraulic behavior and obviously showed underestimating hydraulic conductivity measurement when small permeameter sizes are used (Omidi et al. 1996). 


\subsection{Soil compaction water content}

As soil moisture content change from dry to wet of optimum, the fabric of fine grained soils was found to change from a flocculated to a dispersed arrangement, (Figure 2.16) (Lambe, 1985). Samples of $10 \mathrm{~cm}$ diameter and $5 \mathrm{~cm}$ height of Fire clay were prepared from compacted slabs to evaluate the isotropy of the compacted clayey soils (Boynton and Daniel 1985). The slabs were prepared over a wide range of water content with respect to the soil optimum water content. Samples were extracted parallel and perpendicular to the slab lifts to find a correlation between the vertical and horizontal conductivities. The ratio horizontal to vertical conductivities $\left(\mathrm{K}_{\mathrm{h}} / \mathrm{K}_{\mathrm{v}}\right)$ varied from 1.0 for soils compacted dry of optimum to 1.2 for soils compacted wet of optimum. Even though results referred to some anisotropy as soil's water content changed from dry to wet of optimum, this anisotropy was not linked to the change in soil fabric. This small anisotropy was attributed to the variable densities along the slabs. The lower lifts of the slabs were exposed to higher compacting efforts than the upper lifts. Therefore, vertical flow is controlled by $\mathrm{k}$ of the lower part (denser lifts), while the horizontal flow is controlled by the $\mathrm{k}$ of the upper part (loser lifts). Boynton and Daniel (1985) concluded that the small scale tests can not represent the anisotropy of the soils and large-scale tests are required to study hydraulic anisotropy. 


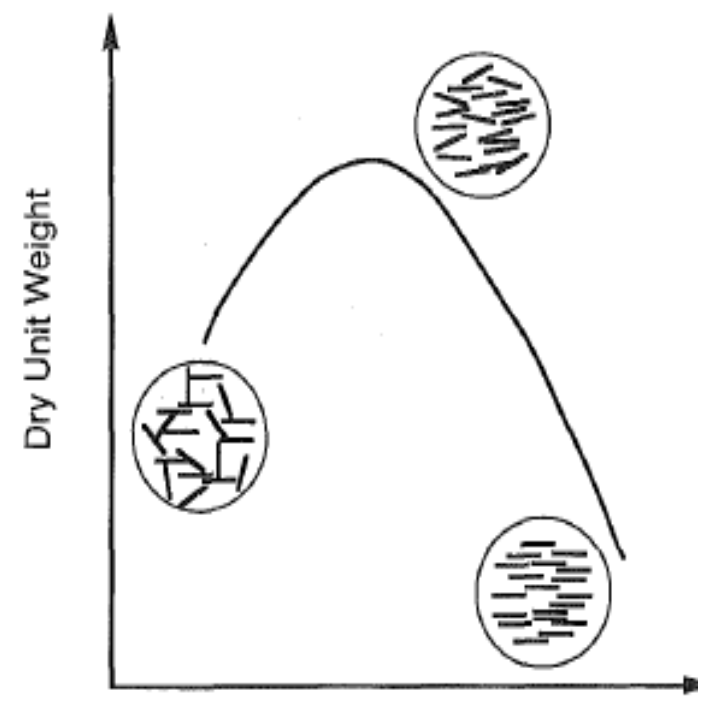

Water Content

Figure 2.16 The correlation between clay soil fabric and water content (Benson and Daniel 1990).

Olsen (1962) stated that water flow through compacted clay layers dominantly happens between the clods "or the aggregates" rather than between clay particles within the clods themselves (Figure 2.17). Benson and Daniel (1990) tried to validate both Lambe and Olsen theories. Scanning electronic photomicrographs technology was employed to assess the change in particle orientation with the change in water content. Samples of soil from Huston city in the US were prepared at different clod sizes. Large clods were represented by $19 \mathrm{~mm}$ clod size, whereas small clods where represented by $4.8 \mathrm{~mm}$ clod size. The samples were prepared by mixing the soil with several water contents $(12 \%, 16 \%$, and $20 \%)$ to evaluate its effect on the fabric change. Rigid wall permeameter was used to carry out the conductivity tests. Results showed 1,000,000 times reduction in hydraulic conductivity values between the driest mixtures and the wettest mixtures. However, no difference was observed between the soil fabrics in both 
cases. Pictures showed a flocculated arrangement for dry of optimum mixture which did not change to dispersed arrangement when the soil was hydrated wet of optimum (Figures 2.18 and 2.19) (Benson and Daniel 1990). This finding was consistent with those reported by Boynton and Daniel (1985). In contrast, Simms and Yanful (2001) reported significant changes in pore size distribution (PSDs) when remolding water content varied from dry to wet of optimum.

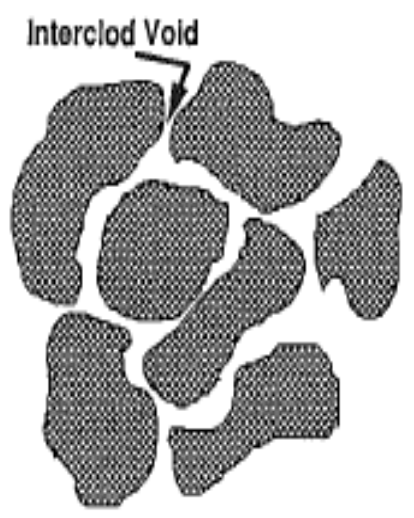

Large Interclod Voids

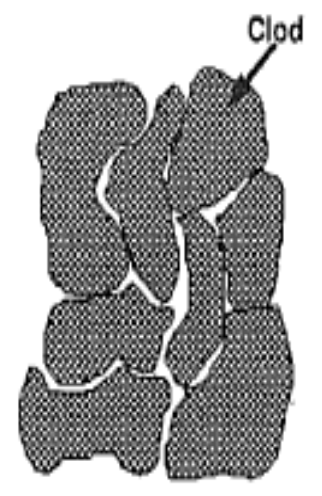

Small Interclod Voids

Figure 2.17 Mechanism of water flow based on theory of clods (Benson and Daniel 1990).

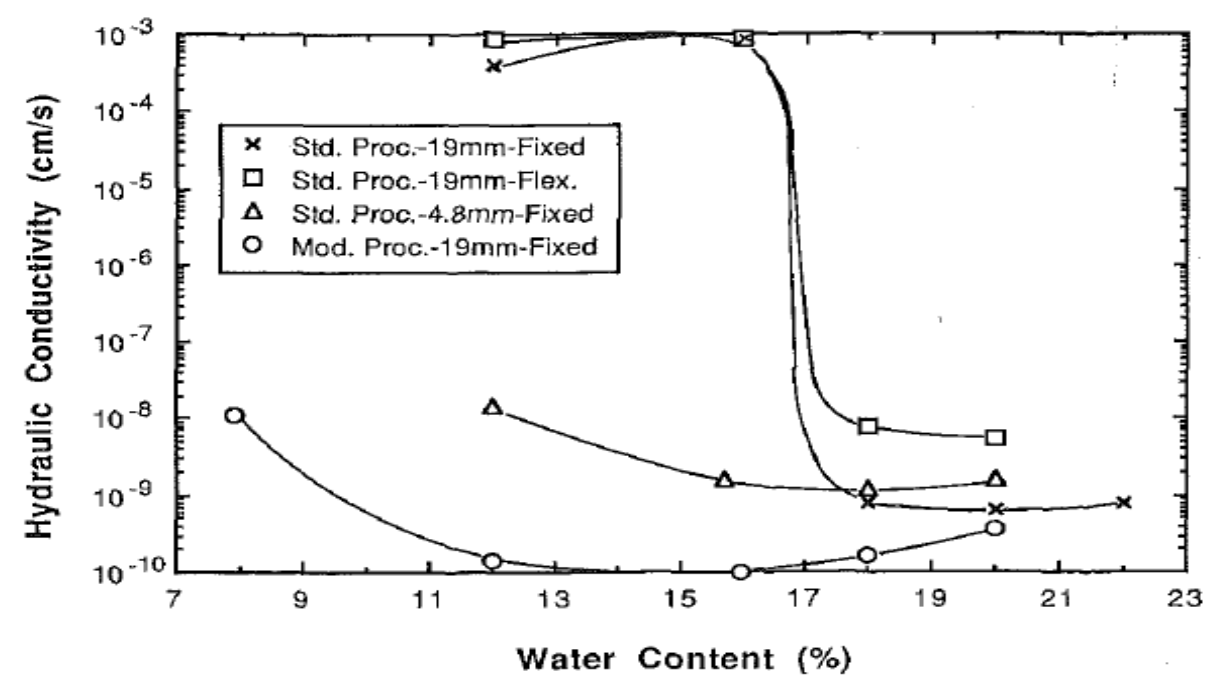

Figure 2.18 Correlation between water content and hydraulic conductivity for different clod sizes of compacted clays (Benson and Daniel 1990). 

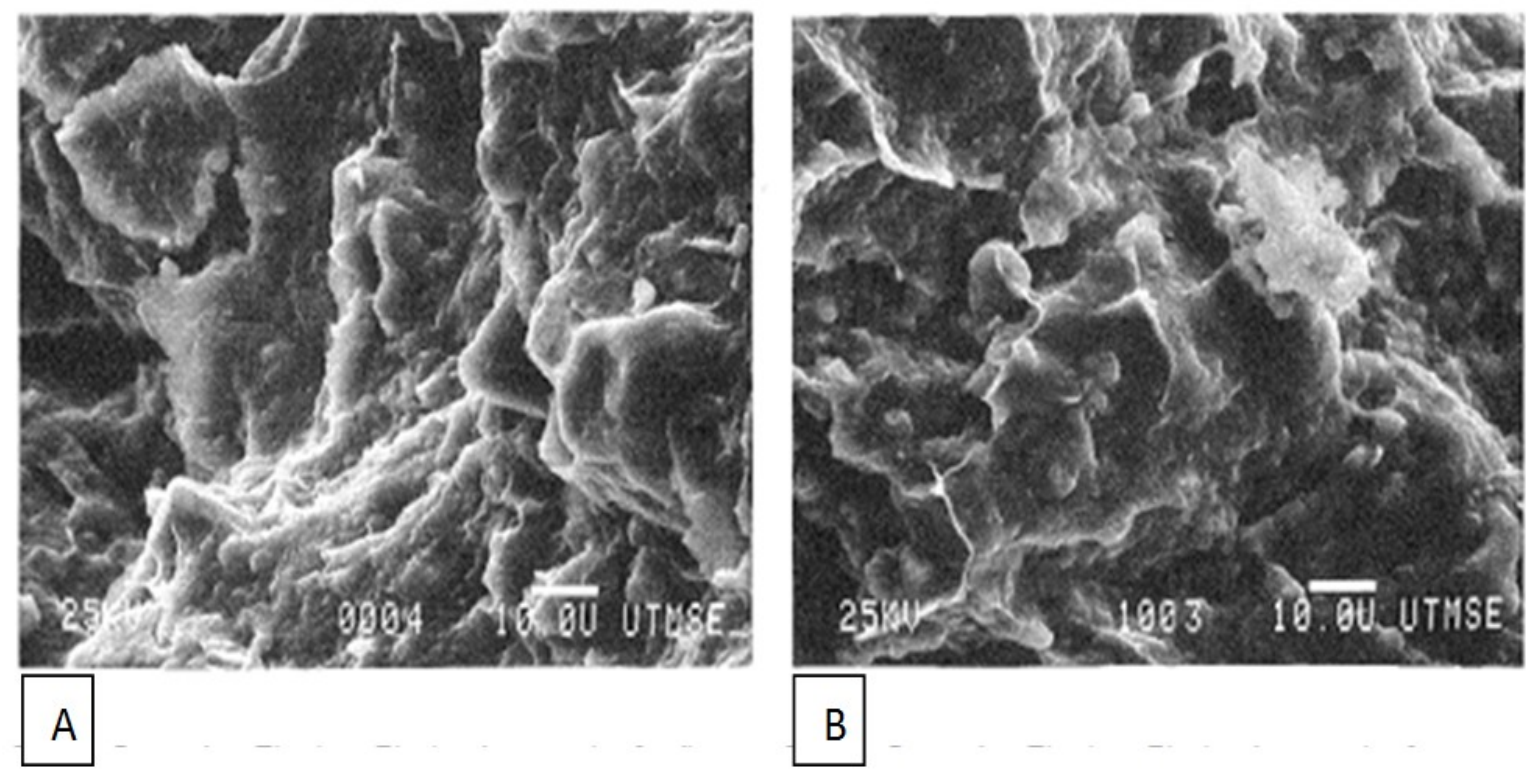

Figure 2.19 Scanning Electronic Photomicrography of soil compacted with standard proctor at water content of A) $12 \%$ and B) $16 \%$ (Benson and Daniel 1990).

Clod theory was correlated to the dry unit weight of soil when Benson and Daniel (1990) found that dry unit weight of soil can provide an indication of the clod size. Hydraulic conductivity tests were carried out for samples made from same soil but on varieties of compaction effort and clod size. Decrease in hydraulic conductivity associated with increase in dry unit weight was clearly the trend of the test results. The trend was attributed to the large visible interclod voids, which serve water movement in low dry unit weight soil. However, high dry unit weight refers to the elimination of interclod voids (Figure 2.20) (Benson and Daniel 1990). Conclusion has been made that highly plasticity soils that may form clods, clods must be broken down and large voids between them must be eliminated. Dry unit weight can provide vicarious computing for the degree of the interclod voids elimination (Benson and Daniel 1990). 
In summary, hydraulic conductivity was found to be sensitive to molding water content. Water content 1-2 \% wet of the optimum was found to yield the lowest hydraulic conductivity providing same compacting effort. Indeed, hydraulic conductivity becomes more sensitive to water content as the compacting effort decrease (Benson and Trast 1995).

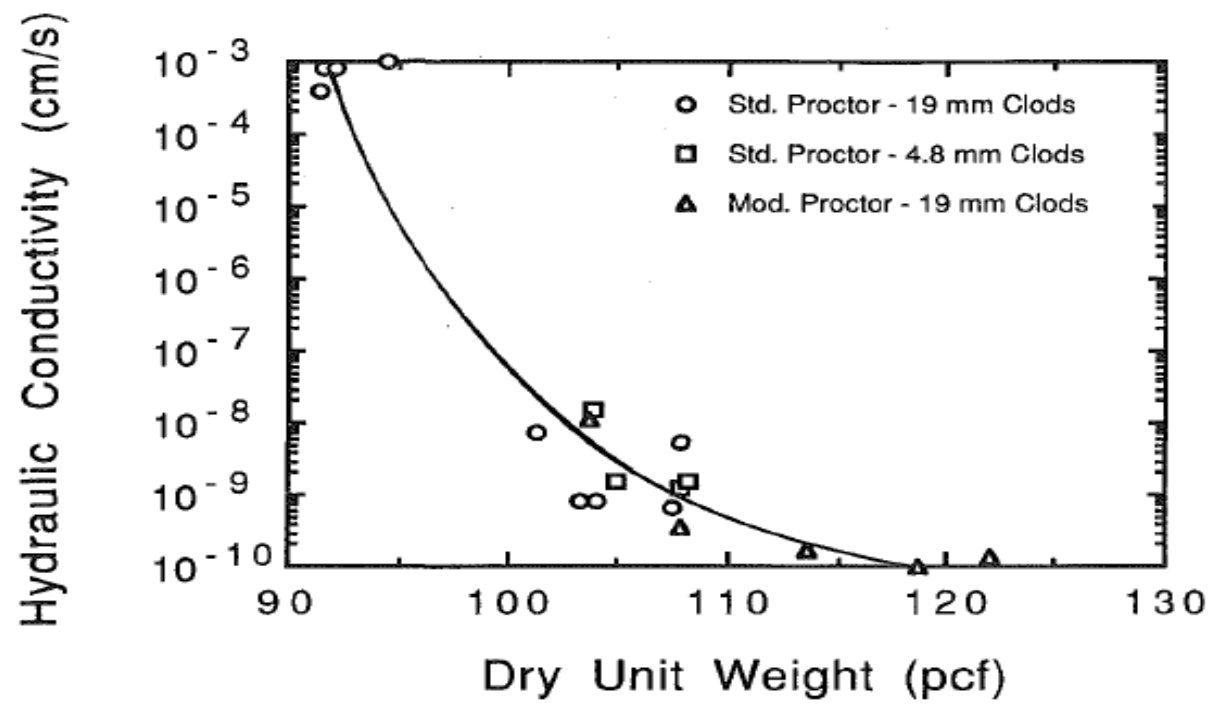

Figure 2.20 Dry unit weight V.s hydraulic conductivity (Benson and Daniel 1990).

Field investigations were carried out on 85 CCLs at different landfill sites to assess their field hydraulic conductivity. Database for these sites were collected and compared with the results achieved from large-scale conductivity tests. Results indicated a deficiency of $26 \%$ of the sites in achieving the minimum requirement of hydraulic conductivities $\left(\mathrm{k}_{\mathrm{f}} \leq 1 * 10^{-7} \mathrm{~cm} / \mathrm{sec}\right)$. The study concluded that the main factors that influence the hydraulic conductivity were the soil water content relative to the line of optimum and the thickness of the compacted clay linear. This conclusion was adopted based on the trend of $\left(\mathrm{k}_{\mathrm{f}}\right)$ decrease with water content increase (Figure 2.21). However, wide range of $\left(\mathrm{k}_{\mathrm{f}}\right)$ appeared even for samples with water content $3-4 \%$ of optimum. This 
was attributed to the variation in compaction effort which can make water content deviates from wet to dry in regard to the line of optimum, (Benson et al., 1994; Benson et al., 1999).

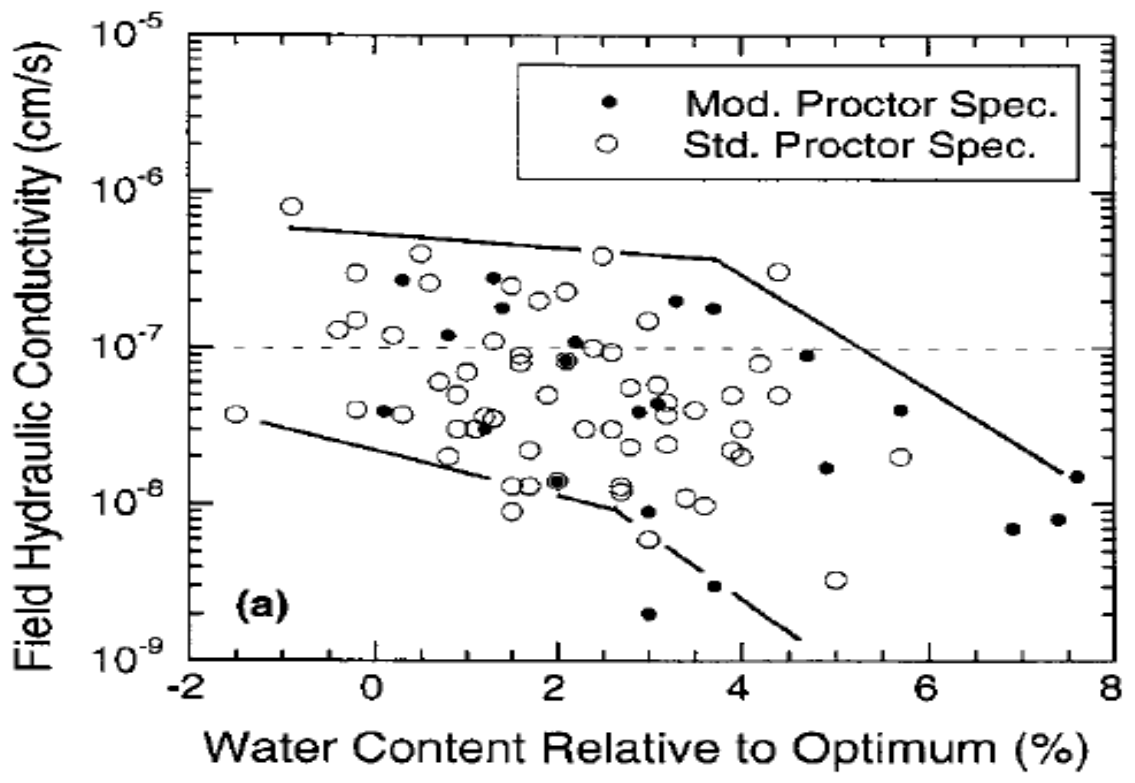

Figure 2.21 Water content V.s hydraulic conductivity (Benson et al., 1999)

\subsection{Soil initial saturation}

Since molding water content and the relative unit weight had been reported to vary over a wide range of compaction effort, initial saturation factor was stated to be more appropriate to represent the correlation between water content and (kf). Regardless to compaction efforts, initial saturation can provide an indication of combined dry unit weight and water content related to the line of optimum. Furthermore, initial saturation is quite beneficial for site-to-site comparison since the initial saturation line fails parallel to the line of optimum (Benson et al., 1994). 
Hydraulic conductivity versus initial saturation relationship was obtained when thirteen compacted clay liners at landfill sites throughout the US were studied. Although data showed significant scatter, a trend of decreasing hydraulic conductivity with increasing initial saturation was inferred (Figure 2.22). The scatter sometimes reached an order of magnitude or even more for given value of saturation. This was linked to the variety of composition of test soils that obtained from different sites. Although initial saturation is not a peerless factor that can adequately represent soil hydraulic conductivity, however, in all soils included in the study, initial saturation of $85 \%$ or more mostly yielded the minimum hydraulic conductivity values (Benson and Trast 1995).

On the other hand, Benson and Trast (1995) and Benson et al. (1994) agreed that the increase of initial saturation does not always lead to decrease in the hydraulic conductivity. Initial saturation can be increased by increasing water content with lower compaction effort; however, the conductivity will increase as well. Therefore advantageous of rising the initial saturation can be achieved by increasing compaction effort versus constant water content, or vice versa, or increasing both factors which finally would yield lower hydraulic conductivity. 


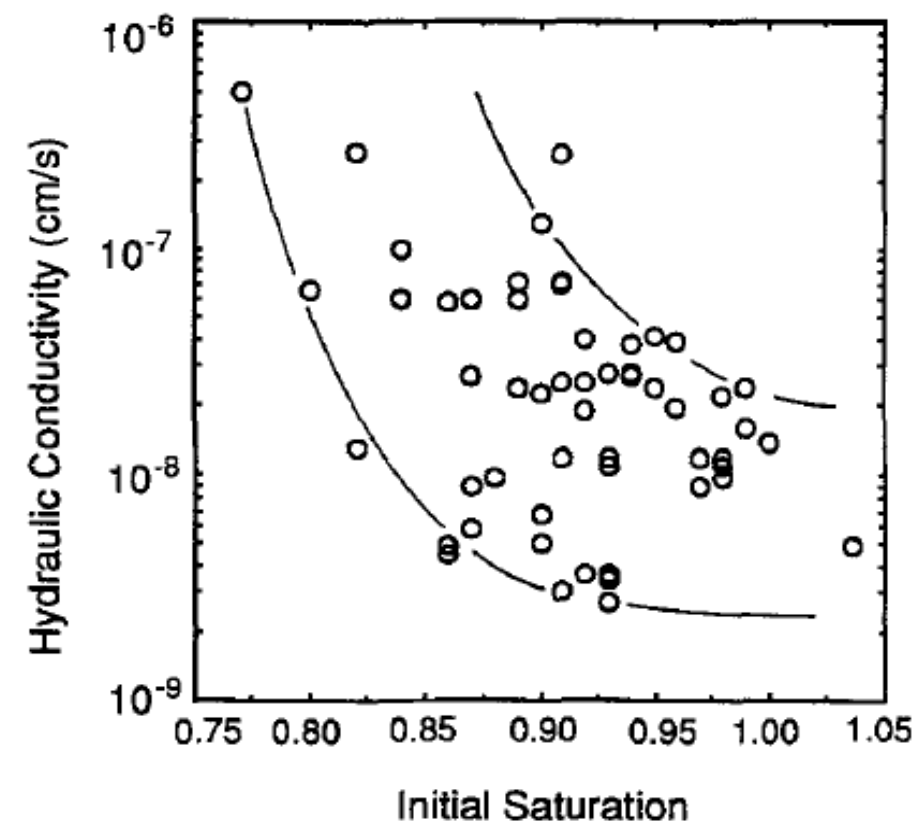

Figure 2.22 Correlation between initial water content and hydraulic conductivity (Benson et al., 1994).

\subsection{Clay content and plasticity}

Liquid limits and plasticity limits are the most used Atterberg limits. Atterberg limits can provide an indication of the percentage of clay particle contents and their mineralogical compositions. Greater content of clay particles leads to higher liquid limit and plasticity indices. Since Terzagie (1925) expected a positive correlation between Atterberg limits and hydraulic conductivity, several studies have been carried out in this regard. A study was conducted on 67 landfill sites, which consisted of several types of clayey soils, to evaluate the effect of soil composition on hydraulic conductivity (Benson et al., 1994). The investigation indicated that the increase of liquid limit and plasticity limit leads to decrease in hydraulic conductivity. Rapid decrease in hydraulic conductivity coincides with increase of plasticity index from $10 \%$ to $30 \%$ (Figure. 2.23). Similar results were 
reported by Benson and Trast (1995) who observed decrease in hydraulic conductivity as the plasticity index increased from 10 to $30 \%$ and liquid limit increased from 20 to $40 \%$. This was attributed to the decrease in size of microscale pores as a result of increase in the clay content (Fig. 2.24) (Benson and Trast 1995).
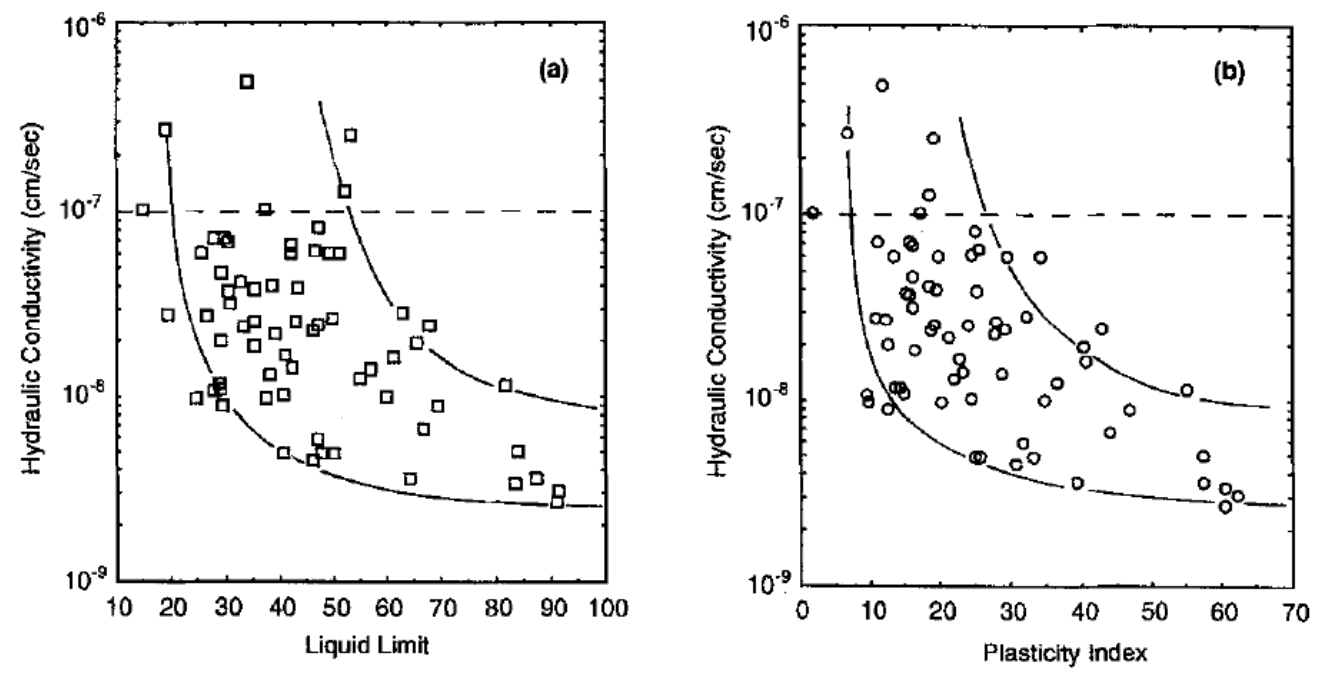

Figure 2.23 Hydraulic conductivity versus: (a) liquid limit; (b) plasticity index (Benson et al., 1994).
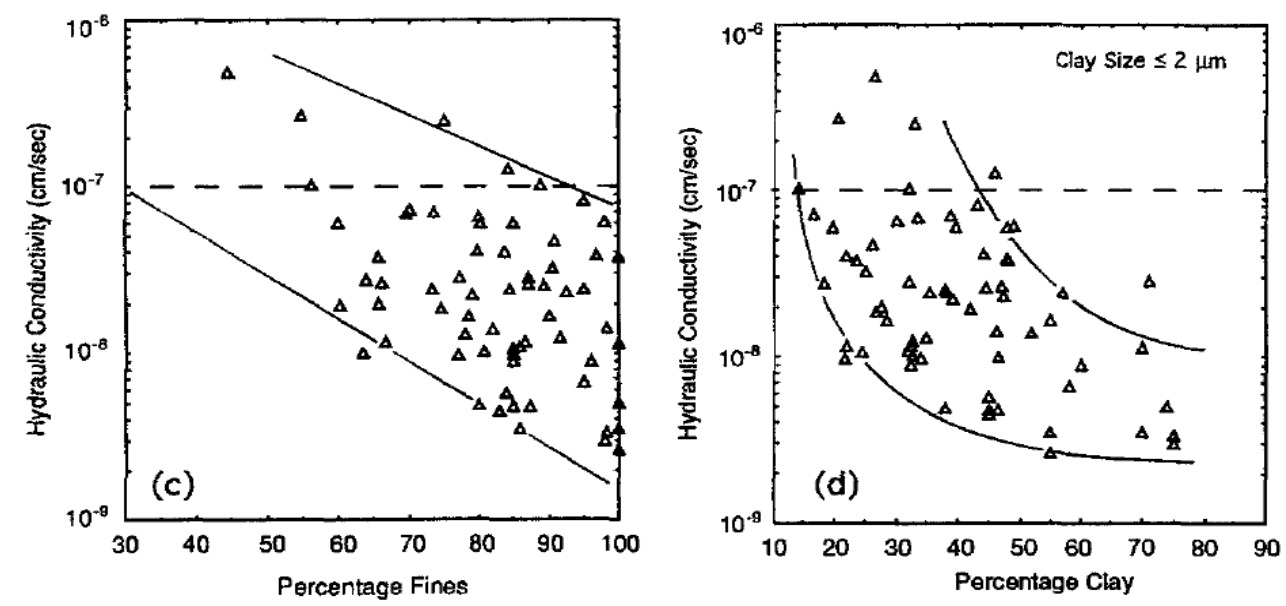

Figure 2.24 Hydraulic conductivity versus: (c) percentage of fines; (d) percentage of clay (Benson and Trast 1995). 


\subsection{Hydraulic Performance of CCL after Waste Placement}

Compacted clay liners in landfills may undergo different exposure circumstances and chemical interactions during their lifespan. After waste placement, CCL might be isolated from the effect of the atmosphere. However, the impact of elevated temperature and chemical leachate exposure would exist and might affect the hydraulic performance of CCLs. As waste being deposited in landfill, vertical stresses would be generated and applied on the barrier system underneath. Moreover, this barrier system may be exposed to combined thermo-chemical effects. These factors would facilitate the depletion of the geomembrane (Rowe et al., 2010c), thus, CCL might be in an immediate confrontation to the combined influences of vertical stresses, landfill leachate, and elevated temperature. The increase in vertical stresses due to waste placement was reported to be beneficial when simultaneous decrease in CCLs' void ration and hydraulic conductivity were recorded (e.g., Quigley et al., 1988; Quigley et al., 1989; Frempong, 2006). While an agreement was reached about the negative effect of elevated temperature on the hydraulic performance of the CCLs, the effect of landfill leachate on hydraulic performance of the CCLs encountered scattering in conclusions. The following sections of literature review present some field and laboratory investigations that have been conducted in an attempt to address the issue of hydraulic performance of CCL after waste placement.

\subsubsection{Influence of elevated temperature on the hydraulic performance of landfill barrier system.}

The released temperature at the bottom of landfills significantly affects their mechanical functions and hydraulic aspects (Rowe, 1998). Hydraulic performance of the CCL can be assessed by potential fluid movement throughout the soil matrix. The fluid movement is 
widely affected by landfill temperature, which can also changes the water content of the CCL. Moreover, landfill temperature may impact the mechanism of contaminant transport since it affects the diffusion rate across the low permeable barriers such as CCL, GCL, and GM (Rowe, 1998).

CCLs in conventional landfills, where the heat release is expected, might undergo severe desiccation cracking. Even with low level of temperature, i.e., as low as $25^{\circ} \mathrm{C}$ on top of the CCL, such critical level of desiccation may be encountered (Doll, 1997). Heibrock (1997) emphasised the negative effect of temperature on the durability of CCL. He presaged a generation of $1 \mathrm{~m}$ depth crack in 20 years period, if the top layer of the CCL left exposed to $40^{\circ} \mathrm{C}$. However, $\mathrm{CCL}$ was predicted to not to undergo any cracking for 50 years period, if the temperature does not exceed $25^{\circ} \mathrm{C}$ keeping all other factors constant.

\subsubsection{Factors affecting heat generation within landfills}

Barrier systems are mainly used to control the flow of leachate out of landfill boundary. This leachate is formed due to aerobic and anaerobic biodegradation of the organic matter, which was reported to form about $50-70 \% \mathrm{w} / \mathrm{w}$ of the total waste component (USEPA, 2003). Chemical reaction that happens due to organic matter decomposition most likely would be combined with heat generation that would last as long as the organic matter exists (Southen and Rowe 2005). Heat starts to generate and temperature increases after waste placement and along the different biodegradation stages. However, the maximum temperature increase was observed at the transition stage as well as at the anaerobic phase (Hanson et al., 2010; Yesiller and Yoshida 2011;). 
Many factors were reported to influence the level of heat generation (e.g., Rowe, 1998; Hanson et al., 2010; Yesiller and Yoshida 2011). The level of released heat was reported to be proportional with the waste moisture content (Barone et al., 1997). Failure to maintain the level of leachate in landfills would likely result in temperature increase, and hence increase the desiccation cracking potential for CCLs, facilitate the diffusion across the clay liner, and decrease the geomembrane service life (Rowe, 1998).

Low ranges of temperature were recorded at three different landfills in the US, including $10-30^{\circ} \mathrm{C}$ in California, $20-30^{\circ} \mathrm{C}$ in Florida, and $18-23^{\circ} \mathrm{C}$ in Pennsylvania. In contrast, a higher temperature of $40^{\circ} \mathrm{C}$ was reported at Keele Valley landfill. Barone et al. (1997) proposed that the rate of landfilling and waste water content affect the landfill temperatures. The head of leachate at Keele Valley Landfill was higher than the leachate mound at the other three landfills, which seemed to cause higher level of heat generation (Figure 2.25).

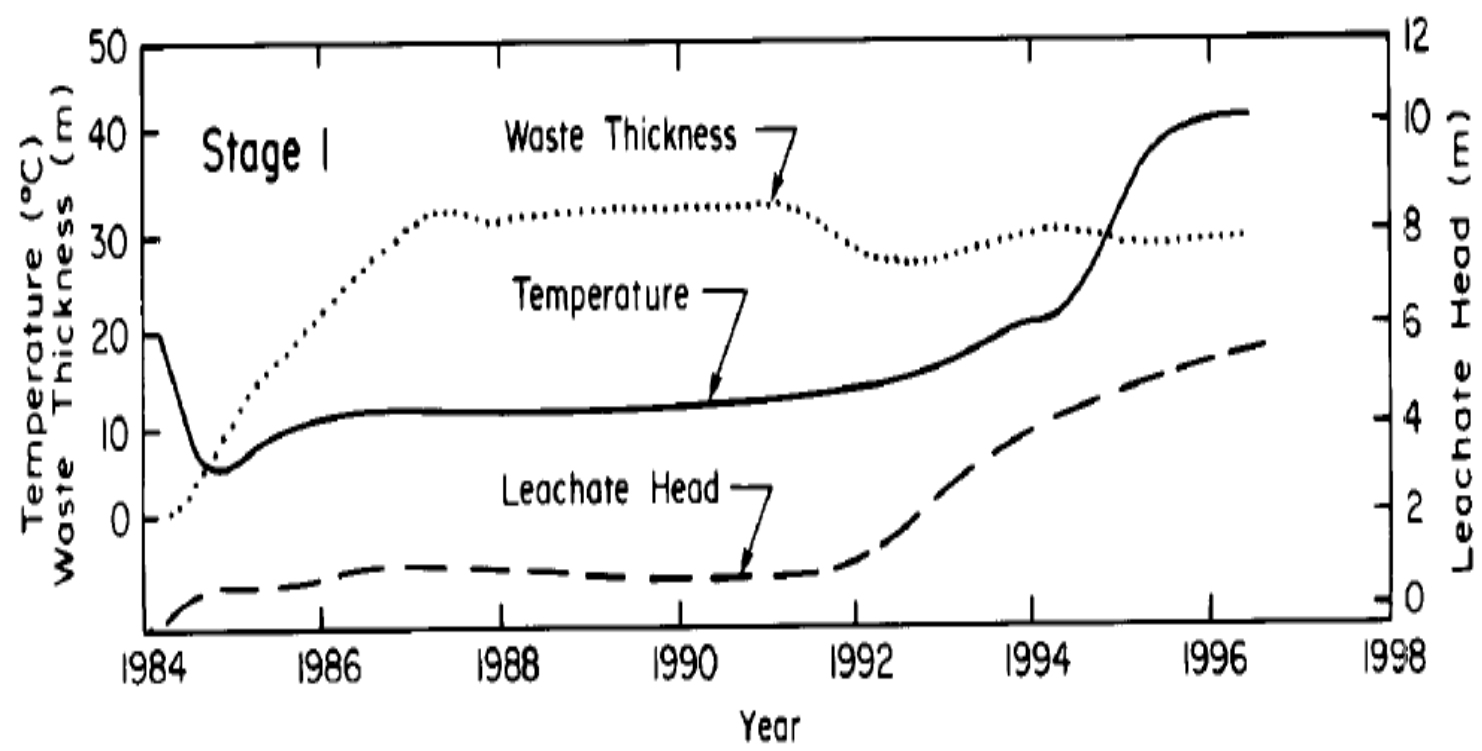

Figure 2.25 Relationship between temperature, leachate head, and waste thickness within Keele Valley Landfill, Canada (Barone et al., 1997). 
In contrast, Yesiller and Yoshida (2011) reported higher temperature within landfills with low leachate mound, whereas landfills with high leachate mound were reported to release lower temperature. The temperature level was further decreased when the temperature measurements conducted within leachate mound itself.

The level of released temperature was also found to be varied along the vertical profile of the landfill. Relationship between temperature and waste depth was achieved for an old landfill in Germany (Collins, 1993) as well as a landfill in Japan (Yoshida et al., 1996). In the old German landfill, temperature increase with depth was observed and reached its maximum value at $30 \mathrm{~m}$ from the surface. Temperature then decreased toward the landfill base. After 10 years of closure, the temperature in the old German landfill ranged from $30-60^{\circ} \mathrm{C}$ at the base where the leachate mound ranged from 4 to $6 \mathrm{~m}$ above the base (Figure 2.26). Identical trend was recorded in the rapid filled landfill in Japan. A maximum temperature of $70^{\circ} \mathrm{C}$ was reached at the middle of the waste profile in 6 years after closure. A temperature of $50^{\circ} \mathrm{C}$ was recorded at the base of the landfill after 9 years of closure with leachate mound ranged between 20-25m (Figure 2.27).

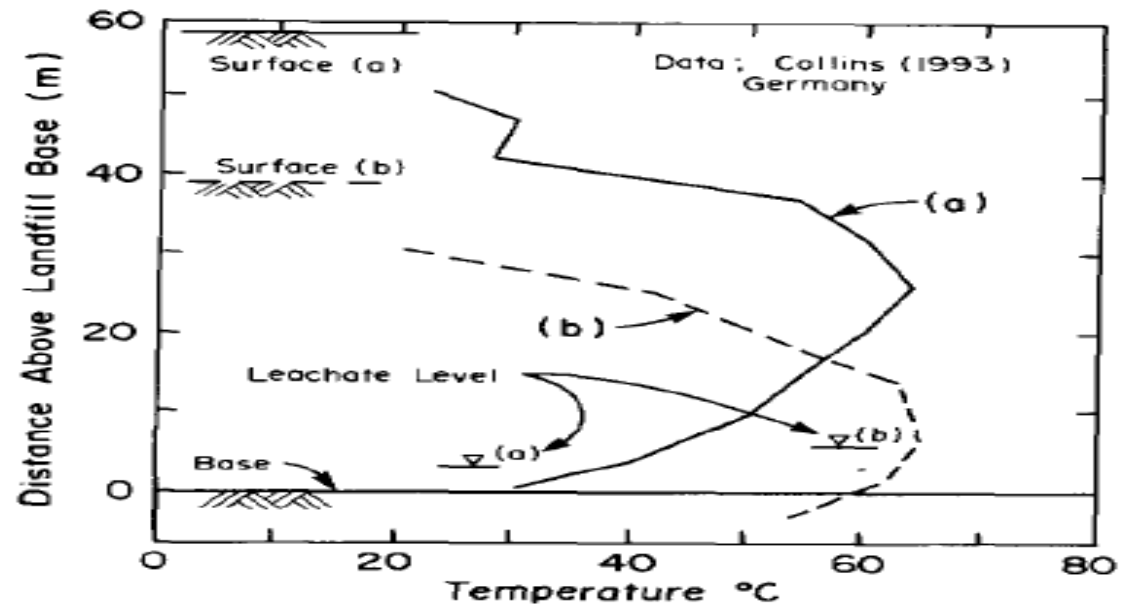

Figure 2.26 Correlation between temperature and depth in an old German's landfill (Collins, 1993). 


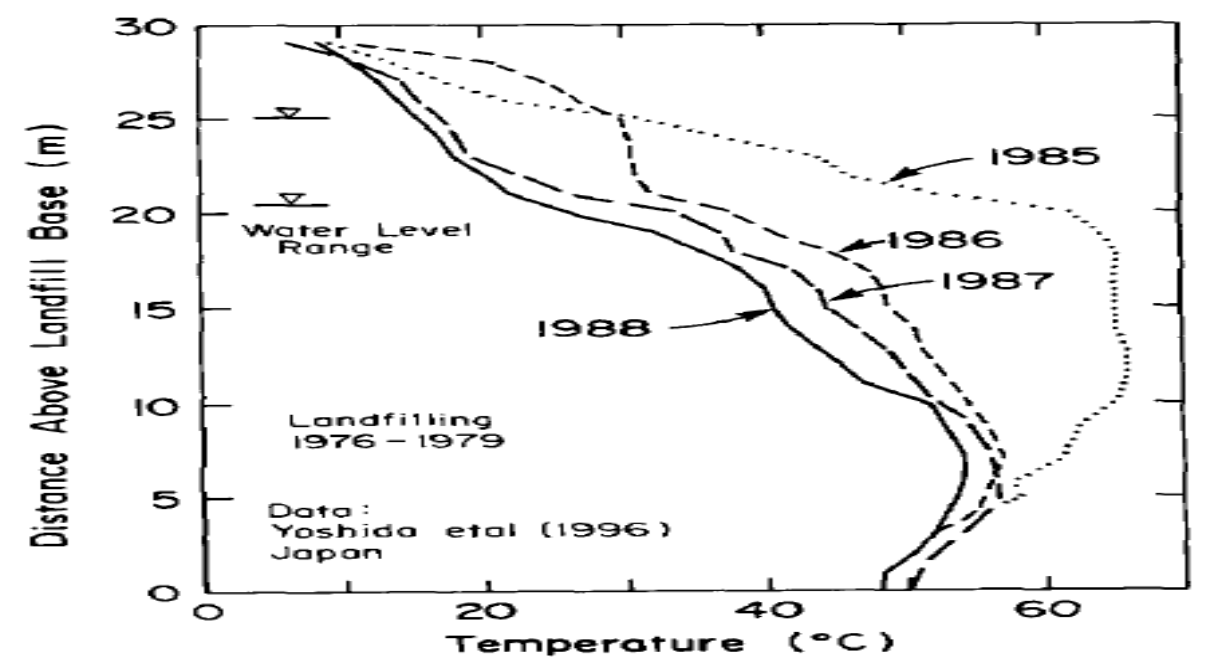

Figure 2.27 Correlation between temperature and depth in Japanese landfill (Yoshida et al., 1996).

The operational system and waste nature in landfills was also found to affect the level of released temperature (Rowe, 1998; Hanson et al., 2010). Altwarmbuchen was a 6 years old European landfill that rapidly filed with a rate of $10-20 \mathrm{~m} / \mathrm{a}$. The temperature that was recorded beneath this landfill ranged from $24^{\circ} \mathrm{C}$ to $38^{\circ} \mathrm{C}$. In contrary, a slower filling rate of $2 \mathrm{~m} / \mathrm{a}$ in Venneberg Landfill yielded much lower temperature that ranged from $14^{\circ} \mathrm{C}$ to $20^{\circ} \mathrm{C}$ (Brune et al., 1991). Very rapid temperature increase was reported by Hanson et al. (2010) at British Columbia landfill and by Rowe (1998) at Keele Valley landfill in Toronto. This was attributed to their rapid rate of filling and more significantly to the high moisture content of the dumped waste that contributed to the rapid elevated temperature.

Hanson et al. (2010) stated that the seasonal time of waste placement affects the level of heat generation (Figure 2.28). Moreover, Hanson et al. (2010) suggested that the high level of precipitation and waste density correlate proportionally to the landfill temperature. Higher temperature was observed in Michigan landfill that contained high density waste and exposed to high level of precipitation, while lower level of temperature 
was recorded in New Mexico landfill which was attributed to lower density and dry climate.

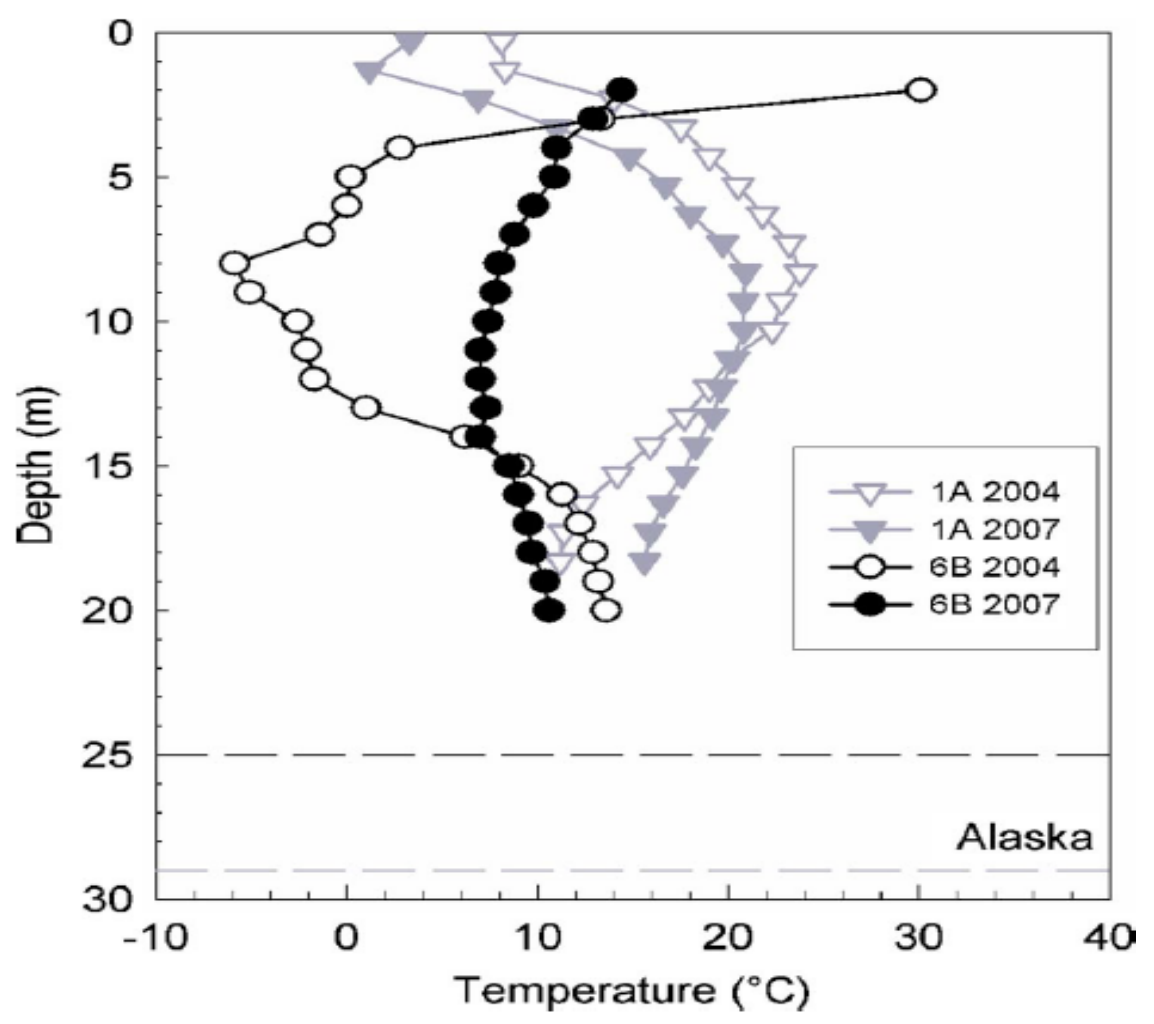

Figure 2.28 Temperature profile for frozen and unfrozen waste in Alaska (Hanson et al., 2010).

\subsubsection{Effect of elevated temperature on physical and mechanical properties of clay soils}

Although municipal solid waste landfills provide reliable protection to the surrounding environment, the level of heat that landfills produce might influence the integrity of their barrier system. When CCL is a part of the barrier system, the impact of thermal exposure would likely lead to crack generation and volume shrinkage. Moreover, physical properties and mechanical behaviours were reported to be sensitive to the thermal effects 
(Jefferson and Rogers 1998; Romero et al., 2001; Villar and Lloret 2004; Romero et al., 2005; Villar et al., 2005).

Some researchers have reported a decrease in liquid limits as temperature elevated, whereas they witnessed less significant correlation to plasticity limits (e.g., Youssef et al., 1961; Ctori, 1989). Jefferson and Rogers (1998) stated slight decrease in liquid limit of kaolinite clay when the temperature was increased. This behaviour was attributed to the decrease in the inter-particles bond strength as the temperature increased (Figure 2.29). For smectite clays, the elevated temperature caused an increase in soil liquid limit (Figure 2.29). This was attributed to the rearrangement of the soil particles that resulted in heavier texture or what was called coagulation.

The presence of smectite friction in the smectite-kaolinite mixtures contributed to greater temperature effects. Liquid limits for the mixtures were further increased under effect of temperature when the soil contained greater smectite content. This behaviour is illustrated in (Figure 2.30) where liquid limits at certain temperatures are normalized by their initial liquid limits at room temperature. Factors such as mineralogy, surface contact, surface charge, and specific surface area were all suggested to be controlling parameters for the change in Atterberg limits due to temperature effect (Jefferson and Rogers 1998). 


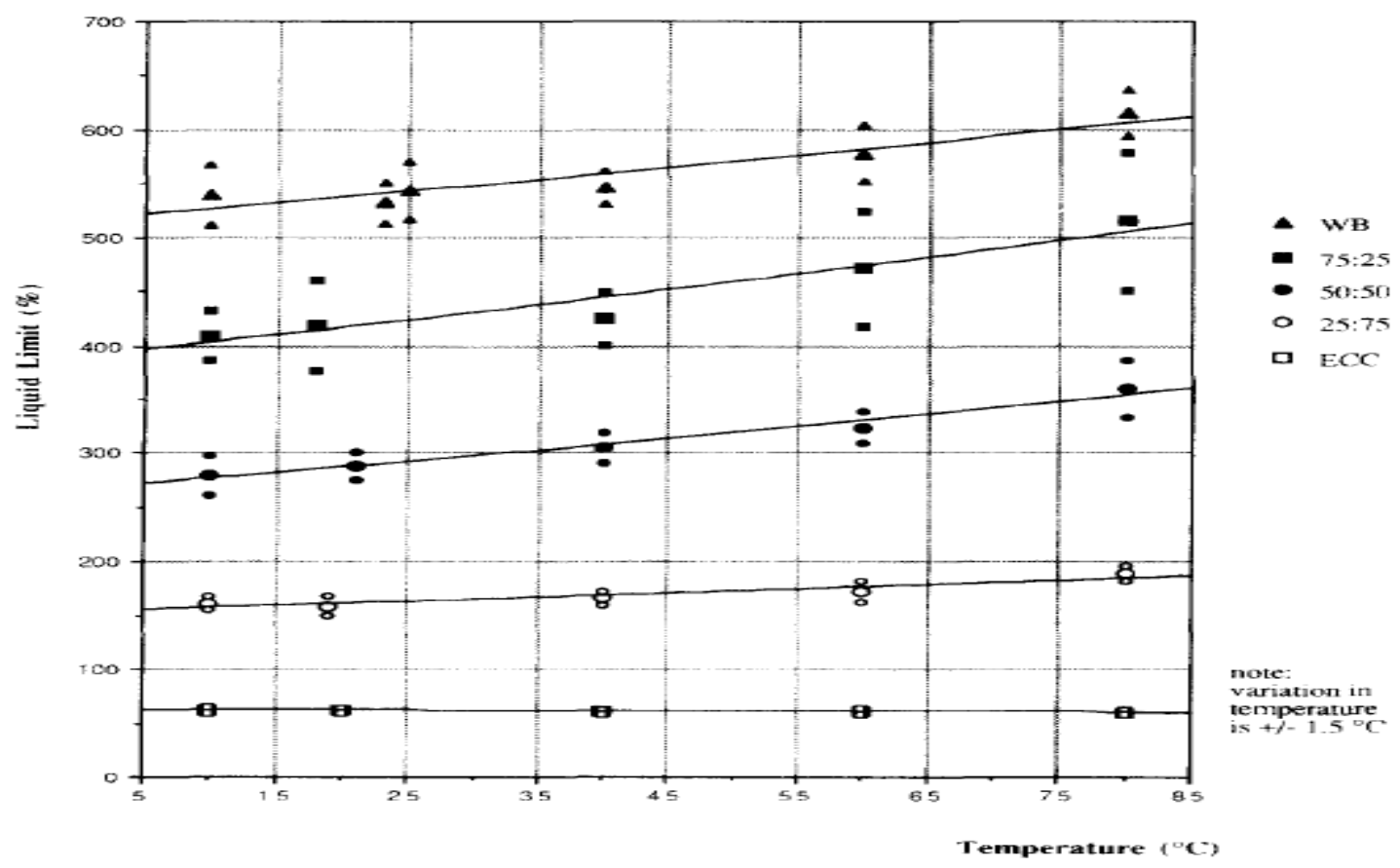

Figure 2.29 Relationship between Liquid limit and temperature (Jefferson and Rogers 1998).

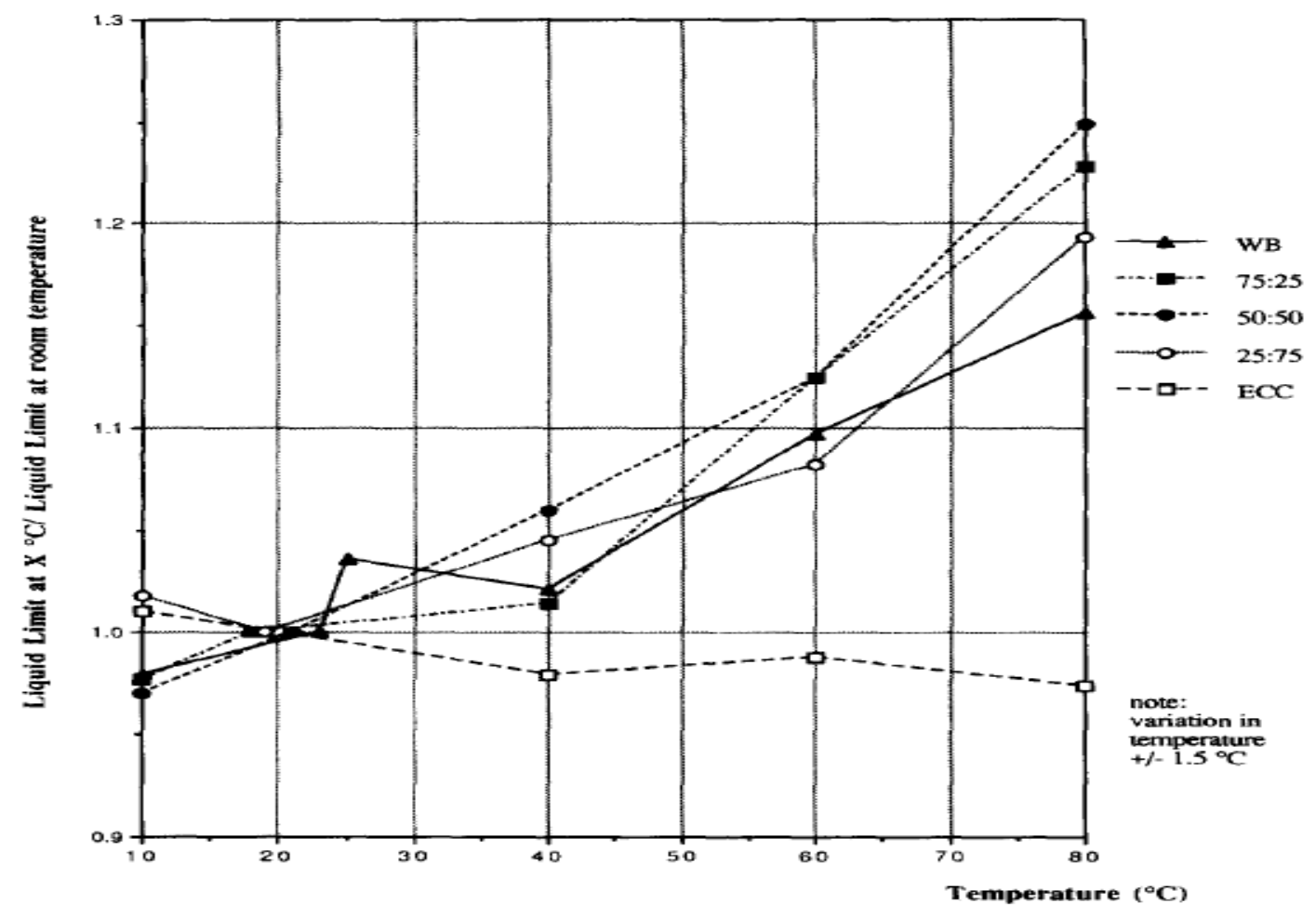

Figure 2.30 Normalized liquid limit versus temperature (Jefferson and Rogers 1998). 
Villar and Lloret (2004) suggested that the change in hydraulic performance of clayey barriers subjected to thermal exposure could be linked to potential changes in water retention characteristics. Furthermore, physical properties such as hydration rate and saturation time, and mechanical behaviours such as swelling pressure, contraction and dilatation are expected to be undergone significant changes upon temperature effect (Romero et al., 2001; Villar and Lloret 2004; Romero et al., 2005; Villar et al., 2005).

To estimate the effect of temperature on water retention capacity for clay soils, Villar and Lloret (2004) established SWCCs at different levels of temperatures. Results showed a decrease in the water retention capacity as the temperature increased (Figure 2.31). This behaviour was attributed to the change in water properties such as water viscosity. Moreover, water micropores within the micro-fabric were also reported to contribute to the dependency of water retention capacity on the temperature. Similar finding was suggested by Romero et al. (2001) when water retention curve was determined at low and high water contents under effect of different levels of temperature. For low water content and at a given constant suction value, increase of temperature resulted in decrease in water content. However, given constant water content, total suction was found to decrease when temperature increased (Figure 2.32). This was attributed to temperature dependence of surface tension as well as changeable clay fabric and pore water chemistry (Romero et al., 2001; Romero et al., 2005) 


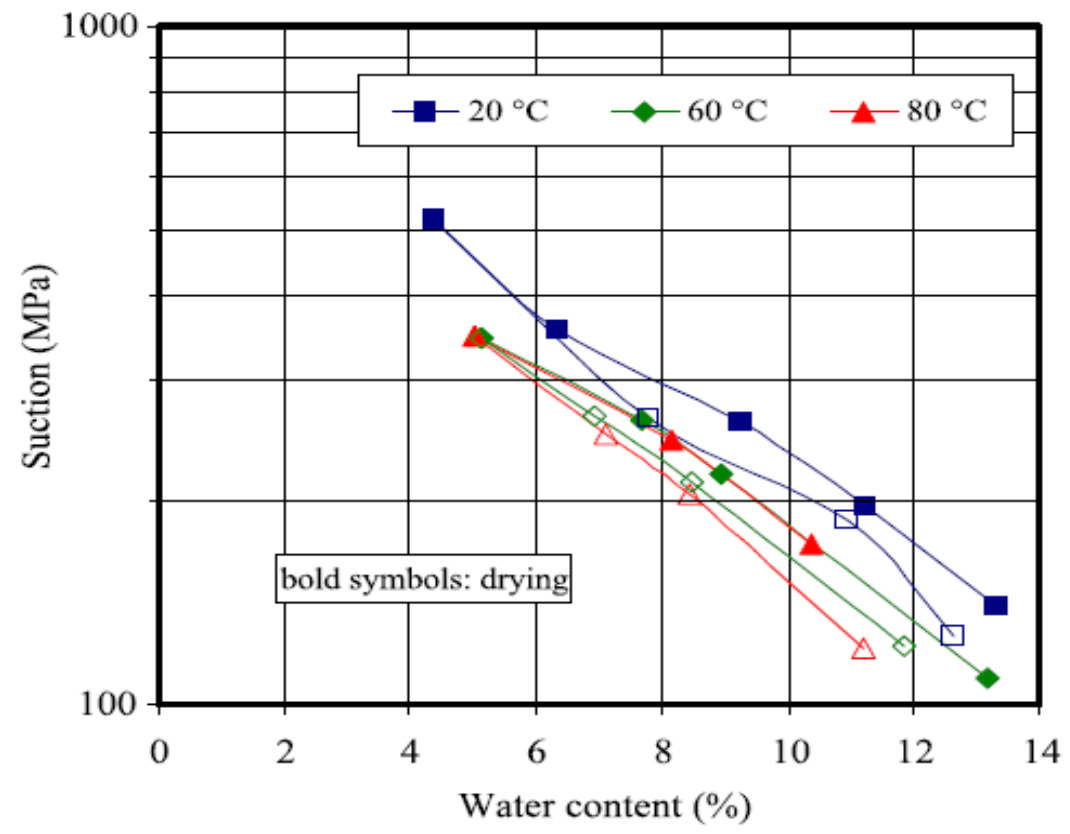

Figure 2.31 Water retention curves for compacted bentonite at different temperature (Villar and Lloret 2004).

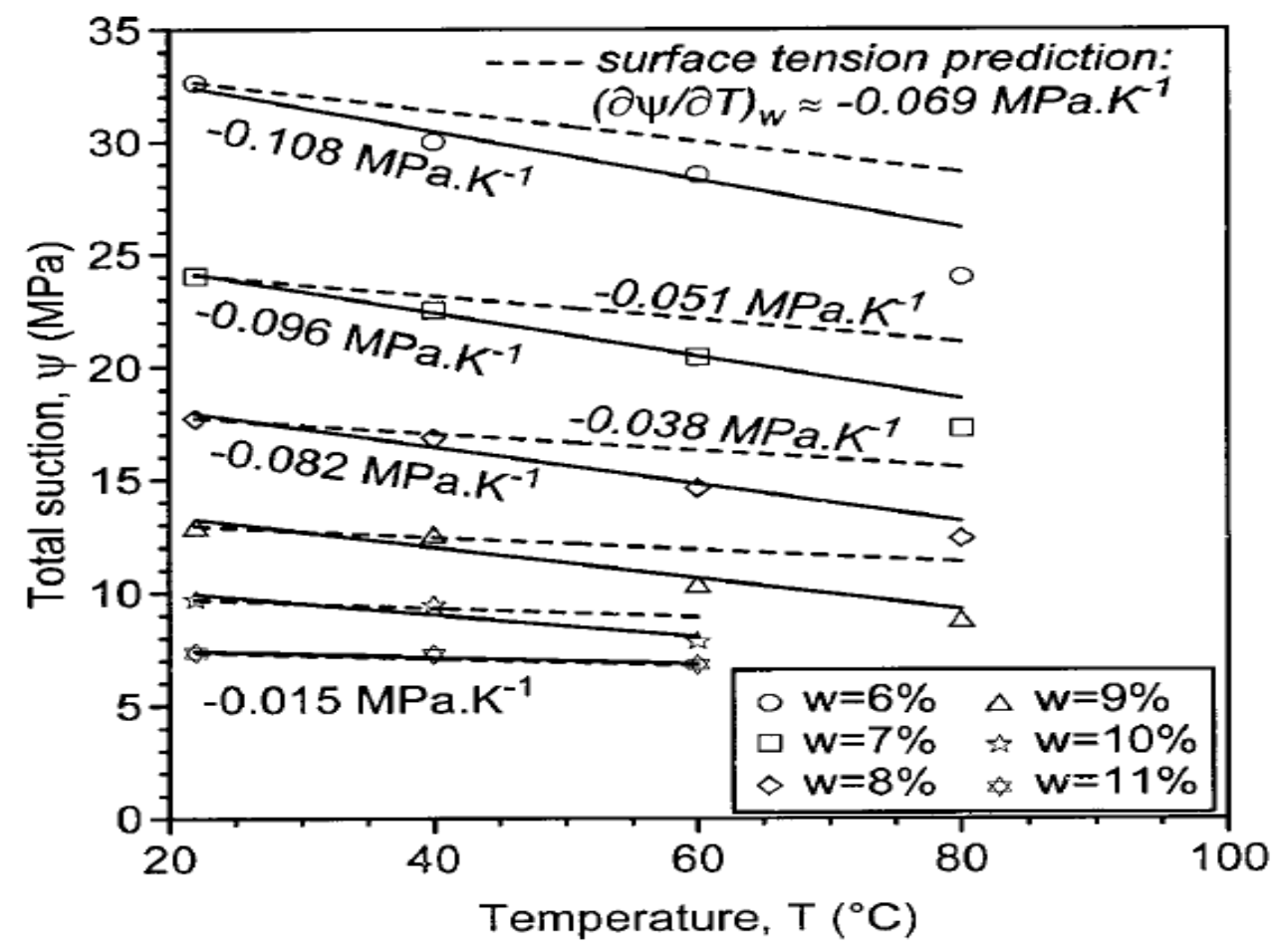

Figure 2.32 Temperature versus total suction at constant water content (Romero et al., 2001). 
Romero et al. (2005) studied the effect of temperature on the soil suction through a series of heat-cool and wet-dry cycles (Figure 2.33). Lower water content was recorded at higher temperature values. This trend indicated lower water adsorption capacity for the test samples at higher temperature which referred to lower soil suction at higher temperature.

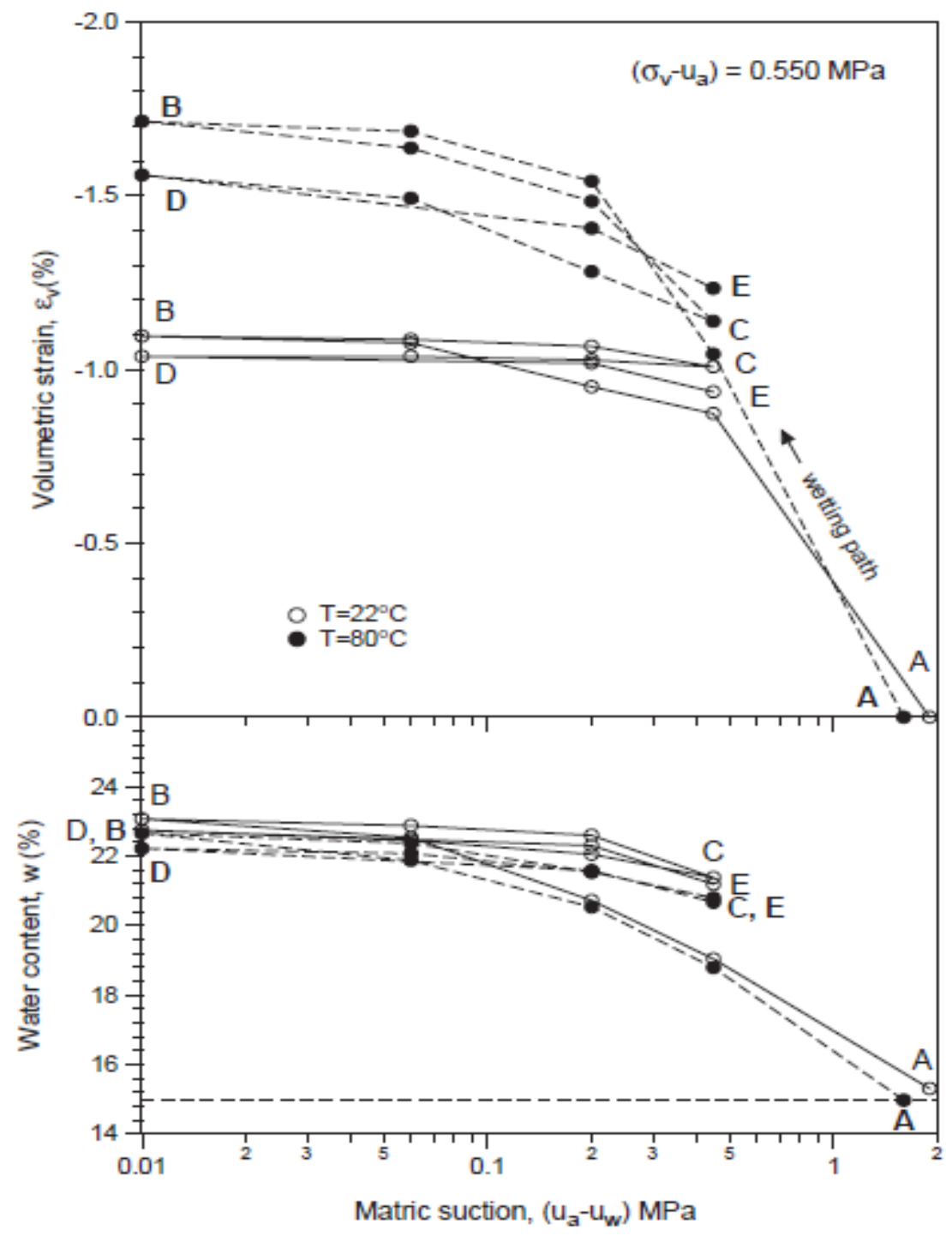

Figure 2.33 Changes in water content and volumetric strain during wet-dry cycles at two different temperatures and constant vertical stress (Romero et al., 2005). 
Villar and Lloret (2004) investigated hydraulic performance of clayey soils at different temperature levels. The test results indicated a slight increase in hydraulic conductivity as the temperature increased, which was linked to the decrease in water viscosity (Figure 2.34).

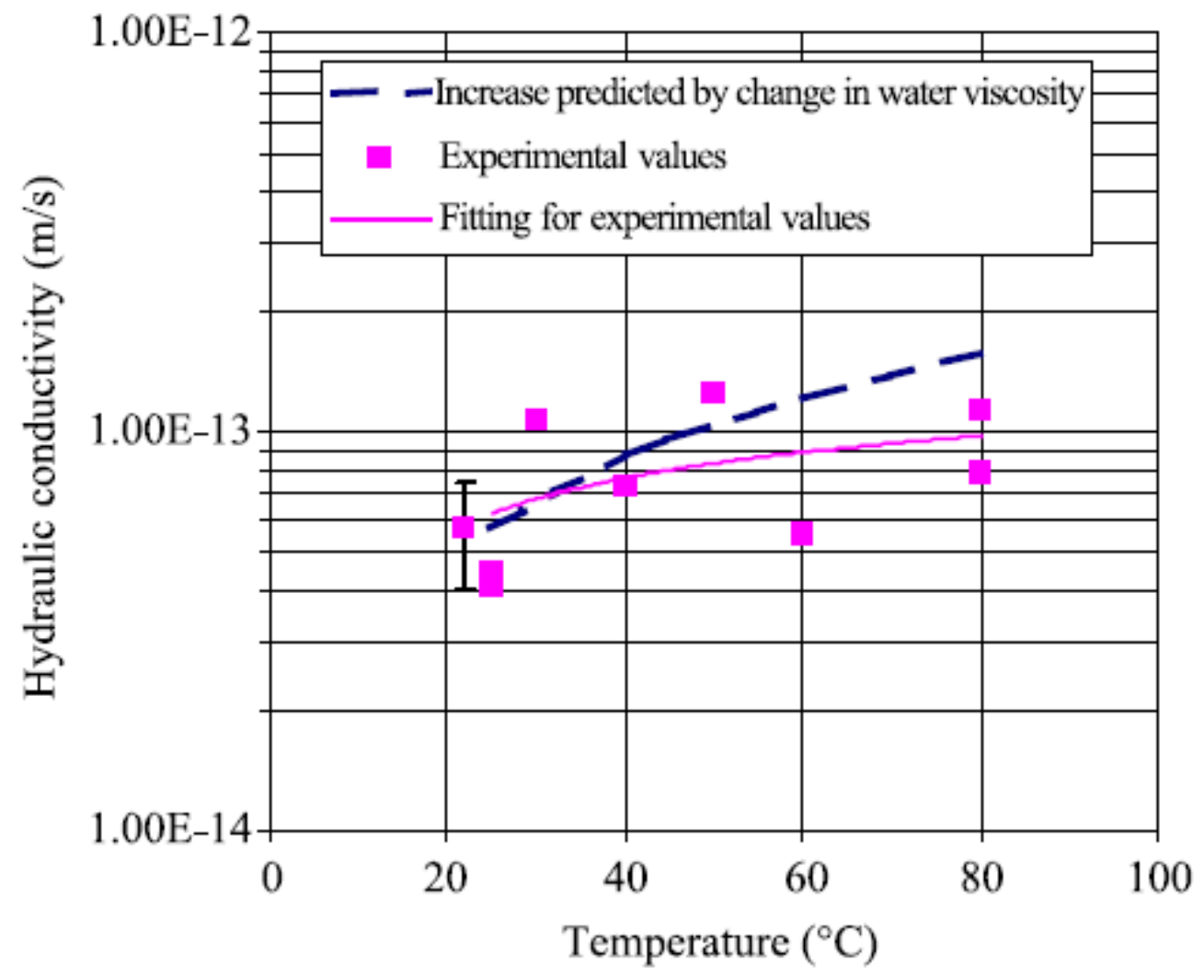

Figure 2.34 Comparison between experimental hydraulic conductivity and predicted hydraulic conductivity at different temperature (Villar and Lloret 2004).

Villar et al. (2005) prepared a $0.6 \mathrm{~m}$ column FEBEX bentonite simulating the radioactive repository wall to investigate the effect of elevated temperature on swelling capacity. The result indicated higher swelling pressure toward hotter zones. This was 
linked to the higher dry density closer to the heat source and higher water content further away from heat source. However, the difference in swelling capacity was attributed solely to variation in dry density due to moisture heterogeneity of soil sample at different distance from the heat source (Figure 2.35).

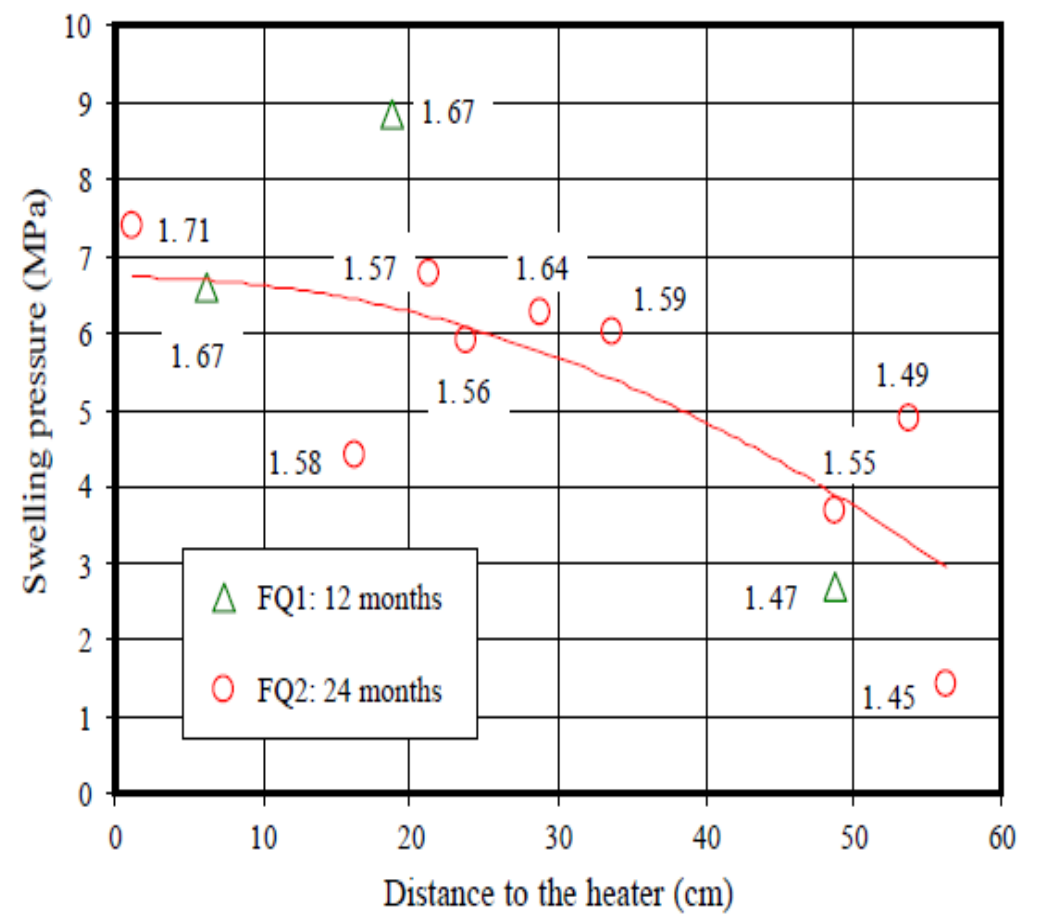

Figure 2.35 Relationship between swelling pressure and temperature (Villar et al., 2005).

\subsubsection{Influence of landfill leachate on hydraulic performance of landfill liners}

Landfill leachate is resulted from waste leaching and organic waste degradation. When clay liner is exposed to landfill leachate, different chemical interactions and mineral transformations are expected. These interactions most likely would cause changes in the soils' chemical compositions (Quigley et al., 1988; Narasimha and Mathew 1995; Allen, 2005; Frempong, 2006), mineral compositions (Quigley et al., 1988; Joseph at al., 2001; 
Frempong, 2006;), and physical properties (i.e. Atterberg limits) (Allen, 2005; Frempong, 2006). Following to these changes, the hydraulic performance of the treated clay might change. Cation Exchange Capacity (CEC), thickness of double layer, and mineral composition are parameters that were used to assess the effect of landfill leachate on hydraulic performance of clay barriers. Griffin et al. (1976) proposed a decrease in hydraulic conductivity of clayey soils upon exposure to domestic waste leachate due to bacterial clogging, double layer expansion, and $\mathrm{Na}^{+}$adsorption. In contrast, Petrov and Rowe (1997) stated that the hydraulic conductivity of GCLs could be an order of magnitude larger when the GCL permeated with landfill leachate instead of distilled or tap water providing the same level of applied stresses. Joet al. (2005) attributed the increase in hydraulic conductivity of sodium bentonite to the replacing of sodium ions by other cations available in the solution and this replacement would change the water adsorption capacity.

Liner/leachate incompatibility may promote leachate to escape and reach groundwater and contaminate the local water sources (Quigley et al., 1989). Thus, longterm effects of landfill leachate on hydraulic performance of clay barriers requires special attention.

\subsubsection{Effect of leachate on chemistry and mineral composition of clay liners}

Different ions can replace each other when chemical interaction occurs. However, the way, in which cations are exchanged, is controlled by many factors. Within clay soil matrix, ion valency is one of these factors that contribute to ion exchange occurrence. Ions with positive charge and higher valency are much difficult to be replaced than the ions with lower valency (Allen, 2005). This behaviour is attributed to the stronger 
attraction to the negative clay surface charge. Providing same concentrations, the different cations would exchange each other in the following order:

$$
\mathrm{Na}^{+}<\mathrm{K}^{+}<\mathrm{Mg}^{2+}<\mathrm{Ca}^{2+}
$$

However, this trend can be different if the concentrations of the ions are changed. Therefore, ion concentration is another factor that can play an important role in determining the mechanism of cation exchange occurrence (Allen, 2005).

Landfill leachate typically has high concentrated ions of sodium, calcium, magnesium and potassium. These ions most likely would interact with clay soil's ions and impose chemical changes. Thereby, changes in hydraulic performance of clay barrier might be resulted. Shackelford et al. (2000) believes that the divalent calcium ions can easily replace the sodium ions in sodium bentonite. However, the higher valency of calcium ions would reduce the ion concentration between clay sheets. Lower ion concentration results in lower repulsive force, which in turn would cause double layer contraction (Shackelford et al., 2000; Van Olphen, 1964). In contrast, Quigley et al. (1988), Frempong (2006), and Quigley et al. (1989) indicated absorption of sodium and potassium ions and desorption of calcium and magnesium ions out of the soil matrix (Figure 2.36). However, the period and the number of pore volumes that were required to reach the chemical equilibrium were varied from soil to soil. Quigley et al. (1989) referred to soil salinity as a controlling factor of ion exchange. High saline soils showed a drop in their salt concentrations because of exposure to leachate with lower ion concentration. However, low saline soils had tendency to adsorb sodium and potassium ions and desorb calcium and magnesium when the leachate ion concentration was higher. Furthermore, Quigley et al. (1988) observed that the compacted clay samples with lower 
void ratio $(\mathrm{e}=0.54)$ exhibited lower sodium and potassium adsorption and faster chemical equilibrium than the soil with higher void ratio $(e=0.74)$. This behaviour was linked to the flow channels that happened due to compaction-induced fractures in the denser soil structure (Figure 2.36) (Quigley et al. 1988).
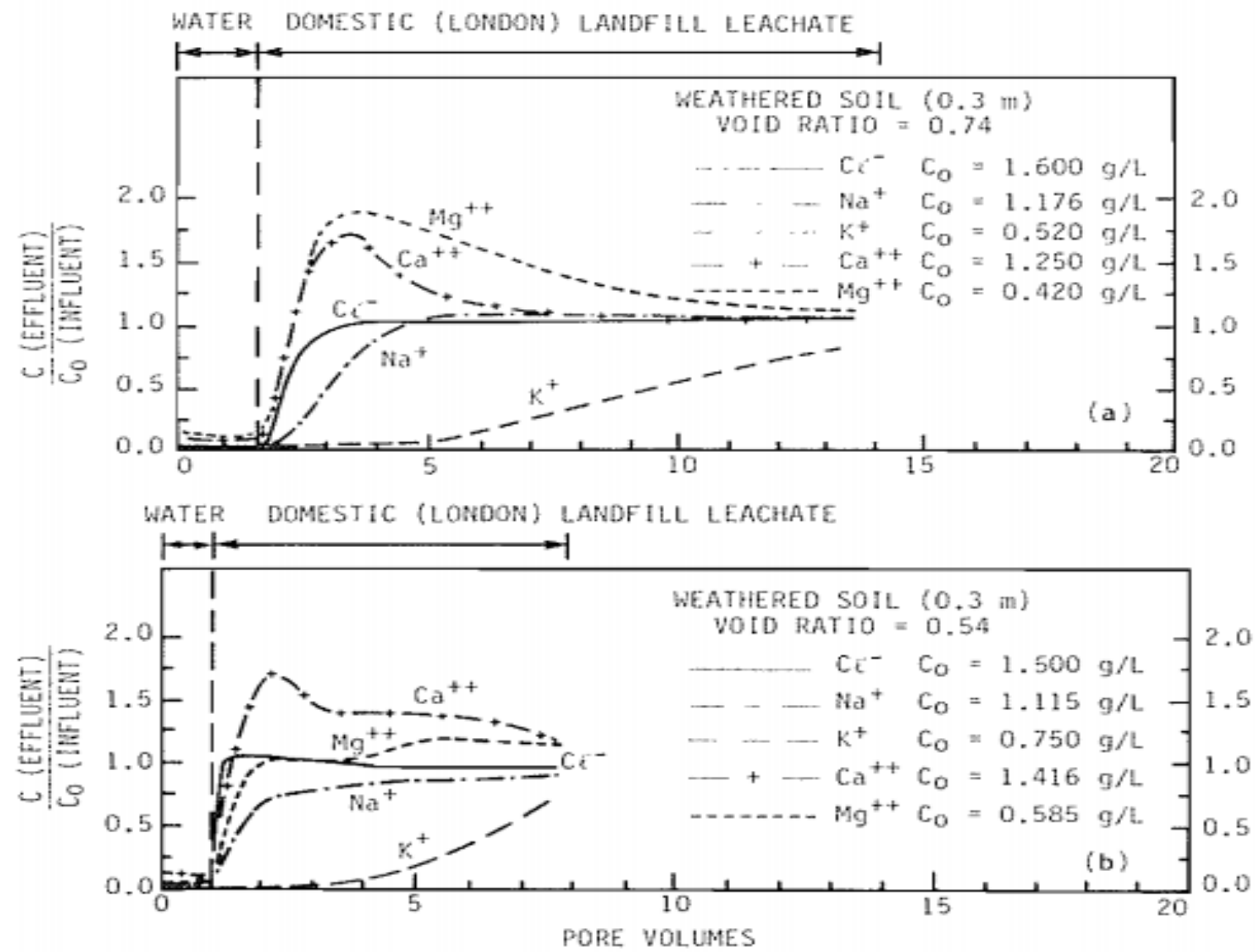

Figure 2.36 No. of pore volumes versus effluent chemistry that passed through samples with two different void ratios: (a) $\mathrm{e}=\mathbf{0 . 7 4}$; (b) $\mathrm{e}=\mathbf{0 . 5 4}$ (Quigley et al. 1988).

Sodium bentonite is distinguished by its richness of monovalent sodium ions between clay sheets that is to equilibrate the negative charge of clay particles. When sodium bentonite is hydrated, water molecules would be attracted by sodium ions, which would increase the spacing between clay sheets known as swelling. Swelling would 
decrease the effective pore space and consequentially decrease the hydraulic conductivity (Shackelford et al., 2000). Marine clays commonly show lower potassium concentration than sodium (Quigley et al., 1988; Quigley et al., 1989). On the other hand, significant concentration of potassium ions in landfill leachate has been reported (e.g., Joseph et al., 2001; and Quigley et al., 1989). For instance, potassium concentration in the Westminster landfill leachate (London, Ontario) was $372 \mathrm{mg} / 1$, while the highest potassium concentration among the liner soils (marine clay) was $57 \mathrm{mg} / 1$ (Quigley et al. 1989). This considerable difference in concentration would induce soil particles to absorb potassium and desorb other ions such as sodium ions in order to reach the chemical equilibrium. In addition, the lower sodium concentration in landfill leachate compared to marine clays might lead to leaching the sodium ions out of the soil matrix. This scenario was reported by Quigley et al. (1989) for a high saline clay sample that was extracted from a depth of $11.5 \mathrm{~m}$. Chloride and sodium ion concentrations in the soil sample reduced upon leachate permeation after 2 and 4 pore volumes respectively. Chloride concentration decreased from $3555 \mathrm{mg} / \mathrm{l}$ to $1200 \mathrm{mg} / \mathrm{l}$, while sodium ions decreased from $1500 \mathrm{mg} / 1$ to reach the equilibrium at $600 \mathrm{mg} / \mathrm{l}$. On the other hand, potassium ion concentration achieved its equilibrium after 7 pore volumes to demonstrate substantial increase from initial value of $57 \mathrm{mg} / 1$ to finial concentration of $275 \mathrm{mg} / 1$. Decreasing sodium concentration and trapping potassium ions, which is known as potassium fixation phenomenon, would decrease both the repulsive force and the swelling capacity. Although sodium and potassium ions have the same valency, sodium ions can yield higher hydrated radius than the potassium ions. Therefore, potassium fixation would decrease the hydrated radius and cause reduction of the double layer thickness. Moreover, reduction in the cation exchange capacity would 
happen parallel to potassium fixation. This would increase the potential contraction in the crystal volume. Thus, an increase in effective pore space would be resulted and consequently lead to an increase in hydraulic conductivity (Quigley et al., 1988; Shackelford et al., 2000).

Clay particle arrangement is also affected by ion charges. Clay particles commonly have positive charge at the edges and negative charge on the surface. Fluctuation in particle arrangement would be resulted due to the attraction between different charges of the edges and surfaces of clay particles. When clay soil is exposed to concentrated chemical solution, ion concentrations within the soil would increase. This increase might cause the clay layers to be arranged in parallel manner (dispersion) under the effect of ion charges and result in lower hydraulic conductivity (Das, 2002). However, increase in the ion valency and hence decrease in ion concentration, would decrease the repulsive forces as well as double layer thickness (Van Olphen, 1964). Repulsive force depression might lead to flocculation arrangement. Thus, increase in hydraulic conductivity most likely would be encountered. Narasimha and Mathew (1995) observed dispersed arrangement for low valency clay $\left(\mathrm{Na}^{+}\right.$clay) and flocculated arrangement for high valency clay $\left(\mathrm{Al}^{3+}\right.$ clay). In term of hydraulic performance, hydraulic conductivity of $\mathrm{Al}^{3+}$ clay was 13 times higher than the $\mathrm{Na}^{+}$clay because of soil particles flocculation toward $\mathrm{Al}^{+3}$ clay(Figure 2.37). 


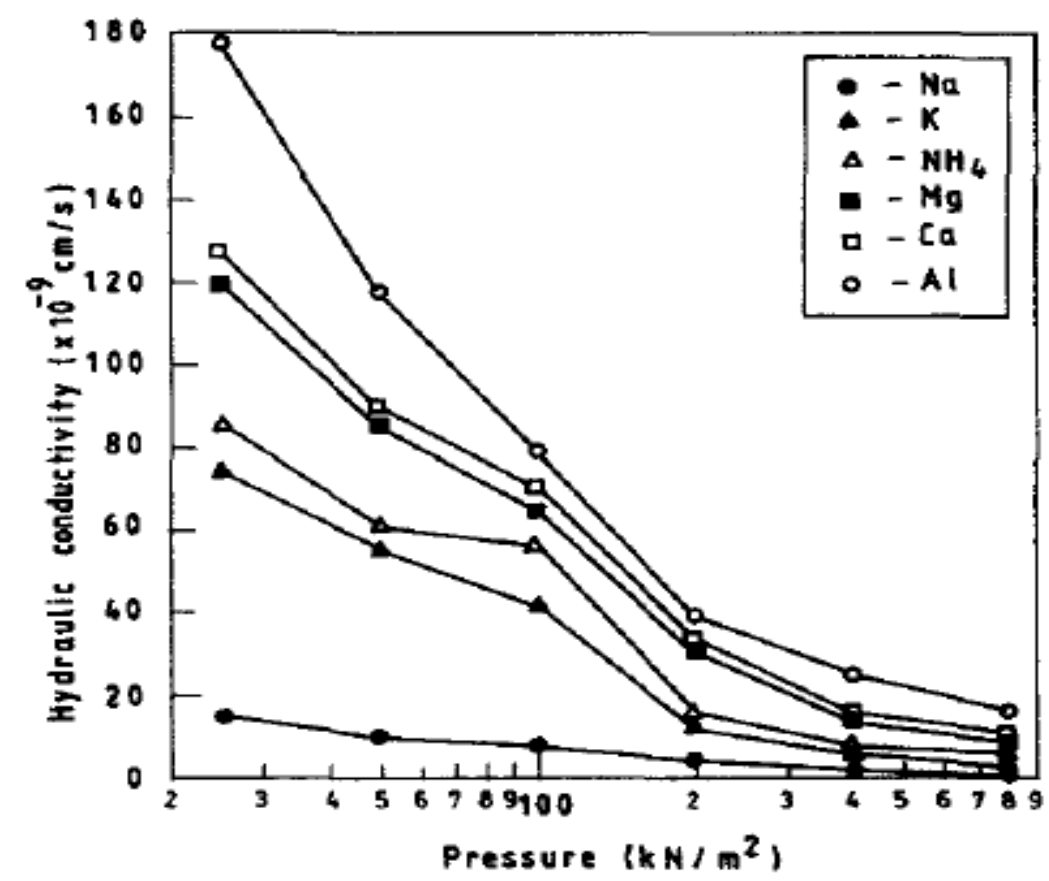

Figure 2.37 Hydraulic conductivity for homoionic clays at different level of vertical stress (Narasimha and Mathew 1995).

Potential mineral transformation due to chemical interaction between clay soils and landfill leachate was intensively studied. Quigley et al. (1988) compared the mineral composition of two soils at initial state and after being treated with $0.5 \mathrm{~N} \mathrm{KCl}$ for air-dried soil and water-wet soil samples. Results showed significant collapse of smectite clays to form illite mineral when the air-dried soil samples were treated with $0.5 \mathrm{~N} \mathrm{KCl}$. However, for the case of water-wet samples, less smectite collapse was observed. Therefore, the mineral analysis for water-wet samples would be more relevant to real field condition, with less potential for mineral transformation (Quigley et al., 1988; Joseph et al. 2001). In contrary, Frempong, (2006) reported significant mineral transformation upon leachate permeation. Mixed layer mineral of illite/vermiculate was collapsed and formed single 
illite and vermiculate minerals. Moreover, smectite and Fe-chlorite minerals were transformed to smectite-organic minerals and chlorite-organic minerals.

\subsubsection{Effect of leachate on physical properties (Atterberg limits) of clay liner}

Atterberg limits are practical indicators that can be used to choose the most appropriate material for clay barrier construction. Clay soils with higher plasticity indices would generally yield lower hydraulic conductivity. Upon leachate permeation, clay may experience chemical and mineral changes. When the dominant ions change from sodium to potassium and smectite group mineral collapse and form illite minerals, the water capacity of the soil would be lower. Thus, Atterberg limits will differ. Therefore, the assessment of long-term effect of leachate permeation on Atterberg limits would be a necessity for clay/leachate compatibility evaluation. Figure (2.38) shows decrease in plasticity indices for four bentonite test samples as the salt concentrations of the permeants increased (Allen, 2005). On the other hand, Frempong (2006) reported no significant change in plastic limits for tropical clay soils. However, the liquid limits and the relevant plasticity indices experienced reduction that sometimes reached $17 \%$ (Table 2.3). This reduction was linked to possible alternation of the soil fabric from dispersed to fluctuated fabric due to reduction in the repulsive force. This fluctuation, however, should have caused increase in hydraulic conductivity of the soils; although, no significant increases have been reported. 
The maximum dry densities for test soils were also determined after leachate permeation. An increase in dry density and a decrease in water content was recorded for soils $\mathrm{A}$ and $\mathrm{H}$ with medium plasticity indices of $24 \%$ and $28 \%$ respectively. However, soil K with higher plasticity index (44\%) showed an opposed behaviour (Table 2.3). Organic matter was shown to increase to $100 \%$ due to permeation with leachate. However, unexpected decrease in specific surface occurred which linked to mineralogical transformation (Frempong, 2006).

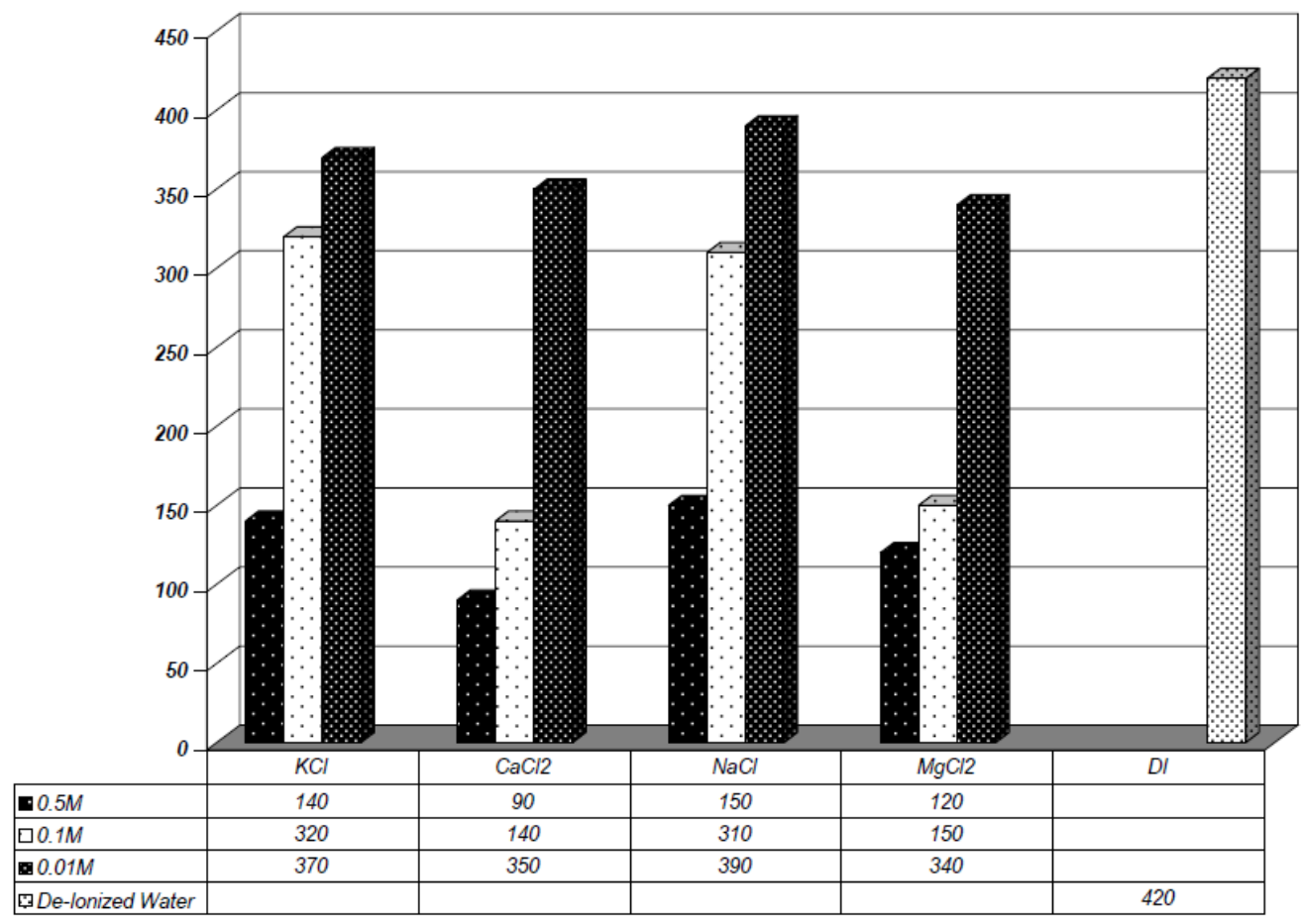

Figure 2.38 Plasticity indices for bentonite permeated with different salt types and concentrations

(Allen, 2005).

Table 2.3 Changes in Atterberg limits upon leachate permeation (Frempong, 2006)

\begin{tabular}{|l|l|l|l|l|l|l|}
\hline \multirow{2}{*}{ Soil type } & \multicolumn{2}{|c|}{ LL } & \multicolumn{2}{c|}{ PL } & \multicolumn{2}{c|}{ PI } \\
\cline { 2 - 7 } & Initial & Final & Initial & Final & Initial & Final \\
\hline A & 54 & 50 & 28 & 26 & 26 & 24 \\
\hline H & 56 & 54 & 26 & 26 & 30 & 28 \\
\hline K & 87 & 70 & 26 & 26 & 61 & 44 \\
\hline
\end{tabular}




\subsubsection{Impact of leachate properties on hydraulic performance of clay liner}

Waste management plan and landfill operation system would control the properties of landfill leachate. For example, landfill leachate generated from bioreactor landfills would be different in composition and concentration from leachate produced in regular landfills. Therefore, the level of clay/leachate compatibility would be site-dependent. The hydraulic performance of GCL can widely vary based on the leachate component with which the GCL is permeated (Quigley et al. 1988). For example, a hydraulic conductivity of $7 \times 10^{-12} \mathrm{~m} / \mathrm{s}$ was recorded when a sample of GCL permeated with tap water, while permeating with real and synthetic leachate yielded hydraulic conductivities of $1 \times 10^{-}$ ${ }^{12} \mathrm{~m} / \mathrm{s}$ and $2 \times 10^{-8} \mathrm{~m} / \mathrm{s}$ respectively (Ruhl and Daniel 1997). The real leachate yielded lower permeability, even though it had lower salt concentration. This was attributed to the presence of bacteria that might cause $\mathrm{pH}$ increasing and pore medium clogging due to bacterial precipitation (Rowe, 1998). Therefore, Rowe (1998) suggested using simulated chemical leachate (synthetic leachate) for laboratory investigations as a conservative procedure since it may be difficult to predict the bacterial behavior whether would be beneficial or not.

Landfill leachate in form of water- soluble organic liquids could result in raising the hydraulic conductivity of water-compacted clay. Many factors are involved in this phenomenon such as viscosity and dielectric constant of the permeant, which all influence the ease of permeant flow and the thickness of double layer (Fernandez and Quigley 1988). Attempts were made to quantify the concentration of the organic liquids in a leachate solution at which the hydraulic conductivity of water-compacted clay would 
significantly increase. Permeant viscosity was shown to increase as the organic content increased to reach a maximum viscosity value at $60 \%$ dioxane concentration and at $40 \%$ ethanol concentration (Fernandez and Quigley, 1988). Further increases in the organic contents beyond these values exhibited decrease in the permeant viscosities. On the other hand, dielectric constant for different solutions significantly decreased as the organic content increased.

Hydraulic conductivity for samples exposed to permeants with different concentration of ethanol, on one hand, and dioxane on the other hand was determined and plotted in Figures $(2.39,2.40)$ respectively. Slight decrease in hydraulic conductivity was reported when methanol and dioxane concentrations were increased in the permeants up to $60 \%$ and $70 \%$ respectively. Soil samples experienced an increase in hydraulic conductivity by half an order of magnitude and two orders of magnitude when permeated with $80 \%$ and $85 \%$ ethanol and dioxane respectively. Maximum increases in hydraulic conductivities by two and three orders of magnitudes were recorded for the soil samples permeated with concentrated methanol and concentrated dioxane respectively. 


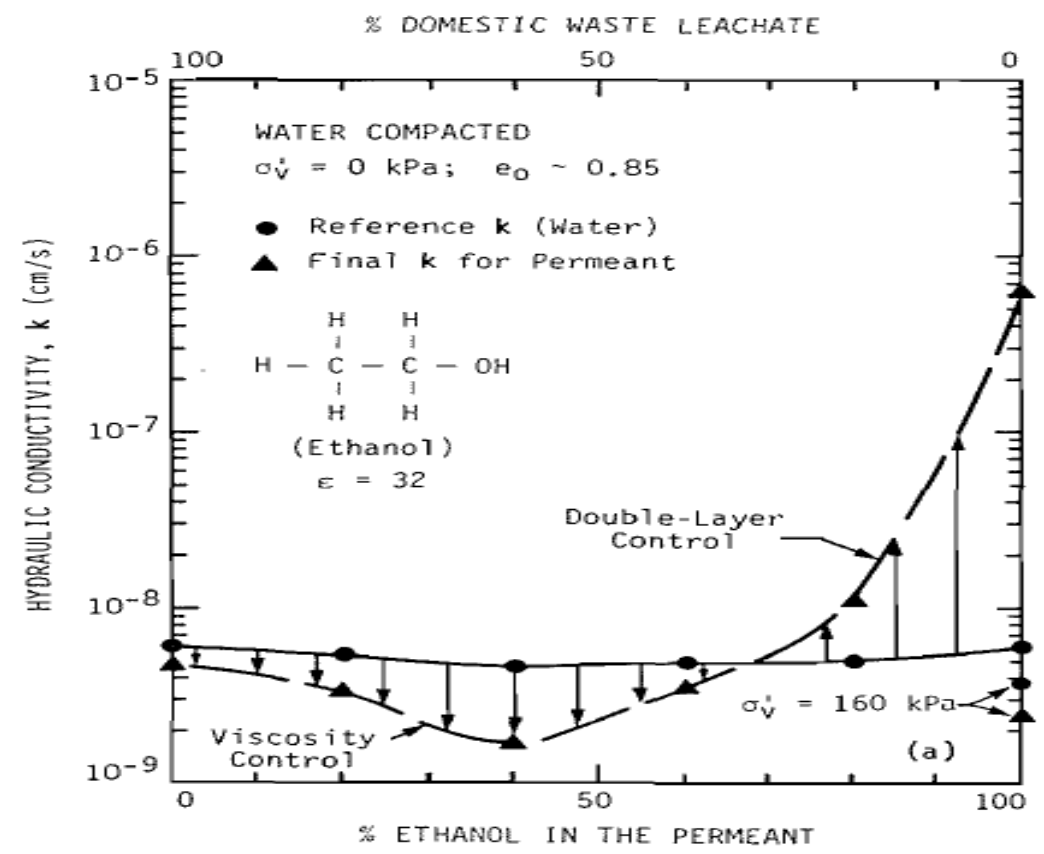

Figure 2.39 Hydraulic conductivity of water-compacted Sarnia clay permeated with leachate-ethanol mixtures. Black dots show reference water conductivity, while rectangular shape shows conductivity of leachates that vary from leachate to commercial ethanol (Fernandez \& Quigley 1988).

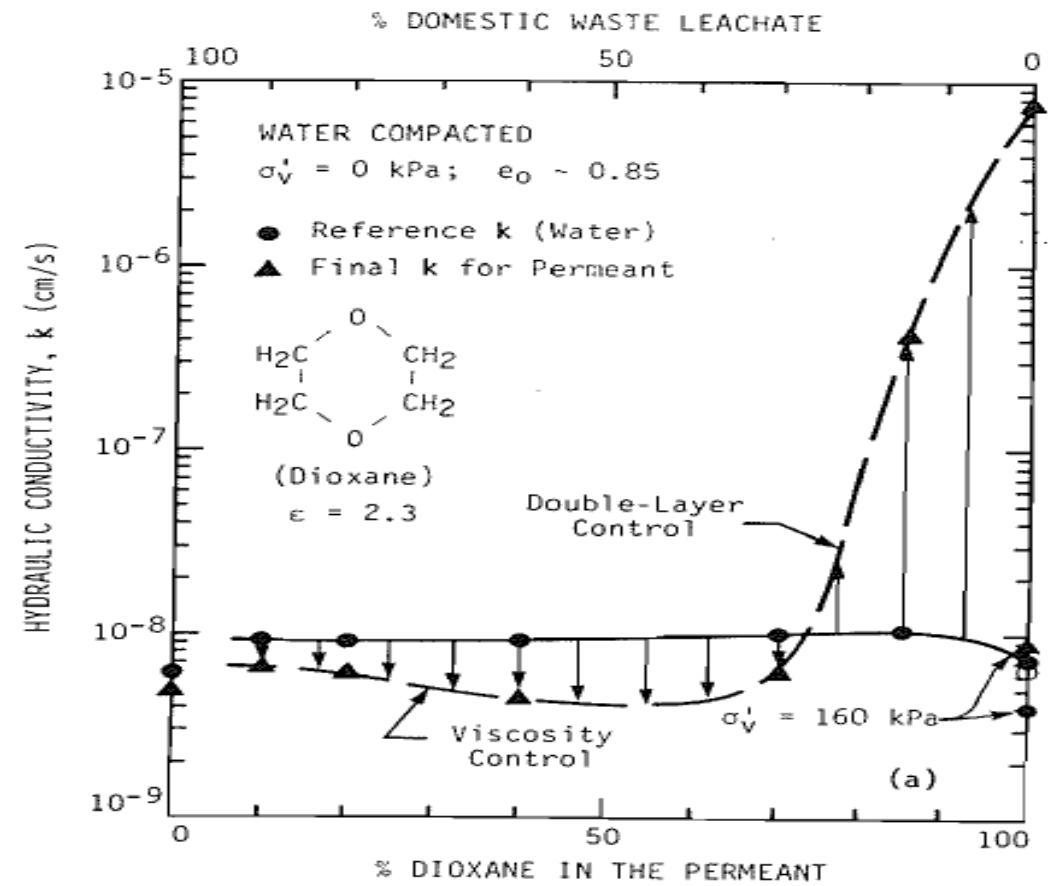

Figure 2.40 Hydraulic conductivity of water-compacted Sarnia clay permeated with leachatedioxane mixtures. Black dots show reference water conductivity, while rectangular shape shows conductivity of leachates that vary from leachate to dioxane (Fernandez and Quigley 1988). 
The decrease in hydraulic conductivity at the beginning was referred to the increase of viscosities as the ethanol and dioxane concentrations increased. The maximum permeants viscosities were achieved when the ethanol and dioxane contents in the permeants reached $40 \%$ and $60 \%$ respectively. When the concentrations of the organic contents (ethanol and dioxane) go beyond these points, the viscosities start to decrease and, in turn, increase the hydraulic conductivity. However, this increase was attributed mainly to the collapse of the double layer, which became dominant over the viscosity effect at high organic contents. Double layer contraction would cause reduction of the water film around the particles. This reduction would increase the effective pore space at constant void ratio and eventually might lead to increase in hydraulic conductivity of the soil (Fernandez and Quigley 1988). 


\section{CHAPTER: Hydraulic Performance of Compacted Clay Liners under Simulated Daily Thermal Cycles}

\subsection{Introduction}

Compacted clay liners (CCL) are used as hydraulic barriers in several landfill applications to isolate contaminants from the surrounding environment and minimize the escape of leachate from the landfill. Prior to waste placement in landfills, CCLs are often exposed to temperature fluctuations which can affect the hydraulic performance of the liner. CCLs might also be exposed to wet-dry cycles during seasonal weather fluctuations. These weather circumstances can cause severe changes in the hydraulic performance of the CCL.

Desiccation and evaporation cause reductions in water content of the soil, which may lead to a decrease in pore-water pressure and gradually an increase in metric suction (Konrad and Ayad, 1997; Nahlawi and Kodikara, 2006; Tang et al., 2011). Outgoing water flow generates voids within soil particles. Following generation of these voids, the soil particles are reorganized due to an internal compression effect, which increases with an increase in soil suction. As a result, a reduction in the soil matrix volume, known as shrinkage, occur (Albrecht and Benson, 2001; Peron et al., 2009; Tang et al., 2011). This shrinkage could induce volumetric change and crack formation in the soil matrix that may lead to a considerable increase in permeability of the CCL.

The shrinkage behaviour of CCLs is influenced by several factors including clay content, clay mineralogy, and the exposure conditions. Albrecht and Benson (2001) reported considerable volumetric shrinkage as the clay content increased in soils where smectite minerals dominated, while illite, kaolinite, and quartz soils demonstrated less 
shrinkage. Similarly, Omidi et al. (1996) reported higher volumetric shrinkage in smectite soils compared to illite soils. This was linked to the capability of smectite to absorb more interlayer water and consequently undergo higher volumetric shrinkage upon drying. If the volumetric shrinkage is restricted, cracks may occur when the soil's tensile strength fails to resist the growing tensile stresses (Nahlawi and Kodikara, 2006; Tang et al., 2011). Volume shrinkage and cracking were shown to significantly affect the hydraulic performance of CCLs (e.g., Omidi et al., 1996; Rayhani et al., 2007, 2008). Omidi et al. (1996) suggested that soils with volumetric shrinkage of less than $11 \%$ would result in quite stable hydraulic performance under desiccation. However, clayey soils with volumetric shrinkage higher than $11 \%$ would experience an increase in their permeability.

Tang at al. (2011) identified soil suction as the mechanical initiator of cracking, and any parameter related to soil suction or soil tensile strength would widely influence the desiccation cracking. Moreover, the generation of tension stresses due to soil shrinkage is mainly related to boundary conditions. If the soil is free to uniformly shrink and no considerable friction is provided by the subgrade, then stresses will not be generated. However, in reality and in real-life field conditions, non-uniform shrinkage is the case only when the upper portion of the soil is exposed to the atmosphere. This nonuniformity leads to the creation of friction between upper soils and the underlying layer, which eventually results in cracking.

In the field, CCLs are often exposed to several wet-dry and/or freeze-thaw cycles during the year. These cycles may result in crack formation as the soil desiccates or freezes. However, subsequent wetting or thawing can lead to partial crack closure which 
results in what is known as the self-healing phenomenon. Investigations into the effects of wet-dry cycles on soil shrinkage and crack formation were widely conducted (DeJong and Warkentin, 1965; Albrecht and Benson, 2001; Zubaydi, 2011). All reported significant crack formation and volumetric shrinkage after the first wet-dry cycle, but the following cycles exhibited a lower impact.

Desiccation cracking and the relevant changes in hydraulic behavior of fine-grained soils have been widely investigated. However, field conditions that CCL materials would be exposed to were neither adequately, nor accurately, simulated. In the literature, most desiccation and dewatering processes were initiated by putting the entire test specimen in an oven thereby exposing it to an all-around (3D) heat (e.g., Omidi et al., 1996; Rayhani et al., 2008). Furthermore, the heating interval, in many cases, was prolonged for several days (e.g. Omidi et al., 1996). This exaggeration of circumstances could result in severe shrinkage and a subsequent increase in permeability of the CCL. In the current study, laboratory tests were carried out to evaluate the effects of daily thermal cycles on the performance of CCLs under simulated field conditions. Hydraulic conductivity tests were also conducted prior to, and after, several thermal and dehydration cycles. Different types of clayey soils were used in this experiment in an attempt to overcome soil variability effects and to create a broad fundamental base for safer design and better performance of CCL in landfill liner systems.

\subsection{Soil Properties}

Clayey soils used as CCL specimens in this research were a natural clay soil and two artificial mixtures. The natural clay soil was extracted from the Halton landfill in Toronto (Halton Clay), whereas the simulated mixtures were created by adding sodium bentonite 
to the Halton clay and Leda clay extracted from the Navan Landfill in Ottawa. The variability in soil types aimed to create a variety of plasticity values and clay contents (Leda caly $+5 \%$ bentonite and Halton clay $+10 \%$ Bentonite mixtures, Table 3.1 ).

Particle size distribution and clay contents of the study soils were estimated by conducting sieve analysis and hydrometer tests based on the ASTM standard (D4221-11) (Figure 3.1). The physical properties of the test soils are summarized in Table (3.1). Liquid limits (LL) for test soils ranged from $23 \%$ to $60 \%$, while plasticity indices (PI) varied from 9.5\% to 37.2\% based on the Atterberg test results (ASTM D4318-10). Maximum dry densities and optimum moisture contents were determined using the Standard Procter test (ASTM D 698-12). Soil-Water Characteristic Curves (SWCC) for all test soils were also established in accordance with ASTM procedure, and the air entry values, transition curves, and the near residual values were obtained (Figure 3.2).

Table 3.1 Physical properties of the test soils.

\begin{tabular}{lccl}
\hline Characteristics $(\%)$ & Halton clay & Halton clay+ Bent. & Leda clay+Bent. \\
\hline Soil type & CL & CL & CH \\
Liquid limit & 23.5 & 43.5 & 60.0 \\
Plasticity index & 9.5 & 25.0 & 37.2 \\
$\rho_{d \text { (Max.), Mg/m }}$ & 1.70 & 1.56 & 1.27 \\
Optimum water content & 13.5 & 17.0 & 34.5 \\
Shrinkage limit & 16.0 & 18.1 & 24.4 \\
Clay content & 24 & 34.0 & 76 \\
Smectite content & 8 & 14 & 16 \\
activity & 0.4 & 0.83 & 0.5 \\
\hline
\end{tabular}




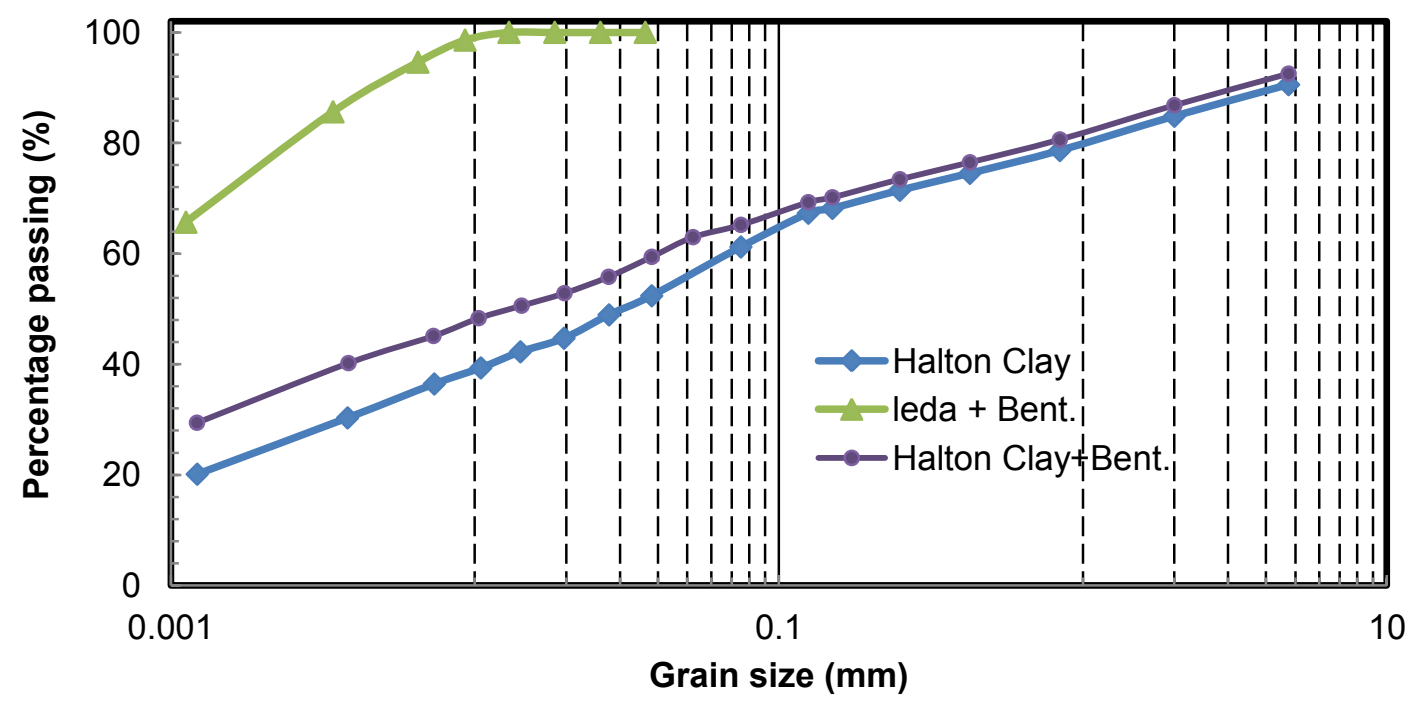

Figure 3.1 Particle size distribution of the test soils.

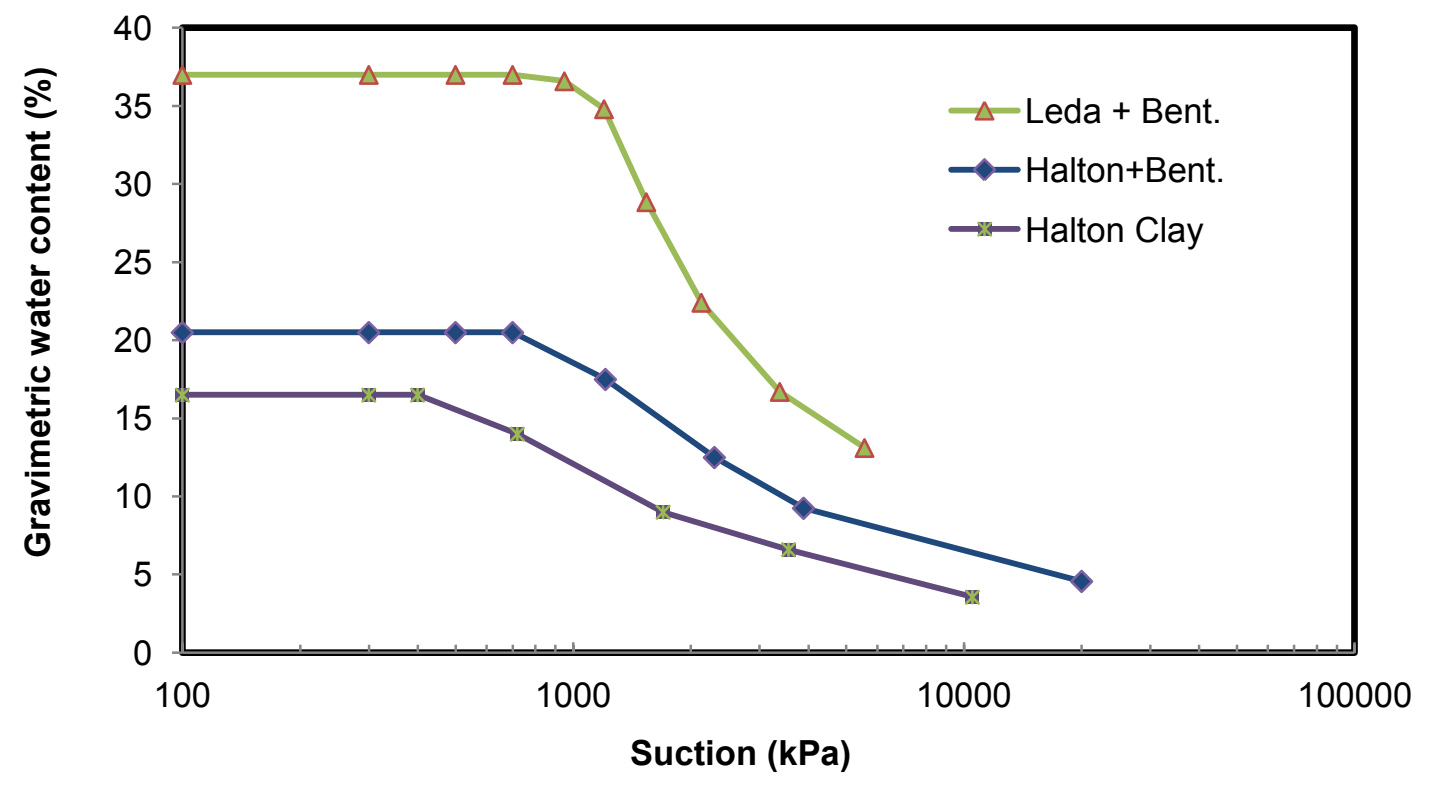

Figure 3.2 Soil-water characteristic curves for test soils (both total and metric suctions). 
A chemical analysis was also performed on the extracted pore waters from the soil specimens. Cation concentrations including potassium, calcium, and magnesium ions were determined in the pore water, while sodium concentration was measured based on acid extractable sodium ions $(\mathrm{mg} / \mathrm{kg})$. Cation exchange capacities (CEC) were determined and the results are presented in Table 3.2.

Table 3.2 Cation concentration in the pore water of the test soils.

\begin{tabular}{ccc}
\hline Characteristics & Halton Till & Leda clay \\
\hline Sodium $(\mathrm{mg} / \mathrm{kg})$ & 160.0 & 1700 \\
Potassium $(\mathrm{mg} / \mathrm{l})$ & 6.0 & 15.0 \\
Calcium $(\mathrm{mg} / \mathrm{l})$ & $\mathbf{7 2 1 . 0}$ & $\mathbf{8 3 . 0}$ \\
Magnesium $(\mathrm{mg} / \mathrm{l})$ & 25.0 & 40.0 \\
$(\mathrm{CEC})^{1} \mathrm{meq} / \mathbf{1 0 0} \mathrm{g}$ & 67.0 & 18.0 \\
\hline
\end{tabular}

\subsection{Experimental program}

\subsubsection{Experimental cells and specimen preparation}

Plexiglas cells $140 \mathrm{~mm}$ in diameter and $150 \mathrm{~mm}$ in height were used to simulate a typical CCL profile in landfills. The Plexiglas cells were equipped with upper and lower aluminum lids with dimensions of $200 \mathrm{~mm}$ x $200 \mathrm{~mm}$ x $10 \mathrm{~mm}$. The upper lids were manufactured with influent and venting ports, whereas the lower lids featured effluent ports in order to enable the permeant to move throughout the soil columns. Prior to soil compaction, rubber membranes were stretched inside the cells to eliminate the effect of side-wall leakage (Figure 3.3). 


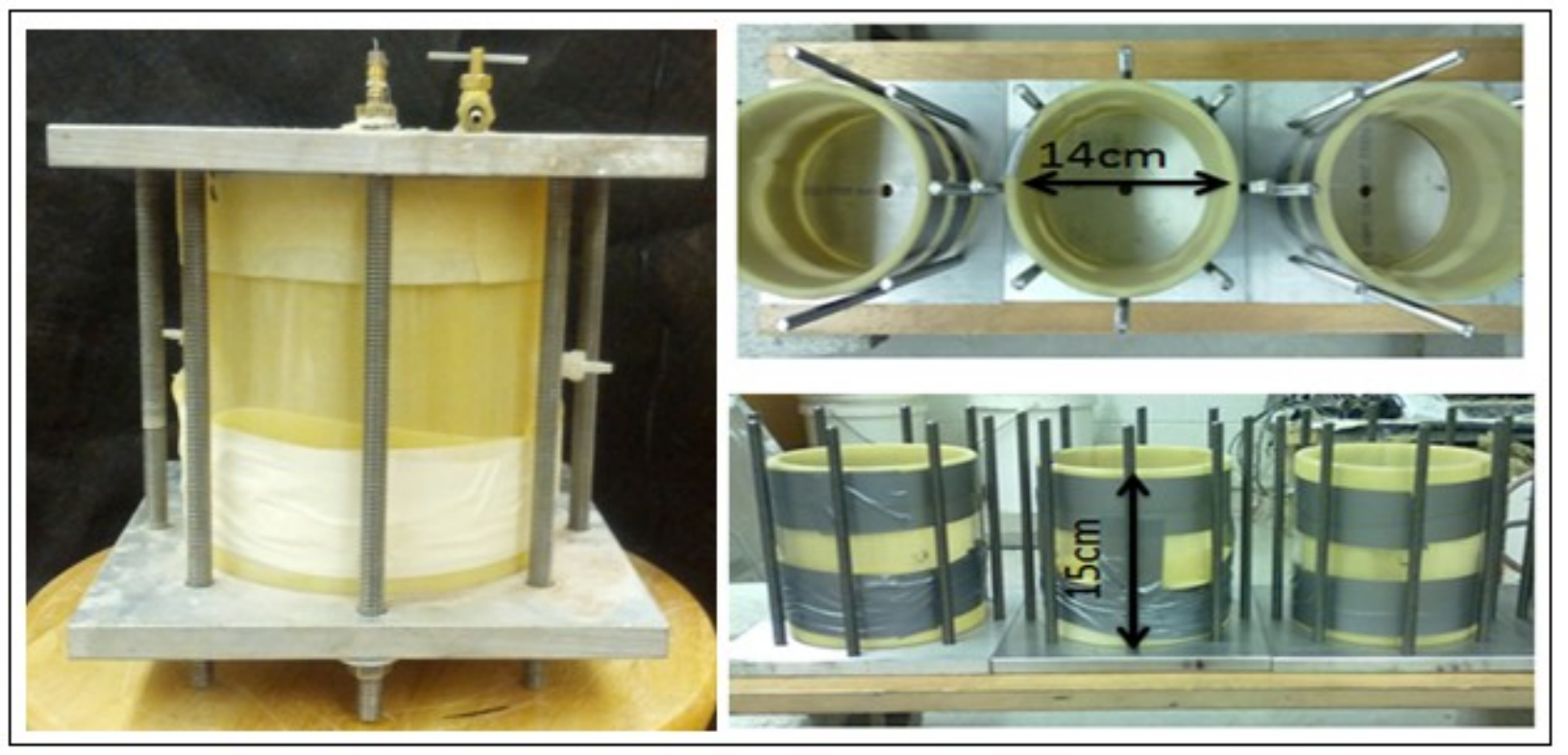

Figure 3.3 Shape and dimensions of test molds.

Prior to sample preparation, bulk soil samples were ground to pass through sieve No. $4(4.75 \mathrm{~mm})$. For soil mixtures, different proportions of sodium bentonite were added to the natural soil powders and carefully mixed in order to obtain uniform mixtures. To prepare the experimental cells, water was added to the dry soil until a moisture content of $\mathrm{w}_{\mathrm{opt}}+2 \%$ was achieved for all soils. The hydrated soils were then allowed to cure in airtight plastic bags for at least 48 hours to ensure uniform moisture distribution. The soil was then compacted in three layers into the cells ( $95 \%$ of the maximum dry density). At each compaction layer, a specimen of soil was obtained to measure the moisture content of the soil throughout the cell.

\subsubsection{Hydraulic conductivity testing}

Saturated hydraulic conductivity tests were performed on the test samples after preparation as well as after exposure to different thermal cycles. The falling head method was adopted to conduct saturated hydraulic conductivity tests using a rigid-wall 
permeameter based on the ASTM standard (ASTM D5856-95). The bottom lids were equipped with porous fabric to ensure better effluent collection. Similar geotextile porous fabric was also placed on top of the soil and the whole system was sealed by the upper lid and then connected to the hydraulic conductivity device for saturation and testing. A hydraulic gradient of 6 was maintained for all test cells during saturation. This value was selected to provide enough hydraulic gradient for the test while avoiding disruption of the soil structure (Bowles, 1979). The saturation time varied from 20 to 35 days depending on soil type. The permeant was allowed to flow upward throughout the soil column to eliminate the gravity effect during saturation. The samples were considered saturated when a steady state flow was observed at the effluent ports. Following the saturation, hydraulic conductivity measurements were taken and final hydraulic conductivity values were recorded when three successive readings were similar (Figure 3.4). 


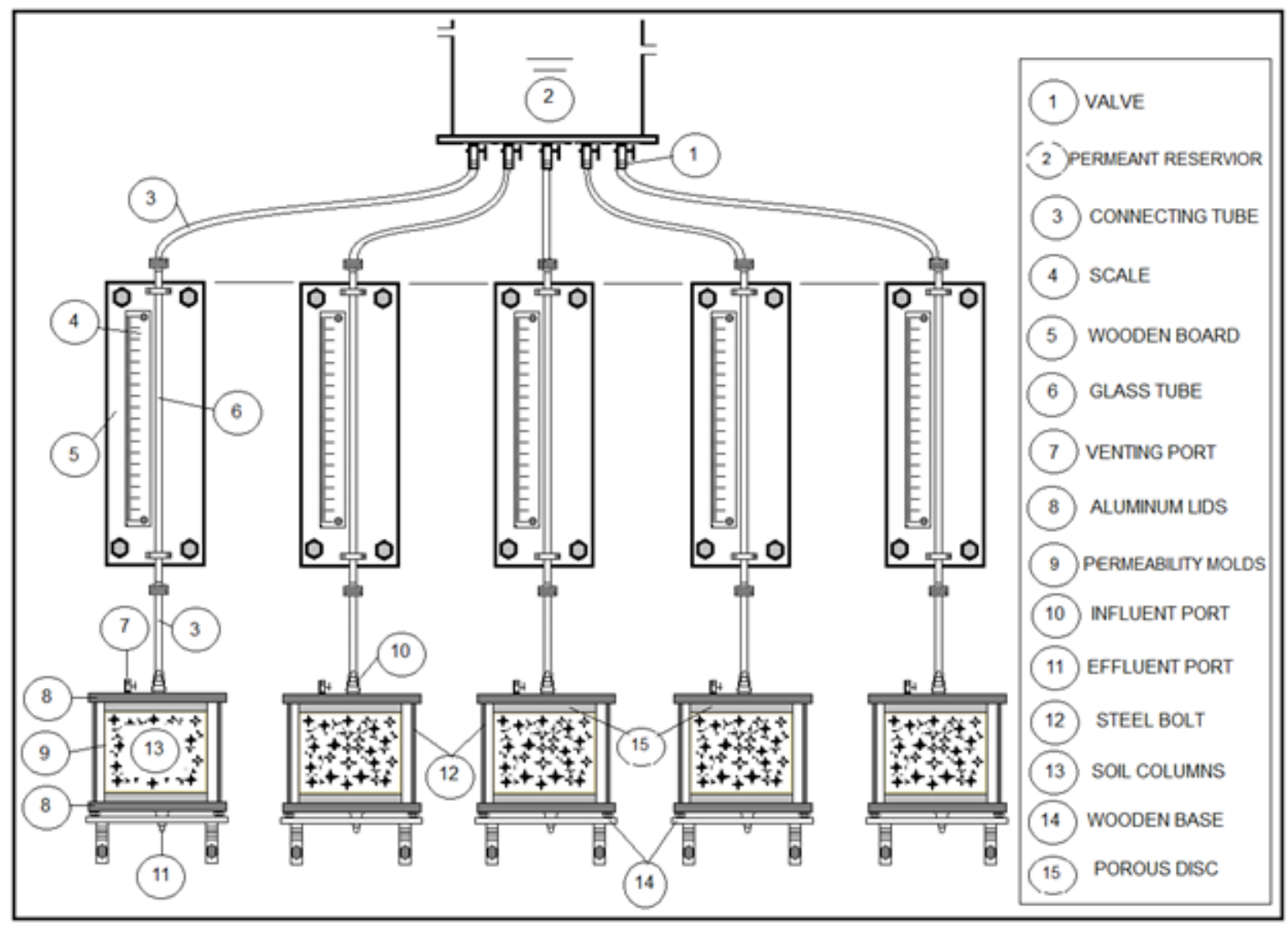

Figure 3.4 Schematic diagram of the falling head method for hydraulic conductivity test.

\subsubsection{Experimental procedure}

CCLs can be used alone or in combination with a geomembrane for landfill barrier systems. Prior to waste placement, CCL might be exposed to daily thermal cycles induced by solar radiation as well as wet-dry cycles. Overlaying the CCL with geomembrane, on one hand, may eliminate the effect of wet-dry cycles, however, the dark color of the geomembrane, on the other hand, was found to enhance the effect of the solar radiation. Thiel et al. (2006) recorded temperature readings underneath the geomembrane as high as $60^{\circ} \mathrm{C}$. Therefore, CCLs in both barrier systems may experience 
damage due to weathering and volume shrinkage. In the current study, the level of change in hydraulic performance of the CCL in both barrier systems (with and without geomembrane) was investigated. For the case of CCL alone, 6 test specimens were prepared using Halton clay, Halton clay+bentonite mixture, and Leda clay+bentonite mixture with an average of two specimens per soil type. After initial hydraulic conductivity measurements, the upper lids were removed and the cells were exposed to simulated daily thermal cycles in an insulated box (Figure 3.5). Insulation materials installed all-around the Plexiglas cells, while upper surfaces of soil specimens were left exposed to a source of heat to encourage one dimensional heat and moisture transfer. Daily thermal cycles were simulated by implementing a heating blanket on top of soil specimens. A controlling system was used to apply a temperature of $55^{\circ} \mathrm{C}$ for eight hours. Soil specimens were then left to cool down for the remaining 16 hours simulating the effect of overnight cooling.

To investigate the effect of the geomembrane on shrinkage and hydraulic performance of the CCL, 8 test specimens were prepared using Halton clay and Leda clay+bentonite mixture (four specimens of each soil). The upper lids were used to simulate the role of the geomembrane, while the soil columns underneath represented the CCLs (Figure 3.5). For all specimens, insulating materials were installed around the test cells to simulate a one-dimensional temperature and moisture transport. Only the top surfaces of the soil cells and the surfaces of upper lids were exposed to thermal cycles provided by a heating blanket placed on top. 


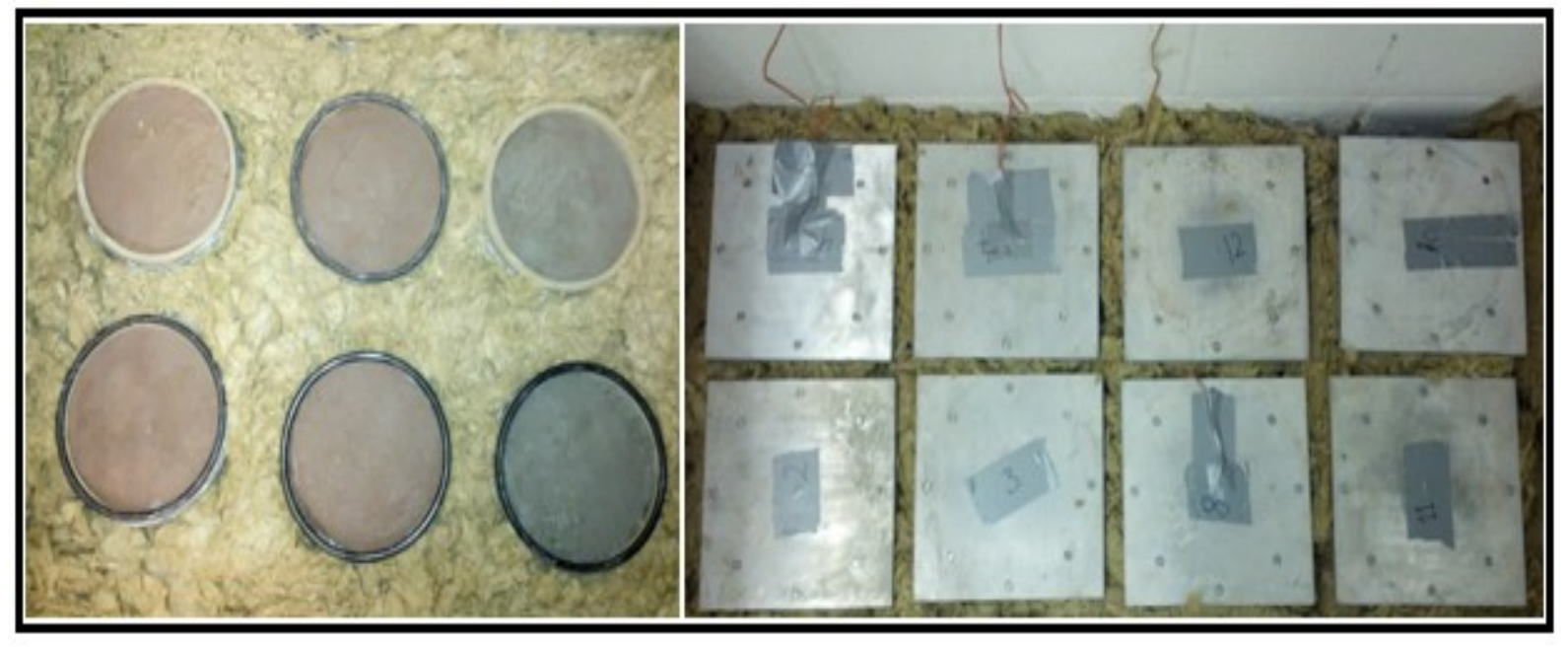

Figure 3.5 The two different test conditions for CCLs.

The heating blanket was connected to a temperature controller to apply the desired level of heat. The controller was programmed to apply a temperature of $55^{\circ} \mathrm{C}$ for 8 hours to simulate the daily heating period, and the heater was then shut down for 16 hours to simulate overnight cooling. The test specimens were removed from the heating system for volume measurements and saturated hydraulic conductivity testing after different elapsed times $(15,30,45$, and 60 days).

A series of specimens was also used to investigate the effects of wet-dry cycles on the hydraulic performance of the CCL under simulated field conditions. One wet-dry cycle included the drying stage which was obtained by exposing the soil specimens to 15 daily thermal cycles and followed be wetting stage which obtained through saturation of the specimens prior to hydraulic conductivity measurement. Saturated hydraulic conductivity measurements were taken following each wet-dry cycle, and repeated until the hydraulic conductivity reading remained constant. Two wet-dry cycles were simulated and the final hydraulic conductivity after each wet-dry cycle was measured and normalized by the initial hydraulic conductivity of the same soil specimens. 


\subsection{Results:}

\subsubsection{CCL shrinkage under daily thermal cycles}

Hydraulic conductivity of clayey soils is a function of the volumetric stability of the soil matrix (Gray, 1989). Thus, volume deformations of the soil matrix could strongly affect its hydraulic performance. Clayey soils may undergo considerable volumetric deformation due to desiccation and dewatering. This deformation could be in the form of cracking and/or volumetric shrinkage, either of which could result in considerable hydraulic defects. In the current study, the type and magnitude of soil deformations due to daily thermal cycles were investigated. The volume changes in the soil columns were estimated by utilising a digital caliper. one dimensional heat application caused soil specimens to shrink non-uniformly along the depth where the radial shrinkage shrinkage decreased with depth. Readings of the heights, average diameters, and related volumetric shrinkage of the soil samples were recorded initially, and after heat exposure (Table 3.2).

Table 3.3 Sample deformation and volumetric strain.

\begin{tabular}{|c|c|c|c|c|c|c|c|c|c|}
\hline \multirow{2}{*}{ soil type } & \multirow{2}{*}{$\begin{array}{l}\text { No. of } \\
\text { daily } \\
\text { cycles }\end{array}$} & \multicolumn{3}{|c|}{ Prior to heat exposure } & \multicolumn{3}{|c|}{$\begin{array}{l}\text { Post heat } \\
\text { exposure }\end{array}$} & \multirow{2}{*}{$\begin{array}{c}\text { Volumetric } \\
\text { shrinkage } \\
\text { (\%) }\end{array}$} & \multirow{2}{*}{$\begin{array}{c}\text { Volumetric } \\
\text { shrinkage } \\
\text { increase } \\
(\%)\end{array}$} \\
\hline & & $\begin{array}{c}D \\
(\mathbf{c m})\end{array}$ & $\begin{array}{c}\mathrm{L} \\
(\mathbf{c m})\end{array}$ & $\begin{array}{c}\mathrm{V} \\
\left(\mathrm{cm}^{3}\right)\end{array}$ & $\begin{array}{c}\mathrm{D} \\
(\mathrm{cm})\end{array}$ & $\begin{array}{c}\mathrm{L} \\
(\mathrm{cm})\end{array}$ & $\begin{array}{c}\mathrm{V} \\
\left(\mathrm{cm}^{3}\right)\end{array}$ & & \\
\hline \multirow{2}{*}{$\begin{array}{l}\text { Leda } \\
\text { clay+Bent }\end{array}$} & 15 & 14.0 & 15.0 & 2309.1 & 13.0 & 14.0 & 1858.3 & 19.5 & \multirow{2}{*}{22.1} \\
\hline & 30 & 14.0 & 14.8 & 2278.3 & 12.8 & 13.5 & 1737.2 & 23.8 & \\
\hline \multirow{2}{*}{$\begin{array}{l}\text { Halton } \\
\text { clay+Bent }\end{array}$} & 15 & 14.0 & 14.8 & 2278.3 & 13.2 & 14.3 & 1956.9 & 14.1 & \multirow{2}{*}{34.8} \\
\hline & 30 & 14.0 & 14.8 & 2278.3 & 13.0 & 13.9 & 1845.0 & 19.0 & \\
\hline \multirow{2}{*}{$\begin{array}{l}\text { Halton } \\
\text { Clay }\end{array}$} & 15 & 14.0 & 15.0 & 2309.1 & 13.8 & 14.3 & 2138.9 & 7.4 & \multirow{2}{*}{83.8} \\
\hline & 30 & 14.0 & 14.0 & 2155.1 & 13.4 & 13.2 & 1861.5 & 13.6 & \\
\hline
\end{tabular}

\footnotetext{
* D: diameter, L: sample height, V: volume
} 
The soil columns were visually inspected, while the volume changes were measured. It was obvious that the specimens of the three soil types experienced volume changes rather than crack formation. The diameters and heights of soil columns had undergone considerable shrinkage. This manner of volume deformation is attributed to the unrestrained boundary conditions provided by the smooth surface of the test cells. Under restrained boundary conditions, clayey soils would experience increasing horizontal stresses. These stresses, which are generated due to the shrinkage forces that work against the horizontal restraint, would likely be relieved by crack formation. Thus, soil specimens in a cell would probably move freely and experience significant volumetric shrinkage without forming any considerable areas of cracking. Similar behaviour has been reported in the literature where increasing the diameter of the test specimens increased amount and dimensions of the cracks (e.g., Omidi et al., 1996; Rayhani et al., 2008).

Moreover, the volumetric shrinkage was directly proportional to the number of daily thermal cycles. For high plasticity soil $(\mathrm{PI}=37.2 \%)$, volumetric shrinkage increased from $19.5 \%$ to $23.8 \%$ when the number of daily thermal cycles increased from 15 to 30 cycles. A similar trend was observed for medium and low plasticity soils which also exhibit higher volumetric shrinkage with increasing daily thermal cycles (Figure 3.6). However, the rate of change in volumetric shrinkage between the 15 and 30 daily cycles was the lowest for high plasticity soil $(22.1 \%)$, and the highest for the low plasticity soil (83.8\%) (Figure 3.7). This indicated faster volume stabilization for high plasticity soils compared to the medium and low plasticity soils, which may be attributed to the soil structure as well as the soil-water characteristic curves. 


\subsubsection{Hydraulic behaviour of CCL under daily thermal cycles}

The saturated hydraulic conductivity results at the beginning and after exposure to 15 and 30 daily thermal cycles are presented in Table (3.3). The saturated hydraulic conductivity after daily thermal exposure was generally higher than the initial value. The change in hydraulic conductivity due to thermal exposure is expressed by the normalized hydraulic conductivity $\left(\mathrm{K}_{\mathrm{r}}\right)$, where the measured hydraulic conductivities at set intervals of thermal exposure were normalized by their initial values.

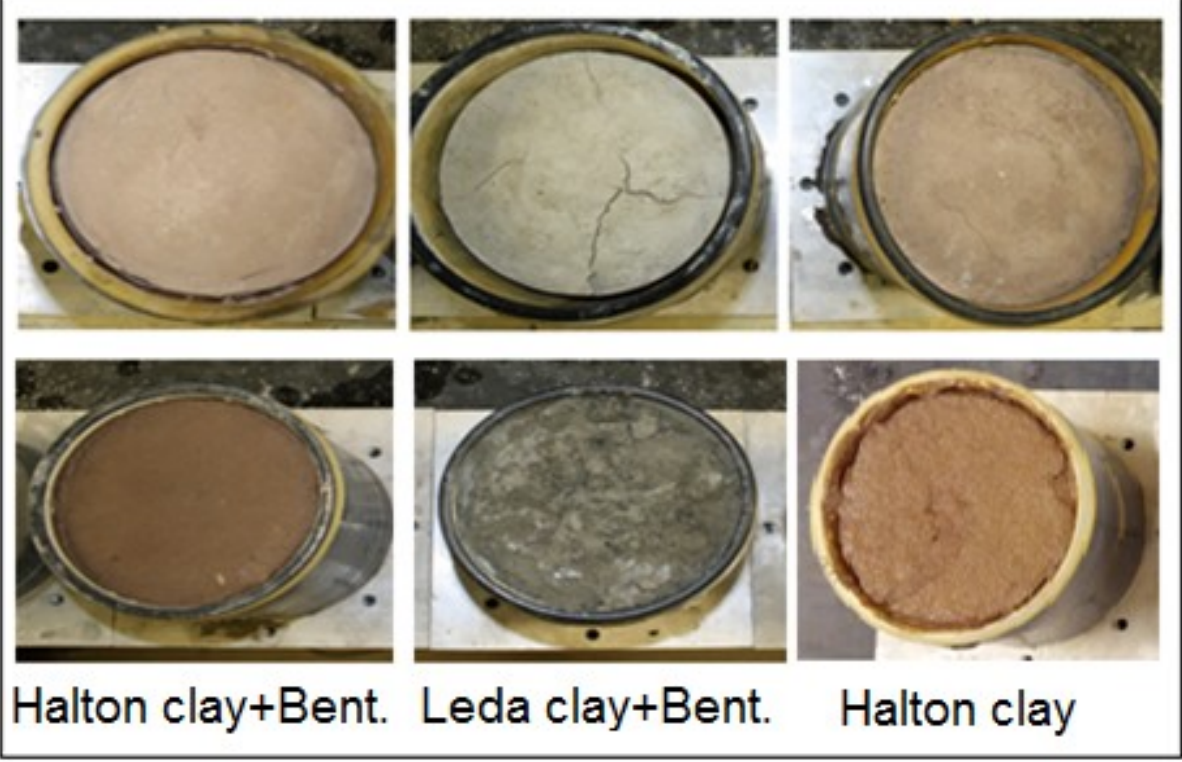

Figure 3.6 Volume shrinkage after 30 daily thermal cycles, and the subsequent swelling and selfhealing following saturation and hydraulic conductivity measurement. 


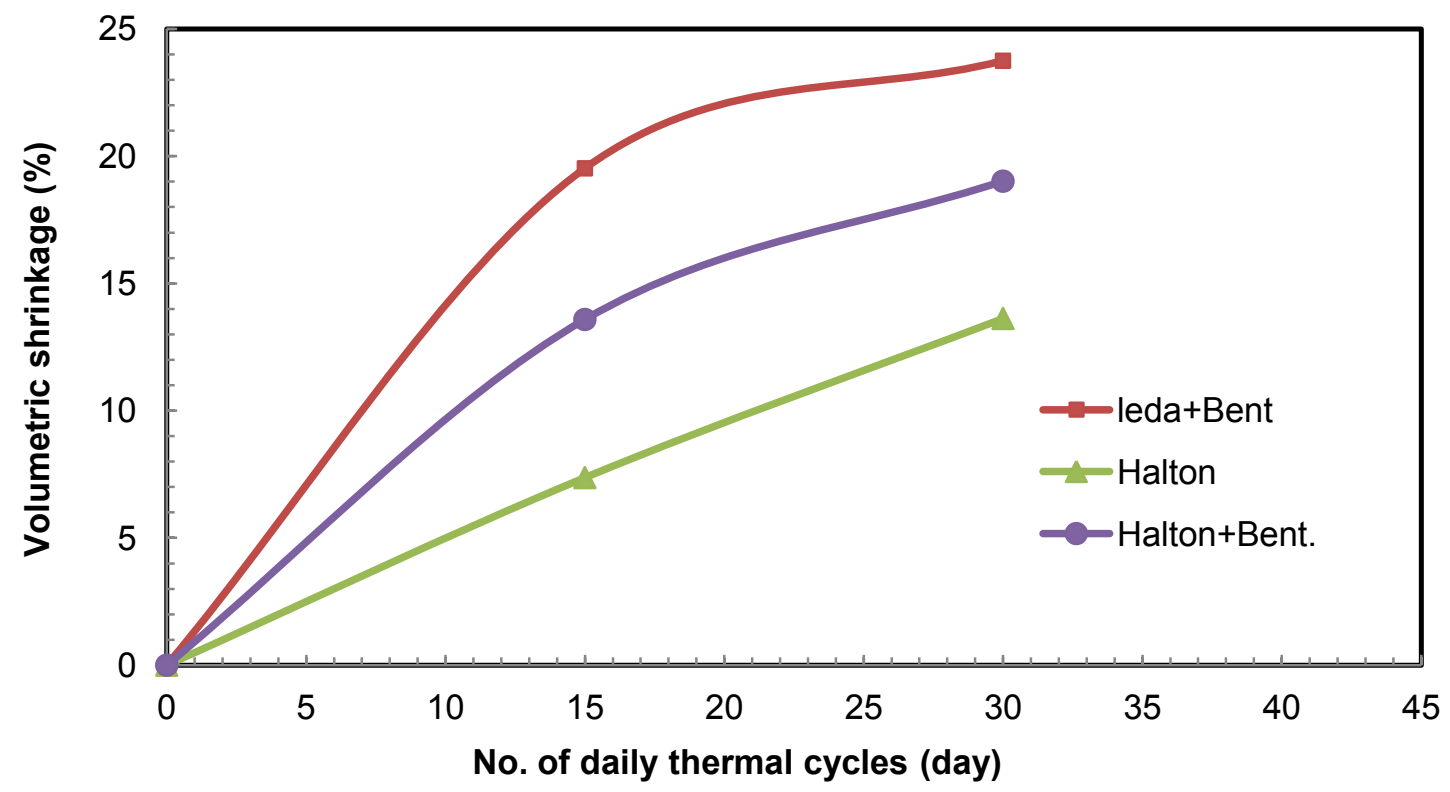

Figure 3.7 Soil volume shrinkage under daily thermal cycles.

Table 3.4 Results of hydraulic conductivity at the beginning and after exposure to daily thermal cycles.

\begin{tabular}{lllllll}
\hline & Halton Clay & \multicolumn{2}{c}{ Halton clay+Bent } & \multicolumn{2}{c}{ Leda clay+Bent } \\
\hline (days) & 15 & 30 & 15 & 30 & 15 & 30 \\
\hline$K_{0}{ }^{1}$ & $8.26 \mathrm{E}-10$ & $1.50 \mathrm{E}-09$ & $3.74 \mathrm{E}-10$ & $1.20 \mathrm{E}-10$ & $1.28 \mathrm{E}-09$ & $1.50 \mathrm{E}-9$ \\
$\mathrm{~K}_{\mathrm{f}}{ }^{2}$ & $4.78 \mathrm{E}-09$ & $1.20 \mathrm{E}-08$ & $6.57 \mathrm{E}-10$ & $3.10 \mathrm{E}-10$ & $1.96 \mathrm{E}-09$ & $2.20 \mathrm{E}-9$ \\
$\mathrm{~K}_{\mathrm{r}}{ }^{3}$ & 5.78 & 8.00 & 1.76 & 2.58 & 1.53 & 1.47 \\
\hline 1
\end{tabular}

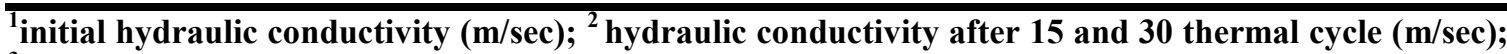
${ }^{3}$ normalized hydraulic conductivity $\left(K_{\mathrm{f}} / K_{0}\right)$.

Different soil types showed different levels of hydraulic deviation. The hydraulic conductivity value for Halton clay $\left(\mathrm{PI}=9.5 \%\right.$ ) increased from $8.3 \times 10^{-10} \mathrm{~m} / \mathrm{sec}$ to $4.7 \times 10^{-09} \mathrm{~m} / \mathrm{sec}$ after exposure to 15 daily thermal cycles (Figure 3.8 ). Moreover the 
normalized hydraulic conductivity value was equal to 5.8 which represented more than half an order of magnitude increase in the hydraulic conductivity at the end of 15 thermal cycles for this soil. A further increase in hydraulic conductivity was recorded after 30 daily thermal cycles reaching approximately one order of magnitude with a $\mathrm{k}_{\mathrm{r}}$ value equal to 8 (Table 3.3). However, this level of change in hydraulic performance for medium and high plasticity soils was not achievable even after exposure to 30 thermal cycles. Leda clay+bentonite and Halton clay+bentonite mixtures maintained almost constant hydraulic performance even though they underwent greater volume deformations. Their normalized hydraulic conductivity values were about 2.6 and 1.5 for medium and high plasticity soils respectively (Figure 3.8). The better hydraulic performance of medium and high plasticity soils could be related to their higher self-healing capacity.

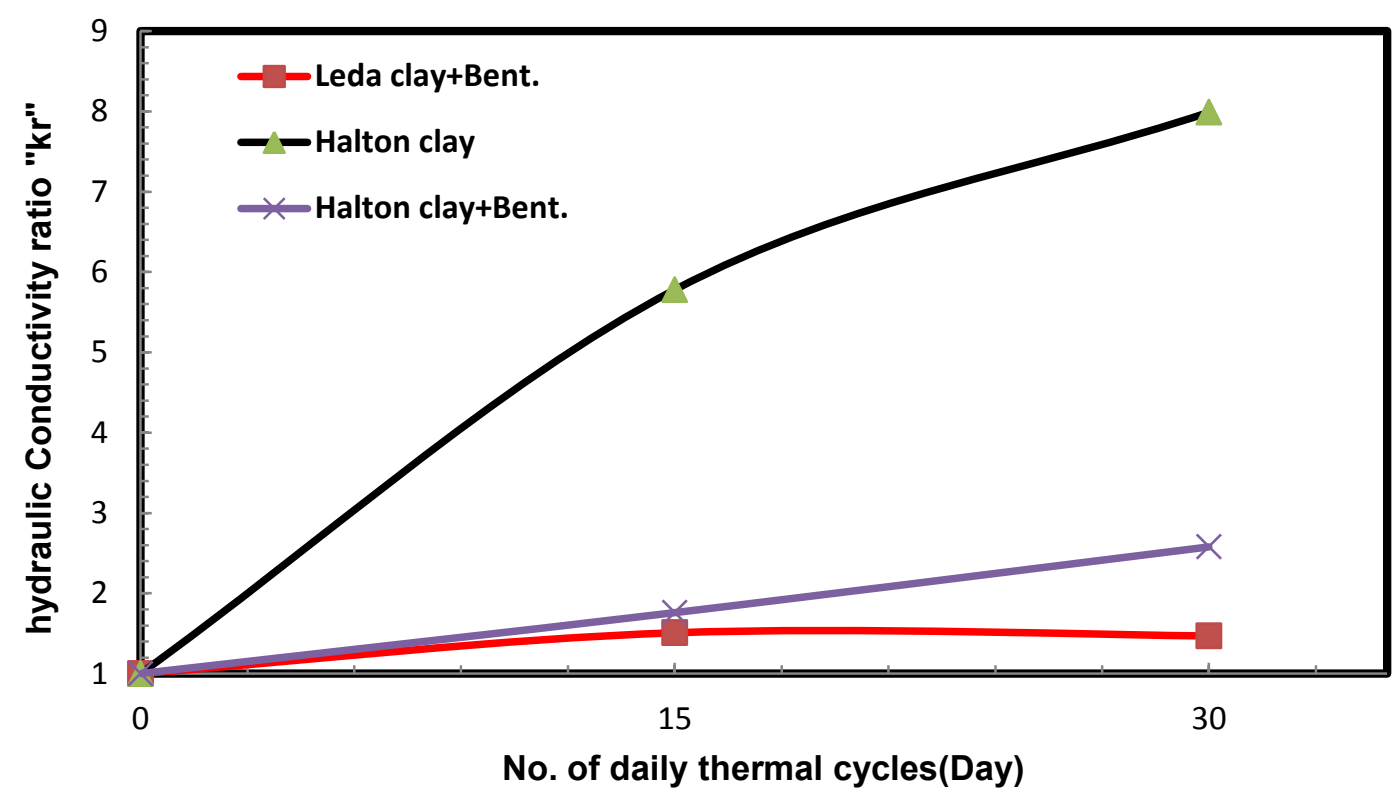

Figure 3.8 Normalized hydraulic conductivity versus the number of daily thermal cycles. 


\subsection{Analysis and Discussion}

\subsubsection{Correlation between Soil-Water Characteristic Curves and CCL shrinkage}

Clay soils shrink when they lose water and swell when they regain water (Holtz and Kovacs, 1981). Thus, a flow of water through the soil matrix would influence the swelling/shrinkage behaviour of CCLs. Therefore, the soil-water characteristic curve (SWCC) can provide a reasonable explanation of soil volume change as it characterizes the water sorption and desorption by the soil matrix.

In order to understand the shrinkage behaviours of the study soils, the SWCCs for these soils were established and presented in Figure (3.2). Volume change before air entry stage was assumed to be negligible. The curves clearly show higher air-entry values for medium and high plasticity soils (Halton clay+bentonite and Leda clay+bentonite) compared to the low plasticity soil (Halton clay). Soils with greater clay content, and hence higher plasticity indices, contain smaller particle sizes, which eventually would yield smaller effective pore sizes. Thus, higher suction forces are required to extract water from such soil types. However, upon air entry, soils with higher plasticity showed steeper slopes of the SWCCs compared to the low plasticity soils. This indicates a faster

decrease in water content for high plasticity soils with respect to the suction value. This behaviour can be attributed to the higher initial water content used for sample preparation and compaction. Upon air-entry, soils with higher plasticity and water content would experience rapid water loss within a narrow suction range due to the greater mobilised pore water volume. For soils with higher plasticity indices, the dominant shrinkage was mostly normal, while for low plasticity soils the dominant shrinkage was mostly residual shrinkage. This could explain the higher volumetric shrinkage and faster volume 
stabilization for medium and high plasticity soils compared to low plasticity soil. Similar results were proposed by other researches such as Bronswijk (1988).

Moreover, the shape of SWCC can also be correlated to the unsaturated hydraulic conductivity, which controls the water movement throughout the soil matrix. For low plasticity soils, the unsaturated hydraulic conductivity was found to decrease much faster than the high plasticity soils (Meerdink et al., 1996). This is attributed to the larger pores that low plasticity soils yield which would be dewatered earlier and cause air to be trapped instead. This would eventually result in lower unsaturated hydraulic conductivity, less steep SWCC, and hence lower volumetric shrinkage in low plasticity soils.

\subsubsection{Effect of soil index properties on CCL shrinkage and hydraulic conductivity}

Soil index properties and Atterberg limits, in particular, have shown strong correlation to the volume deformation as well as hydraulic behaviour of clayey soils (Benson et al., 1994; Omidi et al., 1996; Albrecht and Benson, 2001; Rayhani et al. 2007). In the current study, the plasticity index (PI) and shrinkage index (SI) were discussed and their impact on the hydraulic performance of the study soils was investigated.

\subsubsection{Effect of plasticity index on shrinkage and hydraulic conductivity}

Plasticity indices (PI) of the test soils varied from 9.5\% to 37.2\% (Table 3.1). Figure (3.9a) shows the relationship between the volumetric shrinkage and plasticity index for specimens exposed to 15 and 30 thermal cycles. For specimens exposed to 30 thermal cycles, volumetric shrinkage increased from $13.6 \%$ to $23.8 \%$ when the plasticity index of the soils increased from $9.5 \%$ to $37.2 \%$. The increase in volume deformation for soils 
with higher plasticity can be attributed to their higher clay contents, which yield a larger specific surface area (White, 1949; Locat et al., 1984), and in turn lead to more interaction of water molecules with the soil particles. Therefore, soils with larger specific surface areas exhibit higher adsorption capacity, which eventually results in higher optimum water content and higher saturation water content. Thus, the soil matrix would accommodate a larger pore water volume as the PI increases. Eventually, when these high plasticity soils dewater, they would experience higher water loss than the low plasticity soils at the same level of suction (Figure 3.2). As a result, higher volumetric shrinkage, and potentially crack formation, would be expected for soils with higher plasticity indices. These results are consistent with the findings that were reported by many researchers in this field (e.g., White, 1949; Albrecht and Benson, 2001; Rayhani et al., 2008).

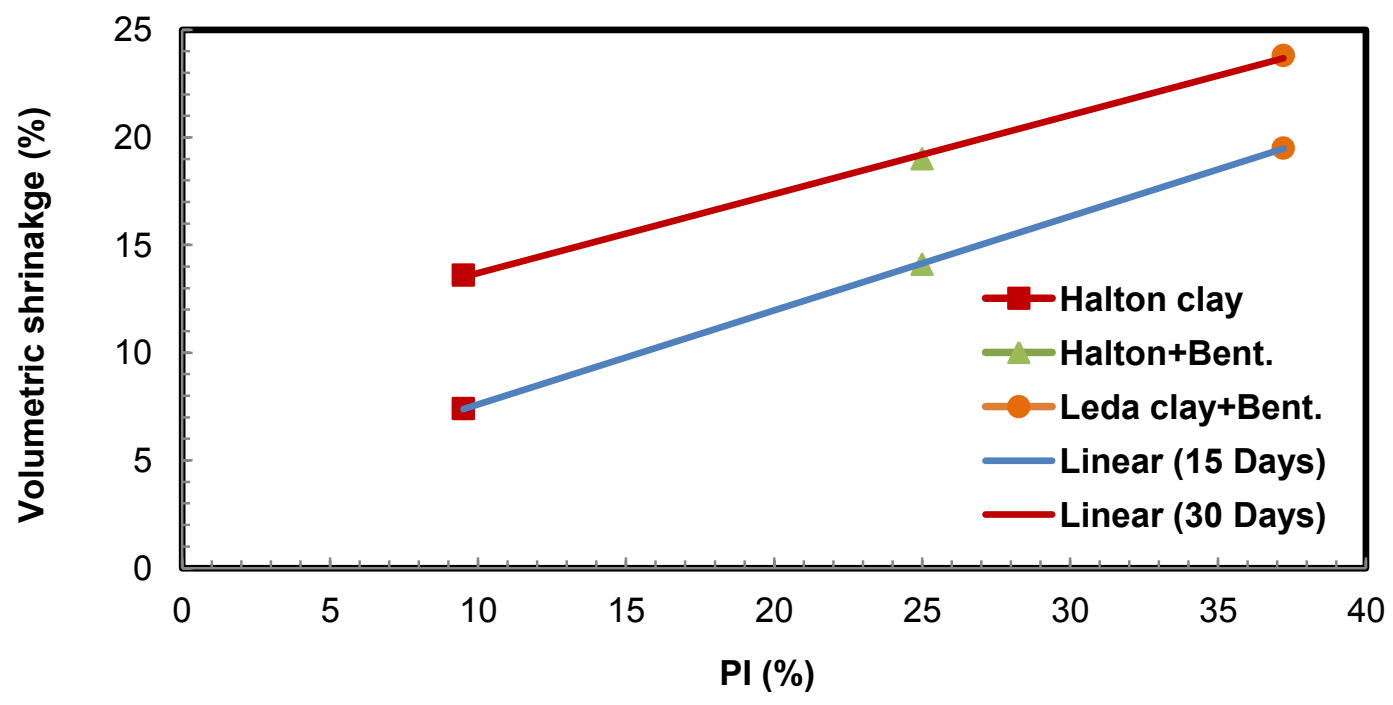




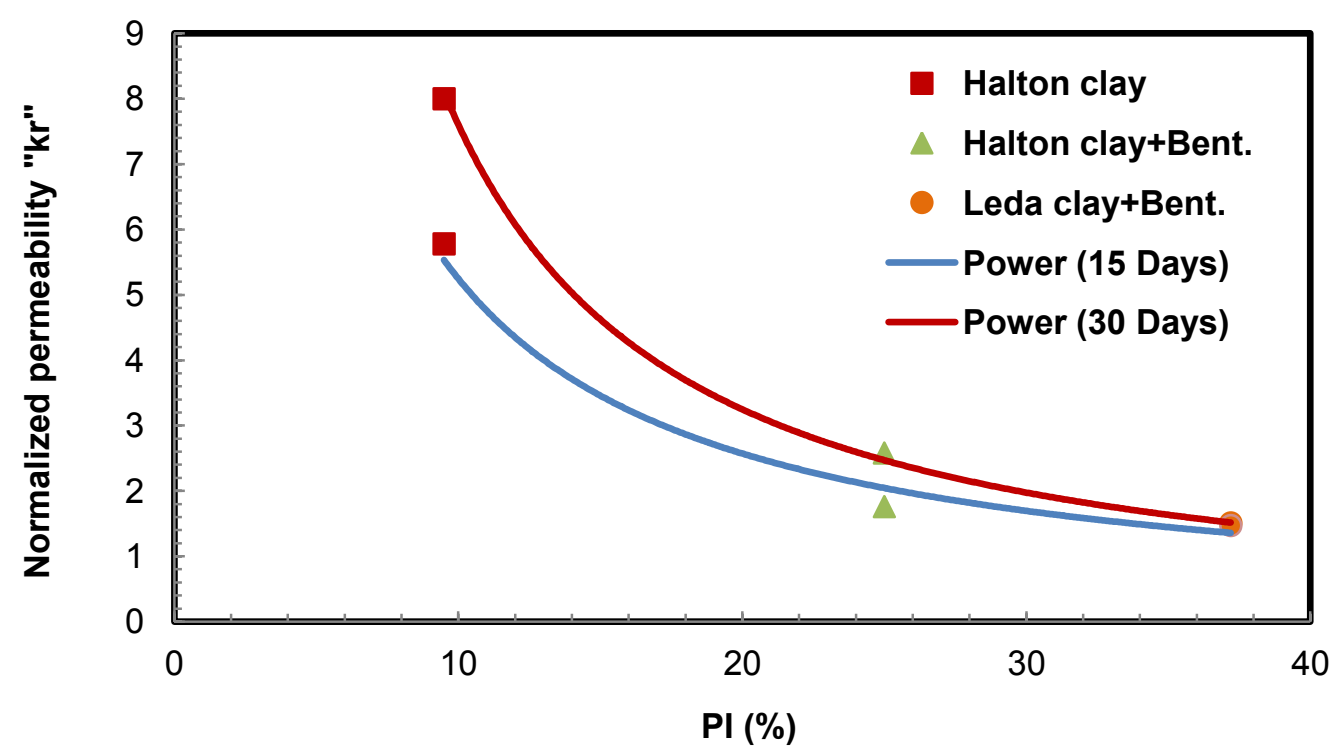

Figure 3.9 Correlation between soil plasticity and normalized hydraulic conductivity.

The relationship between normalized hydraulic conductivity (Kr) and the plasticity index (PI) for the test soils is presented in Figure (3.9b). The power trend lines show a decrease in $\mathrm{Kr}$ values as the plasticity index increases. After 30 days of thermal exposure, soils with medium and high plasticity demonstrated higher volume deformation compared to low plasticity soil. However, both these soils maintained a constant hydraulic performance with hydraulic conductivity values that remained close to their initial values, while the low plasticity soil ( $\mathrm{PI}=9.5 \%)$ experienced an increase in hydraulic conductivity value by 8 times its initial value. This consistent hydraulic performance in soils with PI higher than 25\% could be explained by their self-healing capacities which depend on the clay content (especially the expandable-clay fraction). Soils with medium and high plasticity indices typically have greater amount of expandable fractions, which in turn can lead to higher water adsorption capacity. Thus, higher swelling potentials would help the soil specimens to regain their initial volumes and fill in the fissures and 
gaps that may facilitate the water movement throughout the soil matrix. Smectite has minerals have the highest swelling potential amongst clay minerals. In most cases, high plasticity soils contain larger amounts of smectite than the low plasticity soil (Table 3.1). Thus, they would show higher self-healing and swelling potential, which would result in lower hydraulic conductivity. These findings are in agreement with other results reported in the literature (e.g., Rayhani et al., 2007; Rayhani et al., 2008; Eigenbrod, 2003).

\subsubsection{Influence of shrinkage index on shrinkage and hydraulic conductivity}

Previous studies have shown volume shrinkage and crack generation at moisture contents close to the shrinkage limit values (e.g., Peron et al., 2009). These findings demonstrate the importance of the shrinkage limit and related shrinkage index in characterizing the volume deformation of the soil matrix. The shrinkage index expresses the difference between the liquid limit and the shrinkage limit (SI=LL-SL). Therefore, the shrinkage index can indicate the mobilized pore water volume that would be lost in the case of shrinkage or gained in the case of swelling. In the current study, a proportional relationship between SI and volumetric shrinkage was observed when the soil specimens were exposed to thermal cycles (Figure 3.10). Soils with higher SI yielded higher volumetric shrinkage, which could be attributed to the greater amount of water that soils with higher SI tend to sacrifice when subjected to thermal cycles. 


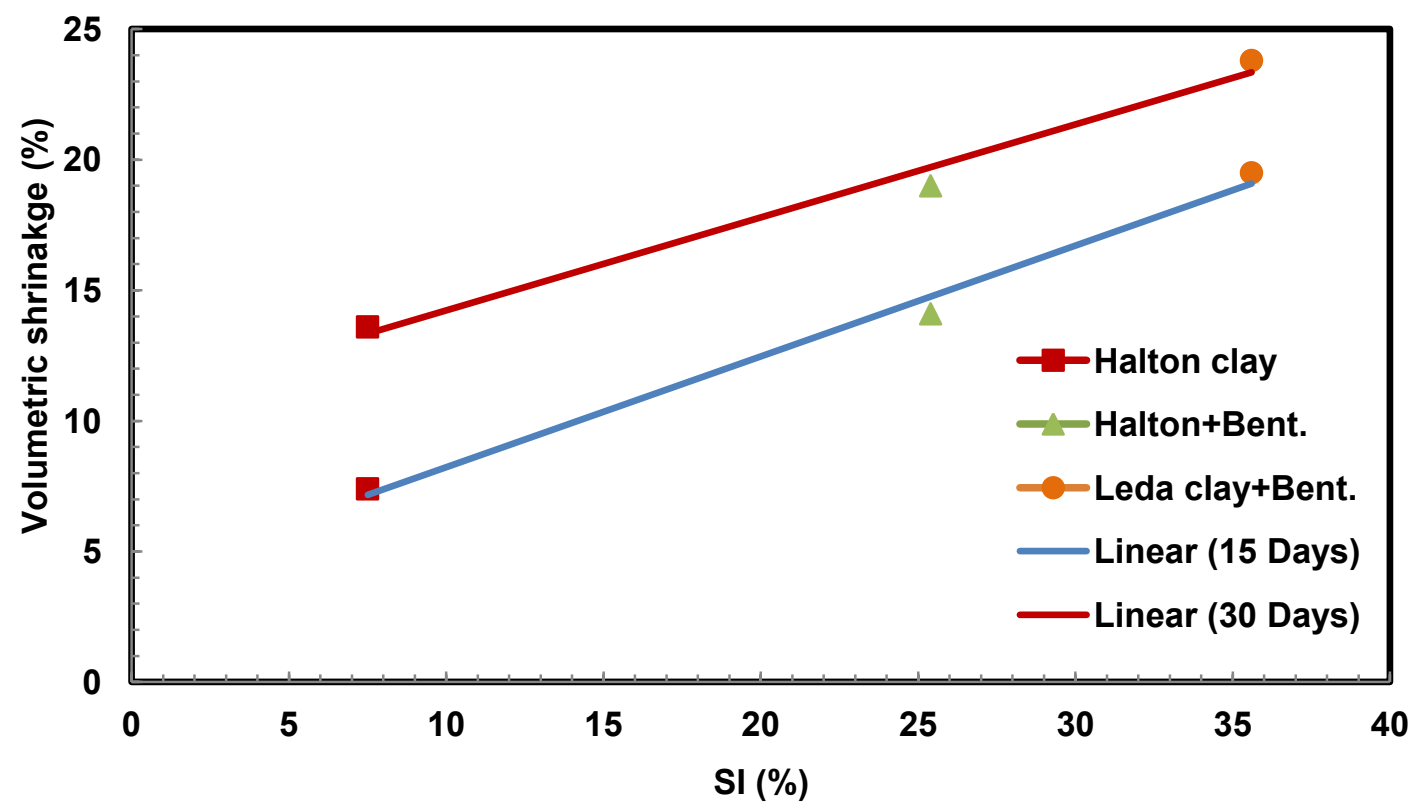

Figure 3.10 Correlation between shrinkage index and soil deformation.

In terms of hydraulic performance, the relationship between the normalized hydraulic conductivity $(\mathrm{Kr})$ and the volumetric shrinkage for the test soils is presented in Figure (3.11). The change in hydraulic conductivity was shown to be smaller for soils that demonstrated greater volumetric shrinkage. After exposure to 30 daily thermal cycles, the Halton clay+bentonite mixture and Leda clay+bentonite mixture showed hydraulic conductivity values close to their initial values even though they had experienced higher volume deformation. On the other hand, Halton clay with lower volumetric shrinkage showed an increase in its hydraulic conductivity of almost one order of magnitude. This indicated that, even though the soils with higher shrinkage potential would undergo higher volumetric shrinkage and water loss, they have higher capacities for swelling (self-healing) and regaining their original volume and hydraulic aspects. Clay content and mineralogy play important roles in soil volume stabilization. In 
general, sodium bentonite contains about $70-80 \%$ smectite fraction by total mass. Therefore, adding $10 \%$ bentonite to the Halton clay and $5 \%$ to Leda clay seemed to modify their plastic behaviours and swelling/shrinkage potentials, which eventually improved their hydraulic performance.

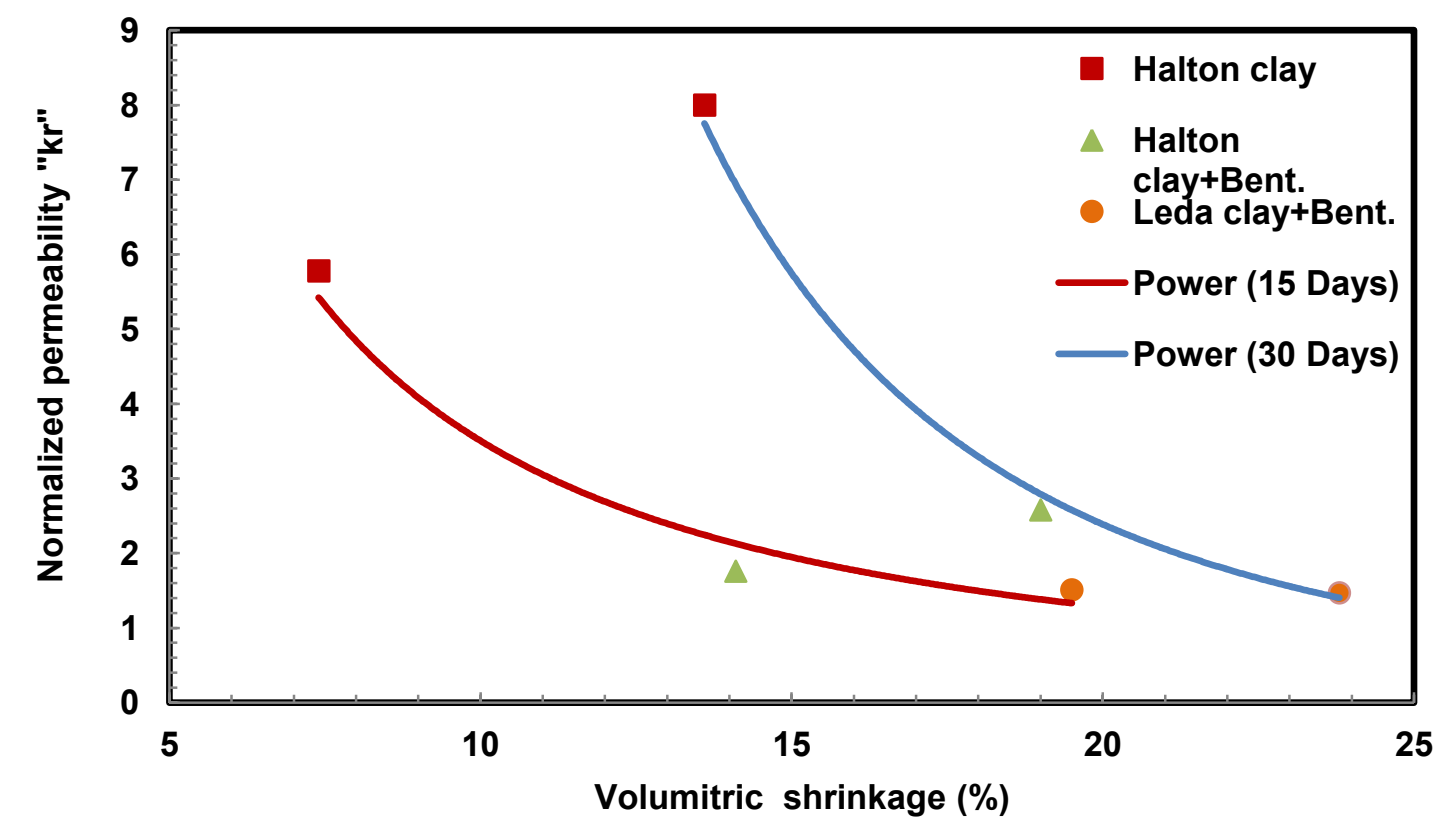

Figure 3.11 Correlation between volumetric shrinkage and normalized hydraulic conductivity (Kr).

\subsection{Impact of Geomembrane in a Composite Liner on CCL Shrinkage and Hydraulic Conductivity}

In composite landfill liner systems, a layer of geomembrane overlays the CCL for more isolation and protection. A series of experiments with 8 specimens were employed to study the effect of geomembrane on the hydraulic performance of CCLs under simulated field conditions. Following the initial saturated hydraulic conductivity measurements, all test specimens were exposed to daily thermal cycles and sequentially extracted from the 
heating system at $15,30,45$, and 60 days for post-heating saturated hydraulic conductivity tests (Table 3.4).

To visualize the results and highlight the role of the geomembrane, normalized hydraulic conductivities for Halton clay versus the number of daily thermal cycles are presented in Figure 12 both with and without the geomembrane cover. After 30 thermal cycles, Halton clay experienced about one order of magnitude increase in its hydraulic conductivity when geomembrane was not used. However, when geomembrane overlaid the CCL, Halton clay showed significantly lower variation in hydraulic conductivity and maintained constant hydraulic performance. Thus, when geomembrane exists and overlays the CCL, daily thermal cycles are found not to have any significant impact on the hydraulic performance of the CCL. These results underscore the importance of geomembrane in providing protection and sealing from weathering effects for CCLs. This can be explained by the lower moisture loss of the CCL when covered by a geomembrane. Suction force is applied by the atmosphere in order to reach humidity equilibrium with the soil matrix. However, when a geomembrane overlays the CCL, there would not be an immediate exposure to the atmosphere, thereby diminishing the role of suction, preventing water movement out of the soil, and minimizing the risk of volume shrinkage and crack generation. 
Table 3. 5 Results of hydraulic conductivity $(\mathrm{m} / \mathrm{sec})$ at the start and after exposure to daily thermal cycles when geomembrane overlays the CCLs.

\begin{tabular}{cccccccc}
\hline \multirow{2}{*}{$\begin{array}{c}\text { No. Daily thermal } \\
\text { cycles }\end{array}$} & \multicolumn{3}{c}{ Leda + Bento. } & \multicolumn{5}{c}{ Halton Clay } \\
\cline { 2 - 7 } & \multicolumn{1}{c}{$K_{0}$} & $K_{\mathrm{f}}$ & $K_{\mathrm{r}}$ & $K_{0}$ & $K_{\mathrm{f}}$ & $K_{\mathrm{r}}$ \\
\hline 15 & $1.24 \mathrm{E}-09$ & $1.37 \mathrm{E}-09$ & 1.10 & $7.65 \mathrm{E}-10$ & $9.40 \mathrm{E}-10$ & 1.23 \\
30 & $8.65 \mathrm{E}-10$ & $9.68 \mathrm{E}-10$ & 1.12 & $7.45 \mathrm{E}-10$ & $9.15 \mathrm{E}-10$ & 1.23 \\
45 & $1.26 \mathrm{E}-09$ & $1.44 \mathrm{E}-09$ & 1.14 & $7.16 \mathrm{E}-10$ & $9.81 \mathrm{E}-10$ & 1.37 \\
60 & & & & & & \\
& $1.20 \mathrm{E}-09$ & $1.36 \mathrm{E}-09$ & 1.13 & $1.0 \mathrm{E}-9$ & $1.68 \mathrm{E}-09$ & 1.68 \\
\hline
\end{tabular}

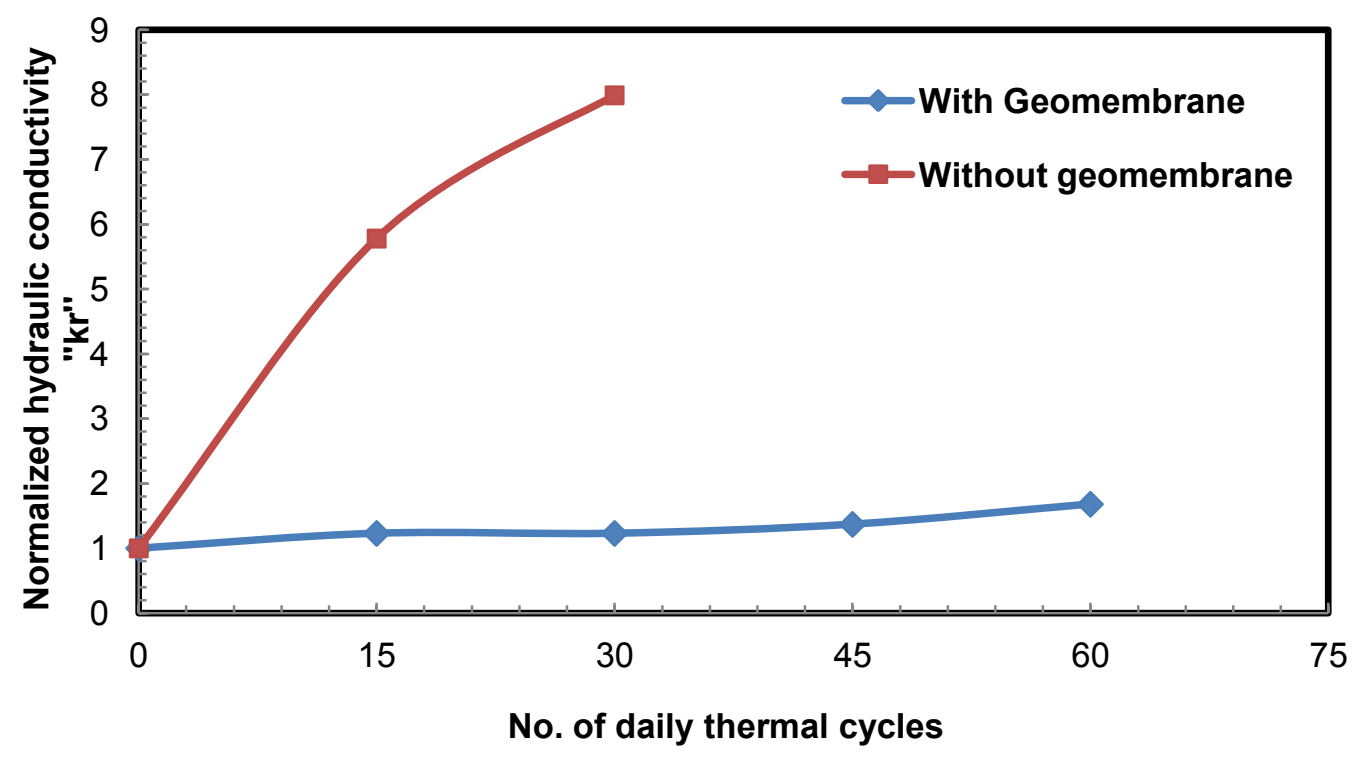

Figure 3.12 Hydraulic performances of Halton clay with and without geomembrane.

\subsection{Effect of Wet/Dry Cycles on the Hydraulic Performance of CCLs}

One of the weather circumstances that may affect the CCL performance is wet-dry cycles generated by rainfall and subsequent thermal exposure due to solar radiation. Two series of specimens were used to investigate the effect of these wet-dry cycles on the hydraulic 
performance of CCLs. The normalized hydraulic conductivity (i.e., ratio between the hydraulic conductivity values after a specific number of wet-dry cycles to the initial hydraulic conductivity value) was employed to express the effect of wet-dry cycles on the hydraulic performance of the CCLs (Table 3.5, Figure 3.13).

Table 3. 6 Effect of wet-dry cycles on the hydraulic performance of CCL..

\begin{tabular}{|c|c|c|c|c|c|c|}
\hline \multirow{2}{*}{$\begin{array}{l}\text { No. of } \\
\text { wet-dry } \\
\text { cycles }\end{array}$} & \multicolumn{2}{|l|}{ Halton clay } & \multicolumn{2}{|c|}{ Halton clay+bent. } & \multicolumn{2}{|c|}{ Leda clay+bent. } \\
\hline & K (m/sec) & $\mathbf{K}_{\mathbf{r}}$ & $\mathrm{K}(\mathrm{m} / \mathrm{sec})$ & $\mathbf{K}_{\mathbf{r}}$ & $\mathrm{K}(\mathrm{m} / \mathrm{sec})$ & $\mathbf{K}_{\mathbf{r}}$ \\
\hline $\mathbf{0}$ & 8.26E-10 & 1.00 & 3.74E-10 & 1.00 & 1.27E-09 & 1.00 \\
\hline 1 & 4.78E-09 & 5.78 & 6.57E-10 & 1.76 & 1.94E-09 & 1.53 \\
\hline 2 & 9.8E-09 & 11.85 & $4.54 \mathrm{E}-10$ & 1.21 & 1.37E-09 & 1.08 \\
\hline
\end{tabular}

Results show a significant increase in the hydraulic conductivity values for Halton clay $(\mathrm{PI}=9.5 \%)$ as the number of wet-dry cycles increased. After two wet-dry cycles, the Halton clay experienced about a 12 -fold increase in its hydraulic conductivity compared to its initial value. However, medium and high plasticity soils (Halton clay+bentonite and Leda clay+bentonite) did not show any marked change in their hydraulic performance neither at first nor at the second wet-dry cycle. In contrast to previous daily thermal cycle experiments, the high plasticity soil (Leda clay+bentonite mixture) experienced crack formation during the second drying period (Figure 3.14), however, this soil maintained its hydraulic performance without any noticeable change, and the cracks totally disappeared during the wetting period. Soil plasticity, swelling potential, and self-healing are the three factors that control the level of hydraulic change due to wet-dry cycles. However, soil with a low plasticity index would show low swelling and self-healing capacity, and thus would undergo significant hydraulic conductivity changes when exposed to wet-dry or thermal cycles. 


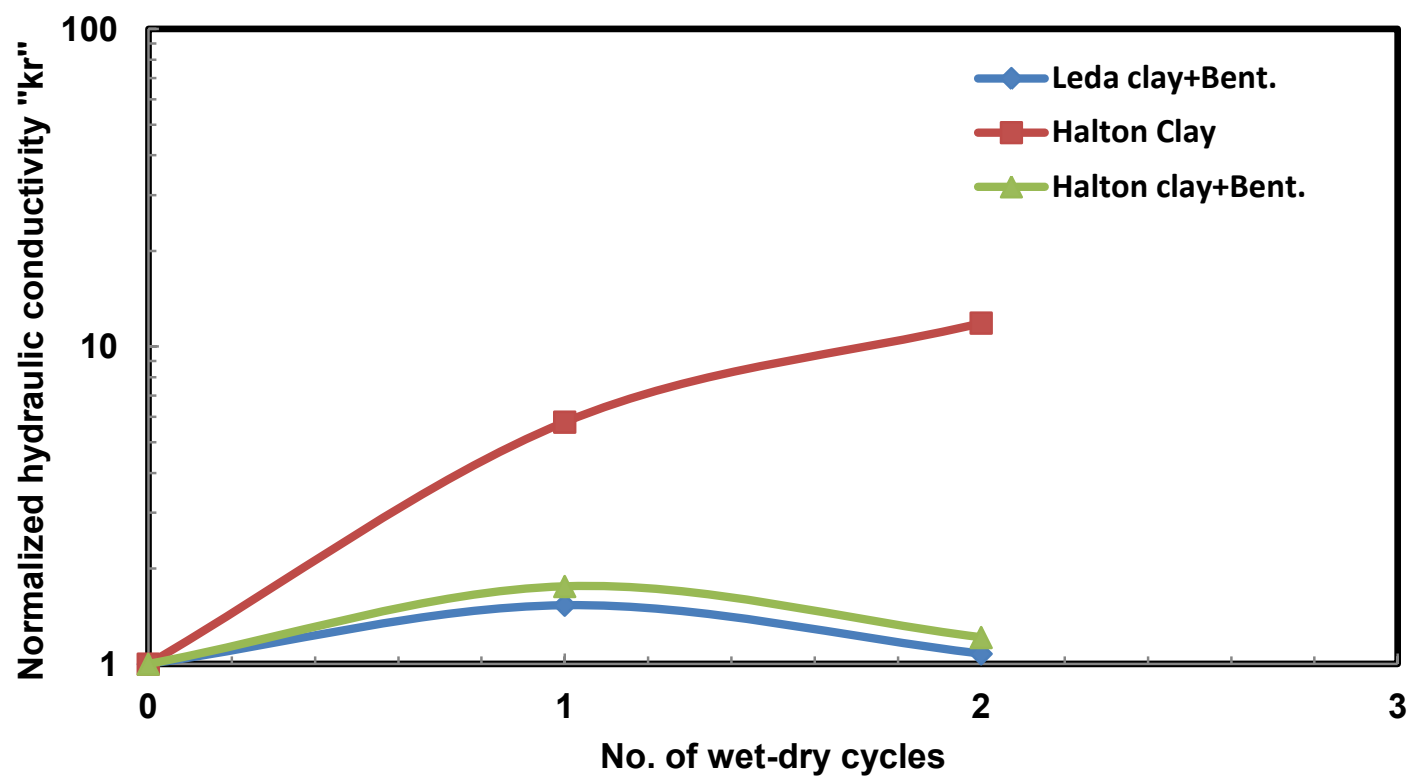

Figure 3.13 Effect of wet-dry cycles on the hydraulic performance of CCL.

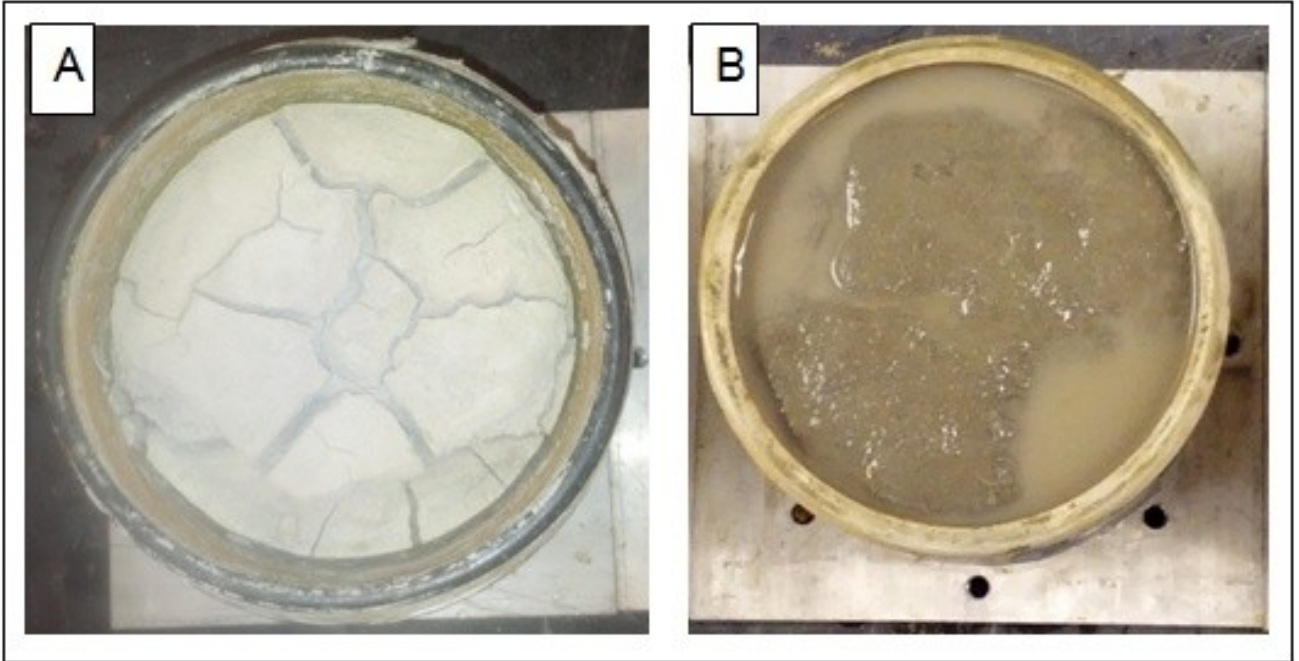

Figure 3.14 A) Shrinkage and cracking after 15 thermal cycles for Leda clay+bent. B) Swelling and self-healing effect after wetting and hydraulic conductivity measurement. 


\subsection{Summary}

Effects of daily thermal cycles on the hydraulic performance and volumetric deformation of various CCL specimens were investigated. SWCC correlated fairly well to the shrinkage behaviour of the test soils and provided reliable prediction of soil volume stabilization. In terms of hydraulic performance, CCLs with plasticity indices ranging from $25 \%$ to $37 \%$ most likely would withstand the thermal cycle effects, and would show a reliable hydraulic performance. Therefore, CCLs with such properties can provide protection to the surrounding environment even without a geomembrane liner. This conclusion is, however, in disagreement with other previous reports that underestimated the capacity of such CCLs to withstand the effects of thermal exposure. The difference could be related to the way in which the thermal cycles were applied. In the current research, thermal cycles were applied to the upper surface of the specimens while they were surrounded by insulating materials to encourage 1D heat transfer as would be the case in field conditions. In most previous works, the entire test specimens were placed in an oven, and therefore unrealistically heated.

Overlaying the CCL by a layer of geomembrane provided a high level moisture barrier and minimized the moisture loss from the CCL. Thus, very stable hydraulic performance for all test soils was observed. This finding highlights the importance of using geomembrane on top of CCLs, especially when low plasticity soils are involved.

Wet-dry cycles were found to cause a remarkable increase in the hydraulic conductivity of low plasticity soils $(\mathrm{PI}=9.2 \%)$, however, soils with medium and high plasticity indices showed almost constant hydraulic performance. The importance of the geomembrane is highlighted again since the presence of the geomembrane on top of the 
CCL will eliminate the effects of wet-dry cycles. Shrinkage index and plasticity index are two soil properties that can be used as key criteria when choosing proper soils for CCL construction. They showed similar trend in predicting hydraulic and shrinkage behaviours of the test soils under the effects of thermal cycles as well as wet-dry cycles. 


\section{CHAPTER: Hydraulic Performance of CCLs under Combined Temperature and Leachate Exposures}

\subsection{Introduction}

Compacted clay liners in landfills may undergo different exposure circumstances and chemical interactions during their lifespan. After waste placement, CCLs might be isolated from the effect of the atmosphere. However, the impact of elevated temperature and chemical leachate exposure would exist and might affect the hydraulic performance of CCLs. Vertical stresses would also be generated and applied on the barrier system as waste being deposited in landfills. These factors would facilitate the depletion of the geomembrane in composite liner systems (Rowe et al., 2010c) and, thus, CCLs might be in an immediate confrontation to the combined influences of vertical stresses, landfill leachate, and elevated temperature. The increase in vertical stresses due to waste placement was reported to be beneficial as it can decrease the CCLs' void ration and hence hydraulic conductivity (Quigley et al., 1988; Quigley et al., 1989; Frempong, 2006).

Landfill leachate could change the hydraulic conductivity of the CCLs through dissolution of clay minerals. Leachate is produced when the field capacity moisture content of deposited waste is exceeded. Free water can also reach the deposited waste from several sources such as surface infiltration, atmosphere water entrapment, and upward ground water flow. Leachate would be generated when the deposited waste 
leached out by the free water after the waste had exceeded its field capacity. The organic waste decomposition would also contribute to the volume of landfill leachate.

On the other hand, biodegradation would likely be accompanied with significant heat generation. Wide range of temperatures was recorded at the level of landfill barrier system. Collins (1993) observed temperatures between $30^{\circ} \mathrm{C}$ and $60^{\circ} \mathrm{C} 10$ years post closure at an old landfill in Germany. These temperature conditions may impact the hydraulic conductivity of the CCLs by decreasing the leachate viscosity. However, temperature effects on other phenomena involved in hydraulic performance such as thermo-chemical interactions, which can impact the clay fabric and pore fluid, are not well understood. In fact, the combined effect of chemical exposure and elevated temperature, due to waste biodegradation, on CCLs performance has received very little attention. This chapter is devoted to evaluate the combined effects of thermo-chemical exposures on hydraulic performance of CCLs simulating field conditions in landfill after waste placement.

\subsection{Soil and Leachate Properties}

The pilot study reported in this chapter was carried out in the laboratory. It aimed at providing complete assessment of clay/leachate compatibility when realistic boundary conditions are applied.

\subsubsection{Soil properties}

Soil materials for the study were collected from two active landfills namely the Navan landfill in Ottawa (Leda Clay) and the Halton landfill in Toronto (Halton Clay). Two artificial clay mixtures were also prepared by mixing sodium bentonite with the original 
Leda clay and Halton clay. Leda caly $+5 \%$ bentonite and Halton clay $+10 \%$ bentonite mixtures were fabricated to provide variety in plasticity index of soil specimens. The basic geotechnical properties of the four clayey soils including particle size distribution, Atterberg limits, metric suction potential and the optimum water content were determined (Table 4.1). Particle size distribution and clay contents of the study soils were estimated by conducting sieve analysis and hydrometer tests following ASTM standard (D4221-11) (Figure 4.1). The liquid limits of the soils ranged from $23.5 \%$ to $60 \%$, while plasticity indices varied from $9.5 \%$ to $37.2 \%$ based on the Atterberg limits test results (ASTM D4318-10). Maximum dry density and the corresponding optimum moisture content for the four soil types was determined using Standard Procter test (ASTM D 698-12). The air entry metric suction of the soils at optimum moisture content varied from $400 \mathrm{kPa}$ for Halton clay to $950 \mathrm{kPa}$ for Leda clay $+5 \%$ bentonite mixture based on Soil-Water Characteristic Curves (SWCC) (Figure 4.2). The volume change before air entry stage was assumed to be negligible.

A random X-ray powder diffraction analysis was carried out to determine the mineralogical composition of the two original test soils (Leda clay and Halton clay). Semi-quantitative analysis was conducted on X-Ray results to measure the clay mineral component. The abundant clay mineral for both soils is illite which comprises $83 \%$ and $63 \%$ for Leda and Halton clays respectively. Halton clay contains considerable amount of kaolinite and very little chlorite of $32 \%$ and $5 \%$ respectively. However, there is no evidence of having any expandable clay minerals (here defined as vermiculite, montmorillonite, or interlayered illite/smectite) (Table 4.2). 
Table 4.1 Physical properties of the test soils.

\begin{tabular}{lllll}
\hline Characteristics (\%) & Halton Till & Leda clay & Halton+ Bent. & Leda+Bent. \\
\hline Soil type & CL & CH & CL & CH \\
Liquid limit & 23.5 & 50.8 & 43.5 & 60.0 \\
Plasticity index & 9.5 & 23.3 & 25.0 & 37.2 \\
$\rho_{\text {d (Max.) }}, \mathrm{Mg} / \mathbf{m}^{3}$ & 1.70 & 1.41 & 1.56 & 1.27 \\
Gravimetric water content & 13.5 & 30 & 17.0 & 34.5 \\
Shrinkage limit & 16.0 & 22.5 & 18.1 & 24.4 \\
Shrinkage index & 7.5 & 28.3 & 25.4 & 35.6 \\
Clay content & 24 & 71 & 34.0 & 76 \\
Smectite content & 8 & 12 & 14 & 16 \\
activity & 0.4 & 0.33 & 0.83 & 0.5 \\
\hline
\end{tabular}

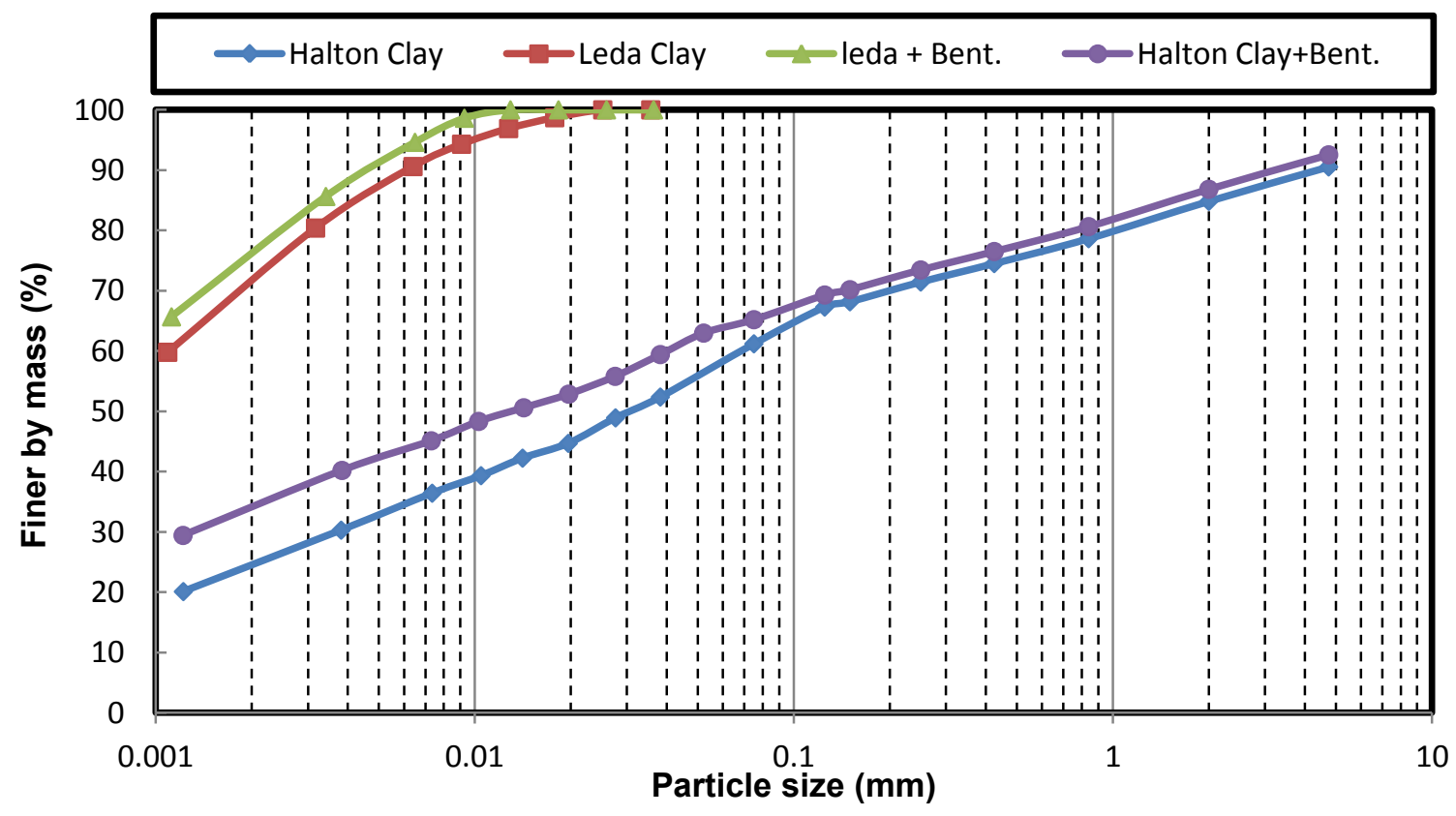

Figure 4.1 Particle size distribution of the test soils. 


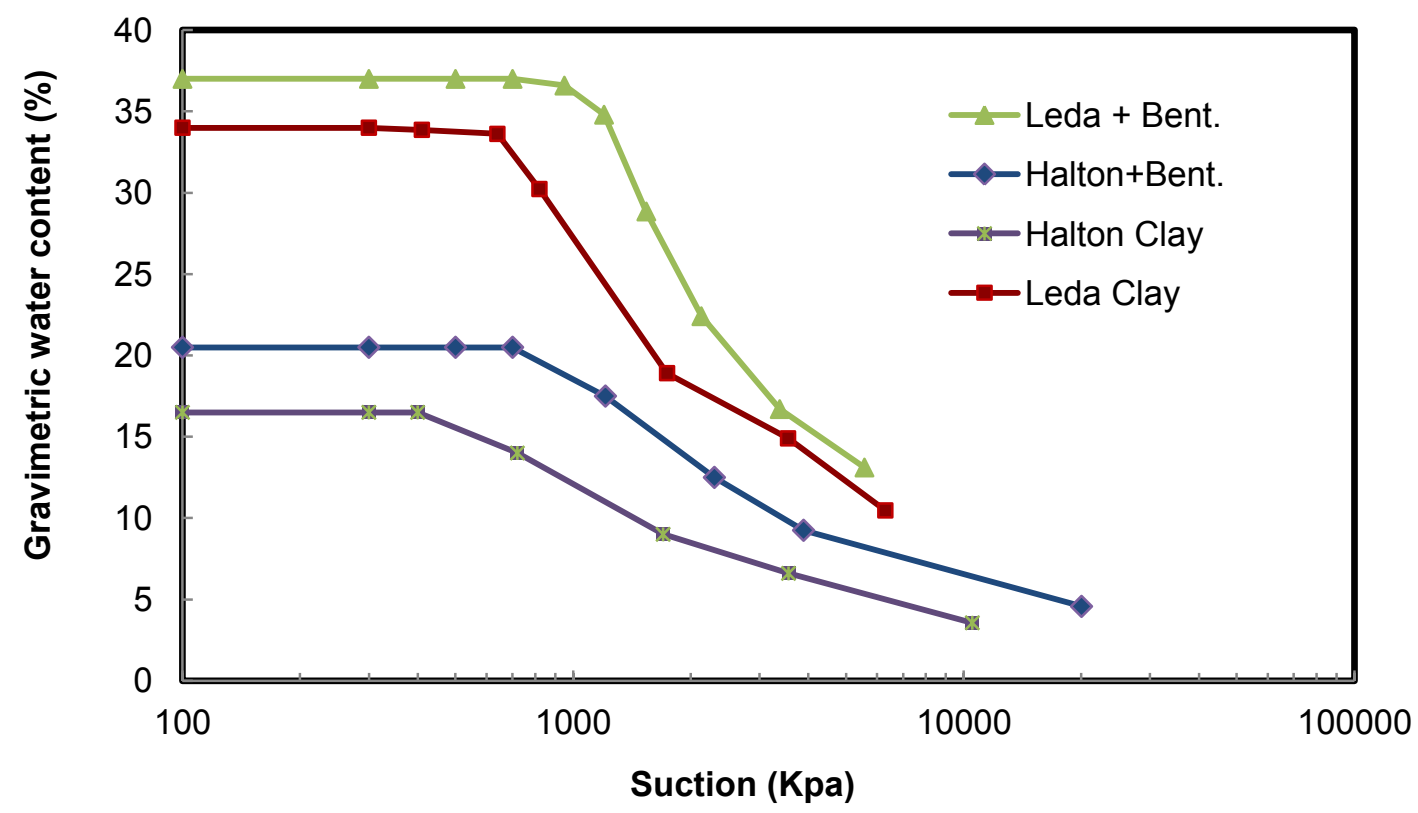

Figure 4.2 Soil-water characteristic curves for test soils (both metric and total suctions).

Table 4.2 Mineralogical composition of the test soils.

\begin{tabular}{ccc}
\hline Component (\%) & Halton Till & Leda clay \\
\hline Montmorillonite & -- & -- \\
Illite & 63 & 83 \\
Chlorite & 5 & 6 \\
Kaolinite & 32 & 11 \\
\hline
\end{tabular}

A chemical analysis was also performed on the extracted pore waters that obtained by squeezing the soil samples under very high pressure. Cation concentrations including potassium, calcium, and magnesium ions were determined in the pore water, while, sodium concentration was measured based on acid extractable sodium ions $(\mathrm{mg} / \mathrm{kg})$. Cation exchange capacities (CEC) were determined and the results presented in Table (4.3). 
Table 4.3 cation concentration in the pore water of the test soils.

\begin{tabular}{ccc}
\hline Characteristics & Halton Till & Leda clay \\
\hline Sodium $(\mathrm{mg} / \mathrm{kg})$ & $\mathbf{1 6 0 . 0}$ & 1700 \\
Potassium $(\mathrm{mg} / \mathrm{l})$ & 6.0 & 15.0 \\
Calcium $(\mathrm{mg} / \mathrm{l})$ & 721.0 & $\mathbf{8 3 . 0}$ \\
Magnesium $(\mathrm{mg} / \mathrm{l})$ & 25.0 & 40.0 \\
$(\mathrm{CEC})^{1} \mathrm{meq} / \mathbf{1 0 0} \mathrm{g}$ & $\mathbf{6 7 . 0}$ & 18.0 \\
\hline
\end{tabular}

\subsubsection{Leachate properties}

Leachate produced in landfills is usually unstable and prone to change under lab conditions. To avoid this, a synthetic leachate was devised for this study based on the instructions provided by Hrapovic (2001) (Table 4.4). The chemical composition of this synthetic leachate is similar to the composition of the leachate extracted from the Keele Valley Landfill in Ontario. A similar synthetic leachate was utilized by Islam and Rowe (2007), Rowe et al. (2008), and Rowe and Rimal (2008b) to evaluate the antioxidants depletion from HDPE geomembranes. Rowe et al. (2008) also highlighted the importance of inclduding the surfactant within the synthetic leachate components, since it had been detected in real MSW landfill leachates by many researches (e.g. Hrapovic 2001; Kjeldsen et al. 2002; Borghi et al. 2003). Existence of surfactant in the leachate is attributed to the disposal of laundry detergents or bath soaps in the waste stream. 
Table 4.4 Composition of synthetic leachates and trace metal solution (Hrapovic 2001).

\begin{tabular}{|c|c|c|c|}
\hline Leachate component & $(\mathrm{mg} / \mathrm{L})$ & * Composition of trace metal & $(\mathrm{mg} / \mathrm{L})$ \\
\hline Volatile fatty acids & & Ferrous sulphate & 2000 \\
\hline Acetic acid (ml/l) & 7 & Boric acid & 50 \\
\hline Propionic acid (ml/l) & 5 & Zinc sulphate heptahydrate & 50 \\
\hline Butyric acid (ml/l) & 1 & Cupric sulphate pentahydrate & 40 \\
\hline Inorganic nutrients & & Manganous sulphate monohydrate & 500 \\
\hline $\mathrm{NaHCO}_{3}$ & 3012 & Ammonium molybdate tetrahydrate & 50 \\
\hline $\mathrm{CaCl}_{2}$ & 2882 & Aluminium sulphate 16 -hydrate & 30 \\
\hline $\mathrm{MgCl}_{2} \cdot 6 \mathrm{H}_{2} \mathrm{O}$ & 3114 & Cobaltous sulphate heptahydrate & 150 \\
\hline $\mathrm{MgSO}_{4} \cdot 7 \mathrm{H}_{2} \mathrm{O}$ & 319 & Nickel (II) sulphate & 500 \\
\hline $\mathrm{NH}_{4} \mathrm{HCO}_{3}$ & 2439 & Sulphuric acid (ml/l) & 1 \\
\hline $\mathrm{CO}\left(\mathrm{NH}_{2}\right)_{2}$ & 695 & & \\
\hline $\mathrm{NaNO}_{3}$ & 50 & & \\
\hline $\mathrm{K}_{2} \mathrm{CO}_{3}$ & 324 & & \\
\hline $\mathrm{KHCO}_{3}$ & 312 & & \\
\hline $\mathrm{K}_{2} \mathrm{HPO}_{4}$ & 30 & & \\
\hline Trace metal solution* (ml/l) & 1 & & \\
\hline \multicolumn{4}{|l|}{ Others } \\
\hline \multicolumn{3}{|l|}{ Surfactant, Igepal CA720 (ml/l) } & 5 \\
\hline \multicolumn{3}{|c|}{ pH (adjusted by adding either $\mathrm{NaOH}$ or $\left.\mathrm{H}_{2} \mathrm{SO}_{4}\right)(-)$} & 6 \\
\hline \multicolumn{3}{|c|}{ Eh (adjusted by adding $3 \%$ w/v $\left.\mathrm{Na}_{2} \mathrm{~S}_{9} 9 \mathrm{H}_{2} \mathrm{O}\right)(\mathrm{mV})$} & -120 \\
\hline
\end{tabular}




\subsection{Experimental Program}

\subsubsection{Experimental cells and specimen preparation}

Cylindrical Plexiglas cells were adopted to prepare compacted soil specimens of $140 \mathrm{~mm}$ in diameter and $150 \mathrm{~mm}$ in height simulating a typical CCL profile in landfills. Prior to soil compaction, rubber membranes were stretched inside the cells to eliminate the effect of side-wall leakage during saturation and leachate permeation (Figure 4.3). Bulk samples Halton and Leda clays were oven-dried at $105^{\circ} \mathrm{C}$ for 24 hours and smashed to pass through a No. 4 sieve. Leda caly $+5 \%$ bentonite and Halton clay $+10 \%$ bentonite mixtures were obtained by adding $5 \%$ and $10 \%$ sodium bentonite to Leda and Halton clay powders respectively. All four soil types were then hydrated up to moisture contents $2 \%$ above their optimum moisture contents. Water sprinkler and a mechanical mixer were used for mixing and hydration of the soils to achieve uniform mixtures and eliminate water heterogeneity. The hydrated soils were then allowed to cure in airtight plastic bags for at least 48 hours to ensure uniform moisture distribution. The hydrated soils were then compacted into the test cells in three layers to obtain $95 \%$ their maximum dry densities. At each compaction layer a sample of soil was obtained to measure the moisture content of the soil throughout the cell. Geotextile fabrics were placed on top and bottom of the soil specimens for uniform permeant distribution. The specimens were eventually sealed using upper and lower aluminum lids (Figure 4.3). The upper lids were manufactured with influent and venting ports, whereas the lower lids featured with effluent ports in order to enable the permeant to move throughout the soil columns. 


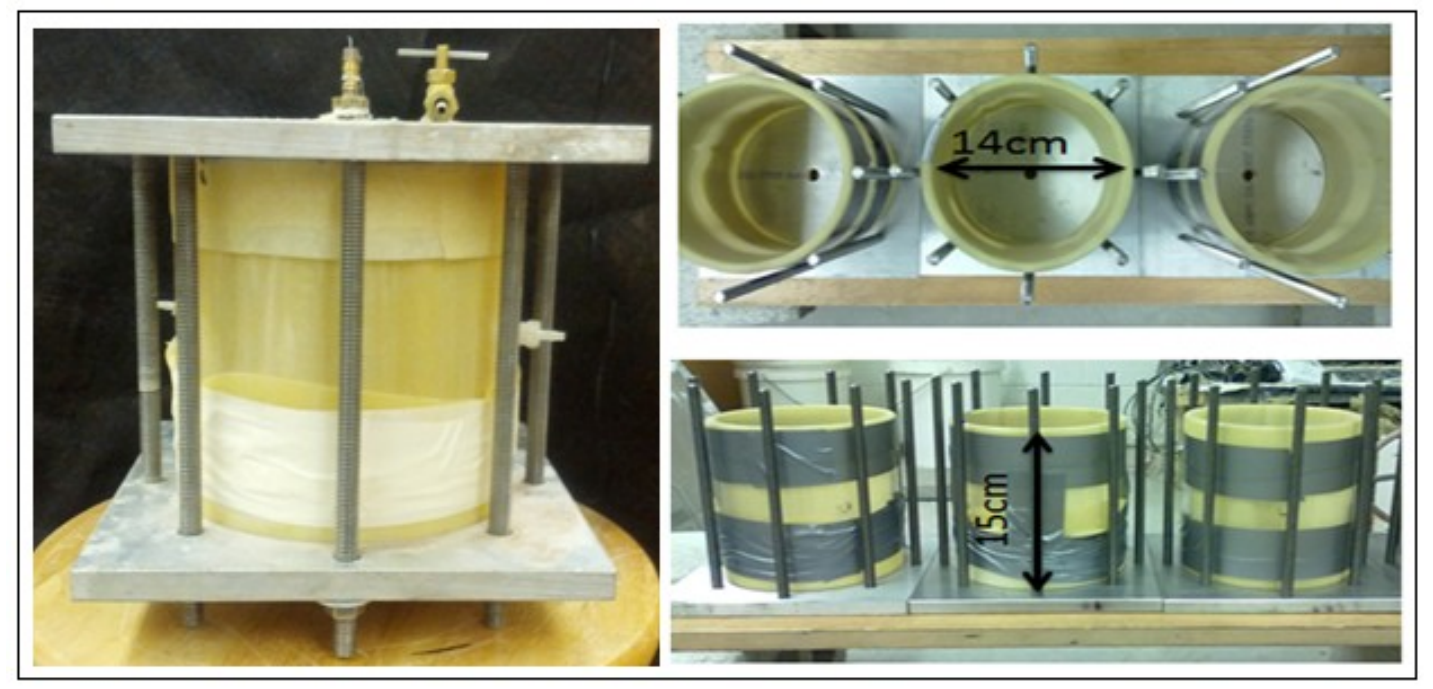

Figure 4.3 Shape and dimensions of test molds.

\subsubsection{Hydraulic conductivity testing}

A testing platform was designed and manufactured in the lab to ensure stable and accurate measurements of hydraulic conductivity along with the heat application on test specimens. The platform was designed to accommodate up to 20 test specimens for permeation and hydraulic conductivity testing. The platform was equipped with two Plexiglas reservoirs for storage and application of water and synthetic leachate during testing (Figure 4.4). The test specimens were placed on the platform board for saturation and testing. A series of mini-Plexiglas tubes were connected to the reservoirs as well as to the soil specimens by using rubber tubes for hydraulic conductivity measurements. The height of reservoirs was adjusted to apply a hydraulic gradient of 6 for all test specimens during saturation, permeation, and hydraulic conductivity testing. This hydraulic gradient value represents moderate flow force that would overcome the molecular force, while avoiding the disturbance of soil structure. The saturation time varied from 20 to 35 days depending on soil type. During saturation, the permeant was allowed to flow upward 
throughout the soil column to eliminate the gravity effect. The specimens were considered saturated when a steady state flow was observed at the effluent ports. Falling head method was adopted to conduct saturated hydraulic conductivity tests using a rigidwall permeameter (ASTM D5856-95). Following the saturation, hydraulic conductivity measurements were taken and final saturated hydraulic conductivity values were recorded when three successive readings were similar (Figure 4.4).

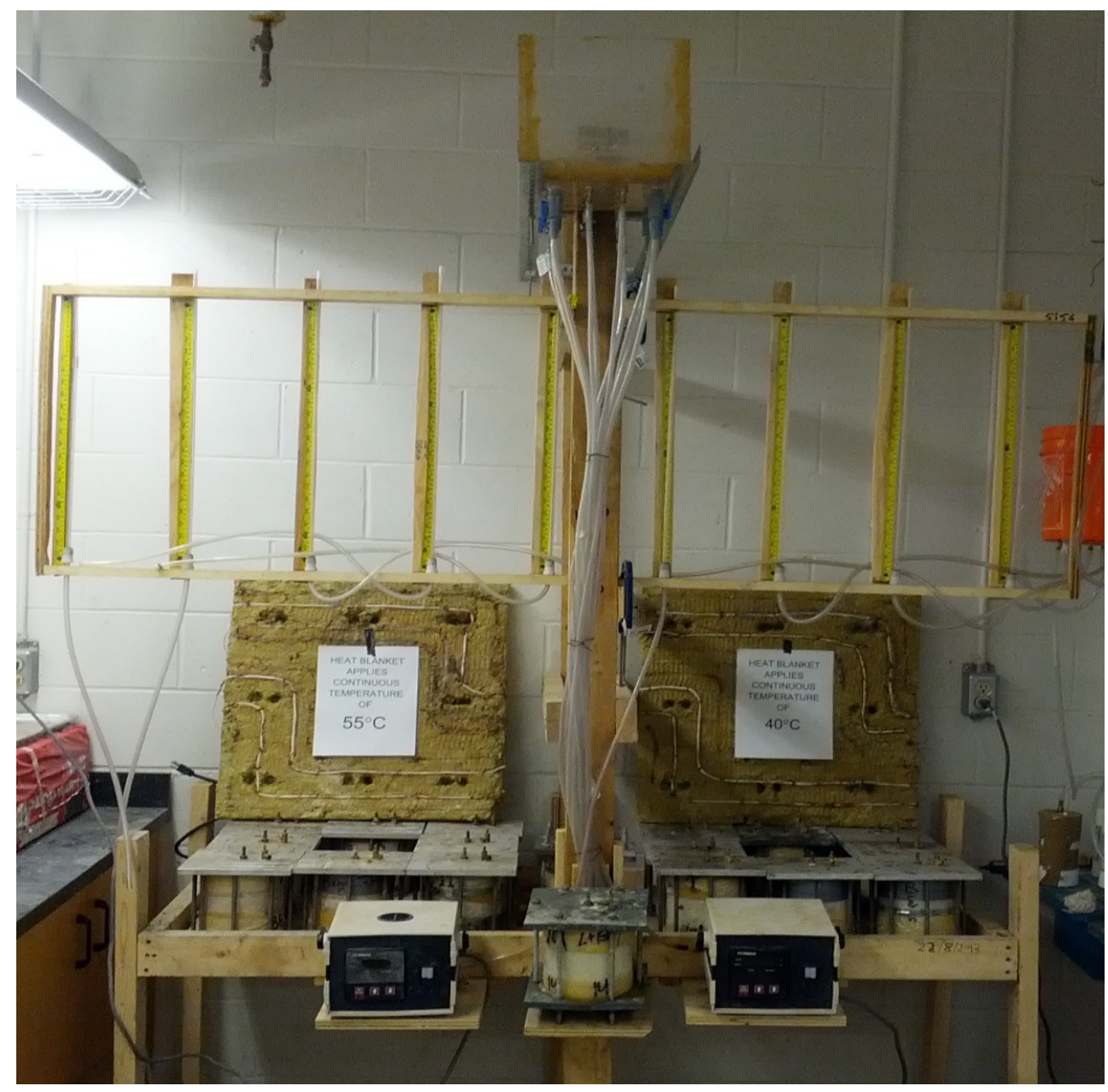

Figure 4.4 Testing platform and the experimental setup. 


\subsubsection{Experimental procedure}

The testing procedure started with preparing five soil specimens for each soil type (a total numbers of 20 specimens). After specimen preparation and saturation, the initial hydraulic conductivity of the specimens was determined based on the instructions provided above. The specimens were then divided into three groups based on the temperature to which the specimens would be exposed $\left(22^{\circ} \mathrm{C}, 40^{\circ} \mathrm{C}\right.$, and $\left.55^{\circ} \mathrm{C}\right)$. Two heating blankets were placed on top of the cells and connected to controller systems to apply 1D heat on top of the test specimens while they were exposed to the synthetic leachate to simulate the combined temperature and leachate exposure conditions in the landfill (Figure 4.5). The side of the test cells were also surrounded by fibreglass insulation leaving only the top of the cells exposed to provide one dimensional heat and moisture transfer conditions.
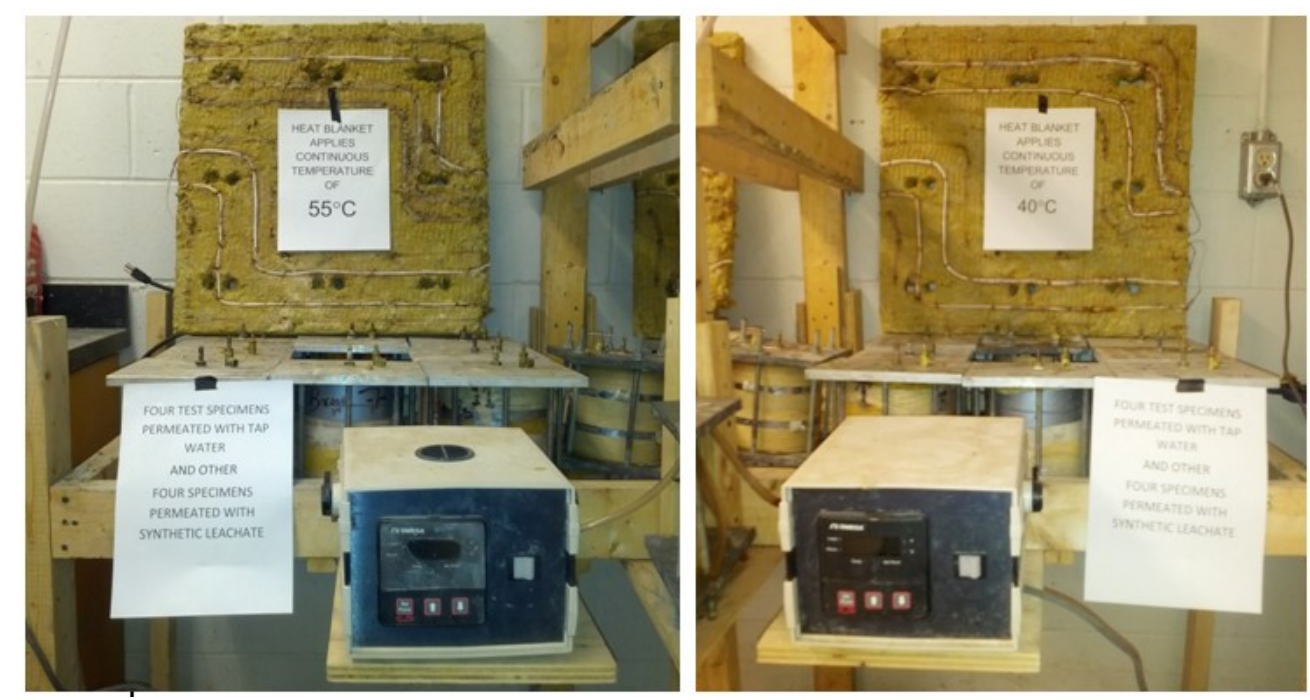

Figure 4.5 Heater blankets and controllers. 
Hydraulic conductivity for all specimens was measured every 15 days to detect any possible change in hydraulic performance due to thermo-chemical exposure. After termination of the specimens, soil samples were taken to conduct post-testing chemical and mineral analysis. Moreover, Atterberg limits tests were conducted on soil specimens after termination to evaluate the effect of leachate permeation on soil plasticity indices.

\subsection{Test Results}

\subsubsection{Hydraulic performance of CCLs under combined thermo-chemical effects}

The initial hydraulic conductivity of the study specimens as well as the consequent hydraulic conductivity readings over different elapsed time are presented in Tables 4.54.9. Hydraulic conductivity results for specimens permeated with synthetic leachate and exposed to $22^{\circ} \mathrm{C}, 40^{\circ} \mathrm{C}$, and $55^{\circ} \mathrm{C}$ are shown in Tables 4.5 , 4.6, and 4.7 respectively. Tables 4.8 and 4.9 show hydraulic conductivity results for the specimens permeated with tap water and exposed to $40^{\circ} \mathrm{C}$ and $55^{\circ} \mathrm{C}$ respectively. To recognize possible difference between the hydraulic conductivities of different specimens, and demonstrate the effect of exposure conditions on hydraulic performance of the CCLs, the measured hydraulic conductivities at set exposure intervals are normalized by their initial hydraulic conductivity (Tables 4.5-4.9).

After 15 days of combined thermo-chemical exposure, the test specimens showed a sharp increase in their hydraulic conductivity values compared to their initial hydraulic conductivities with water (Tables 4.5-4.7). This increase could be attributed to the change of the permeant from water to synthetic leachate as well as applying different levels of temperatures, which resulted in hydraulic conductivity increase 3-folds higher than the 
initial hydraulic conductivity values. However, this increase in hydraulic conductivity was also recorded for the soil specimens exposed to synthetic leachate at room temperature (Table 4.5). This indicates that the change in hydraulic performance during the first 15 days of testing could be dominantly controlled by the leachate effect rather than the thermal impact.

Table 4.5 Hydraulic conductivity of specimens permeated with leachate at room temperature $\left(22^{\circ} \mathrm{C}\right)$.

\begin{tabular}{|c|c|c|c|c|c|c|c|}
\hline \multirow{3}{*}{ Soil type } & \multirow{3}{*}{ Description } & $22^{\circ} \mathrm{C}$ & \multicolumn{5}{|c|}{ Temperature exposure , $22^{\circ} \mathrm{C}$} \\
\hline & & Water & \multicolumn{5}{|c|}{ Leachate } \\
\hline & & $\mathbf{0}$ & 15 & 30 & 45 & 60 & 75 \\
\hline \multirow{4}{*}{$\begin{array}{l}\text { Halton clay } \\
\text { (HC) }\end{array}$} & $\mathbf{K i}$ & $3.2 \mathrm{E}-10$ & & & & & \\
\hline & Kf & 3.2E-10 & 8.8E-10 & 1.8E-10 & 1.8E-10 & $1.6 E-10$ & 2.1E-10 \\
\hline & Kr (water) & 1.00 & 2.75 & 0.56 & 0.56 & 0.50 & 0.66 \\
\hline & Kr (leachate) & & 1.00 & 0.20 & 0.20 & 0.18 & 0.24 \\
\hline \multirow{4}{*}{$\begin{array}{l}\text { Leda clay } \\
\quad \text { (LC) }\end{array}$} & $\mathbf{K i}$ & 7.3E-10 & & & & & \\
\hline & Kf & 7.3E-10 & 1.5E-09 & 5.3E-10 & 2.7E-10 & $2.51 \mathrm{E}-10$ & $2.47 \mathrm{E}-10$ \\
\hline & Kr (water) & 1.00 & 2.05 & 0.73 & 0.37 & 0.34 & 0.34 \\
\hline & Kr (leachate) & & 1.00 & 0.35 & 0.18 & 0.17 & 0.16 \\
\hline \multirow{4}{*}{$\begin{array}{c}\text { Halton clay+Bent. } \\
\text { (HB) }\end{array}$} & $\mathbf{K i}$ & $1.9 \mathrm{E}-10$ & & & & & \\
\hline & $\mathbf{K f}$ & 1.9E-10 & 4.2E-10 & 1.9E-10 & $1.2 \mathrm{E}-10$ & 1.9E-10 & $7.1 \mathrm{E}-11$ \\
\hline & Kr (water) & 1.00 & 2.21 & 1.00 & 0.63 & 1.00 & 0.37 \\
\hline & Kr (leachate) & & 1.00 & 0.45 & 0.29 & 0.45 & 0.17 \\
\hline \multirow{4}{*}{$\begin{array}{c}\text { Leda clay+Bent. } \\
\text { (LB) }\end{array}$} & $\mathbf{K i}$ & 4.4E-10 & & & & & \\
\hline & $\mathbf{K f}$ & 4.4E-10 & 7.9E-10 & 4.1E-10 & 4.1E-10 & $1.4 E-10$ & 8.7E-11 \\
\hline & Kr (water) & 1.00 & 1.80 & 0.93 & 0.93 & 0.32 & 0.20 \\
\hline & Kr (leachate) & & 1.00 & 0.52 & 0.52 & 0.18 & 0.11 \\
\hline
\end{tabular}


Table 4.6 Hydraulic conductivity of specimens permeated with leachate and exposed to $40^{\circ} \mathrm{C}$ heat.

\begin{tabular}{|c|c|c|c|c|c|c|c|}
\hline \multirow{3}{*}{ Soil type } & \multirow{3}{*}{ Description } & $22^{\circ} \mathrm{C}$ & \multicolumn{5}{|c|}{ Temperature exposure, $40^{\circ} \mathrm{C}$} \\
\hline & & water & \multicolumn{5}{|c|}{ Leachate } \\
\hline & & $\mathbf{0}$ & 15 & 30 & 45 & 60 & 75 \\
\hline \multirow{4}{*}{ Halton clay $(\mathrm{HC})$} & Ki & 4.6E-10 & & & & & \\
\hline & Kf & 4.6E-10 & 7.2E-10 & $1.7 \mathrm{E}-10$ & 2.2E-10 & 3.1E-10 & $2.5 \mathrm{E}-10$ \\
\hline & Kr (water) & 1 & 1.57 & 0.37 & 0.48 & 0.67 & 0.54 \\
\hline & Kr (leachate) & & 1.00 & 0.24 & 0.31 & 0.43 & 0.35 \\
\hline \multirow{4}{*}{ Leda clay (LC) } & $\mathbf{K i}$ & $1.3 \mathrm{E}-09$ & & & & & \\
\hline & Kf & $1.3 \mathrm{E}-09$ & 3.4E-09 & 2.6E-09 & 1.0E-09 & $9.8 \mathrm{E}-10$ & $9.0 \mathrm{E}-10$ \\
\hline & Kr (water) & 1 & 2.62 & 2.00 & 0.77 & 0.75 & 0.69 \\
\hline & Kr (leachate) & & 1.00 & 0.76 & 0.29 & 0.29 & 0.26 \\
\hline \multirow{4}{*}{$\begin{array}{c}\text { Halton clay+Bent. } \\
\text { (HB) }\end{array}$} & Ki & $1.9 \mathrm{E}-10$ & & & 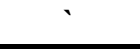 & & \\
\hline & Kf & $1.9 \mathrm{E}-10$ & 4.4E-10 & $3.6 \mathrm{E}-10$ & 3.3E-10 & 2.2E-10 & $1.5 \mathrm{E}-10$ \\
\hline & Kr (water) & 1 & 2.32 & 1.89 & 1.74 & 1.16 & 0.79 \\
\hline & Kr (leachate) & & 1.00 & 0.82 & 0.75 & 0.50 & 0.34 \\
\hline \multirow{4}{*}{$\begin{array}{l}\text { Leda clay+Bent. } \\
\text { (LB) }\end{array}$} & $\mathbf{K i}$ & $7.4 \mathrm{E}-10$ & & & & & \\
\hline & Kf & 7.4E-10 & $6.9 \mathrm{E}-10$ & $7.5 \mathrm{E}-10$ & $3.4 \mathrm{E}-10$ & $3.5 \mathrm{E}-10$ & 1.1E-10 \\
\hline & Kr (water) & 1 & 0.93 & 1.01 & 0.46 & 0.47 & 0.15 \\
\hline & Kr (leachate) & & 1.00 & 1.09 & 0.49 & 0.51 & 0.16 \\
\hline
\end{tabular}

Table 4.7 Hydraulic conductivity of specimens permeated with leachate and exposed to $55^{\circ} \mathrm{C}$ heat.

\begin{tabular}{|c|c|c|c|c|c|c|c|}
\hline \multirow{3}{*}{ Soil type } & \multirow{3}{*}{ Description } & $22^{\circ} \mathrm{C}$ & \multicolumn{5}{|c|}{ Temperature exposure,, $55^{\circ} \mathrm{C}$} \\
\hline & & water & \multicolumn{5}{|c|}{ Leachate } \\
\hline & & 0 & 15 & 30 & 45 & 60 & 75 \\
\hline \multirow{4}{*}{$\begin{array}{l}\text { Halton clay } \\
\quad \text { (HC) }\end{array}$} & $\mathbf{K i}$ & $4.0 \mathrm{E}-10$ & & & & & \\
\hline & Kf & $4.0 \mathrm{E}-10$ & $7.6 \mathrm{E}-10$ & $7.8 \mathrm{E}-10$ & $6.5 \mathrm{E}-10$ & $7.0 \mathrm{E}-10$ & $4.8 \mathrm{E}-10$ \\
\hline & Kr water & 1.00 & 1.90 & 1.95 & 1.63 & 1.75 & 1.20 \\
\hline & Kr leachate & & 1.00 & 1.03 & 0.86 & 0.92 & 0.63 \\
\hline \multirow{4}{*}{$\begin{array}{l}\text { Leda clay } \\
\text { (LC) }\end{array}$} & $\mathbf{K i}$ & $4.6 \mathrm{E}-10$ & & & & & \\
\hline & Kf & 4.6E-10 & 8.0E-10 & 9.4E-10 & $5.4 \mathrm{E}-10$ & 4.6E-10 & 4.3E-10 \\
\hline & Kr water & 1.00 & 1.74 & 2.04 & 1.17 & 1.00 & 0.93 \\
\hline & Kr leachate & & 1.00 & 1.18 & 0.68 & 0.58 & 0.54 \\
\hline \multirow{4}{*}{$\begin{array}{c}\text { Halton clay+Bent. } \\
\text { (HB) }\end{array}$} & $\mathbf{K i}$ & $1.9 \mathrm{E}-10$ & & & & & \\
\hline & $\mathbf{K f}$ & $1.9 \mathrm{E}-10$ & 4.2E-10 & 3.7E-10 & 2.6E-10 & 2.5E-10 & 2.1E-10 \\
\hline & Kr (water) & 1.00 & 2.21 & 1.95 & 1.37 & 1.32 & 1.11 \\
\hline & Kr (leachate) & & 1.00 & $\mathbf{0 . 8 8}$ & 0.62 & 0.60 & 0.50 \\
\hline \multirow{4}{*}{$\begin{array}{l}\text { Leda clay+Bent. } \\
\text { (LB) }\end{array}$} & $\mathbf{K i}$ & $2.8 \mathrm{E}-10$ & & & & & \\
\hline & Kf & 2.8E-10 & 7.9E-10 & $6.8 \mathrm{E}-10$ & 5.8E-10 & 4.8E-10 & $3.5 \mathrm{E}-10$ \\
\hline & Kr water & 1.00 & 2.82 & 2.43 & 2.07 & 1.71 & 1.25 \\
\hline & Kr leachate & & 1.00 & 0.86 & 0.73 & 0.61 & 0.44 \\
\hline
\end{tabular}


Table 4.8 Hydraulic conductivity of specimens permeated with water and exposed to $40^{\circ} \mathrm{C}$ heat.

\begin{tabular}{|c|c|c|c|c|c|c|c|}
\hline \multirow{3}{*}{ Soil type } & \multirow{3}{*}{ Description } & $22^{\circ} \mathrm{C}$ & \multicolumn{5}{|c|}{ Temperature exposure, $40^{\circ} \mathrm{C}$} \\
\hline & & water & \multicolumn{5}{|c|}{ water } \\
\hline & & $\mathbf{0}$ & 15 & 30 & 45 & 60 & 75 \\
\hline \multirow{3}{*}{$\begin{array}{l}\text { Halton clay } \\
\quad(\text { HC) }\end{array}$} & $\mathbf{K i}$ & $3.4 \mathrm{E}-10$ & & & & & \\
\hline & Kf & $3.4 \mathrm{E}-10$ & $5.1 \mathrm{E}-10$ & $5.5 \mathrm{E}-10$ & $6.6 \mathrm{E}-10$ & 5.8E-10 & $5.7 \mathrm{E}-10$ \\
\hline & Kr (water) & 1 & 1.50 & 1.62 & 1.94 & 1.71 & 1.68 \\
\hline \multirow{3}{*}{$\begin{array}{l}\text { Leda clay } \\
\text { (LC) }\end{array}$} & Ki & $5.9 \mathrm{E}-10$ & & & & & \\
\hline & Kf & $5.9 \mathrm{E}-10$ & 7.6E-10 & 8.6E-10 & $9.4 \mathrm{E}-10$ & 1.0E-09 & 1.1E-09 \\
\hline & Kr (water) & 1 & 1.29 & 1.46 & 1.59 & 1.69 & 1.86 \\
\hline \multirow{3}{*}{$\begin{array}{c}\text { Halton clay+Bent. } \\
\text { (HB) }\end{array}$} & $\mathbf{K i}$ & $2.2 \mathrm{E}-10$ & & & & & \\
\hline & Kf & 2.2E-10 & 2.23E-10 & 2.4E-10 & 2.63E-10 & 2.8E-10 & 2.9E-10 \\
\hline & Kr (water) & 1 & 1.01 & 1.09 & 1.20 & 1.27 & 1.32 \\
\hline \multirow{3}{*}{$\begin{array}{l}\text { Leda clay+Bent. } \\
\text { (LB) }\end{array}$} & $\mathbf{K i}$ & $4.7 \mathrm{E}-10$ & & & & & \\
\hline & Kf & $4.7 \mathrm{E}-10$ & $6.6 \mathrm{E}-10$ & $6.9 \mathrm{E}-10$ & $7.8 \mathrm{E}-10$ & 6.3E-10 & 6.7E-10 \\
\hline & Kr (water) & 1 & 1.40 & 1.47 & 1.66 & 1.34 & 1.43 \\
\hline
\end{tabular}

Table 4.9 Hydraulic conductivity of specimens permeated with water and exposed to $55^{\circ} \mathrm{C}$ heat.

\begin{tabular}{|c|c|c|c|c|c|c|c|}
\hline \multirow{3}{*}{ Soil type } & \multirow{3}{*}{ Description } & $22^{\circ} \mathrm{C}$ & \multicolumn{5}{|c|}{ Temperature exposure, $55^{\circ} \mathrm{C}$} \\
\hline & & water & \multicolumn{5}{|c|}{ water } \\
\hline & & 0 & 15 & 30 & 45 & 60 & 75 \\
\hline \multirow{3}{*}{$\begin{array}{l}\text { Halton clay } \\
\text { (HC) }\end{array}$} & $\mathbf{K i}$ & $3.8 \mathrm{E}-10$ & & & & & \\
\hline & $\mathbf{K f}$ & $3.8 \mathrm{E}-10$ & $6.7 \mathrm{E}-10$ & $8.1 E-10$ & $8.8 \mathrm{E}-10$ & $9.6 \mathrm{E}-10$ & $8.5 E-10$ \\
\hline & Kr (water) & 1 & 1.76 & 2.13 & 2.32 & 2.53 & 2.24 \\
\hline \multirow{3}{*}{$\begin{array}{l}\text { Leda clay } \\
\text { (LC) }\end{array}$} & $\mathbf{K i}$ & $5.8 \mathrm{E}-10$ & & & & & \\
\hline & Kf & $5.8 \mathrm{E}-10$ & $8.5 \mathrm{E}-10$ & $8.5 \mathrm{E}-10$ & 8.4E-10 & 7.8E-10 & 1.1E-09 \\
\hline & Kr (water) & 1 & 1.47 & 1.47 & 1.45 & 1.34 & 1.90 \\
\hline \multirow{3}{*}{$\begin{array}{c}\text { Halton clay+Bent. } \\
\text { (HB) }\end{array}$} & $\mathbf{K i}$ & 2.6E-10 & & & & & \\
\hline & Kf & 2.6E-10 & 3.7E-10 & 4.6E-10 & 4.8E-10 & 4.9E-10 & $5.0 \mathrm{E}-10$ \\
\hline & Kr (water) & 1 & 1.42 & 1.77 & 1.85 & 1.88 & 1.92 \\
\hline \multirow{3}{*}{$\begin{array}{l}\text { Leda clay+Bent. } \\
\text { (LB) }\end{array}$} & $\mathbf{K i}$ & $5.1 \mathrm{E}-10$ & & & & & \\
\hline & $\mathbf{K f}$ & $5.1 \mathrm{E}-10$ & $5.2 \mathrm{E}-10$ & $6.8 \mathrm{E}-10$ & $7.4 \mathrm{E}-10$ & 6.0E-10 & $6.7 \mathrm{E}-10$ \\
\hline & Kr (water) & 1 & 1.02 & 1.33 & 1.45 & 1.18 & 1.31 \\
\hline
\end{tabular}


Beyond the 15 days threshold, the trend of hydraulic performance changed adversely. Soil specimens experienced gradual decrease in their hydraulic conductivity values along the next 60 days of thermo-chemical exposure. However, the rate of reduction of hydraulic conductivity was different for different temperatures. The soil specimens exposed to synthetic leachate at room temperature showed much lower hydraulic conductivity values after 75 days of exposure, while the highest final hydraulic conductivity was recorded for soil specimens exposed to synthetic leachate at $55^{\circ} \mathrm{C}$ (Tables $4.5 \& 4.7$ ). Soil specimens permeated with leachate and exposed to $40^{\circ} \mathrm{C}$ resulted in moderate hydraulic conductivity decrease that fell in between. Numerically, an order of magnitude decrease was recorded for the Leda clay $+5 \%$ bentonite (LB) specimen when its hydraulic conductivity value was reduced from $7.9 \times 10^{-10} \mathrm{~m} / \mathrm{s}$ to $8.7 \times 10^{-11} \mathrm{~m} / \mathrm{s}$ at room temperature (Table 4.5). However, the same soil (LB) when permeated with leachate but exposed to temperatures of $40^{\circ} \mathrm{C}$ and $55^{\circ} \mathrm{C}$, experienced 6.3 and 2.3 times reductions in their hydraulic conductivity respectively (Tables $4.6 \& 4.7$ ). This behaviour highlights the impact of temperature on hydraulic performance of the CCLs when combined thermo-chemical exposures are applied.

\subsubsection{Mineral analysis of CCLs under combined thermo-chemical effects}

Chemical interactions are expected between clay and synthetic leachate ions upon leachate permeation. This interaction might change the type and/or concentration of the interlayer ions located between clay sheets. Ion substitutions, as a result, might cause mineral transformation, which may lead to possible hydraulic deviation. Therefore, random X-Ray powder diffraction analysis was conducted to compute the mineral compositions for Leda clay and Halton clay specimens before and after exposure to 
combined thermo-chemical conditions. Semi-quantitative analysis was conducted on XRay results to measure the clay mineral components. The initial and final clay minerals are presented in Table 4.10 along with the initial and final cation exchange capacities. The X-Ray graphs for natural water-wet specimens and leachate permeated specimens are also presented in Appendix A. Results show almost identical mineral compositions for the soil samples before and after exposure to thermo-chemical effects. This behaviour might be attributed to the deficiency of real chemical interaction occurrence between test soils and the synthetic leachate as the cation exchange capacity (CEC) also remains constant before and after treatment.

Table 4.10 Clay minerals initially and after exposure to combined thermo-chemical effects.

\begin{tabular}{|c|c|c|c|c|}
\hline \multirow{2}{*}{ Component } & \multicolumn{2}{|c|}{ Halton Clay } & \multicolumn{2}{|c|}{ Leda Clay } \\
\hline & Initial & Final & Initial & Final \\
\hline Montmorillonite (\%) & -- & -- & -- & -- \\
\hline Illite & 63 & 62 & 83 & 84 \\
\hline Chlorite & 5 & 5 & 6 & 7 \\
\hline Kaolinite & 32 & 33 & 11 & 9 \\
\hline$(\mathrm{meq}+/ 100 \mathrm{~g})$ & 67 & 65 & 18 & 20 \\
\hline
\end{tabular}

\subsubsection{Chemical alternation of CCLs under combined thermo-chemical effects}

Chemical analysis was carried out on samples of Leda clay and Halton clay initially and after 75 days of exposure to combined thermo-chemical effects. This analysis was conducted on the leachates that were physically squeezed out from the pore volume of the soil samples. However, sodium ion was not available from leachate analysis for the test soils before and after exposure. Therefore, the concentration of sodium ions was 
determined based on acid extractable sodium from the soil samples before and after the exposure. Table 4.11 presents the ion concentrations in the leachate as well as those extracted from the soil specimens before and after the exposure.

Table 4.11 Cation concentration in the pore water of the test soils.

\begin{tabular}{|c|c|c|c|c|c|}
\hline \multirow{2}{*}{ Characteristics } & \multirow{2}{*}{ Synthetic leachate** } & \multicolumn{2}{|c|}{ Halton clay } & \multicolumn{2}{|c|}{ Leda clay } \\
\cline { 3 - 6 } & & Initial & Final & Initial & Final \\
\hline Sodium (mg/l) & 1615 & & & & \\
\hline Sodium & & & & & \\
\hline Potassium (mg/kg) & --- & 160 & 790 & 15 & 18 \\
\hline Calcium (mg/l) & 354 & 6 & 700 & 135 \\
\hline Magnesium (mg/l) & 1224 & 721 & 1030 & 83 & 56 \\
\hline
\end{tabular}

"Acid extractable sodium (mg/kg), ${ }^{* *}$ ion concentration adopted from Hrapovic (2001).

Results indicate significant increase in sodium and calcium ion concentrations for both clayey soils upon leachate permeation. For Halton clay, sodium and calcium concentrations increased from initial values of $160 \mathrm{mg} / \mathrm{l}$ and $721 \mathrm{mg} / \mathrm{l}$ to reach final values of $790 \mathrm{mg} / \mathrm{l}$ and $1030 \mathrm{mg} / \mathrm{l}$ respectively. Similarly, for Leda clay, the concentrations increased from $1700 \mathrm{mg} / \mathrm{l}$ and $83 \mathrm{mg} / 1$ to reach $2500 \mathrm{mg} / 1$ and $135 \mathrm{mg} / \mathrm{l}$ for sodium and calcium ions respectively. A slight increase was also observed for magnesium ion concentration after leachate exposure. However, there was no evidence of potassium fixation due to leachate permeation, since the potassium concentrations remained almost constant and was not changed upon leachate permeation. The increase in sodium and calcium concentrations after leachate exposure might be attributed to the high concentration of these ions in the synthetic leachate $(1615 \mathrm{mg} / \mathrm{l}$ sodium and 1224 $\mathrm{mg} / \mathrm{l}$ calcium) and chemical precipitation within the pore voids of the soil. These results 
are consistent with the results of mineral analyses, which show no change in cation exchange capacity as well as no change in mineral compositions of the test soils upon leachate permeation.

\subsection{Analysis and discussion}

\subsubsection{Effect of elevated temperature on hydraulic performance of CCLs}

Elevated temperature in landfills might facilitate the migration of the leachate throughout the CCL matrix. The elevated temperature can also affect the properties of the clayey barrier as well as the landfill leachate. Higher landfill temperature might decrease the leachate viscosity, cause micro-crack generation, and decrease the water retention capacity, which all would increase the hydraulic conductivity. In current study, eight soil specimens prepared (in average of two specimens per soil type) were utilized to investigate the effect of landfill temperature on hydraulic performance of CCLs after waste placement. After saturation and initial hydraulic conductivity measurements, the specimens were exposed to two different temperatures $\left(40^{\circ} \mathrm{C}\right.$ and $\left.55^{\circ} \mathrm{C}\right)$ while permeated with tap water for 75 days. Figure 4.6 shows the variation in hydraulic conductivity of Halton clay specimens when exposed to $40^{\circ} \mathrm{C}$ and $55^{\circ} \mathrm{C}$ respectively. 


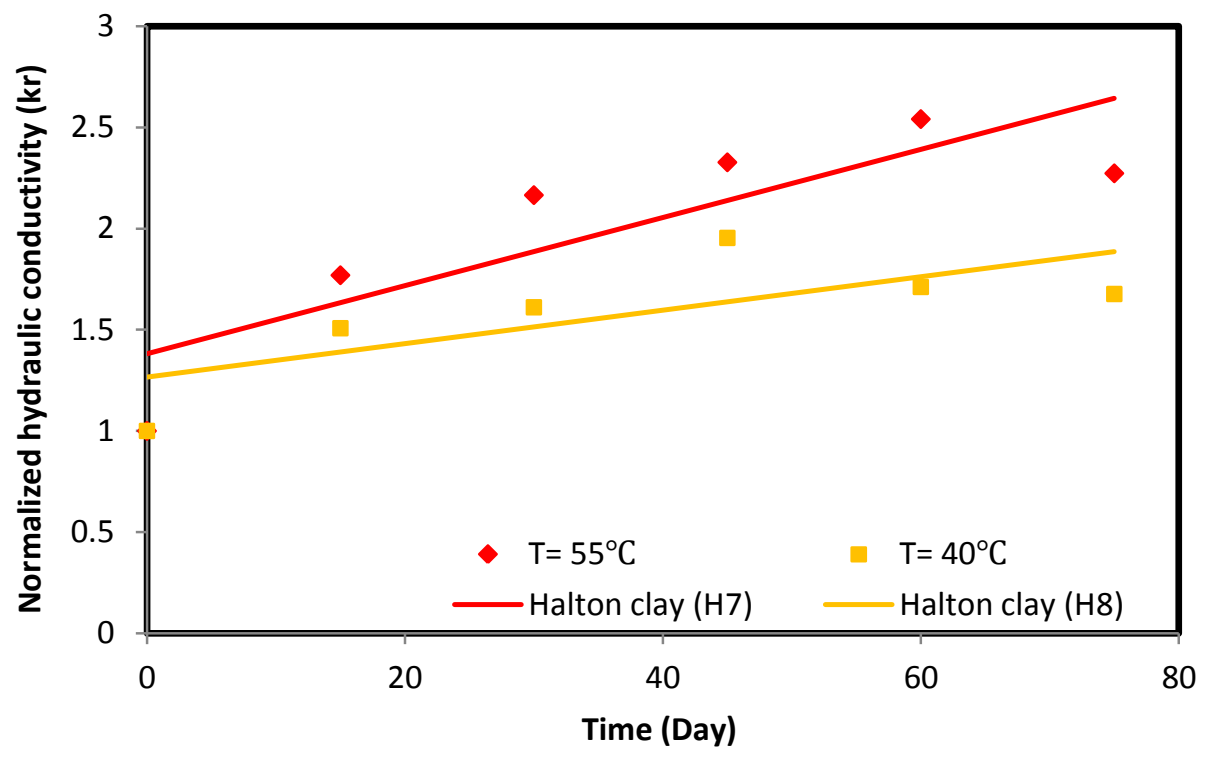

Figure 4.6 Hydraulic performance of CCL specimens when exposed to $40^{\circ} \mathrm{C}$ and $55^{\circ} \mathrm{C}$.

The trend lines for the plotted data clearly indicate the increase of hydraulic conductivities of the CCL specimens with time when exposed to elevated temperatures. Furthermore, the rate of increase in hydraulic conductivity was more pronounced for the CCL specimens exposed to higher temperature $\left(55^{\circ} \mathrm{C}\right)$. This can be inferred from the steeper slope of the trend line that represented the data points for the two series of the specimens (Figure 4.6).

This increase in hydraulic conductivity could be related to changes in properties of the permeant as well as the soil characteristics. As the temperature increases the viscosity of the permeant decreases, which in turn could increase its diffusion capacity and, thus, facilitate its movement through the CCL matrix and increase the hydraulic conductivity. This inverse relationship between viscosity and hydraulic conductivity can be expressed as follow: 


$$
\mathrm{K}=\frac{(-\mathrm{k} * \rho * \mathrm{~g})}{(\mu)}
$$

where, $\mathrm{K}=$ hydraulic conductivity, $\rho=$ density of fluid $\left(\mathrm{g} / \mathrm{cm}^{3}\right), g=$ gravitation constant $\left(\mathrm{cm} / \mathrm{sec}^{2}\right), \mu=$ viscosity of the fluid $(\mathrm{g} / \mathrm{cm} \cdot \mathrm{sec})$, and $\mathrm{k}=$ coefficient of permeability or intrinsic permeability $\left(\mathrm{cm}^{2}\right)$.

Elevated temperature could also induce generation of micro-cracks within the soil matrix. When the upper surface of the CCLs are exposed to elevated temperature, thermal gradient would be generated between the hotter zone, which is the upper surface of the CCLs, and the cooler zone, which is the bottom part of the CCLs. This thermal gradient would cause moisture content withdrawing from the upper surface to the bottom part of the CCLs. The downward movement of the moisture content would leave behind voids and fissures, which in turn can contribute to micro-crack generation, and eventually increase the hydraulic conductivity of the CCLs. Many researchers (e.g., Villar et al., 2005; Romero et al., 2005) reported similar behaviour for different clayey barriers. The increase of temperature might also lead to reduction in soil suction and water retaining capacity (Romero et al., 2005). Therefore, the capacity of the soil particles to absorp and keep water would decrease as the applied temperature increase, thereby, increases hydraulic conductivity of the CCLs at higher exposure tmperatures.

\subsubsection{Effect of leachate exposure on hydraulic performance of CCLs}

Clay/leachate compatibility has long been investigated and considered as a significant CCLs performance assessment tool. However, discrepancy in conclusions, whether clay barrier and landfill leachate are compatible or not, has been widely encountered. Some 
reported an increase in hydraulic conductivity of clayey barrier upon leachate permeation (e.g., Petrov and Rowe 1997), while others stated a decrease in hydraulic conductivity of clayey barriers when exposed to domestic waste leachate (Griffin et al., 1976). However, all agreed about chemical interaction occurrence between landfill leachate and the clayey barriers, yet, the outcomes of this interaction might vary based on many factors. This interaction could causes reduction in hydraulic conductivity, if it results in sodium ion absorption, but potassium, calcium and magnesium ions desorption. However, the nature of the chemical interaction mostly is uncontrollable and it depends on many variables such as chemical compositions, cation types, and cation concentrations of both CCLs and landfill leachates.

In the current study, the clay/leachate compatibility was studied using different types of clayey soils in order to provide variety in the chemical, mineral, and physical properties, and enable better judgement on the outcomes of clay/leachate interactions. Furthermore, a synthetic leachate was used in the current investigation to maintain constant chemical composition and properties since real landfill leachate could be prone to changes under effects of laboratory conditions. Hydraulic conductivity results as well as normalized hydraulic conductivities of different specimens exposed to leachate permeation at room temperature are presented in Table 4.5. Results indicate an increase in hydraulic conductivities for all soil specimens ranged from two to three times their initial hydraulic conductivities after 15 days of leachate permeation. This behaviour may be linked to the change in permeant properties. The initial saturation and hydraulic conductivity measurements (ki) for CCL specimens were conducted using tap water. However, the hydraulic conductivities at 15 days $\left(\mathrm{k}_{\mathrm{f}}\right)$ were measured after permeation of 
the soil specimens with synthetic leachate for 15 days. Due to lower viscosity of the leachate compared to the tap water, hydraulic conductivity of all the specimens increased (Table 4.12).

Table 4.12 Hydraulic performance of CCL specimens with different permeates at room temperature.

\begin{tabular}{cccccc}
\hline Permeant & Characteristic & $\begin{array}{c}\text { Halton clay } \\
\text { H10 }\end{array}$ & $\begin{array}{c}\text { Leda clay } \\
\text { L20 }\end{array}$ & $\begin{array}{c}\text { Halton clay+Bent. } \\
\text { H.B5 }\end{array}$ & $\begin{array}{c}\text { Leda clay+Bent. } \\
\text { L.B14 }\end{array}$ \\
\hline Water & ${ }^{1} \mathrm{ki}(\mathrm{m} / \mathrm{sec})$ & $3.2 \mathrm{E}-10$ & $7.3 \mathrm{E}-10$ & $1.9 \mathrm{E}-10$ & $4.4 \mathrm{E}-10$ \\
Leachate & ${ }^{2} \mathrm{kf}(\mathrm{m} / \mathrm{sec})$ & $8.8 \mathrm{E}-10$ & $1.5 \mathrm{E}-09$ & $4.2 \mathrm{E}-10$ & $7.9 \mathrm{E}-10$ \\
\hline & ${ }^{3} \mathrm{kr}$ & 2.75 & 2.05 & 2.21 & 1.80 \\
\hline
\end{tabular}

${ }^{1}$ initial hydraulic conductivity $(\mathrm{m} / \mathrm{sec}) ;{ }^{2}$ hydraulic conductivity after 15 days of leachate permation $(\mathrm{m} / \mathrm{sec}){ }^{3}$ normalized hydraulic conductivity $\left(\mathrm{K}_{\mathrm{f}} / \mathrm{K}_{\mathrm{i}}\right)$.

As synthetic leachate permeation proceeded beyond the elapsed time of 15 days, hydraulic conductivities started showing gradual decrease that continued up to the end of the test period. Hydraulic conductivities at elapsed times of $30,45,60$, and 75 days were respectively measured and normalized by the 15 days hydraulic conductivity for all test specimens. The results were then presented in Table (4.5) and plotted in Figure (4.7) to visualize the effect of leachate permeation. 


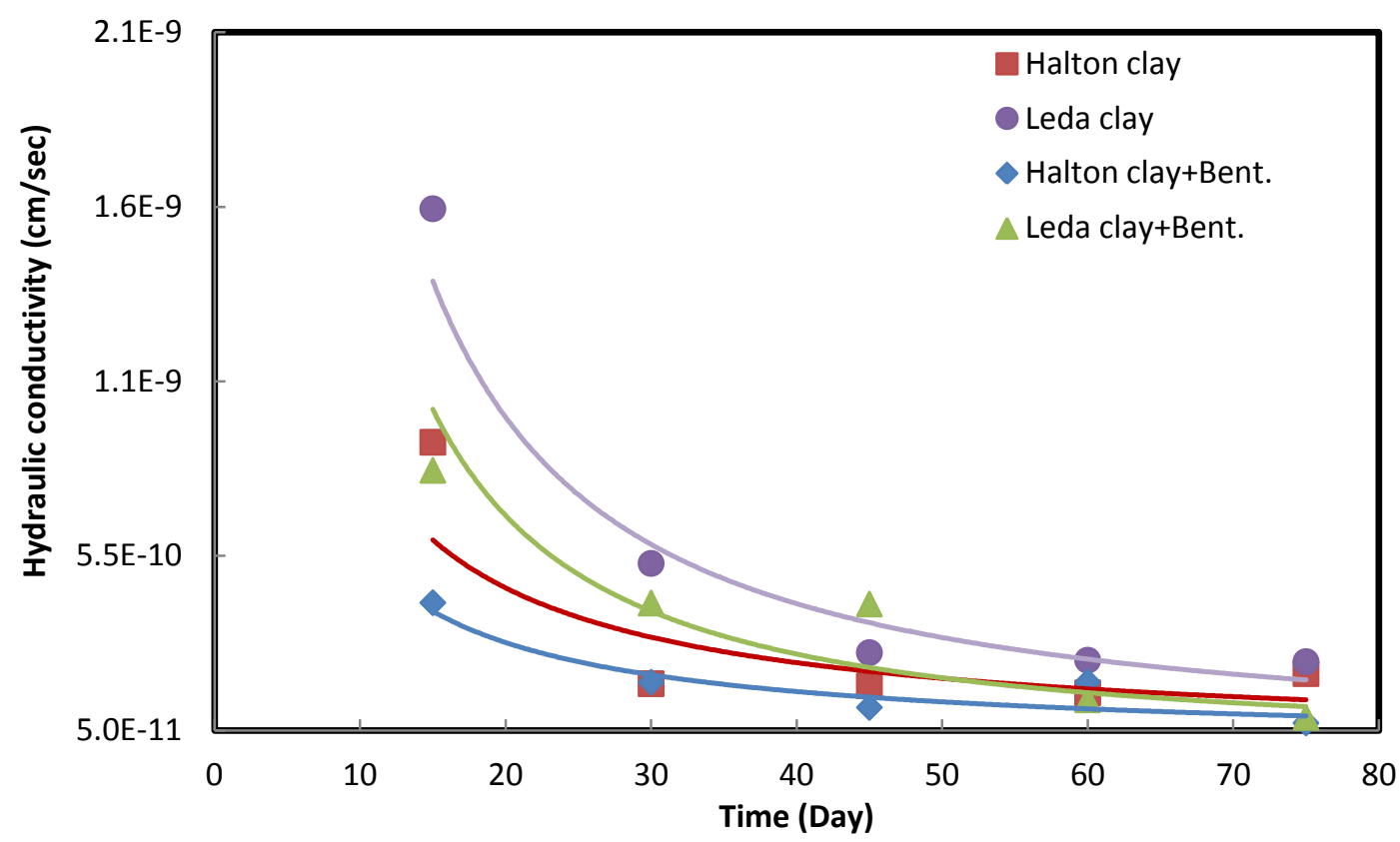

Figure 4.7 Hydraulic performance for CCLs when exposed to leachate permeation at room temperature.

All CCL specimens showed decrease in their hydraulic conductivities beyond the elapsed time of 15 days and continued to decrease until the end of the test. However, different soil types showed different levels of hydraulic conductivity reduction. The rate of decrease in hydraulic conductivity varied from a maximum value of about one order of magnitude for Leda clay + bentonite $(\mathrm{LB})$ to a minimum decrease of more than half an order of magnitude for Leda clay (LC) (Table 4.5). This reduction in hydraulic conductivity might be attributed to the change in chemical compositions of the test soils upon permeation with leachate for 75 days. Sodium and calcium ion concentrations were increased significantly within Leda clay and Halton clay specimens (Table 4.11). This increase in concentration seems to be occurred due to chemical precipitations of these ions as crystal salts within the CCLs voids and fissures, and most likely there was no cation exchange or substitution within the clay sheets. This was inferred from the mineral 
analysis that conducted initially and after test termination. This analysis did not show any mineral changes such as smectite or illite/smectite mixed layers formations, which should occur following to sodium ion substitution. However, the increase of sodium concentration might increase the thickness of double layer when sodium ions precipitate within the soil aggregate, thus, decrease the active pore space and hydraulic conductivity. Moreover, absorption of sodium ions could encourage dispersed arrangement of clay particles, which would further decrease the hydraulic conductivity. On the other hand, the increase of calcium ion concentration could lead to chemical precipitation within the pore volume and hence result in clogging of voids and flow channels within the soils. Rowe and McIsaac (2005) recorded similar observation when hydraulic conductivities of tire shreds and gravel columns decreased due to predominant calcium carbonate precipitation upon leachate permeation. Furthermore, the upper surfaces of the soil specimens were mostly covered by a black film, which seemed to be a biofilm due to bacterial growth. Figure 4.8 shows pictures of Halton clay specimens before and after permeation with leachate. The biofilm generation along with chemical precipitations most likely were the main reasons behind hydraulic conductivity reduction. 

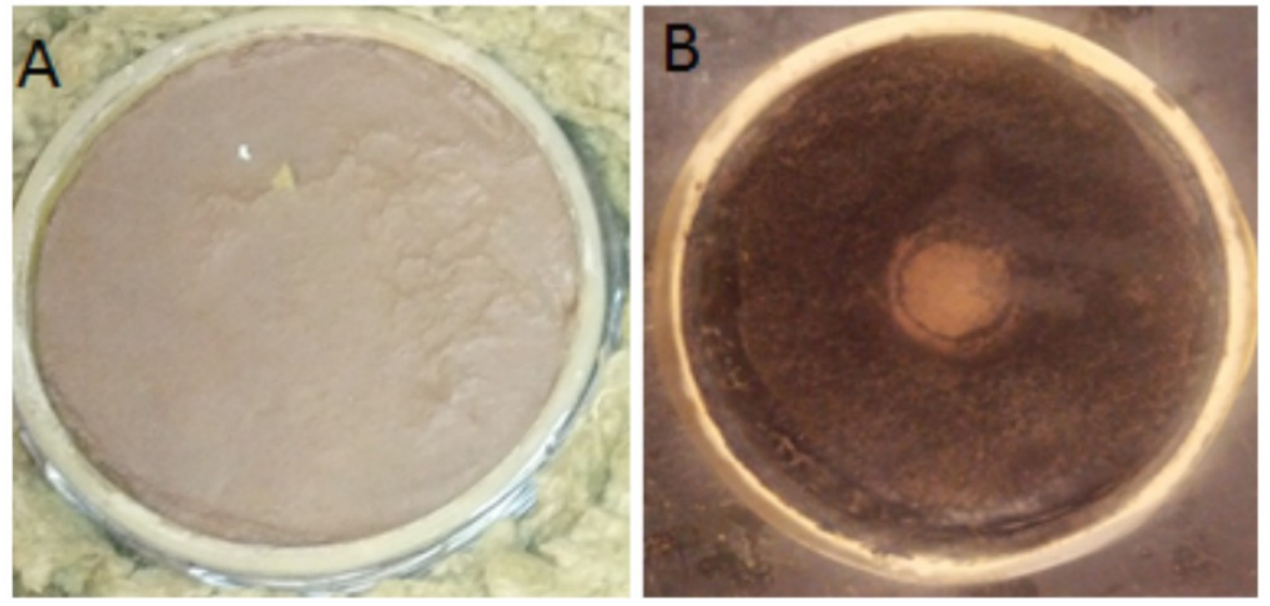

Figure 4.8 Biofilm formation on the surface of Halton clay specimen after $\mathbf{7 5}$ days of leachate exposure at room temperature. A) Prior to leachate exposure B) After leachate exposure.

\subsubsection{Combined thermo-chemical exposure effects on hydraulic performance of CCLs}

After waste placement in landfills, biodegradation of organic waste components would produce gases, liquid (landfill leachate), and heat (landfill temperature). CCLs as part of barrier system at the bottom of the landfill might be exposed to combined effects of landfill leachate and elevated temperature where both of which could impact the hydraulic performance of the CCLs. Elevated temperature has shown to increases CCLs hydraulic conductivities. In contrast, the landfill leachate has led to decreasing the CCLs hydraulic conductivities. However, simultaneous effect of leachate and temperature exposure, which is more relevant to the realistic field conditions, is not well understood. The combined effects of landfill leachate and temperature were investigated using 12 soil specimens exposed to three different temperature exposure conditions $\left(22^{\circ} \mathrm{C}, 40^{\circ} \mathrm{C}, 55^{\circ} \mathrm{C}\right)$ while permeated with leachate. This combined thermo-chemical exposure was persisted 
up to 75 days, where hydraulic conductivity readings recorded every 15 days for all specimens. Hydraulic conductivity results along with normalized hydraulic conductivities were presented in Tables 4.5-4.7 and Figure 4.9.

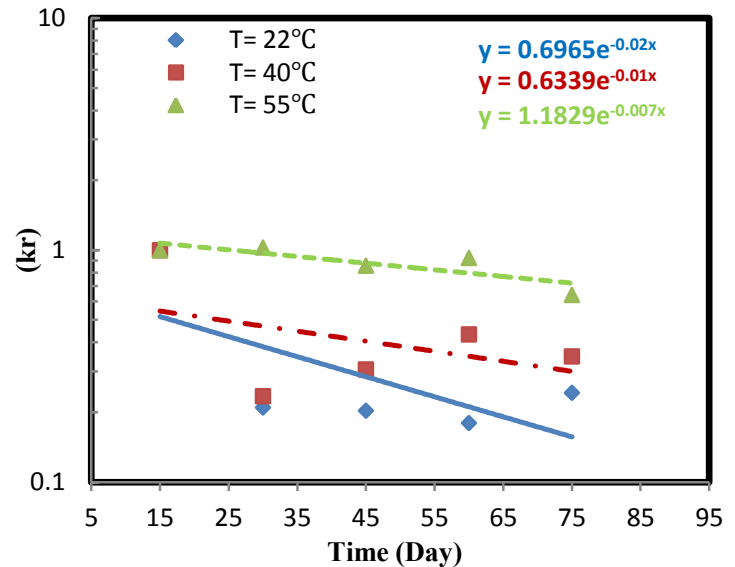

a) Halton clay

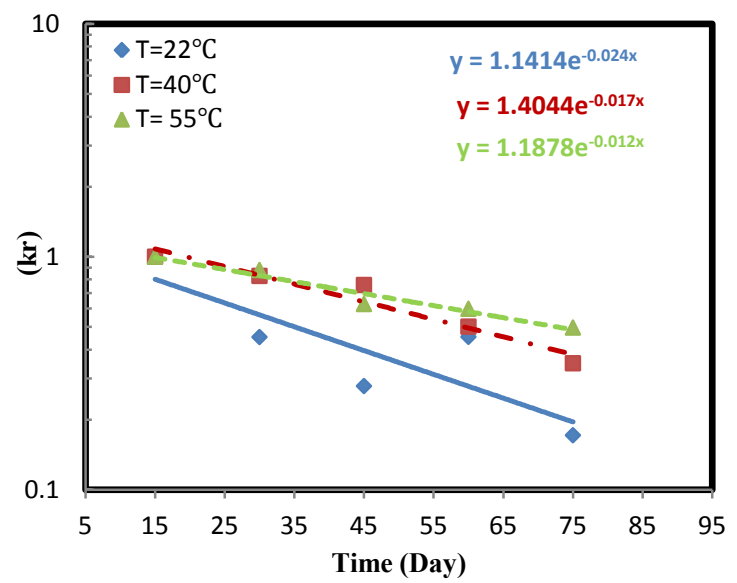

c) Halton clay+Bent.

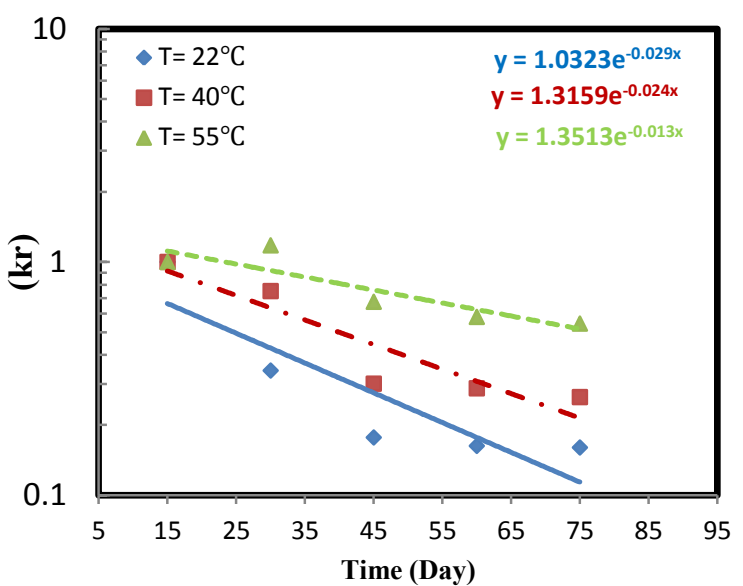

b) Leda clay

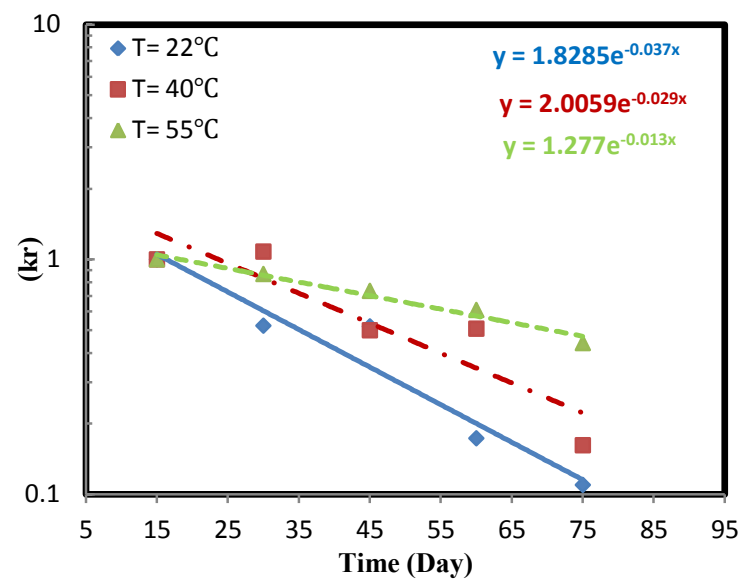

d) Leda clay+Bent.

Figure 4.9 Normalized hydraulic conductivity values versus time for soil specimens permeated with synthetic leachate under $22^{\circ} \mathrm{C}, 40^{\circ} \mathrm{C}$, and $55^{\circ} \mathrm{C}$.

As demonstrated in Figure 4.9, all trend lines show a decrease in hydraulic conductivity with time upon exposure to combined thermo-chemical effects. However, the hydraulic conductivity reduction exhibits an inverse relationship with temperature. For all soil specimens, the rate of reduction in hydraulic conductivity decreases as the 
temperature increases from $22^{\circ} \mathrm{C}$ toward $55^{\circ} \mathrm{C}$. To better visualize this statement, final normalized hydraulic conductivities for each soil type were estimated using the slop equation for the trend lines and plotted versus temperature (Figure 4.10).

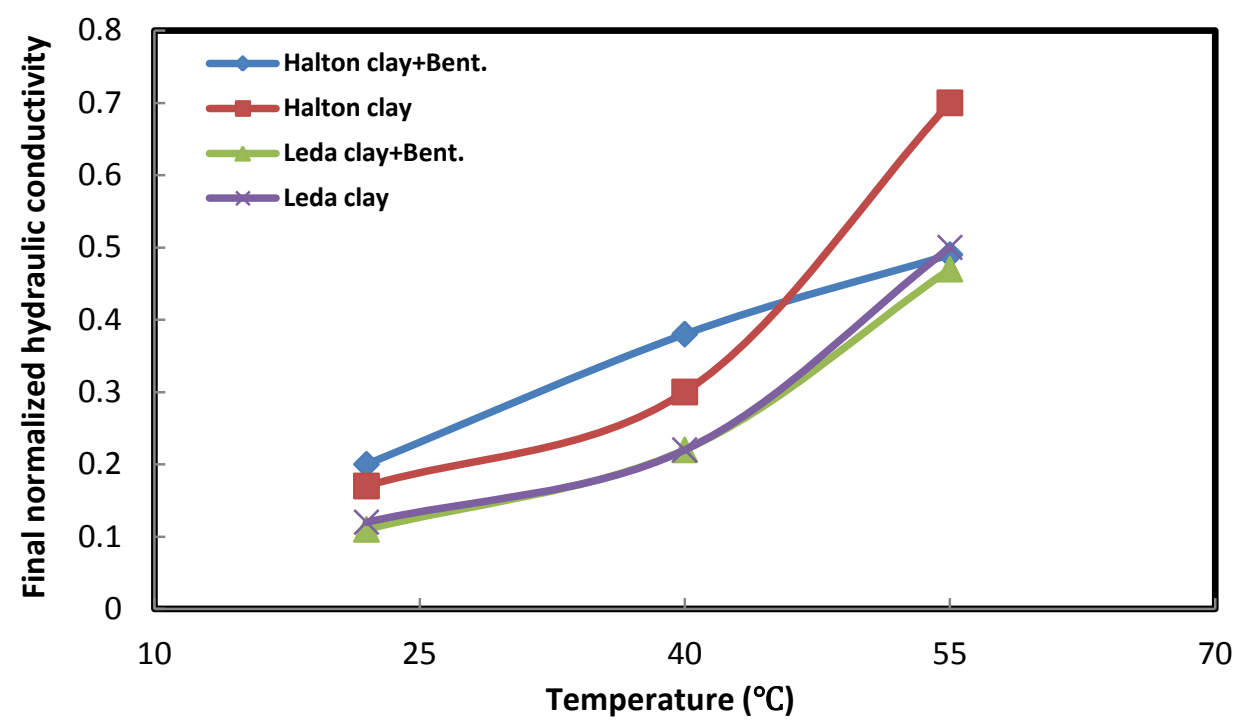

Figure 4.10 Influence of temperature on hydraulic performance of CCLs when exposed to leachate.

The curves demonstrate the inverse correlation between temperature and hydraulic conductivity reduction of CCLs when subjected to combined thermo-chemical exposure. The higher reduction in hydraulic conductivity occurred at lower exposure temperature (room temperature), while the lower hydraulic conductivity reduction corresponded to the higher exposure temperature $\left(55^{\circ} \mathrm{C}\right)$. In other words, as the temperature increases, the final hydraulic conductivity of the soil specimens increases. This behaviour can be attributed to the decrease in permeant viscosity as the temperature increases, which leads to higher hydraulic conductivity at higher temperature. Moreover, the visual inspection after test termination showed a decrease in biofilm generation as the exposure temperature increased (Figure 4.11). Intense biofilm generation due to bacterial growth was observed on the surface and within the soil specimens exposed to leachate 
permeation at room temperature. However, the tendency of biofilm formation was decreased as the temperature increased toward $55^{\circ} \mathrm{C}$. Thus, lower biological clogging may occur at higher temperature, which, along with decreased viscosity, could lead to higher hydraulic conductivity at higher temperature when combined thermo-chemical exposures are applied.

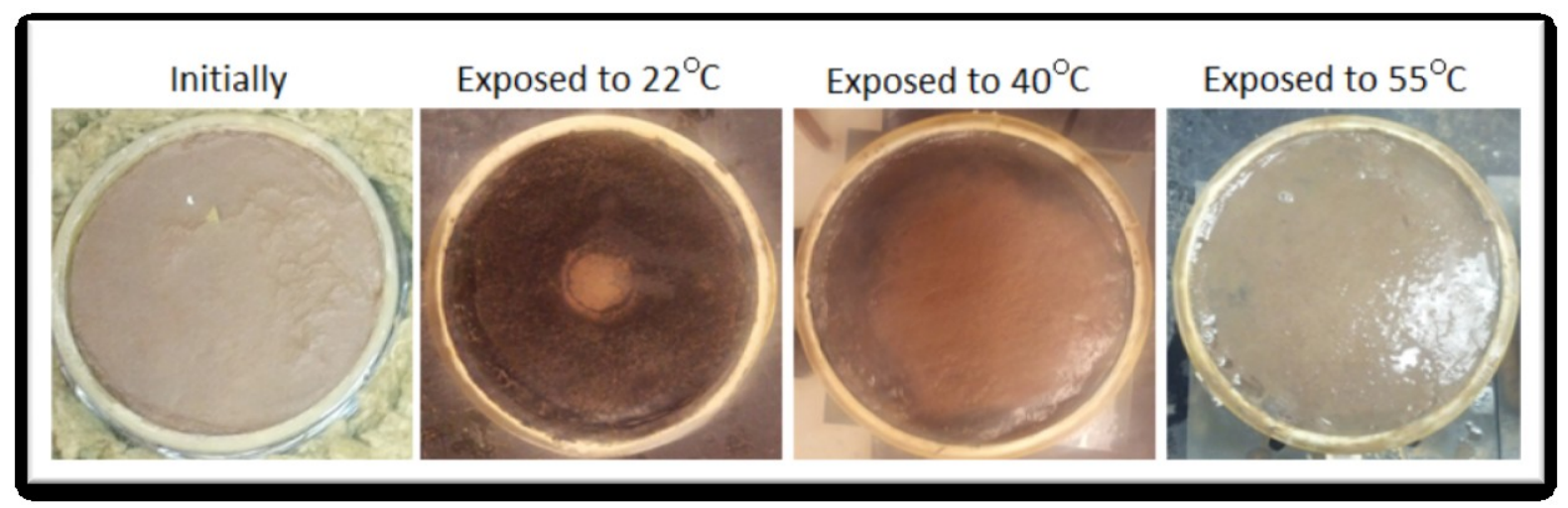

Figure 4.11 Effect of temperature on biofilm formation during leachate permeation.

\subsubsection{Effect of soil properties on CCLs response to combined thermo-chemical exposure}

In order to investigate the hydraulic performance of different soil types when subjected to combined thermo-chemical exposure, the final average normalized hydraulic conductivities of the soil specimens were correlated to their plasticity indices (Figure 4.12). Results showed overall reduction in hydraulic conductivity as the plasticity index increased. The reduction of hydraulic conductivity was more pronounced for soils with higher plasticity and at the highest applied temperature $\left(55^{\circ} \mathrm{C}\right)$. As it is well known, the higher the plasticity index, the smaller the porous media and the larger the surface area encountered per unit volume. This is attributed to the smaller soil particles for soils with higher plasticity indices which leads to lower hydraulic conductivity. Upon leachate 
permeation, biofilm was generated within the soil specimens due to bacterial growth (Figure 11). Since the biofilm is formed around the soil particles, thus, soils with smaller particles and greater surface area would experience greater biofilm growth per unit volume compared to the soils with larger particle size (Rowe et al., 2000a). Therefore, soils with higher plasticity indices would exhibit higher rate of clogging resulting in higher rate of reduction in their active porous media. Faster and higher rate of clogging for finer materials was also reported by many other researchers in this field (e.g., Brune et al., 1991; Rowe et al., 2000a; Rowe and Yu 2010).

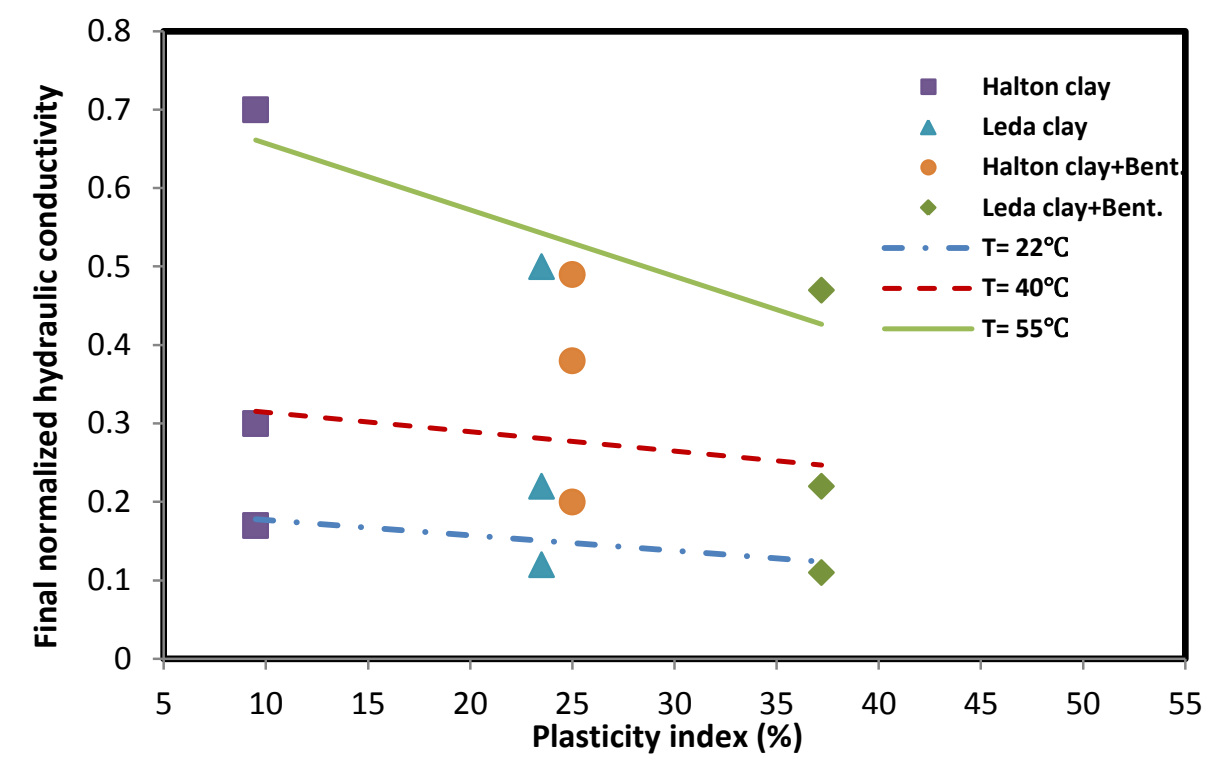

Figure 4.12 Effect of plasticity index on hydraulic performance of CCLs when subjected to combined thermo-chemical affects.

\subsubsection{Combined thermo-chemical exposure effects on Atterberg limits}

The exposure conditions in landfill environment after waste placement might affect the CCLs physical properties as well as mechanical behaviors. High landfill temperatures might cause reduction in the CCLs water contents. In the same time, leachate exposure could lead to changes in chemical and mineral compositions beside potential increase in 
organic matter content and the relevant specific surfaces (Frempong, 2006). In the current study, the initial and post-termination Atterberg limits for Leda and Halton clays were compared to evaluate the impact of thermo-chemical exposures on soil properties (Table 4.13).

Table 4.13 Atterberg limits initially and after thermo-chemical exposure.

\begin{tabular}{|c|c|c|c|c|c|c|c|c|}
\hline \multirow{3}{*}{$\begin{array}{l}\text { Atterberg } \\
\text { limits (\%) }\end{array}$} & \multicolumn{4}{|c|}{ Halton clay } & \multicolumn{4}{|c|}{ Leda clay } \\
\hline & \multirow{2}{*}{ Initial } & \multicolumn{3}{|c|}{ After exposure to leachate at } & \multirow{2}{*}{ Initial } & \multicolumn{3}{|c|}{ After exposure to leachate at } \\
\hline & & $22^{\circ} \mathrm{C}$ & $40^{\circ} \mathrm{C}$ & $55^{\circ} \mathrm{C}$ & & $22^{\circ} \mathrm{C}$ & $40^{\circ} \mathrm{C}$ & $55^{\circ} \mathrm{C}$ \\
\hline $\mathbf{L L}$ & 23.5 & 27.2 & 27.4 & 27.9 & 50.8 & 53.25 & 56.4 & 57.4 \\
\hline PL & 14 & 17.6 & 18 & 18.07 & 27.5 & 26.13 & 27.23 & 26.5 \\
\hline PI & 9.5 & 9.6 & 9.4 & 9.83 & 23.3 & 27.12 & 29.17 & 30.9 \\
\hline
\end{tabular}

Results indicate overall increases in most Atterberg limits for both clayey soils subjected to thermo-chemical exposure effects. These increases become more pronounced as the exposure temperatures increase. Liquid limits showed increases of $18 \%$ and $13 \%$ over the initial values for Halton clay and Leda clay respectively when they permeated with leachate at $55^{\circ} \mathrm{C}$. At the same level of temperature, a considerable increase in plasticity index of about 33\% was recorded for Leda clay, while a slight increase of about 3.5\% was measured for Halton clay. The overall increase in Atterberg limits can be attributed to the increase of organic matter content following to leachate exposure. The increase of organic matter would lead to an increase in specific surface of clay soils, which in turn would increase the water demand that is required by the soil to reach its Atterberg limits. The proportional relationship between Atterberg limits and organic matter content was widely reported by many researchers in this field (e.g., Zentar et ai., 2009; Thiyyakkandi and Annex 2011; Moradi, 2013). 


\subsection{Summary}

Simultaneous effects of landfill temperature and landfill leachate were simulated and their effects on the hydraulic performance of different CCL specimens were investigated. The experimental program was carried out at room temperature $\left(22^{\circ} \mathrm{C}\right), 40^{\circ} \mathrm{C}$, and $55^{\circ} \mathrm{C}$ in order to cover wide range of temperature exposures reported at different landfill sites. Landfill temperature has shown noticeable effect on the hydraulic performance of CCLs. The hydraulic conductivity for most CCL specimens increased by two to three times their initial hydraulic conductivity when exposed to $55^{\circ} \mathrm{C}$ for 75 days. This increase was attributed to the decrease in permeant viscosity due to elevated temperature. Moreover, micro-crack generation may have played a role in increasing hydraulic conductivity values.

Landfill leachate exposure alone has initially increased the hydraulic conductivities for all CCL specimens due to change in viscosity of the permeant. However, as the leachate exposure time increased, hydraulic conductivity readings showed significant reduction that sometimes reached an order of magnitude after 75 days of leachate permeation at room temperature. The gradual decreases in CCLs hydraulic conductivities were most likely due to chemical precipitation and clogging of pore voids within the soils.

The rate of hydraulic conductivity reduction due to leachate permeation was slower at temperatures higher than room temperature. Thus, better CCLs hydraulic performance would be expected at lower landfill temperature due to higher clogging potential. This 
finding underscores the significance of observing landfill temperature and utilizing practical methods to maintain the temperature as low as possible.

The plasticity index was found to have a positive correlation with hydraulic performance of CCLs when exposed to thermo-chemical effects. Lower hydraulic conductivity was measured for CCLs with higher plasticity indices. This highlights the importance of selecting appropriate clayey soils for a better CCLs performance. Combined thermo-chemical effects have shown to increase plasticity indices of the soil, possibly due to an increase in the organic matter content upon leachate permeation. The inverse relationship between biofilm intensity and exposure temperature would need more investigation in order to identify the reasons behind this behaviour. 


\section{CHAPTER: CONCLUSIONS AND RECOMMENDATIONS}

\subsection{Conclusions}

Compacted clay liners are hydraulic barriers that have been used for environmental protection purposes in many waste disposal facilities including municipal solid waste landfills. In landfill environment, CCLs are prone to different exposure conditions, and these exposure conditions may affect the chemical, physical, and mineral properties and hence the hydraulic performance of CCLs. Typically, after CCL instillation and before waste placement, a layer of geomembrane and leachate collection system covers the CCL. However, it is not uncommon for the CCLs to be left exposed to weather, with or without geomembrane cover, for several months prior to waste placement due to practical or economic issues. The exposed CCLs could undergo daily thermal and wet-dry cycles which in turn might impact the CCLs volume stability as well as hydraulic conductivity. In this study, a realistic boundary condition of one dimension heat and moisture transfer into and out the CCL matrix was applied on CCL specimens simulating field conditions before waste placement. The following conclusions were drawn from this experimental investigation:

- Shrinkage behaviours of the test soils were well correlated to their SWCCs, which provided reliable prediction of the test soils' volume stabilizations.

- Hydraulic performance of CCL specimens exhibited positive correlation with their plasticity indices when the CCLs exposed to daily thermal or wet-dry cycles. CCLs with plasticity indices ranging from $25 \%$ to $37 \%$ have shown a reliable 
hydraulic performance when exposed to different weather circumstances. Therefore, medium and high plasticity CCLs were shown to provide higher level of protection to the surrounding environment.

- The low plasticity CCL $(9.5 \%)$ has undergone a significant hydraulic conductivity increase, which reached almost an order of magnitude, when exposed to wet-dry or daily thermal cycles. This was attributed to the irreversible shrinkage and volume deformations that created permanent fissures and flow channels that facilitated the water movement through the soil.

- Geomembrane cover minimized the effects of daily thermal and wet-dry cycles especially for low plasticity soils. Geomembrane cover provides a moisture barrier and minimizes the moisture loss and the relevant volumetric shrinkage of the CCLs. This finding underscores the importance of using geomembrane on top of CCLs, especially when low plasticity soils are involved.

- Shrinkage index and plasticity index showed similar trend in predicting hydraulic aspects and shrinkage behaviours of the test soils under the effects of thermal cycles as well as wet-dry cycles. Thus, these two soil properties can be used as key criteria when choosing proper soils for CCL construction.

After waste placement, the effect of weather fluctuation might be eliminated, yet the new sealed environment would create new exposure conditions that might alter the CCLs hydraulic performance. Waste decomposition would most likely result in heat and leachate generation. The elevated temperature due to heat generation might decrease the CCLs water contents, while landfill leachate could enhance substantial chemical, mineral, and physical changes in CCLs properties. In this study, an experimental program was 
devoted to investigate the combined thermo-chemical effects on CCLs hydraulic performance for different CCL specimens. The experimental results were evaluated and the following conclusions were extracted:

- Landfill temperature caused considerable increase in the CCLs hydraulic conductivity. Most CCL specimens experienced hydraulic conductivity increase by two to three times their initial values due to exposure to $55^{\circ} \mathrm{C}$ for 75 days. This behaviour could be attributed to decrease in permeant viscosity and the potential micro-crack generation within the soils under effect of elevated temperature.

- Leachate permeation at room temperature caused increase in hydraulic conductivities of the CCL specimens by approximately three folds recorded at 15 days elapsed time. This behaviour can be attributed to the change in permeant viscosity when the permeant changed from water to leachate. The used synthetic leachate contains volatile acids that make its viscosity lower than the tap water viscosity. However, as leachate permeation proceeded beyond this threshold, a gradual decrease in hydraulic conductivity occurred that sometimes reached an order of magnitude at the elapsed time of 75 days of leachate permeation at room temperature. Leachate permeation resumption seemed to encourage chemical precipitation and biofilm generation within voids and flow channels which led to gradual decreases in CCLs hydraulic conductivities.

- When leachate permeation was accompanied with elevated temperatures higher than room temperature, the rate of reduction in hydraulic conductivities decreased leading to higher final hydraulic conductivities for higher elevated temperatures. Higher levels of temperatures seemed to minimize chemical precipitations and 
biological clogging, thus, decrease the hydraulic conductivity reductions due to leachate permeation. Therefore, better hydraulic performance would be expected at lower landfill temperature due to higher precipitation and biological clogging potential. This finding underscores the significance of observing landfill temperature and utilizing practical methods to maintain the temperature as low as possible.

- Lower hydraulic conductivity values were measured for soils with higher plasticity indices when exposed to thermo-chemical effects. This finding encourages utilising plasticity indices as an indicator while choosing clayey soils for better CCLs performance.

- Atterberg limits were prone to overall increases upon CCLs exposure to thermochemical effects. Atterberg limits increases were more pronounced for higher plasticity soil and at higher temperature levels. Leachate permeation caused generation biofilm which seemed to increase the organic matter content. Increase of organic matter content would result in higher specific surfaces which in turn would lead to higher water demand to achieve certain Atterberg limit or index.

\subsection{Recommendations}

This research investigated the hydraulic performance of Compacted Clay Liners (CCLs) under different conditions to which CCLs might be exposed in landfill environment. The results of the study provide better understanding of the behaviour of CCLs in landfills and other applications. However, these results and conclusions should be restricted to short-term performance of CCLs tested here especially for combined thermo-chemical exposure. Longer exposure time might lead to different chemical and mineral behaviour 
and results in different hydraulic performance. Although, CCL specimens have shown promising short-term performance under effect of different landfill conditions, the following recommendations might maximise the CCL performance to the optimal:

- Utilizing the soil physical properties especially plasticity and shrinkage indices would be beneficial when choosing clayey soils for CCL constructions. PI and SI were well correlated to the CCLs hydraulic performance under all exposure conditions.

- Applying a layer of geomembrane and leachate collection system immediately after CCL construction would minimise the CCL exposure time to the atmosphere and, hence, eliminate the weather effects.

- Optimising the operational system and providing practical tools that can help to maintain lower landfill temperatures at the barrier level after waste placement.

- It is also highly recommended to examine the hydraulic performance of Geosynthetic Clay Liner (GCL) under similar conditions to which the CCL has been exposed in this study. Intensive investigations have been conducted studying the hydration rate and shrinkage for GCLs, however, the hydraulic performance of GCLs under simulated landfill conditions is not fully understood. 


\section{APPENDICES}

\section{Appendix A}

X-Ray graphs for natural water-wet specimens and leachate permeated specimens

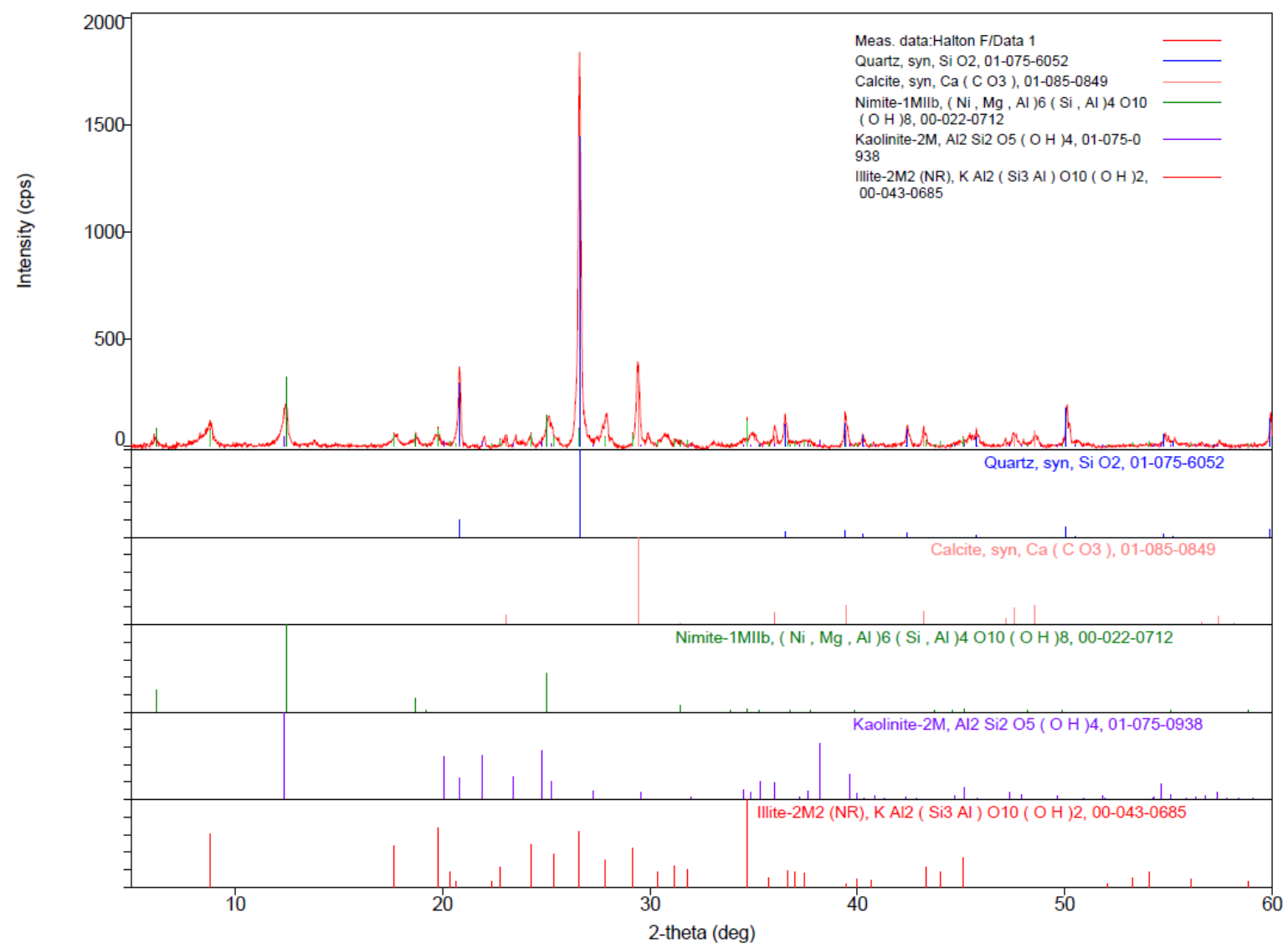

Random X-ray diffraction peaks for water wet Halton clay sample. 


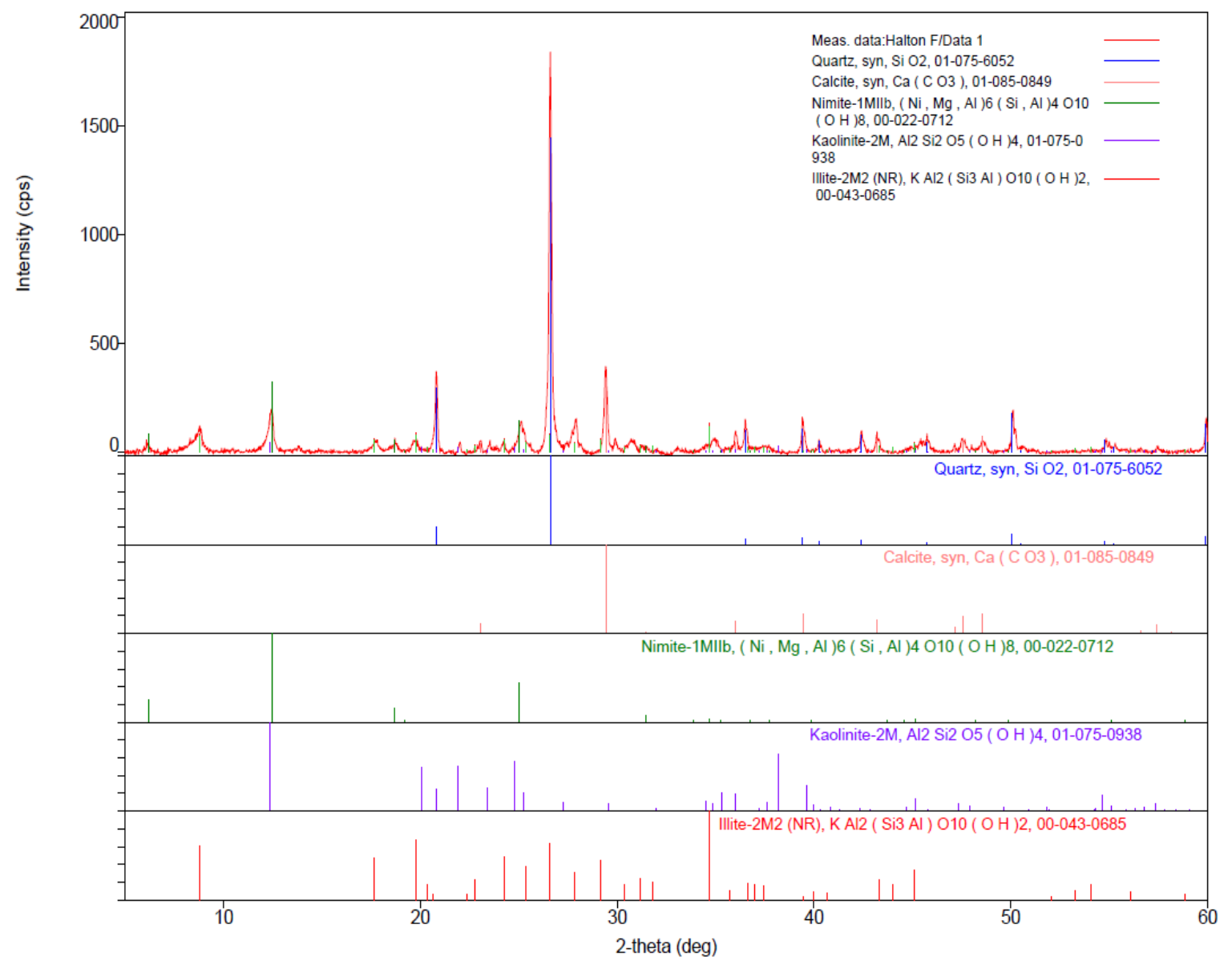

Random X-ray diffraction peaks for leachate treated Halton clay sample. 


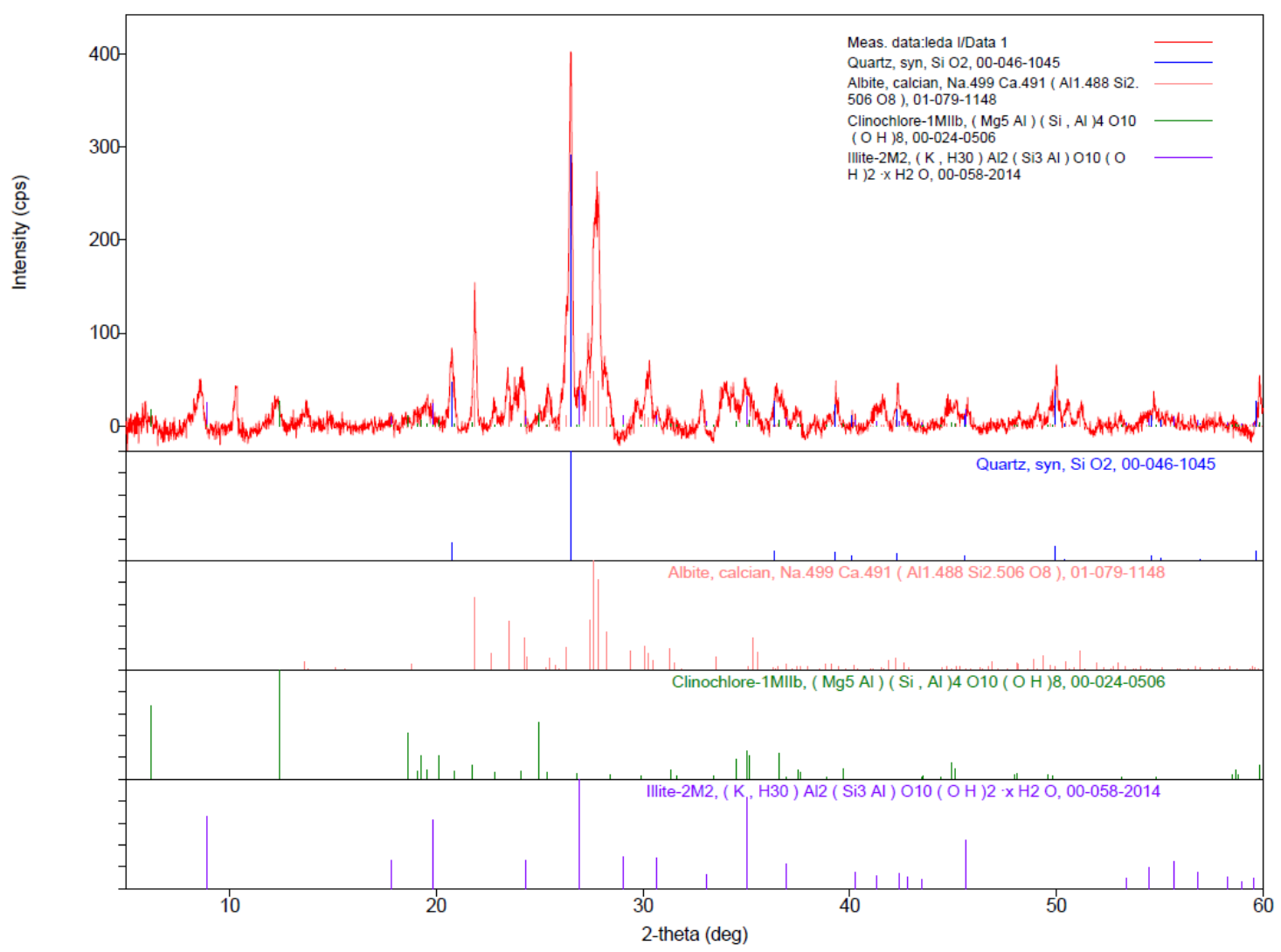

Random X-ray diffraction peaks for water wet Leda clay sample. 


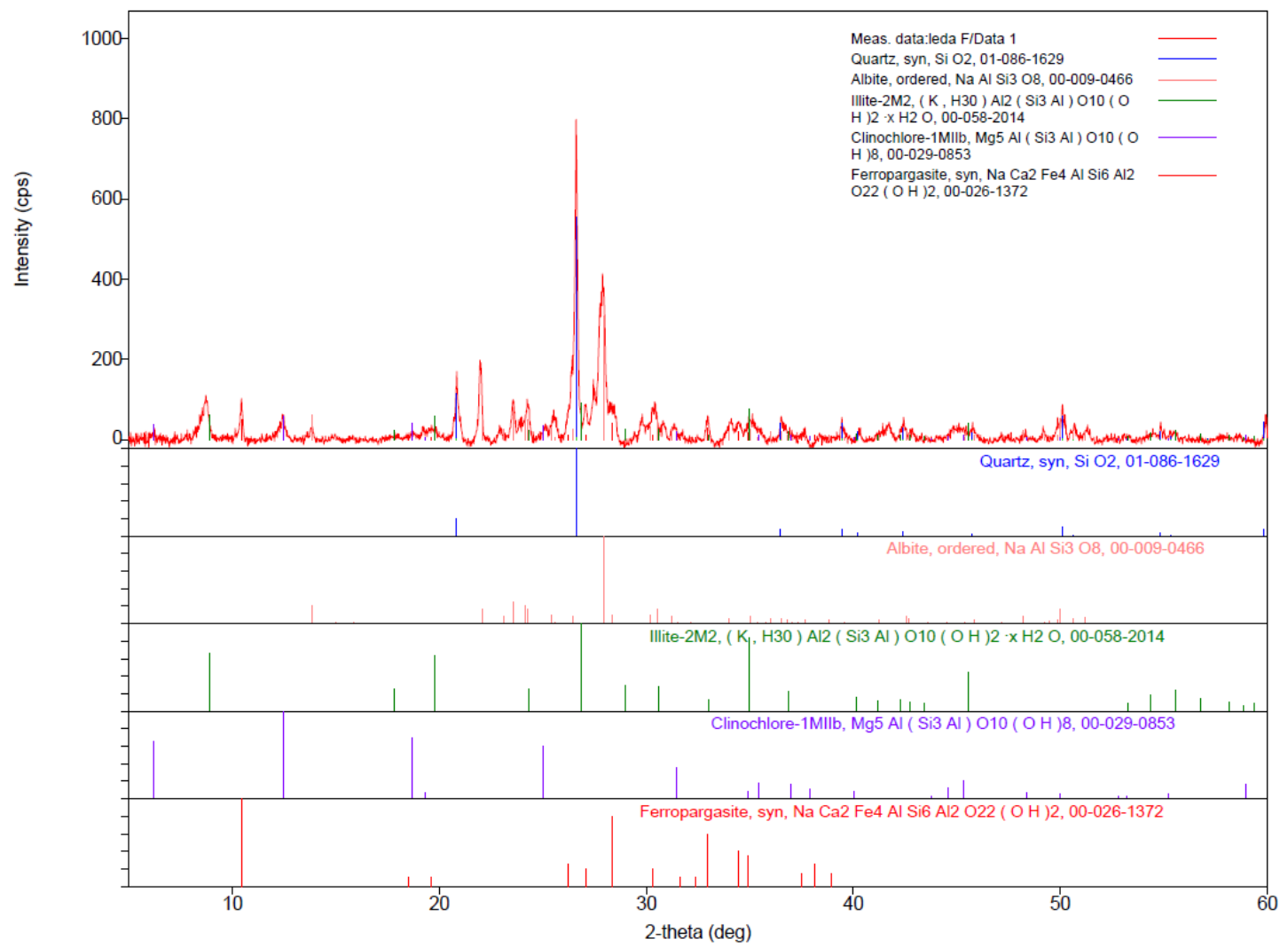

Random X-ray diffraction peaks for leachate treated Leda clay sample. 


\section{REFERENCES}

1. Abuhejleh, A.N., and Znidarcic, D. 1995. Desiccation theory for soft cohesive soils. Journal of Geotechnical Engineering, 121(6), pp. 493-502.

2. Albrecht, B.A., and Benson, C.H. 2001. Effect of desiccation on compacted natural clays. Journal of Geotechnical and Geoenvironmental Engineering, 127(1), pp. 67-75.

3. Allen, W. M. 2005. The relationship between plasticity ratio and hydraulic conductivity bentonite clay during exposure to synthetic landfill leachate. M.Sc. thesis, University of south Florida.

4. Anderson, P. and Klein, L.C. 1987. Shrinkage of lithium aluminosilicate gels during drying. Journal of non-crystalline solids, 93(2-3), pp. 415-422.

5. ASTM D422. 2007. Standard test method for particle-size analysis of soils, West Conshohocken, PA: ASTM International, DOI: 10.1520/D0422-63R07.

6. ASTM D4318. 2010. Standard test methods for liquid limit, plastic limit, and plasticity index of soils, West Conshohocken, PA: ASTM International, DOI: 10.1520/D4318-10.

7. ASTM D698. 2012. Standard test methods for laboratory compaction characteristics of soil using standard effort (12 $400 \mathrm{ft}-\mathrm{lbf} / \mathrm{ft} 3(600 \mathrm{kN}-\mathrm{m} / \mathrm{m} 3)$, West Conshohocken, PA: ASTM International, DOI: 10.1520/D0698-12.

8. ASTM D5856-95. 2007. Standard test methods for measurement of hydraulic conductivity of porous materials using a rigid- wall compaction- mold permeameter. West Conshohocken, PA: ASTM International, DOI: 10.1520/D5856-95R07

9. ASTM D6836-02. 2008. Standard test methods for determination of the soil water characteristic curve for desorption using a hanging column, pressure extractor, chilled mirror hygrometer, and/or centrifuge, West Conshohocken, PA: ASTM International, DOI: 10.1520/D6836-02. 
10. Barone, F.S., Costa, J.M.A., Ciardullo, L. 1997. Temperature at the base of a municipal solid waste landfill. 50th Canadian Geotechnical Conference, Ottawa, Canada, volume 1, pp. $144-152$.

11. Benson, C., and Daniel, D. 1990. Influence of clods on hydraulic conductivity of compacted clay. Journal of Geotechnical Engineering, 116(8), pp. 1231-1248.

12. Benson, C., Zhai, H., and Wang, X. 1994. Estimating the hydraulic conductivity of compacted clay liners. Journal of Geotechnical Engineering, 120(2), pp. 366-387.

13. Benson, C.H., Daniel, D.E., and Boutwell, G.P. 1999. Field performance of compacted clay liners. Journal of Geotechnical and Geoenvironmental Engineering, 125(5), pp. 390403.

14. Benson, H.C. and Trast, J.M. 1995. Hydraulic conductivity of thirteen compacted clays. Clays and Clay Minerals, 43(6), pp. 669-681.

15. Borghi, A. D., Binaghi, L., Converti, A. and Borghi, M. D. 2003. Combined treatment of leachate from sanitary landfill and municipal wastewater by active sludge. Chemical and Biochemical engineering Quarterly, 17(4), pp. 277-283.

16. Bostwick, L. E. 2009. Laboratory study of geosynthetic clay liner shrinkage when subjected to wet/dry cycles. M.Sc. thesis, Queen's Univ., Kingston, ON, Canada.

17. Boynton, S. S. and Daniel, D. E. 1985. Hydraulic conductivity tests on compacted clay. Journal of Geotechnical Engineering, 111(4), pp. 465-478.

18. Bronswijk, J. 1986. Evaporation and cracking of a heavy clay soil. Report 14, ICW, Wageningen, $15 \mathrm{pp}$.

19. Bronswijk, J., 1988. Modeling of water balance, cracking and subsidence of clay soils. Journal of Hydrology, Volume 97, pp. 199-212.

20. Brune, M., Ramke, H.G., Collins, H. and Hanert, H.H. 1991. Incrustation processes in drainage systems of sanitary landfills. Proceedings of the 3rd International Landfill Symposium, Sardinia, pp. 999-1035. 
21. Collins, H. 1993. Impact of the temperature inside the landfill on the behaviour of barrier systems. Proceedings of the 4th International Landfill Symposium, Sardinia '93, Volume 1, pp. $417-432$.

22. Ctori, P. 1989. The effects of temperature on the physical properties of cohesive soils. Ground Engineering, 22(5), pp. 26-27.

23. Das, B. 2002. Principles of geotechnical engineering. 5th ed, Thomas Learning, Inc. ISBN: 0-534-55144-0.

24. DeJong, E., Warkentin, B.P. 1965. Shrinkage of soil samples with varying clay content. Canadian Geotechnical Journal , 2(1), pp. 16-22.

25. Doll, P. 1997. Desiccation of mineral liners below landfills with heat generation. Journal of Geotechnical and Geoenvironmental engineering, 123(11), pp. 1001-1009.

26. Fernandez, F., and Quigley, R.M, 1988. Viscosity and dielectric constant controls on the hydraulic conductivity of clayey soils permeated with water-soluble organics. Canadian Geotechnical Journal, Volume 25, pp. 582-589.

27. Fox, W. 1964. A study of bulk density and water in a swelling soil. Soil Science, 98(5), pp. 307-316.

28. Frempong, E. 2006. Compatibility of tropical clayey soil liners with industrial and domestic leachates, $\mathrm{PhD}$, thesis, University of Western Ontario, ON, Canada.

29. George, K. P. 1968a. Craking in cement-treated bases and to minimizing it. Highway Research Record, Volume 225, pp. 59-71.

30. Gray. C.W., Allbrook. R. 2002. Relationships between shrinkage indices and soil properties in some New Zealand soils. Geoderma, 108(3-4), pp. 287-299.

31. Gray, D. H. 1989. Geotechnical engineering of land disposal systems. The Landfill: reactor and final storage. Lecture Notes in Earth Sciences, Volume 20, pp 145-173

32. Griffin, R.A., Cartwright, K., Shimp, N.F., Steel, J.D., Ruch, R.R., White, W.A., Hughes, G.M., Gilkeson, R.H, 1976. Attenuation of pollutants in municipal landfill leachate by 
clay minerals: Part I-Column leaching and field verification, Environmental Protection Agency, Washington, D.C., EPA/600/2-78/157.

33. Griffith, A. 1924. The theory of rupture. Proceedings, 1st Int. Congr. Applied Mech., Delft, Netherlands, pp. 55-63.

34. Groisman, A., and Kaplan E. 1993. An experimental study of cracking induced by desiccation.. Europhysics Letters, 25(6), pp. 415-420.

35. Haines, W. 1923. The volume change associated with variations of water content in soil. The Journal of agricultural science, 13(3), pp. 296-310.

36. Hanson, J.L., Yeşiller,N., and Oettle, N.K. 2010. Spatial and temporal temperature distributions in municipal solid waste landfills. Journal of Environmental Engineering, 136(8), pp. 1095-1102.

37. Heibrock, G. 1997. Desiccation cracking of mineral sealing liners. Proceedings of $6^{\text {th }}$ International Landfill symposium, S. Margherita di Pula, Cagliari, Italy, October, Vol. 3, pp. 101-113.

38. Holzlohner, U. 1995. Moisture Balance, Risk of Desiccation in Earthen Liners", Chapter $\mathrm{H}$ of the "State of the Art Report: Landfill Liner systems". Eds. U. Holz Iohner, H. August, T. Meggyes, M. Brune, Penshaw Press, pp. H1-H22.

39. Hrapovic, L. 2001. Laboratory study of intrinsic degradation of organic pollutants in compacted clayey soil. Ph.D. thesis, The Univ. of Western Ontario, London, Ont.

40. Islam, M. Z., and Rowe, R. K, 2007. Leachate composition and antixoxidant depletion from HDPE geomembranes. Proc., Geosynthetics 2007 Conf. (CD-ROM), Washington D.C.

41. Jefferson, I., and Rogers, C.D.F. 1998. Liquid limit and the temperature sensitivity of clays. Engineering Geology, Volume 49, pp. 95-109.

42. Jo, H.Y., Benson, C.H., Shackelford, C.D., Lee, J., and Edil, T.B. 2005. Long-term hydraulic conductivity of a geosynthetic clay liner permeated with inorganic salt 
solutions. Journal of Geotechnical and Geoenvironmental Engineering, 131(4), pp. 405417.

43. Joseph, J.B., Styles, J.R., Yuen, S.T.S., and Cressey, G. 2001. Variations in clay mineral performance in the presence of leachates. Proceeding of the Eighth International Landfill Symposium, Sardinia, Italy, 10 p.

44. Kingery. W.D., and Franc. J. 1954. Fundamental study of clay: Drying behavior and plastic properties. Journal of the American Ceramic Society. 37(12), pp. 596-602.

45. Kjeldsen, P., Barlaz, M.A., Rooker, A.P., Baun, A., Ledin, A. and Christensen, T.H. 2002. Present and long-term composition of MSW landfill leachate: A review. Critical Rev. Env. Sci. Technol., 32 (4), pp. 297-336.

46. Koerner, R.M., Wilson-Fahmy, R.F., and Narejo, D. 1996a. Puncture protection of geomembranes part 3: Examples. Geosynthetics Intrrnational, 3(5), pp. 655-675.

47. Konrad, J.M., and Ayad, R. 1997. Desiccation of sensitive clay: Field experimental observations. Canadian Geotechnical Journal , 34(6), pp. 929-942.

48. McIsaac, R., and Rowe, R.K. 2007. Clogging of gravel drainage layers permeated with landfill leachate. Journal of Geotechnical and Geoenvironmental Engineering, 133(8), pp. 1026-1039.

49. Miller. C.J., Mi. H., and Yesiller. N. 1998. Experimental analysis of desiccation crack propagation in clay liners. Journal of American Water Resources Association, 34(3), pp. $677-686$.

50. Moradi, S. 2013. Impacts of organic carbon on consistency limits in different soil textures. International Journal of Agriculture and Crop Sciences. International Journal of Agriculture and Crop Sciences, 5 (12), p. 1381-1388.

51. Morris, P.H., Graham, J., and Williams, D.J. 1991. Cracking in drying soils. Canadian Geotechnical Journal, Volume 29, pp. 263-277. 
52. Nahlawi, H., and Kodikara, J.H. 2006. Laboratory experimental on desiccation cracking of thin soil layers. Geotechnical and Geological Engineering, Volume 24, pp. 1641-1664.

53. Narasimha, R.S., and Mathew, P. 1995. Effect of exchangeable cations on hydraulic conductivity of a marine clay. Clays and Clay Minerals, 43(4), pp. 433-437.

54. Omidi, G.H., Thomas, J.C., and Brown, K.W, 1996. Effect of desiccation cracking on the hydraulic conductivity of compacted clay liner. Water Air and Soil Pollution, Volume 89, pp. 91-103.

55. Or, D., and Tuller, M. 2002. Cavitation during desaturation of porous media under tension. Water Resources Research, 38(5), pp. 19-1-19-4.

56. Peron H., Hueckel, T., Laloui L., and Hu, L. 2009. Fundamentals of desiccation cracking of fine grained soils: Experimental characterisation and mechanisms identification. Canadian Geotechnical Journal, Volume 46, pp. 1177-1201.

57. Petrov, R.J., and Rowe, R.K. 1997. Geosynthetic clay Liner compatibility by hydraulic conductivity testing factors impacting performance. Canadian Geotechnical Journal, 34(6), pp. 863-885.

58. Quigley, R.M., Fernandez, F., Rowe, R.K. 1988. Clayey barrier assessment for impoundment of domestic waste leachate (southern Ontario) including clay - leachate compatibility by hydraulic conductivity testing. Canadian Geotechnical Journal, Volume 25, pp. 574-581.

59. Quigley, R.M., Frenandez, F., and Ohikere, C. 1989. Clay/leachate compatibility study: Hydraulic conductivity of Ottawa/Carleton "Leda" clay barrier soils permeated with domestic waste leachate, Geotechnical Research Centre, Faculty of Engineering Science, University of Western Ontario, ON, Canada.

60. Reeve. M. J., Hall. D. G. M., and Bullock. P. 1980. The Effect of soil composition and environmental factors on the shrinkage of some clayey British soils. Journal of Soil Science, Volume 31, pp. 429-442. 
61. Reifer, G. 1977. The effect of temperature and mineralogy upon the Atterberg Limits and mechanical properties of cohesive soils, Undergraduate Project Report, Lanchester Polytechnic, University of Coventry, Coventry, England.

62. Romero, E., Gens, A., and Lloret, A. 2001. Temperature effects on the hydraulic behaviour of an unsaturated clay. Geotechnical and Geological Engineering, Volume 19, pp. 311-332.

63. Romero, E., Villar, M. V., and Lloret, A., 2005. Thermo-hydro-mechanical behaviour of two heavily overconsolidated clays. Engineering Geology, Volume 81, pp. 255-268.

64. Rowe, R. K., and McIsaac, R. 2005. Clogging of tire shreds and gravel permeated with landfill leachate. Journal of Geotechnical and Geoenvironmental Engineering, 131(6), pp. 682-693.

65. Rowe, R. K., and Yu, Y. 2010. Factors affecting the clogging of leachate collection systems in MSW landfills. Proc. of 6th International Congress on Environmental Geotechnics, Tata McGraw Hill Education, New Delphi, India, Nov. 2010, 3-23.

66. Rowe, R.K., Armstrong, M.D., and Cullimore, D.R. 2000. Particle size and clogging of granular media permeated with leachate. Journal of Geotechnical and Geoenvironmental Engineering, 126(9), pp. 775-786.

67. Rowe, R.K., Islam, M.Z., Brachman, R.W.I., Arnepalli, D.N., and Ewais, A. 2010c. Antioxidant depletion from a high densitypolyethylene geomembrane under simulated landfill conditions. Journal of Geotechnical and Geoenvironmental Engineering, 136(7), pp. 930-939.

68. Rowe, R.K., Islam, M.Z., Hsuan, Y.G. 2008. Leachate chemical composition effects on OIT depletion in an HDPE geomembranes. Geosynthetics International, 15(2), pp. 136157. 
69. Rowe, R.K., Rimal, S, 2008b. Depletion of antioxidants from an HDPE geomembrane in a composite liner. Journal of Geotechnical and Geoenvironmental Engineering, ASCE, 134(1), pp. 68-78.

70. Rowe, R. K., 1998. Geosynthetics and the minimization of contaminant migration through barrier systems beneath solid waste. s.1., s.n., pp. 27-102.

71. Rowe, R. K., 2011. Systems engineering: the design and operation of municipal solid waste landfills to minimize contamination of groundwater, Geosynthetics International, 18(6), p. 391-404.

72. Ruhl, J.L. and Daniel, D.E. 1997. Geosynthetic clay liners permeated with chemical solutions and leachates. Journal of Geotechnical and Geoenvironmental Engineering, 123(4), pp. 369-380.

73. Scherer, G. 1990. Theory of drying. Journal of American Ceramic Society, 73(1), pp. 314.

74. Shackelford, C.D., Benson, C.H., Katsumi, T., Edil, T.B., and Lin, L. 2000. Evaluating the hydraulic conductivity of GCLs permeated with non-standard liquids. Geotextiles and Geomembranes, 18(2-4), pp. 133-161.

75. Simms, P. H. and Yanful, E. K. 2001. Measurement and estimation of pore shrinkage and pore distribution in a clayey till during soil-water characteristic curve tests. Canadian Geotechnical Journal, 38(4), pp. 741-754.

76. Southen, J.M., and Rowe, R.K. 2005. Laboratory investigation of Geosynthetic Clay Liner desiccation in a composite liner subjected to thermal gradients. Journal of Geotechnical and Geoenvironmental Engineering, 131(7), pp. 925-935.

77. Srldharaan. A., and Venkatappa Rao. G. 1971. Effective stress theory of shrinkage phenomena. Canadian Geotechnical Journal, 8(4), pp. 503-513.

78. Srldharaan.A. 1968. Some Studies on the strength of partly saturated soils, Ph.D., Thesis, Purdue University, Indiana. 
79. Stirk, G. 1954. Some aspects of soil shrinkage and effect of cracking upon water entry into the soil. Australian Journal of Agricultural Research, 5(2), pp. 279-290.

80. Tang, C.S., Shi, B., Liu, C., Gao, L., and Inyang, H.I. 2011. Experimental investigation of the desiccation cracking behaviour of soil layers during drying. Journal of Materials in Civil Engineering, 23(6), pp. 873-878.

81. Tang, CS., Shi, B., Liu, C., Zhao, L.Z., and Wang, B.J. 2008. Influencing factors of geometrical structure of surface shrinkage cracks in clayey soils. Engineering Geology, Volume 101, pp. 204-217.

82. Terzaghi, K.. 1925. Structure and volume of voids of soils. Pages 10, 11, 12, and part of 13. Erdbaumechanik auf Bodenphysikalisher Grundlage, translated by Casagrande, A. in: From Theory to Practice in Soil Mechanics, John Wiley and Sons, New York, 1960, pp. $146-148$.

83. Thiyyakkandi, S. and Annex, S. 2011. Effect of organic content on geotechnical properties of Kuttanad clay. Electronic Journal of Geotechnical Engineering, Volume 16, p. $1653-1663$.

84. Tay. Y. Y., Stewart. D. I., and Cousens. T. W. 2001. Shrinkage and desiccation cracking in bentonite-sand landfill liners. Engineering Geology, Volume 60, pp. 263-274.

85. USEPA, U. S. E. P. A. 2003. Municipal solid waste in the United States: 2001 facts and figures, Naragansett.

86. Van Olphen, H. 1964. An introduction to clay colloid chemistry. Interscience Publishers, Div. of John Wiley \& Sons, New York.

87. Viklander, P. 1998. Permeability and volume change in till due to cyclic freeze/thow. Canadian Geotechnical Journal, 35(3), pp. 471-477.

88. Villar, M. V., and Lloret, A. 2004. Influence of temperature on the hydro-mechanical behaviour of a compacted bentonite. Applied Clay Science , 26(1-4), pp. 337-350. 
89. Villar, M.V., Martin, P.L., and Barcala, J.M. 2005. Modification of physical, mechanical and hydraulic properties of bentonite by thermo-hydraulic gradients. Engineering Geology, Volume 81, pp. 284-297.

90. Yeşiller. N., Hanson. J. L., Yoshida. H.. 2011. Landfill temperatures under variable decomposition conditions. In: Proceedings of the Geo-Frontiers 2011 Conference, Dallas, TX, USA, 13 March 2011, pp. 1055-1065. Reston, VA: ASCE, American Society for Civil Engineers, Dallas, TX,

91. Yoshida, H., Hozumi, H., and Tanaka, N. 1996. Theoretical study on temperature distribution in a sanitary landfill. Proc. 2nd Int. Congress on Environ. Geotech., Osaka volume 1, pp. 323-328.

92. Youssef, M.S., Sabry, A., and Ramli, A.H.EI. 1961. Temperature changes and their effects on some physical properties of soils. Proceedings of the 5th International Conference on Soil Mechanics and Foundation Engineering, Paris, Volume 1, pp. 419421.

93. Yuen, K.K., Graham, J., and Janzen, P. 1998. Weathering-induced fissuring and hydraulic conductivity in a natural plastic clay. Canadian Geotechnical Journal, 35(6), pp. 1101-1108.

94. Zentar, R., Abriak, N.E., and Dubois, V. 2009. Effects of salts and organic matter on Atterberg limits of dredged marine sediments. Journal of Applied Clay Science, 42(3-4), pp. 391-397.

95. Zubaydi, A. H. T. A. 2011. Effect of wetting and drying cycles on swell/collapse behavior and cracks of fine - grained soils. Tikrit Journal of Engineering and Sciences, 18(4), pp. 71-79. 